\title{
Decision-making through the grapevine: Winegrowers' perceptions on climate change and the barriers to adaptation planning in New Zealand
}

\section{Alyssa Sarah Zita Ryan}

A 120-point thesis submitted to Victoria University of Wellington as partial fulfilment of requirements for a degree of Master of Environmental Studies

School of Geography, Environment and Earth Sciences

Te Kura Tātai Aro Whenua

Victoria University of Wellington

Te Whare Wānaga o Te Üpoko o Te Ika a Māui 


\section{$\underline{\text { ABSTRACT }}$}

New Zealand wine is cultivated in cool climates that produce distinctive flavours and wine-styles, which are representative of the terroir of the region. The effects of climate change can impact the quality and quantity of winegrapes, and the production of premium wine. The aim of this research was to investigate adaptation planning in the New Zealand wine industry by evaluating winegrowers' decision-making and perceptions of climate change. Research was conducted using primary survey data from New Zealand winegrowers and semi-structured interviews with winegrowers from three case study regions of Marlborough, Central Otago, and Hawke's Bay. The study was designed to assess how climate change is understood throughout the industry, whether adaptation plans are being developed or employed and the barriers hindering winegrowers' implementation of adaptation strategies. The results show that winegrowers are somewhat informed about climate change with some adaptation planning occurring. However, the majority of winegrowers have no plans to adapt to climate change. The uncertainty in the climate science and the availability of information were indicated as a barrier to adaptation planning. Winegrowers convey the need for regional information with a focus on reliable forecasting and climate projections for the next few years. The New Zealand wine industry is in a positive position to undertake adaptation with the opportunity to exploit the benefits of climate change for wine production.

Key words: climate change; wine; decision-making; adaptation planning; barriers 


\section{ACKNOWLEDGMENTS}

There are a number of people who need to be recognised for their contribution to this research. I would like to acknowledge the winegrowers who participated in this research. Without you, this project would not have come to fruition.

I would like to thank my supervisor Dr. Kelli Archie. Your support, patience and feedback has been really appreciated. Every time I leave your office I always felt inspired about my topic and doing research. You have gone above and beyond to encourage me, whether that's writing, doing statistical analysis or presenting at conferences. I am truly lucky to have had you as a supervisor and I cannot express my gratitude for making my postgrad life a positive experience.

I would also like to thank Associate Professor Ralph Chapman. Your detailed feedback and support has been pivotal in the completion of this thesis. Thank you for spending your time reading and offering recommendations. Your support is truly appreciated.

To my friends who kept me sane and made the experience - thank you for your support and encouragement. The CO102A group - thank you for the adventures, weekly baking and daily quiz breaks. Special mentions to Rachel, Andrea, David, Holly, and Josh - thank you all for the support and kind encouragements. Furthermore, a special thank you to Tom. The constant support whether by reading my chapters and providing feedback, or keeping me caffeinated during the final months were essential in helping me finish.

I would like to thank my parents. Mum, you encouraged me to pursue what I am passionate about. You taught me the value of hard work and how I am capable of achieving my goals. Dad, without you this thesis would not be possible. Thank you for always reading my work and being a source of ongoing support. You trusted my decisions and my abilities and always encouraged me. Thank you both for helping me and removing any obstacles that could have limited my continued study. 


\section{$\underline{\text { TABLE OF CONTENTS }}$}

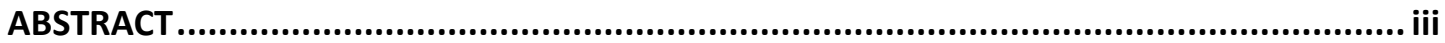

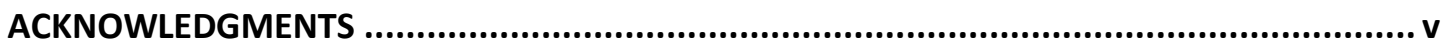

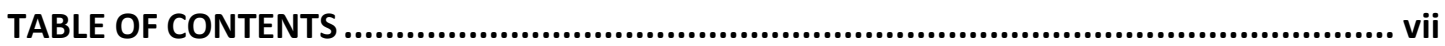

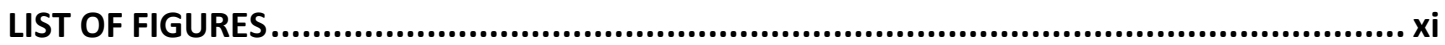

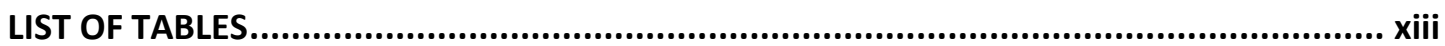

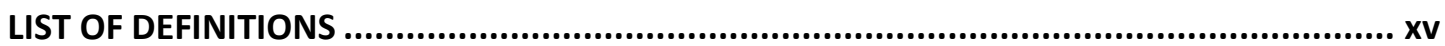

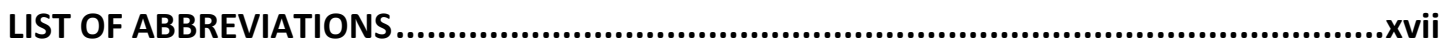

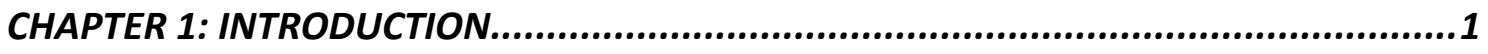

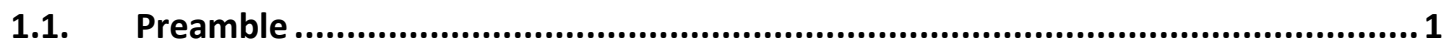

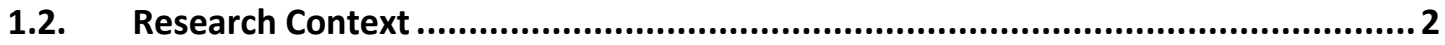

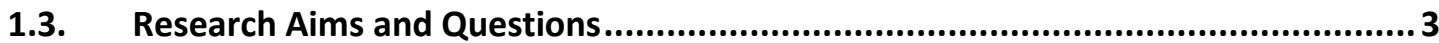

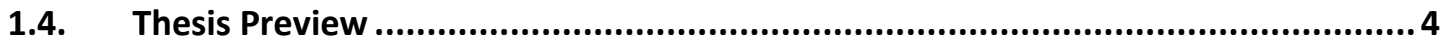

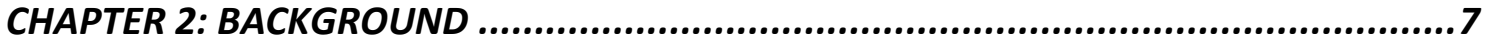

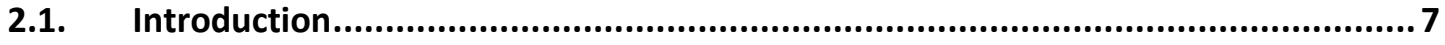

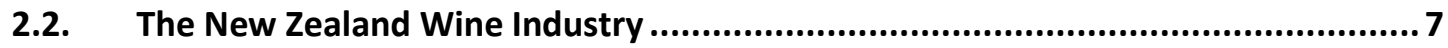

2.3. Geography of New Zealand Wine..................................................................... 10

2.4. Climate Profile of New Zealand......................................................................... 14

2.5. New World Wine Production ........................................................................... 16

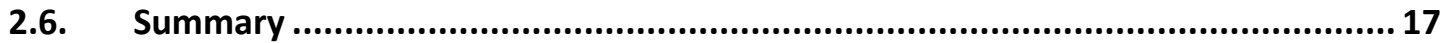

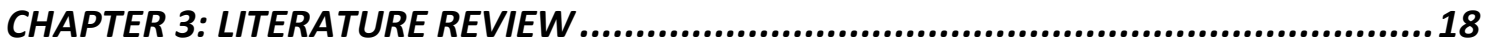

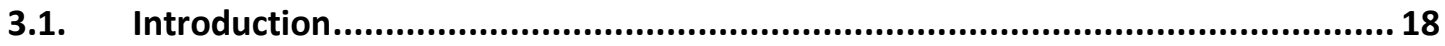

3.2. Climate Change and the Global Wine Industry ................................................. 18

3.2.1. Impact of Climate Change on Phenology and Yield ....................................... 19

3.2.2. Climate Change Impacts on Wine Quality .................................................... 21

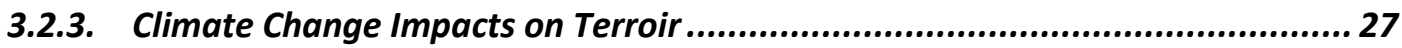




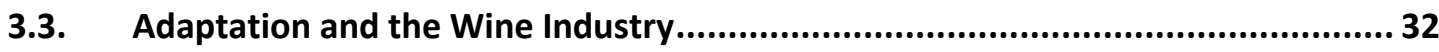

3.3.1. Adaptation and the Wine Industry................................................. 33

3.3.2. Adaptation Capacity of the Wine Industry...................................... 35

3.3.3. Adaptation Strategies ............................................................ 37

3.3.4. Perceptions and Attitudes to Adaptation ................................................. 40

3.4. New Zealand Wine Research ......................................................... 43

3.5. Research Gap and Summary ............................................................... 46

CHAPTER 4: ADAPTATION PLANNING AND CO-PRODUCTION OF KNOWLEDGE ....... 47

4.1. Introduction.............................................................................. 47

4.2. Decision-making for Climate Change Adaptation...................................... 47

4.3. Adaptation Processes Framework................................................... 48

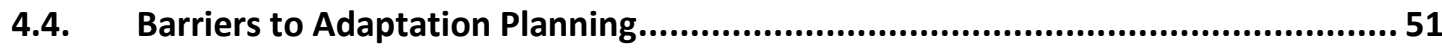

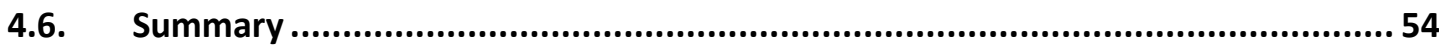

CHAPTER 5: METHODOLOGY .............................................................. 55

5.1. Introduction.............................................................................. 55

5.2. Mixed Methods Research .............................................................. 55

5.2.1. Epistemological Position.................................................................... 56

5.2.2. Positionality...................................................................... 56

5.2.3. Ethical Obligations ................................................................ 58

5.3. Quantitative Survey Research.......................................................... 58

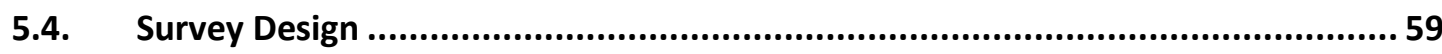

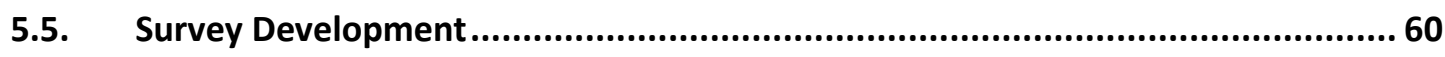

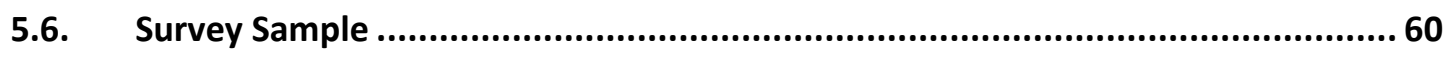

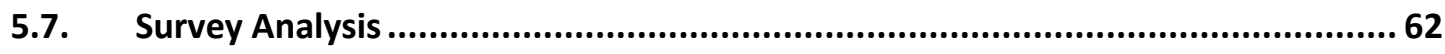

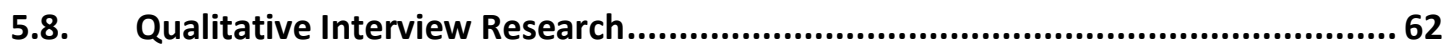

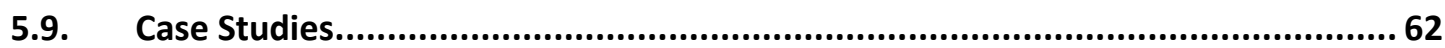

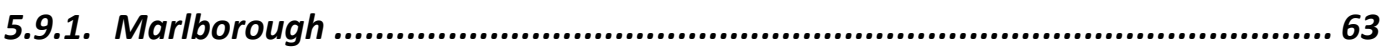

5.9.2. Central Otago ...................................................................... 64

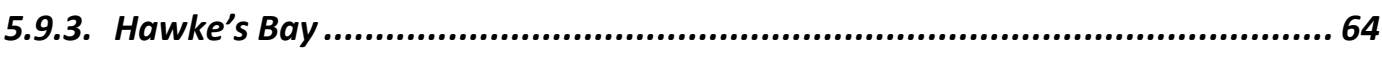

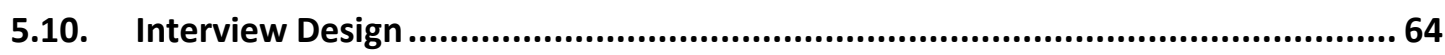




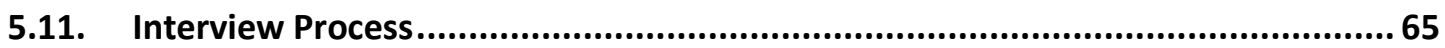

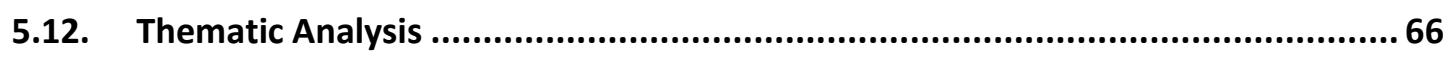

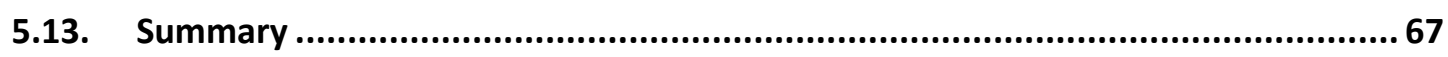

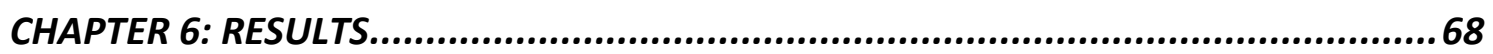

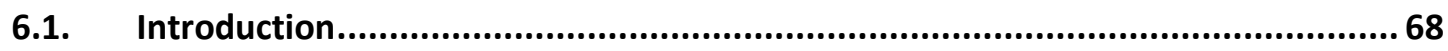

6.2. Climate Change Perceptions .............................................................. 68

6.3. Decision-making and Adaptations.................................................. 85

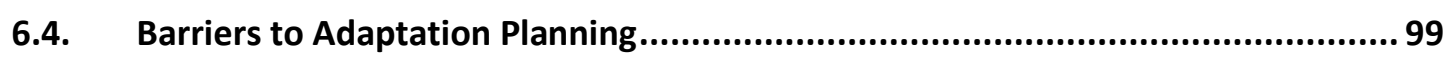

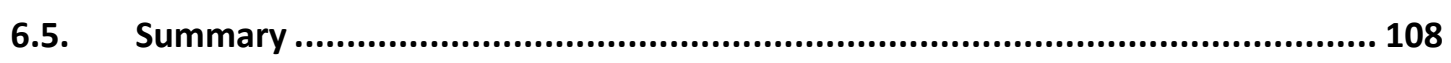

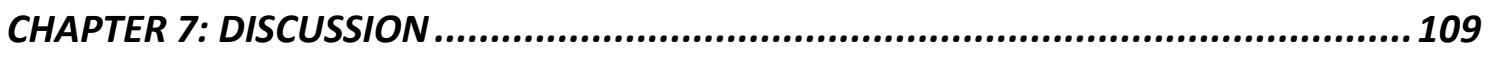

7.1. Introduction.......................................................................... 109

7.2. Winegrowers' Perceptions on Climate Change .............................................. 109

7.3. Adaptation Planning in the New Zealand Wine Industry.......................... 114

7.3.1. Adaptation Strategies for Wine Production ........................................ 115

7.3.2. Varietal Change and Relocation ............................................................ 116

7.3.2. Adaptive Capacity of Winegrowers .......................................................... 118

7.3. Barriers to Adaptation Planning ....................................................... 119

7.4. Winegrowers' Decision-Making Capacity .............................................. 124

7.5. Research Contributions ............................................................. 125

8.1. Limitations of the Study and Future Research ..................................... 126

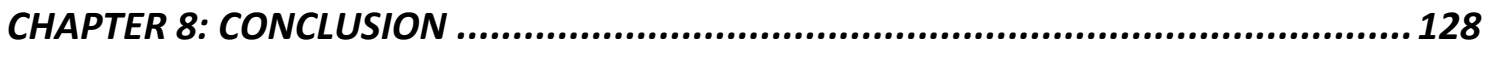

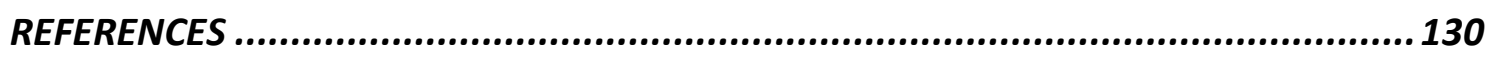

APPENDIX A.................................................................................. 150

APPENDIX B............................................................................... 151

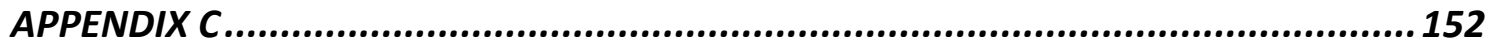

APPENDIX D..................................................................................... 153

APPENDIX E 
APPENDIX F

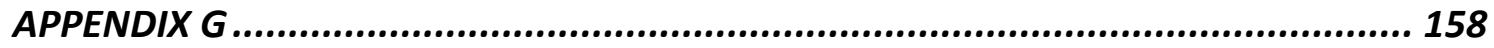

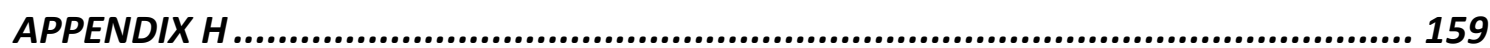

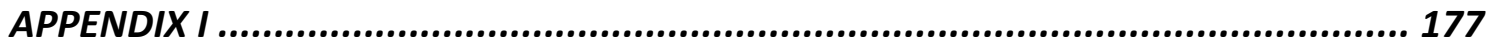

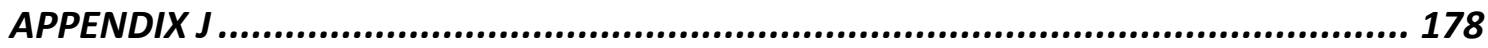

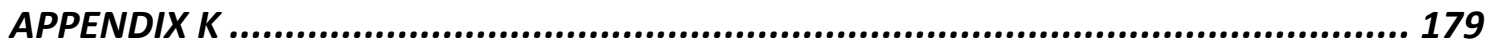

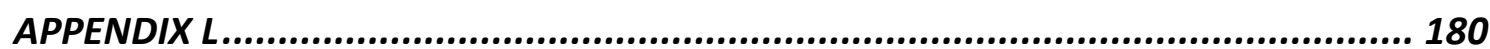

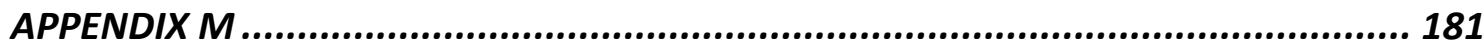

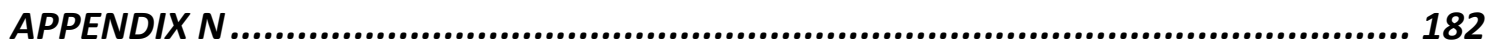

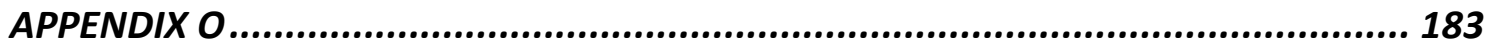

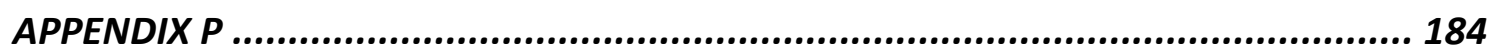

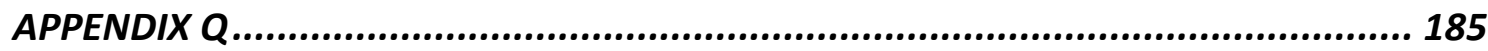

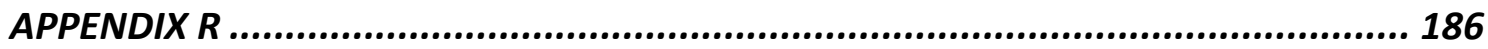

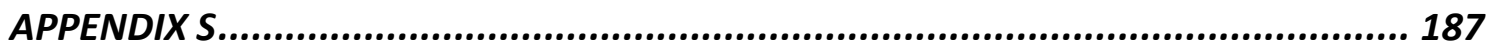




\section{LIST OF FIGURES}

Figure 2.1 The distribution of New Zealand wine regions by total hectares of production and percentage of total production in the New Zealand industry

Figure 3.1 The ongoing impacts of temperature increase to winegrape phenology and berry composition

Figure 3.2 Grapevine climate-maturity based on average growing temperatures in New Zealand

Figure 3.3 Global wine regions based on the growing season temperatures.......28

Figure 4.1 Phases and sub-phases of the adaptation process framework .49

Figure 4.2 Intersection of actors, context and wider system 50

Figure 4.3 Intersection of winegrowers, the organisation New Zealand Wine, and the wine industry system. 50

Figure 5.1 Regional distribution of survey responses. 63

Figure 6.1 Respondent beliefs about climate change as an issue. 69

Figure 6.2 Respondents' perceptions of climate change as an issue based on the case study regions

Figure 6.3 Mind map of different winegrower occupations 70

Figure 6.4 Mind map of themes coded for climate change perceptions .74

Figure 6.5 Respondent perceptions of local vulnerability to climate change by potential impacts to winegrape production

Figure 6.6 Respondents perceptions of the future outlook of the New Zealand wine industry

Figure 6.7 Respondent reported adaptation planning and implementation of strategies in the New Zealand wine industry.

Figure 6.8 Mind map of themes coded for adaptation to climate change

Figure 6.9 Respondent reported plans to change winegrape varietal for climate or market reasons 
Figure 6.10 Respondent reported management plans for climate change adaptation

Figure 6.11 Respondents reported management plans for climate change adaptation based on the three main wine producing regions of New Zealand........ 94

Figure 6.12 Respondent reported factors preventing adaptation planning ..........99

Figure 6.13 Respondent reported hurdles to adaptation implementation ......... 101

Figure 6.14 Mind map of themes coded for barriers to adaptation planning...... 102

Figure 6.15 Respondent reported scale of useful information........................... 104

Figure 6.16 Respondent reported usefulness of additional information for changing adaptation plans....................................................................... 106 


\section{LIST OF TABLES}

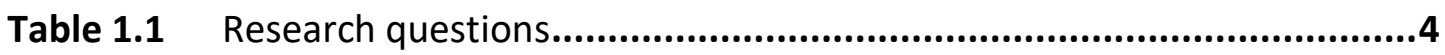

Table 1.2 Thesis structure outlining chapters and objectives ............................5

Table 2.1 New Zealand grape varieties produced by tonnes, $2013-2017$............9

Table 2.2 The top five grape varieties for the main producing wine regions with the percentage of total regional production per variety, $1980-2010$.....................10

Table 2.3 Distribution of production in New Zealand wine regions ....................12

Table 2.4 The soil and climate profile for the wine regions of New Zealand.........18

Table 3.1 Differences in wine characteristics based on climate zones ...............29

Table 3.2 Global wine adaptation types and strategies for climate change..........38

Table 4.1 Barriers to climate change adaptation in the phases of the adaptation processes framework............................................................................52

Table 6.1 Cross-tabulation of climate change belief and wine producers............71

Table 6.2 Chi-Square independence test for climate change belief and wine

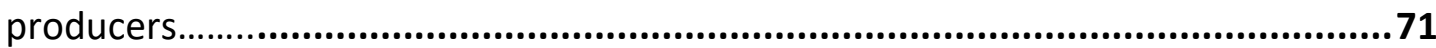

Table 6.3 Symmetric measures for climate change belief and wine producers ...72

Table 6.4 Respondent observed climate change impacts on wine production ... 80

Table 6.5 Chi-Square independence test for reported harvest quantity and wine

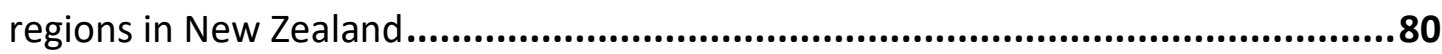

Table 6.6 Chi-Square independence test for reported grape disease and wine regions in New Zealand

Table 6.7 Chi-Square independence test for observed harvest quality and winegrowers' climate change beliefs

Table 6.8 Respondent observed climate change impacts on wine production based the five dominant wine varietals in New Zealand 
Table 6.9 Chi-Square independence test for reported grape disease and Pinot Gris 82

Table 6.10 Respondent reported plans for changing winegrape varieties for market or climate reasons compared to the dominant five wines cultivated in New Zealand 90

Table 6.11 Cross-tabulation of reported varietal change and Merlot cultivation .. 91

Table 6.12 Chi-Square independence test for reported varietal change and observed harvest quality 92

Table 6.13 Chi-Square independence test for reported varietal change and Syrah Cultivation

Table 6.14 Chi-Square independence test for observed grape disease and reported adaptation planning 95

Table 6.15 Respondent reported perceptions of the usefulness of climate information 105 


\section{LIST OF DEFINITIONS}

\section{Adaptive Capacity}

In agriculture, adaptive capacity refers to the ability to build resilience and often requires individual entrepreneurship, financial capital, and effective multi-level governance.

\section{Anthocyanins}

Phenolic-compounds that are natural pigments responsible for the red wine colour.

\section{Balanced}

Wine that has all the main components in equilibrium (tannins, acids, sweetness and alcohol) where no single component stands out.

Brix

Degrees Brix $\left({ }^{\circ} \mathrm{Bx}\right)$ is a measurement of the relative density of dissolved sucrose in unfermented winegrape juice, in grams per 100 millilitres.

\section{Cultivar}

Wines made from a single grape variety. Synonymous with varietal.

\section{Downy Mildew}

Fungal injection of leaves or winegrapes.

\section{Harvest}

Ripened grapes are picked.

Integrated Pest Management

Ecosystem based approach that implements multiple strategies to promote plant production while reducing chemical inputs.

\section{Isotherm}

Geographical temperature indicator that can be drawn on a map. The temperature could be an average for a particular month or in this case a growing season.

\section{Maladaptation}

A form of adaptation that increases vulnerability. Maladaptation occurs when an action is taken that is inappropriate, and results in more harm.

\section{'New World'}

Winegrowing that occurs outside of Europe/'Old World', often countries that were colonies.

\section{'Old World'}

Traditional winegrowing in Europe.

\section{Phenolic in Wine}

Chemical compounds that affect the taste, colour and mouthfeel of wine.

\section{Phenology}

Timing of events in grapevine development - budburst, flowering, verasion, and harvest. In the southern hemisphere grapevine phenological cycle starts in September/October and finished in March/April.

\section{Powdery Mildew}

Fungal injection of leaves or winegrapes. 


\section{Rootstock}

Grapevines that have been grafted onto roots of another winegrape species.

\section{Tannins}

A phenolic compound that adds the bitterness and the dry characteristics.

\section{Terroir}

Complex interaction between the physical, cultural and socioeconomic factors that are used to define wine styles and the type of wine from a particular place.

\section{Typicity}

The wine style that is associated with a particular region.

\section{Winegrape}

A grape specifically used for making wine - Vitis vinifera.

\section{Winegrower}

A person who cultivates grapes for winemaking.

\section{Veraison}

The change of colour of winegrapes indicating the onset of ripening.

\section{Varietal}

Wines made from a single grape variety. Synonymous with cultivar.

\section{Viticulture}

The science of winegrape cultivation.

\section{Viniculture}

The science of winemaking.

\section{Vintage}

The wine harvested and produced in a particular year and location.

\section{Volatiles}

Chemical compounds that constitute wine aroma. 


\section{LIST OF ABBREVIATIONS}

${ }^{\circ} \mathrm{C}$

AAO

BEDD

$\mathrm{CO}_{2}$

ENSO

FAO

GIS

GHGs

GNP

HI

IPCC

IPM

km

m

$\mathrm{mm}$

NIWA

PDO

WI
Degrees Celsius

Antarctic Oscillation

Biologically Effective Degree Days

Carbon Dioxide

El Niño - Southern Oscillation

Food Agricultural Organsiation of the United Nations

Geographical Information Systems

Greenhouse Gases

Gross National Product

Huglin Index

Intergovernmental Panel on Climate change

Integrated Pest Management

Kilometres

Metres

Millimetres

National Institute of Water and Atmospheric Research

Pacific Decadal Oscillation

Winkler Index 


\title{
CHAPTER 1: INTRODUCTION
}

\section{"VITA VINUM EST - WINE IS LIFE"}

\author{
- PETRONIUS
}

\subsection{Preamble}

Climate change is having adverse effects on agriculture, and hence threatening global food security. The increasing concentration of greenhouse gases (GHGs) is influenced by human activity starting from the industrial revolution. According to the Intergovernmental Panel on Climate Change (IPCC) "It is extremely likely that more than half of the observed increase in global average surface temperature from 1951 to 2010 was caused by the anthropogenic increase in GHG concentrations and other anthropogenic forcings together" (IPCC, 2014a, p. 48). In order to assess future impacts, the IPCC (2014) has modelled future global mean surface temperature change under different climate scenarios. Depending on the pathway, the increase in temperature by 2100 is likely to range between $1.5^{\circ} \mathrm{C}$ to $4.5^{\circ} \mathrm{C}$ (IPCC, 2014a).

The Food and Agricultural Organisation of the United Nations (FAO) states that climate change will severely affect global food production both directly or indirectly (FAO, 2015, 2017). Selected agricultural sectors are already experiencing impacts attributable to climate change, which will be exacerbated in the coming years. Examples of the direct impacts include greater frequency and intensity of extreme weather events, such as variability in precipitation leading to droughts and flooding (FAO, 2016). Furthermore, increased temperatures will impact water availability, and affect plant physiology and productivity (FAO, 2016). The indirect effects of temperature change can include increased in pressure from pests and diseases, and the migration of species not previously suited to the climate (FAO, 2017). Sea level rise and coastal flooding can further impact agricultural land and growing conditions with salt water intrusion degrading the fertility of the soil and contaminating the freshwater supply (FAO, 2016). Although exact future outcomes are difficult to predict, the IPCC reports that lowlatitude countries crop production will be negatively affected by climate change (Porter 
et al., 2014). Conversely, there will be more uncertainty in northern latitudes with possible positive or negative consequences for agriculture (Porter et al., 2014).

The future outcomes can be influenced through human intervention (FAO, 2016). The IPCC (2014a, p. 76) defines adaptation as "the process of adjustment to actual or expected climate and its effects in order to either lessen or avoid harm or exploit beneficial opportunities". Adaptation and mitigation are management strategies used to reduce the potential risks of climate change (IPCC, 2014a). The strategies are complementary and can result in the transformation of a system. Successful management is reliant on effective decision-making underpinned by the evaluation of risks and benefits of change (IPCC, 2014a). The research presented here will focus on adaptation strategies, planning and decision-making in the New Zealand wine industry. Mitigation usually occurs at a high level and often excludes the opinions of key industry stakeholders who are directly impacted by climate change. By focusing on adaptation, this research engages with winegrowers and uses a bottom up approach to understand decision-making for adaptation planning.

\subsection{Research Context}

The focus of this research is on winegrower perceptions of climate change and decisionmaking regarding adaptation planning in the context of the New Zealand wine industry. Wine production was selected for this research as it a primary industry within New Zealand that is vulnerable to direct and indirect effects of climate change. Furthermore, winegrapes are a useful indicator species for climate research as they are sensitive to climatic change and are geographically constrained by their optimal growing temperature range (Holland \& Smit, 2010a). Therefore, by assessing the wine industry's adaptive capacity, this research provides an insight into the effects climate change could have on other horticultural products, and the capacity growers have to respond to these impacts of such products.

This research assessed the wine industry's vulnerability to climate change and the perceptions of New Zealand winegrowers to determine the wine industry's adaptive capacity using the adaptation decision-making framework developed by Moser and 
Ekstrom (2010). This framework facilitated the researcher's to evaluation of whether winegrowers were engaged with adaptation planning and the barriers hindering the implementation of strategies. Shared learning between scientists and stakeholders is critical for successful adaptation planning as it allows the decision-makers to make more informed choices (Mastrandrea, Heller, Root, \& Schneider, 2010; Vermeulen et al., 2013). Effective adaptation planning needs to incorporate information about the climatic impacts to the industry as well as assessments of the industry's adaptive capacity (Vermeulen et al., 2013). Therefore, this research uses the principle of the coproduction of knowledge to ensure information is obtained from winegrowers, and their perceptions are included throughout the analysis.

\subsection{Research Aims and Questions}

This research aims to explore aspects of climate change decision-making in the wine industry by assessing the adaptive capacity of winegrowers. The focus of the study is on winegrowers' perceptions of climate change and adaptation planning in the New Zealand industry. Using a mixed methods research design, primary data was collected through a quantitative survey distributed to New Zealand wineries and qualitative interviews with winegrowers in Marlborough, Hawke's Bay and Central Otago.

While recent scholarship has explored the impacts climate change can have on wine production, the adaptation strategies available, and winegrower vulnerabilities throughout different wine regions across the world, a New Zealand perspective is currently absent in contemporary literature (Holland \& Smit, 2010a). New Zealand climate is distinctive with each region experiencing different climatic effects associated with climate change. Generalising climate impacts and other countries' perspectives can limit the industry's understanding, and adaptive capacity, which could lead to maladaptation. Without relevant research, New Zealand winegrowers face greater uncertainty, limiting their capacity to plan for adaptation. This research sought to address this gap by establishing a foundation of what winegrowers understand and experience to facilitate co-production of knowledge for climate change, adaptation and decision-making. The research questions in Table 1.1 are the key areas of interest for this thesis. 
Table 1.1. Research questions.

\begin{tabular}{|l|l|}
\hline \multicolumn{2}{|c|}{ Research Question } \\
\hline Question 1 & $\begin{array}{l}\text { How do winegrowers perceive climate change in the context of } \\
\text { the New Zealand wine industry? }\end{array}$ \\
\hline Question 2 & $\begin{array}{l}\text { How are winegrowers engaging in decision-making for climate } \\
\text { change adaptation? }\end{array}$ \\
\hline Question 3 & $\begin{array}{l}\text { What are the barriers to adaptation planning in the New } \\
\text { Zealand wine industry? }\end{array}$ \\
\hline
\end{tabular}

The research first looked at winegrowers' perceptions of climate change and how they interpret the impacts related to both viticulture and viniculture. By assessing winegrowers' knowledge of the climate change issue, the research determined what stage of the adaptation decision-making framework winegrowers were currently placed. Furthermore, the perceptions of winegrowers gave an insight into the climate variables that are causing sensitivities and exposure in the industry, which is critical for effective adaptation planning. The research then looked at adaptation planning, and what types of strategies were being implemented or developed. The research aimed to understand how winegrowers were employing adaptation to conceptualise the barriers hindering planning. Adaptation strategies being developed by winegrowers in one region may apply to others, supporting the notion of co-production of knowledge between winegrowers and the researcher. Additionally, barriers can prevent the development of adaptation planning and limit the capacity to implement strategies. This information about barriers can be applied to the adaptation decision-making framework to develop a better understanding of the New Zealand wine industry's adaptive capacity and vulnerabilities to climate change.

\subsection{THESIS PREVIEW}

The following section is an overview of the thesis structure. Table 1.2 outlines the content of the research and describes the primary objectives for each chapter. 
Table 1.2. Thesis structure outlining chapters and objectives.

\begin{tabular}{|c|c|}
\hline Chapter & Objective \\
\hline 1. Introduction & $\begin{array}{l}\text { Chapter } 1 \text { outlines the scope of the research and its aims. It } \\
\text { provides the context of the problem and establishes a starting } \\
\text { point for the reader. }\end{array}$ \\
\hline 2. Background & $\begin{array}{l}\text { Chapter } 2 \text { reviews the background of the New Zealand wine } \\
\text { industry. It discusses the profile of New Zealand wine including } \\
\text { the wine regions and the climate of New Zealand to establish } \\
\text { the context of the study. }\end{array}$ \\
\hline $\begin{array}{l}\text { 3. Literature } \\
\text { Review }\end{array}$ & $\begin{array}{l}\text { Chapter } 3 \text { discusses the literature of climate change on the } \\
\text { global wine industry. First, the science of climate change } \\
\text { impacts on wine production is discussed, followed by the } \\
\text { scholarship of adaptive capacity in the wine industry. The } \\
\text { chapter provides evidence that climate change affects wine } \\
\text { production while establishing the gap in New Zealand wine } \\
\text { research. }\end{array}$ \\
\hline $\begin{array}{l}\text { 4. Conceptual } \\
\text { Frameworks }\end{array}$ & $\begin{array}{l}\text { Chapter } 4 \text { provides the frameworks on which this thesis is } \\
\text { built. The adaptation decision-making framework is used to } \\
\text { establish clear stages of adaptation planning and how barriers } \\
\text { affect progress. Furthermore, the co-production of knowledge } \\
\text { is discussed as the foundation for the research and the } \\
\text { importance of incorporating winegrowers as active research } \\
\text { participants. }\end{array}$ \\
\hline 5. Methodology & $\begin{array}{l}\text { Chapter } 5 \text { outlines the mixed methodology used in the thesis. } \\
\text { The chapter describes the epistemological approach employed } \\
\text { for the research design and the researchers' positionality to } \\
\text { set the context of the study. The methods of a quantitative } \\
\text { survey and qualitative interviews are discussed, including } \\
\text { details of sample recruitment, participants and the method of } \\
\text { analysis. }\end{array}$ \\
\hline 6. Results & $\begin{array}{l}\text { Chapter } 6 \text { presents the results from both the survey and } \\
\text { interviews. The results are structured based on the research } \\
\text { questions. The chapter discusses the findings from the survey, } \\
\text { supplemented by a thematic analysis from the interviews. }\end{array}$ \\
\hline 7. Discussion & $\begin{array}{l}\text { Chapter } 7 \text { discusses the findings and interprets the results in } \\
\text { the context of the literature and previous research. It outlines } \\
\text { the implications of the findings and how this research } \\
\text { contributes to building adaptive capacity for the wine industry. }\end{array}$ \\
\hline 8. Conclusion & $\begin{array}{l}\text { Chapter } 8 \text { summarises the key findings of this thesis. It outlines } \\
\text { how the research could be improved, and areas for future } \\
\text { research are identified. The chapter gives an overview of the } \\
\text { research with final remarks addressed as an outlook for the } \\
\text { future. }\end{array}$ \\
\hline
\end{tabular}




\begin{tabular}{|l|l|}
\hline References & Reference list in APA 6th format. \\
\hline Appendix A & Wine styles produced in New Zealand \\
\hline Appendix B & Human ethics committee approval letter amendment \\
\hline Appendix C & Human ethics committee approval letter original \\
\hline Appendix D & Survey information sheet \\
\hline Appendix E & Interview information sheet \\
\hline Appendix F & Survey informed consent \\
\hline Appendix G & Interview informed consent \\
\hline Appendix H & Survey questions \\
\hline Appendix I & Survey recruitment email \\
\hline Appendix J & Interview question guide \\
\hline Appendix K & Interview recruitment email \\
\hline Appendix L & Statistical analysis of harvest quantity and wine regions \\
\hline Appendix M & Statistical analysis of grape disease and wine regions \\
\hline Appendix N & Statistical analysis of harvest quality and climate change belief \\
\hline Appendix O & Statistical analysis of grape disease and Pinot Gris \\
\hline Appendix $P$ & Statistical analysis of varietal change and Merlot cultivation \\
\hline Appendix Q & Statistical analysis of varietal change and harvest quality \\
\hline Appendix R & Statistical analysis of varietal change and Syrah cultivation \\
\hline Appendix S & Statistical analysis of grape disease and adaptation planning \\
\hline
\end{tabular}




\section{CHAPTER 2: BACKGROUND}

\section{"GOÛT DE TERROIR - TASTE OF THE SOIL"}

- FRENCH EXPRESSION

\subsection{INTRODUCTION}

New Zealand is internationally recognised for producing cool climate wines that are distinctive in flavour, quality and style (Moran, 2016). The geography of New Zealandincluding climate and soils - can contribute to the terroir of New Zealand wine style, and with climate changing, the regions will be affected independently of one another. This chapter outlines the New Zealand wine industry's profile to characterise the wine regions and to give context to the circumstances winegrowers are facing due to climate change. The chapter discusses the industry and the wines being produced, the geography of the wine regions, and the general climate of New Zealand. To supplement the New Zealand focus, the chapter will briefly comment on 'New World' and 'Old World' wine regulations and the implications for New Zealand wine. The objective of the background chapter is to explore the significance and characteristics of the New Zealand wine industry and why research needs to be conducted in the realm of climate change and wine.

\subsection{The NeW Zealand Wine Industry}

The New Zealand wine industry is young as production was not a commercially viable until the mid-1980s (New Zealand Wine, 2017e). In 2017, the wine industry was worth $\$ 1.66$ billion in export value, with wine being the fifth largest export product in New Zealand (New Zealand Winegrowers, 2017). Domestically, the wine industry contributed for $0.4 \%$ to the Gross National Product (GNP) of New Zealand in 2015 (Destremau, 2015). Wine is exported to over 90 countries, with the primary markets being the United States, the United Kingdom and Australia (New Zealand Winegrowers, 2017). There are 677 wineries throughout New Zealand, and 726 winegrowers (New Zealand Winegrowers, 2017). The industry employs over 10,000 workers, including those who whom work 
directly in wine production, and indirectly in the tourism sector (Gabzdylova, Raffensperger, \& Castka, 2009). Furthermore, the industry is planning to increase wine production to reach a target of \$2 billion in export value by 2020 (New Zealand Winegrowers, 2017). From a global perspective, New Zealand is the $18^{\text {th }}$ largest wine producer but only accounts for $0.6 \%$ of the global wine production (Coriolis, 2014). The New Zealand wine industry may be small on an international scale, but domestically it is a small, yet valuable primary industry contributing to the economy and providing various levels of employment.

The New Zealand industry favours cool climate wines with the principal winegrape varieties being Sauvignon Blanc; Pinot Noir; Chardonnay; Pinot Gris; and Merlot (New Zealand Winegrowers, 2017). Sauvignon Blanc is the primary winegrape, accounting for $75 \%$ of total grape varieties produced in 2017, as shown in Table 2.1. Pinot Noir is the primary red variety grown and is the second largest winegrape produced but only accounted for 7.5\% of total grape varieties produced in 2017 . 
Table 2.1. New Zealand grape varieties produced by tonnes, 2013 - 2017. Adapted from New Zealand Winegrowers (2017, p. 37).

\begin{tabular}{|c|c|c|c|c|c|}
\hline Grape Variety (Tonnes) & 2013 & 2014 & 2015 & 2016 & 2017 \\
\hline Sauvignon Blanc & 228,781 & 310,240 & 216,078 & 303,711 & 285,862 \\
\hline Pinot Noir & 31,775 & 36,499 & 25,763 & 35,661 & 28,760 \\
\hline Chardonnay & 27,184 & 28,985 & 27,015 & 29,162 & 26,843 \\
\hline Pinot Gris & 22,042 & 23,880 & 19,707 & 24,892 & 20,755 \\
\hline Merlot & 10,076 & 10,756 & 9,397 & 9,321 & 7,714 \\
\hline Riesling & 5,932 & 6,013 & 4,535 & 5,937 & 3,880 \\
\hline Syrah & 2,240 & 2,178 & 1,497 & 1,756 & 1,733 \\
\hline Gewürztraminer & 1,788 & 2,264 & 1,761 & 2,221 & 1,047 \\
\hline Cabernet Sauvignon & 1,465 & 1,742 & 1,376 & 1,537 & 974 \\
\hline Sauvignon Gris & - & - & - & 1,182 & 944 \\
\hline Other Whites & 1,052 & 1,646 & 1,294 & 727 & 824 \\
\hline Malbec & 825 & 1,135 & 586 & 483 & 697 \\
\hline Muscat Varieties & 634 & 455 & 301 & 329 & 450 \\
\hline Other Reds & 262 & 537 & 457 & 677 & 401 \\
\hline Cabernet Franc & 421 & 582 & 485 & 616 & 373 \\
\hline Viognier & 519 & 1,148 & 720 & 771 & 266 \\
\hline Grüner Veltliner & & 341 & 228 & 276 & 253 \\
\hline Semillon & 721 & 507 & 425 & 466 & 249 \\
\hline Arneis & 220 & 336 & 268 & 257 & 239 \\
\hline Pinotage & 400 & 425 & 494 & 374 & 145 \\
\hline
\end{tabular}

Sauvignon Blanc is internationally the most sought-after grape variety and a reputation has been built on 'Marlborough Sauvignon Blanc'. The wine style has been described as being unique and representative of the region, supporting the concept of terroir (Moran, 2006). Marlborough Sauvignon Blanc has a distinctive combination of ripe fruit and green flavour characteristics (Parr, Green, White, \& Sherlock, 2007), with some reporting the green characteristics intensity as green capsicum, with fresh-cut grassy notes (Green, Parr, Breitmeyer, Valentin, \& Sherlock, 2011; Parr, Sherlock, \& Green, 2007). New Zealand Wine (2017f) describes Sauvignon Blanc flavour characteristics as including red capsicum, gooseberry characters, tropical fruit overtones, fresh cut grass, tomato stalks, and grapefruit or lime. The flavour characteristics alter according to where the winegrape is cultivated (New Zealand Wine, 2017f). Although Sauvignon Blanc is the dominant wine variety, there has been a history of varietal change. The 
winegrape Müller Thurgau was the leading variety grown throughout New Zealand until the 2000s when Sauvignon Blanc and Chardonnay became more popular (Table 2.2). The shift to more classic winegrape varieties like Sauvignon Blanc and Chardonnay arose as they can be internationally marketed and hence more profitable for the industry.

Table 2.2. The top five grape varieties for the main producing wine regions with the percentage of total regional production per variety, 1980 - 2010. Adapted from Moran (2016, p. 52).

\begin{tabular}{|c|c|}
\hline Marlborough & Hawke's Bay \\
\hline \multicolumn{2}{|c|}{1980} \\
\hline Müller Thurgau (42) & Müller Thurgau (50) \\
\hline Cabernet Sauvignon (12) & Chenin Blanc (9) \\
\hline Gewürztraminer (11) & Palomino (8) \\
\hline Chardonnay (7) & Cabernet Sauvignon (6) \\
\hline Riesling (5) & Chasselas (5) \\
\hline \multicolumn{2}{|c|}{1990} \\
\hline Müller Thurgau (29) & Müller Thurgau (30) \\
\hline Chardonnay (18) & Chardonnay (12) \\
\hline Sauvignon Blanc (15) & Cabernet Sauvignon (12) \\
\hline Riesling (10) & Chenin Blanc (8) \\
\hline Cabernet Sauvignon (8) & Sauvignon Blanc (7) \\
\hline \multicolumn{2}{|c|}{2000} \\
\hline Sauvignon Blanc (47) & Chardonnay (28) \\
\hline Chardonnay (22) & Cabernet Sauvignon (17) \\
\hline Pinot Noir (13) & Merlot (16) \\
\hline Riesling (7) & Sauvignon Blanc (11) \\
\hline Semillon (3) & Müller Thurgau (6) \\
\hline \multicolumn{2}{|c|}{2010} \\
\hline Sauvignon Blanc (76) & Chardonnay (24) \\
\hline Pinot Noir (10) & Merlot (21) \\
\hline Chardonnay (6) & Sauvignon Blanc (18) \\
\hline Pinot Gris (4) & Cabernet Sauvignon (8) \\
\hline Riesling (2) & Pinot Gris (7) \\
\hline
\end{tabular}

\subsection{Geography of NeW Zealand Wine}

Winegrapes are cultivated throughout New Zealand but are mostly located along the east coast and the northern part of both the North and South Islands. There are 12 wine regions extending from $36^{\circ} \mathrm{S}$ to $46^{\circ} \mathrm{S}$, covering $1,600 \mathrm{~km}$ (New Zealand Wine, 2017b). Comparing the latitude zoning for New Zealand wine, the equivalent in Europe would be Jerez, Spain $\left(35.5^{\circ} \mathrm{N}\right.$ to $\left.36.5^{\circ} \mathrm{N}\right)$ to Bordeaux, France $\left(45^{\circ} \mathrm{N}\right.$ to $\left.46^{\circ} \mathrm{N}\right)$. Whereas, the 
United States zoning would be Paso Robles, California $\left(35.5^{\circ} \mathrm{N}\right.$ to $\left.36.5^{\circ} \mathrm{N}\right)$ to Willamette Valley, Oregon $45^{\circ} \mathrm{N}$ to $46^{\circ} \mathrm{N}$ ) (J. D. Anderson, Jones, Tait, Hall, \& Trought, 2012).

Marlborough is the largest wine region in New Zealand and accounts for $67.7 \%$ of total wine production, as shown in Figure 2.1. Hawke's Bay is the second largest and the oldest wine region with $12.6 \%$ of total wine production. Central Otago is the third largest wine-producing region, which only accounts for $5.1 \%$ of total New Zealand wine (New Zealand Winegrowers, 2017).

\section{NORTHERN WINE REGIONS} $67 \mathrm{HA}(0.2 \%)$

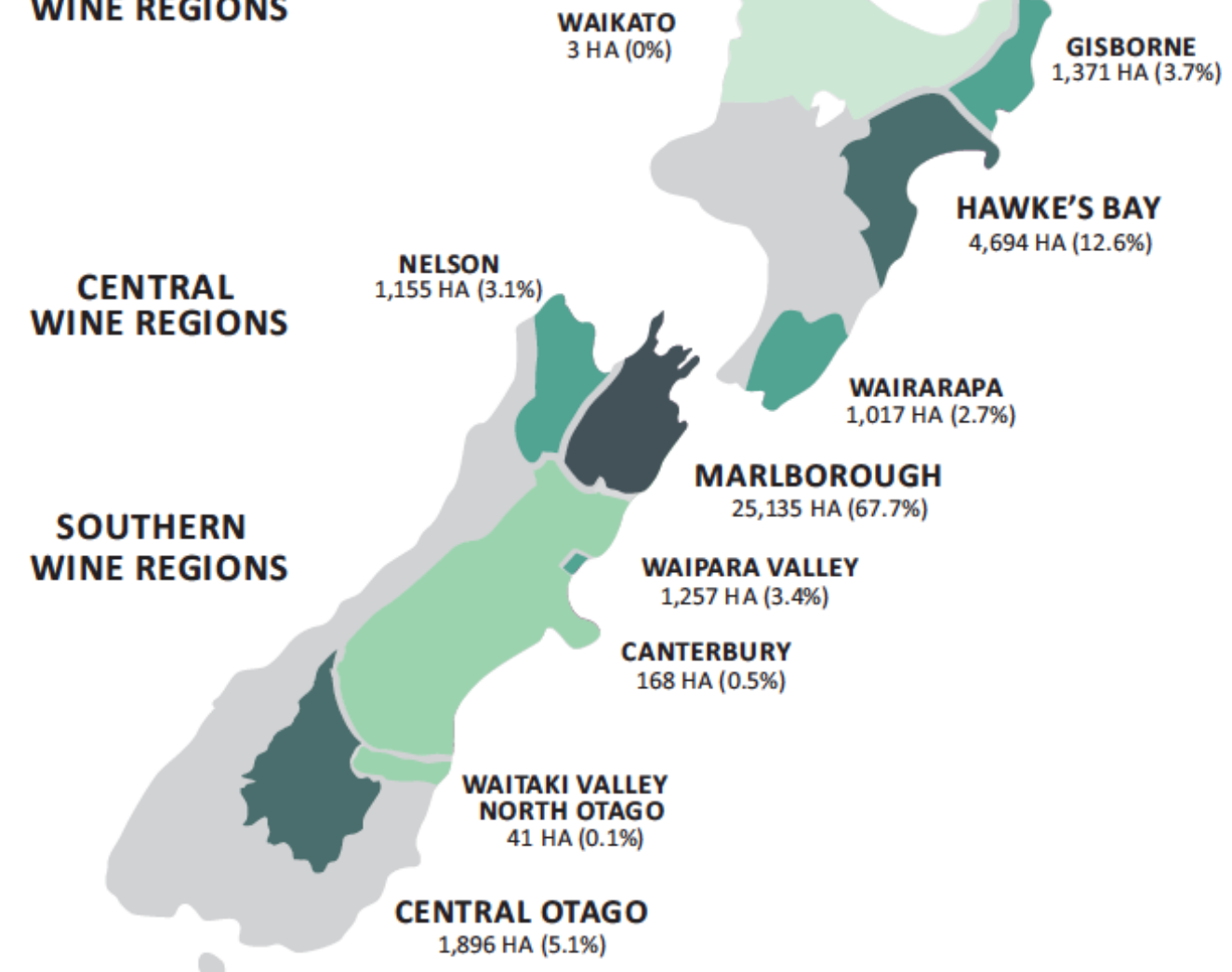

Fig. 2.1. The distribution of New Zealand wine regions by total hectares of production and percentage of total production in the New Zealand industry. Adapted from New Zealand Winegrowers (2017, p. 33). 
The regions overlap in the varieties they produce, but the specialisation of some winegrapes is apparent across the industry, as shown in Table 2.3. Although Table 2.3 gives a regional analysis of the main winegrapes produced, some varietal data is excluded as it could not be regionally analysed. For a comprehensive list of all wine varieties produced per hectare, see Appendix A.

Table 2.3. Distribution of production in New Zealand wine regions. Data adapted from New Zealand Winegrowers (2017); New Zealand Wine (2017h); (New Zealand Wine, 2017b).

\begin{tabular}{|c|c|c|}
\hline Region & White Winegrape Varieties & Red Winegrape Varieties \\
\hline Northland & No Data & No Data \\
\hline Auckland & $\begin{array}{l}\text { Chardonnay }(28.3 \%) \\
\text { Pinot Gris }(14.6 \%)\end{array}$ & $\begin{array}{l}\text { Merlot (17.4\%) } \\
\text { Cabernet Sauvignon (10.5\%) } \\
\text { Cabernet Franc (8.5\%) } \\
\text { Syrah }(20.7 \%)\end{array}$ \\
\hline $\begin{array}{l}\text { Waikato } \\
\text { Bay of Plenty }\end{array}$ & $\begin{array}{l}\text { Chardonnay (9.1\%) } \\
\text { Pinot Gris }(90.9 \%)\end{array}$ & \\
\hline Gisborne & $\begin{array}{l}\text { Chardonnay (54.2\%) } \\
\text { Pinot Gris (28.0\%) } \\
\text { Gewürztraminer (3.6\%) } \\
\text { Viognier }(2.4 \%) \\
\text { Sauvignon Blanc }(5.8 \%)\end{array}$ & Merlot (6.0\%) \\
\hline Hawke's Bay & $\begin{array}{l}\text { Chardonnay }(23.3 \%) \\
\text { Sauvignon Blanc }(21.4 \%) \\
\text { Pinot Gris }(9.8 \%)\end{array}$ & $\begin{array}{l}\text { Merlot (23.3\%) } \\
\text { Cabernet Sauvignon (5.0\%) } \\
\text { Malbec (2.1\%) } \\
\text { Cabernet Franc (1.6\%) } \\
\text { Syrah (7.3\%) } \\
\text { Pinot Noir }(5.9 \%)\end{array}$ \\
\hline Wairarapa & $\begin{array}{l}\text { Sauvignon Blanc (35.2\%) } \\
\text { Pinot Gris (6.3\%) } \\
\text { Riesling }(3.3 \%) \\
\text { Gewürztraminer }(0.3 \%) \\
\text { Viognier }(0.3 \%)\end{array}$ & $\begin{array}{l}\text { Pinot Noir (53.5\%) } \\
\text { Syrah (1.1\%) }\end{array}$ \\
\hline Nelson & $\begin{array}{l}\text { Sauvignon Blanc (52.1\%) } \\
\text { Pinot Gris (13.1\%) } \\
\text { Riesling (3.7\%) } \\
\text { Gewürztraminer (2.2\%) } \\
\text { Chardonnay }(8.8 \%)\end{array}$ & Pinot Noir (20.2\%) \\
\hline Marlborough & $\begin{array}{l}\text { Sauvignon Blanc }(79.0 \%) \\
\text { Pinot Gris }(4.2 \%) \\
\text { Gewürztraminer }(0.4 \%) \\
\text { Riesling }(1.3 \%) \\
\text { Viognier }(0.1 \%) \\
\text { Chardonnay }(4.3 \%)\end{array}$ & Pinot Noir (10.7\%) \\
\hline
\end{tabular}




\begin{tabular}{|l|l|l|}
\hline $\begin{array}{l}\text { Waipara Valley } \\
\text { Canterbury }\end{array}$ & $\begin{array}{l}\text { Riesling (20.9\%) } \\
\text { Pinot Gris (14.4\%) } \\
\text { Sauvignon Blanc (29.0\%) } \\
\text { Chardonnay (6.0\%) }\end{array}$ & Pinot Noir (29.7\%) \\
\hline $\begin{array}{l}\text { Waitaki Valley } \\
\text { North Otago }\end{array}$ & No Data & No Data \\
\hline Central Otago & $\begin{array}{l}\text { Pinot Gris (11.1\%) } \\
\text { Riesling (4.1\%) } \\
\text { Gewürztraminer (0.7\%) } \\
\text { Chardonnay (2.9\%) } \\
\text { Sauvignon Blanc (2.2\%) }\end{array}$ & Pinot Noir (79.1\%) \\
\hline
\end{tabular}

The northern wine regions of New Zealand produce more varieties of red wine than the south, with Chardonnay being the predominant white wine variety cultivated. The southern wine regions mostly produce a range of white wine varieties, with Pinot Noir as the only red wine produced. While, Sauvignon Blanc accounts for $75 \%$ of total wine produced in New Zealand (Table 2.1), it's production is limited to central New Zealand.

Regional specialisation is apparent in the different wine styles being produced. Place of origin has become an important factor for the industry of wine. The place name becomes an identity for a bottle of wine, which can impact the reputation and the market of the wine style. French 'Champagne', for example is a Geographical Indicator that is designed to protect the producers and their reputations, while also reassuring consumers that the product is authentic (Jay \& Taylor, 2013). Geographical Indicators are regulated labels of origin throughout Europe designed to safeguard the intellectual property of a region. In November 2016, New Zealand parliament passed the Geographical Indications (Wine and Spirits) Registration Amendment Act. The government describes Geographical Indicators as "a sign used on wines and spirits from a specific geographical location which possess a quality, reputation or other characteristic linked to that location" (Ministry of Business Innovation and Employment, 2018a). There have been 18 applications registered, and at July 2018, Auckland, Kumeu, Nelson, Waitaki Valley North Otago/Waitaki Valley; and Central Otago have been accepted. The following regions are under examination to determine whether they possess a quality or reputation based on the location: Central Hawke's Bay; Gladstone; North Canterbury; and Waipara Valley/Waipara. The following locations have registered but have yet to be processed: Matakana; Waiheke Island; Gisborne; Hawke's Bay; 
Wairarapa; Martinborough; Marlborough; and Canterbury (Ministry of Business Innovation and Employment, 2018b).

\subsection{Climate Profile of New Zealand}

New Zealand climate is strongly moderated by the ocean. The maritime climate generally results in cooler summers and milder winters. Approximately $95 \%$ of vineyards are planted within $50 \mathrm{~km}$ of the coastline, with the exclusion of Central Otago (J. D. Anderson et al., 2012). With summer temperatures being restricted, the ripening period for the winegrapes occurs when the temperatures are generally cooling in later summer to early autumn, which produces the high-quality wine (Sluys, 2006). The wine regions generally have low annual rainfall due to the rain shadows to the east of New Zealand (J. D. Anderson et al., 2012). Each wine region has different growing conditions that influence the quality of wine produced (Table 2.4). 
Table 2.4. The soil and climate profile for the wine regions of New Zealand. Adapted from Jackson and Schuster (2001, p. 42).

\begin{tabular}{|c|c|c|c|c|}
\hline Region & Soil Type and Position & $\begin{array}{c}\text { Annual } \\
\text { Rainfall } \\
\text { (mm) }\end{array}$ & $\begin{array}{l}\text { Heat Units } \\
\text { in growing } \\
\text { season } \\
\left({ }^{\circ} \mathrm{C}\right)\end{array}$ & $\begin{array}{l}\text { Latitude } \\
\text { Temperature } \\
\text { Index }\end{array}$ \\
\hline Northland & $\begin{array}{l}\text { Shallow clay soils over } \\
\text { sandy-clay subsoils. Flats } \\
\text { and mild slopes. }\end{array}$ & 1600 & $1300-1400$ & 450 \\
\hline Auckland & $\begin{array}{l}\text { Shallow clay soils over } \\
\text { hard silty-clay subsoils. } \\
\text { Mainly flats. }\end{array}$ & 1500 & $1300-1350$ & 440 \\
\hline $\begin{array}{l}\text { Waikato } \\
\text { Bay of Plenty }\end{array}$ & $\begin{array}{l}\text { Heavy loams over clay } \\
\text { subsoils. Flats and mild } \\
\text { slopes. }\end{array}$ & $\begin{array}{l}1100- \\
1200\end{array}$ & $1250-1300$ & 414 \\
\hline Gisborne & $\begin{array}{l}\text { Fertile, alluvial loams over } \\
\text { sandy or volcanic subsoils. } \\
\text { Flats. }\end{array}$ & $\begin{array}{l}1000- \\
1050\end{array}$ & $1250-1300$ & 394 \\
\hline Hawke's Bay & $\begin{array}{l}\text { Clay loams of medium to } \\
\text { high fertility over gravelly } \\
\text { or volcanic subsoils. Flats. }\end{array}$ & $750-800$ & $1200-1250$ & 384 \\
\hline Wairarapa & $\begin{array}{l}\text { Deep stony and silt loams } \\
\text { over gravel. }\end{array}$ & 1050 & $1080-1150$ & 332 \\
\hline Nelson & $\begin{array}{l}\text { Clay loams over hard clay } \\
\text { subsoils. Slopes. }\end{array}$ & $\begin{array}{l}1000- \\
1250\end{array}$ & $1050-1100$ & 320 \\
\hline Marlborough & $\begin{array}{l}\text { Silty-alluvial loams over } \\
\text { gravelly subsoils. In parts } \\
\text { compacted silt of clay } \\
\text { pans of various thickness } \\
\text { and depth are found. } \\
\text { Flats. }\end{array}$ & $650-750$ & $1150-1250$ & 327 \\
\hline $\begin{array}{l}\text { Waipara } \\
\text { Valley } \\
\text { Canterbury }\end{array}$ & $\begin{array}{l}\text { Alluvial silt loams over } \\
\text { gravel subsoils in the } \\
\text { central parts. Chalky loam } \\
\text { soils often rich in } \\
\text { limestone in the northern } \\
\text { part. Gentle slopes. }\end{array}$ & $600-750$ & $900-1100$ & 277 \\
\hline $\begin{array}{l}\text { Waitaki } \\
\text { Valley } \\
\text { North Otago }\end{array}$ & No Data & No Data & No Data & No Data \\
\hline $\begin{array}{l}\text { Central } \\
\text { Otago }\end{array}$ & $\begin{array}{l}\text { Silt loams with mica and } \\
\text { schists. Moderate to steep } \\
\text { slopes. }\end{array}$ & $400-450$ & $850-1000$ & 260 \\
\hline
\end{tabular}


Furthermore, atmospheric and oceanic mechanisms influence climate variability. The effects of the El Niño-Southern Oscillation (ENSO) can impact growing conditions on a year-to-year basis. Often, El Niño summers result in stronger and more frequent winds from the west in New Zealand, resulting in more rain along the west coast and droughts in the east. In the winter, the winds become more southerly, bringing colder conditions (Gordon, 1986). La Niña years generally have warmer temperatures across the country. In the South Island, there is reduced rainfall, while in the North Island conditions tend to be moister, often with increased rainfall (Gordon, 1986). The Antarctic Oscillation (AAO) influences seasonal climate variability as it is a measure of changes in windiness and storm activity in mid to high latitudes of the Southern Hemisphere (Jones, Reid, \& Vilks, 2012). During the positive phase of AAO, the mid-latitude westerlies are contracted poleward which results in warming over New Zealand, with a decrease in precipitation (Gillett, Thompson, Kell, \& Jones, 2006; Hendon, Thompson, \& Wheeler, 2007). During the negative phase of AAO, there is a stronger mid-latitude position that increases storm activity in the south (Jones et al., 2012). The North Island is reported to be more influenced by the ENSO, whereas the South Island is more affected by AAO (Jones et al., 2012).

\subsection{NeW World Wine Production}

New Zealand is referred to as a 'New World' wine producer. 'New World' regions have a shorter history and are less regulated than their more traditional counterparts - 'Old World' regions (Morgan, 2016). The 'Old World' wine regions are predominantly European and mainly include Austria, Bulgaria, Spain, France, Greece, Hungary, Italy, Portugal, Romania and Switzerland. The 'New World' wine regions consist of Argentina, Chile, Brazil, Uruguay, Peru, Mexico, United States of America, Canada, Australia, New Zealand and South Africa (Aleixandre, Aleixandre-Tudó, Bolaños-Pizarro, \& AleixandreBenavent, 2016).

Winemaking in the 'New World' was restricted until the 1990s due to limited markets, poor technology and difficulties in transportation (Campbell \& Guibert, 2007). However, with globalisation and access to better technology, the 'New World' wine regions increased their production from $3 \%$ of global wine exports in the 1980 s to more than 
$25 \%$ of the current industry (Plant and Food Research, 2013). There are notable differences between the 'Old World' and 'New World' wines, with regard to terroir, varieties, technology and policies (Aleixandre et al., 2016). 'Old World' winemakers have a long history of producing wine and are under strict regulations through a legal framework (Appellation d'origine côntrollée) to maintain the original wine styles through traditional practices (Campbell \& Guibert, 2007). The 'Old World' appellations have resulted in strict viticultural zoning and policies that limit additional inputs into the system, which restricts adaptation implementation.

The difference between the 'New' and 'Old' World wines has created controversy and debate around "traditional versus industrial production and protectionism versus experimentation" (M. A. White, Whalen, \& Jones, 2009, p. 83). Winegrowers in the 'Old World' rely on their long-standing reputation for producing high-quality wines to ascertain that their viticultural practices are effective (Moran, 2016). In the 'New World', the industry is comparably new and lacking the long-term cultural associations with wine. This allows the industry to be more flexible in their winemaking practices and deviate from traditional techniques (Moran, 2016). New Zealand has minimal restrictions, enabling winegrowers to experiment in both viticultural and viniculture techniques while producing wine styles that compete with traditional wines (Aleixandre et al., 2016; Moran, 2016).

\subsection{SUMMARY}

This chapter discussed the New Zealand wine industry and provides the background for the research. The purpose of the chapter was to characterise the wine industry to provide context for consideration of the climate change issue. There are 12 wine regions across New Zealand, with Marlborough, Hawke's Bay and Central Otago being the primary producers. Sauvignon Blanc is the dominant winegrape grown, especially in Marlborough, followed by Pinot Noir. The New Zealand wine industry is only a small part of the international market. However, it is a valuable commodity for the New Zealand economy. 


\section{CHAPTER 3: LITERATURE REVIEW}

\section{"IN VINO VERITAS - IN WINE THERE IS TRUTH" \\ -PLINY THE ELDER}

\subsection{INTRODUCTION}

The study of climate change impacts on viticulture is an emerging discourse that has seen a steady increase in literature since the early 2000s, with the number of publications doubling every five years (Marx, Haunschild, \& Bornmann, 2017). This chapter reviews the scientific literature on climate change, viticulture and viniculture. Variations of keywords - including 'wine', 'climate change', 'viticulture', and 'adaptation' - were used in a selection of search engines and databases to filter peer-reviewed literature. Literature from websites, reports and books were used as supplementary material to elaborate on the information. Initially, the impact of climate change on the wine industry will be discussed to provide the context of how climate change can impact wine production. Next, the chapter will review the literature on adaptation. This focuses on the types of adaptation available and the adaptive capacity of the wine industry. Work on winegrower perceptions and attitudes toward adaptation is analysed to provide support for the study's focus. The chapter concludes by highlighting the gap in New Zealand wine research to provide the context for this study.

\subsection{Climate Change and the Global Wine Industry}

Wine is one of the oldest agricultural products in the world, dating back 8,000 years (Dougherty, 2012; Schultz \& Jones, 2010). The history and culture of wine has changed over time with winemaking closely associated to the climates of premium wine regions (Jones et al., 2012). The history of European grape growing has been documented with approximately 500 years of data collected. These accounts indicate that wine regions developed when the climate was most conducive to growing grapes, and that the regions would shift with changes in climate (Chuine, Yiou, Seguin, Daux, \& Laudurie, 2004; Dougherty, 2012; Jones \& Alves, 2012; Mira de Orduña, 2010; Schultz \& Jones, 
2010). The effects of climate change on wine production are noted throughout the literature, and three central themes of research are apparent. Therefore, this section reviews the scholarship of phenology and yield; wine quality and terroir.

\subsubsection{Impact of Climate Change on Phenology and Yield}

Winegrapes have a distinct annual cycle of growth and reproduction known as phenology. For grapevines, the process starts with budburst, followed by flowering, veraison, (the stage of berry growth, colouring and maturation), and harvest. Postharvest, the grapevine begins leaf fall and enters winter dormancy (Amerine \& Winkler, 1944; Ashenfelter \& Storchmann, 2016a; Jones et al., 2012; Winkler, Cook, Kliewer, \& Lider, 1974). Temperature drives phenology, and an increase can cause grapes to ripen faster (van Leeuwen \& Darriet, 2016). When temperatures exceed the plant's optimum level, the grapevines produce a lower fruit yield, and there is a decrease in both berry fertility and size (Kliewer, 1977). Temperature drives phenology, and without the winter chill the vines skip dormancy and are in a continuous cycle of production, which can be seen in the tropics (Possingham, 2004). If a grapevine does not enter a dormant stage, the overall productivity of the vine is affected and has shown to produce low quality fruit (Gladstones, 1992; Possingham, 2004). Warmer winters can make budburst will be more irregular and the following season's yields could be affected (Keller, 2010). Furthermore, an increase in temperature can lead to an advance in the phenological cycle, resulting in an earlier harvest (Figure 3.1).

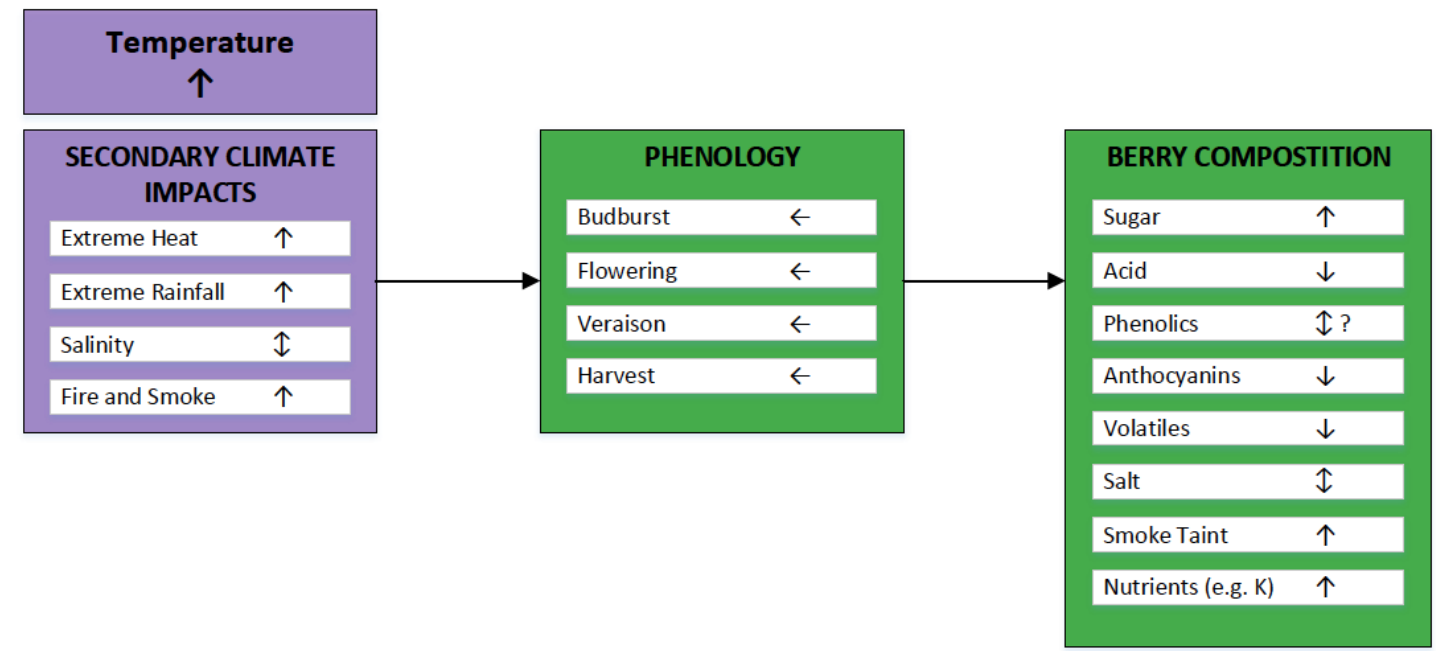

Fig. 3.1. The ongoing impacts of temperature increase to winegrape phenology and berry composition. Adapted from Webb, Clingeleffer, and Tyerman (2011, p. 466). 
As shown in Figure 3.1. when grapevine phenology advances, the overall development of the berry is altered. This can change the style of wine produced and influence the consistency between vintages (Keller, 2010). The changes in berry composition are predominantly negative as the wine can have a different typicity. An increase in sugar leads to a higher alcohol concentration in some wines creating an unbalanced product (Duchêne \& Schneider, 2005; Godden \& Gishen, 2005). Conversely, a decline in anthocyanins and phenolics restricts the colour development of the berry, which is essential for producing high-quality wine (Barnuud, Zerihun, Mpelasoka, Gibberd, \& Bates, 2014; Bergvist, Dokoozlian, \& Ebisuda, 2001; Haselgrove et al., 2000; Spayd, Tarara, Mee, \& Ferguson, 2002). Furthermore, the rise in temperature can also decrease berry volatiles. Volatiles control the aroma compounds of the winegrape influencing its flavour profile (Bureau, Razungles, \& Baumes, 2000). Smoke taint is another issue that is already apparent in Australia. Extreme heat has caused an increase in wildfires, and the smoke exposure taints the flavours and aroma of the wine (Kennison, Gibberd, Pollnitz, \& Wilkinson, 2008). The increase in heat has additional effects to water availability and plant transpiration rates (McCarthy, Jones, \& Due, 1992; Schultz \& Lebon, 2005; Schultz \& Stoll, 2010). Extreme heat results in berry shrivel, leaf drop, sunburn and can stall plant development (Webb et al., 2011).

As phenological stages are affected by the geography of the region, the research within the scholarship of climate, phenology, and yield should be analysed at the regional scale (K. Anderson, Findlay, Fuentes, \& Tyerman, 2008; Gladstones, 2004; Holland \& Smit, 2010a). There has been a recent trend of harvest dates occurring earlier throughout Europe. Duchêne and Schneider (2005) found that harvest dates in Alsace, France have advanced by two weeks since the 1980s. Similarly, Jones and Davis (2000) have found that harvest was 13 days earlier in 1997 than in 1952, in Bordeaux. Another region, Châteauneuf-du-Pape have observed harvests advancing by approximately four weeks (van Leeuwen \& Darriet, 2016). In Italy, Tomasi and colleagues (2011) followed the cycle of phenology from 1964 to 2009. Their research found a 13 to 19-day trend of earlier stages following budburst. It was argued that the shift average was eight days per $1^{\circ} \mathrm{C}$ of warming (Tomasi, Jones, Giust, Lovat, \& Gaiotti, 2011). 
Another Italian study focused on yield variability, and climate showed that higher temperatures have more of an impact on season duration (Bindi, Fibbi, Gozzini, Orlandini, \& Miglietta, 1996). Bindi and colleagues (1996) found that an increase of carbon dioxide $\left(\mathrm{CO}_{2}\right)$ can lead to an increase in the annual yield variability. A rise in $\mathrm{CO}_{2}$ is thought to increase light-saturation photosynthesis (Schultz, 2000). In some cases, the increase in photosynthetic material comes in the form of sugars rather than starches, changing the balance of the grape (Tate, 2001). Furthermore, the quality and reliability of the winegrape yield cannot be guaranteed and can be a high risk for winegrowers (Bindi et al., 1996; Holland \& Smit, 2010a).

Harvest advancement has also been observed in California, between 1951 and 1997. The growing season was found to be advancing by 18 and 24 days (Nemani et al., 2001), which is earlier than Europe records. Other 'New World' countries are limited in reproducing similar findings due to inadequate historical data. However, climate modelling has been used predict how increased temperatures will change phenology. Climate modelling of Australian winegrowing regions show that although outcomes between regions are significantly different, overall the date of budburst and harvest for Chardonnay and Cabernet Sauvignon in several regions will advance (Webb, Whetton, \& Barlow, 2007). An example of different outcomes in models can be seen with the Okanagan Valley in Canada. For the Merlot winegrape, potential warming is expected to have a positive effect as it will lead to higher yields; whereas the valley will be too hot for the Chardonnay grapevine to produce fruit (Rayne, Forest, \& Friesen, 2009). As temperature is the main driver of phenological events, analysing harvest dates is useful in indicating what to expect in future years. The research shows that over the last 30 to 50 years, grapevine phenology has a three to six-day response to $1^{\circ} \mathrm{C}$ warming (Jones, 2007b).

\subsubsection{Climate Change ImPacts on Wine Quality}

Achieving high-quality wine requires environmental conditions suited to the optimal ripening of the winegrapes, and human aptitude in vineyard management and winemaking (Cahill, Lobell, Field, Bonfils, \& Hayhoe, 2007). Winegrapes have an optimal range of growing temperatures conducive to producing high-premium quality berries (Figure 3.2). 


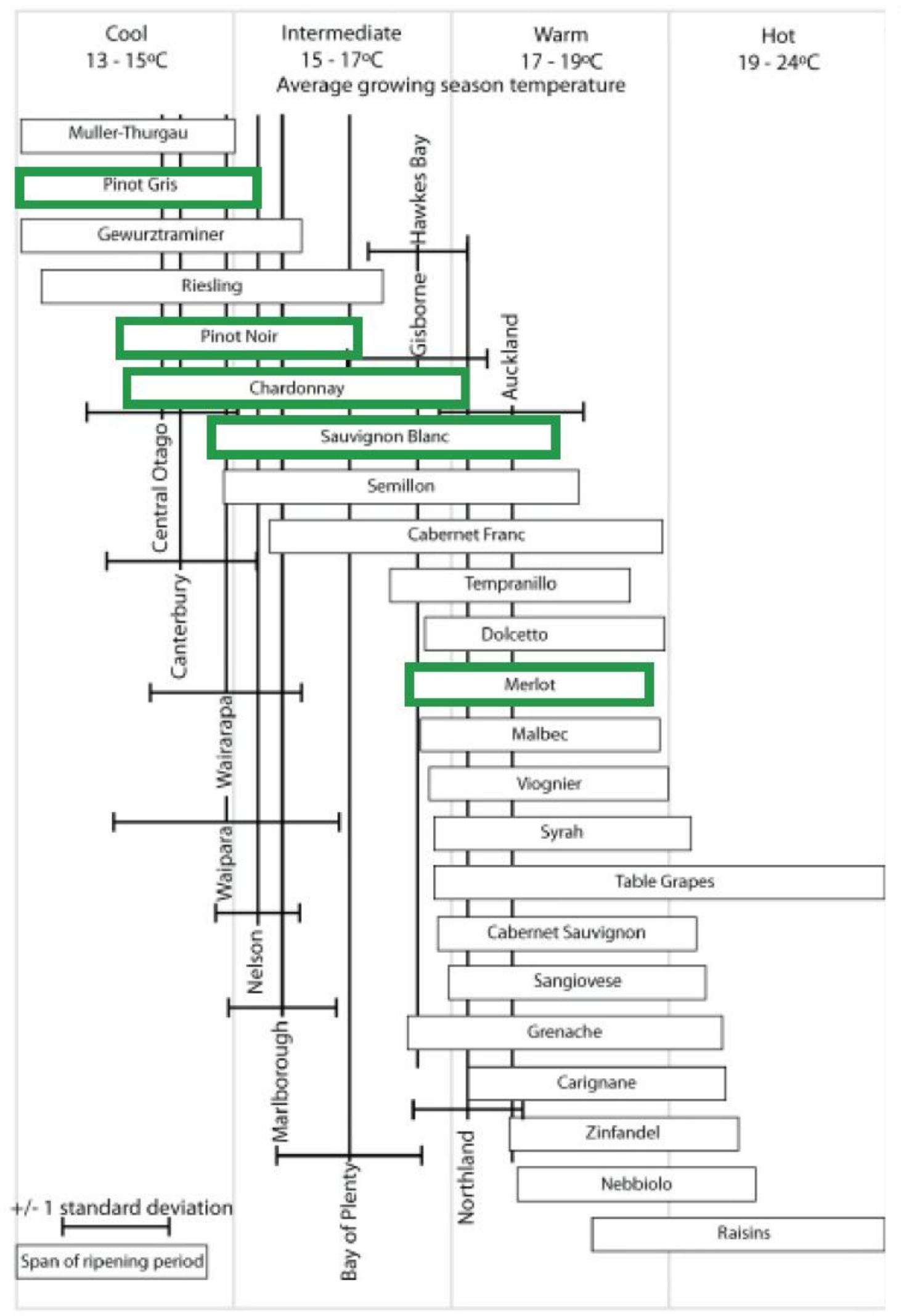

Fig. 3.2. Grapevine climate-maturity based on average growing temperatures in New Zealand. The top five winegrapes grown in New Zealand are highlighted to provide context. Adapted from Imre and Mauk (2009, p. 151), based on previous work from Jones (2006a). 
High-quality wine production is limited to $13-21^{\circ} \mathrm{C}$ as most of the premium cultivars grow in this range (Jones, 2006a). Some of the winegrapes produced outside these parameters are high yielding but are used as bulk wines for the lower end markets as the wine styles do not have the typicity or quality as they would when grown in their ideal climate zone (Jones, 2006a; Jones et al., 2012). Winegrapes produced in temperatures below $13^{\circ} \mathrm{C}$ are usually limited to hybrids or very early ripening cultivars that have a restricted commercial appeal. By contrast, winegrapes grown above $21^{\circ} \mathrm{C}$ are usually fortified wines, table grapes and raisins (Jones et al., 2012).

Quality wines are determined by the chemical composition of the winegrape. The chemistry gives the flavours, styles and characteristics to wine that can make the difference between a good and a poor vintage (Tate, 2001). The temperature at ripening is proven to influence colour production, flavour and aroma profiles, tannin type and levels, and the sugar to acid ratio (Coombe \& Iland, 2004). Cooler than normal temperatures lead to the incomplete ripening of the winegrapes as they have a high acidity, low sugar, and unripe flavours; whereas warmer than normal temperatures can produce winegrapes with low acidity, high sugar and high alcohol content, resulting in 'cooked' flavours (Santisi, 2011). The advancement of veraison has been linked to the elevated sugars and lower acidic concentrations, forming a better quality wine (Jones \& Davis, 2000).

Keller (2010) argues that higher temperatures will make it more expensive for winemakers to compensate for the chemical alterations. Low acid grape juice needs tartaric acid added in processing to enhance microbial stability and mouthfeel, whereas white wines that suit high acidity (like Riesling) do not undergo malolactic fermentation, and can suffer from too low concentrations of malate, which can create tartness (Keller, 2010). The literature suggests the titratable acids will decline and under the highest climate scenario, the concentrations will be below the threshold for well-balanced wines (Barnuud et al., 2014; Conde et al., 2007). Furthermore, red wine quality is expected to decline as higher daytime temperatures affect the accumulation of anthocyanin and reduce the colouring potential (Keller, 2010). The modelled projections of anthocyanin concentrations in Australia show a decline below the optimum level for both Cabernet Sauvignon and Shiraz, which will affect the overall wine style (Barnuud et al., 2014). 
Conversely, warmer growing seasons can be linked to higher amino acids (Pereira et al., 2006), which cause a decline in the vitamins necessary for natural fermentation (Hagen, Keller, \& Edwards, 2008; Keller, 2010). Adding acids and changing the natural composition in wine is considered less satisfactory in winemaking (Gladstones, 1992). Nevertheless, under future climate scenarios, chemical manipulation may be the only option to create well-balanced wines.

There has been a trend towards making wine with higher alcohol concentrations (Webb, 2006). It has become standard to harvest winegrapes with a potential alcohol level above $14 \%$ by volume (van Leeuwen \& Darriet, 2016). Although some may view higher alcohol concentrations as a good thing, generally wine becomes less food friendly and cannot age as well as lower alcohol wines (Jones \& Alves, 2012). Whist this change can be partially attributed to wine critics' preference for bigger, bolder wines, the relevant research suggests climate variability is responsible for approximately $50 \%$ of the reported trend (Jones, 2007a). Sugar content- measured in Brix - can determine the potential alcohol content of the wine as sugar converts to alcohol. An increase in the sugar content means an increase in alcohol concentrations, which can change the balance and value of the wine (Ashenfelter \& Storchmann, 2016b). In California, between 1980 and 2005, the Brix levels increased by $0.23 \%$ per year for premium red and white varieties (Alston, Fuller, Lapsley, \& Soleas, 2011). While the reported average alcohol content between 1971 and 2001 has increased from $12.5 \%$ to $14.8 \%$ by volume (Vierra, 2004). In Alsace, France, Reisling alcohol concentrations have increased by an average of $2.5 \%$ by volume, which is strongly correlated with warmer ripening periods (Duchêne \& Schneider, 2005). In Australia, the alcohol content in red wines increased from $12.3 \%$ to $13.9 \%$ and for white wines from $12.2 \%$ to $13.2 \%$ between 1984 and 2004 (Godden \& Gishen, 2005). The changes in sugar content can be attributed to winegrowers leaving fruit hanging on the vines longer due to frost occurring later in the season (Jones \& Alves, 2012; Schultz \& Jones, 2010).

Wood type for barrel making is another variable affecting wine quality. Traditionally, oak is the wood used in viniculture for storage. The main role for oak barrels is to influence aromas in wines during the fermentation and aging processes. Aside from storage, oak products like powders and chips can also be added to manipulate the flavour profile 
(Mira de Orduña, 2010). Climate change can effect oak production globally as additional atmospheric $\mathrm{CO}_{2}$ can impact oak development and quality (Mozell \& Thach, 2014). Tate (2001) analysed oak types for wine barrels and found that $\mathrm{CO}_{2}$ increased the rate of growth of oak, resulting in the wood having expanded passages susceptible to damage and failure. Furthermore, an increase in $\mathrm{CO}_{2}$ causes a decline in tannins present in the wood making a lower quality barrel. A reduction in oak tannins also affects wine quality as the chemicals will not be released into the wine, restricting flavour development (Mozell \& Thach, 2014; Tate, 2001).

The quality of wine is difficult to define within the literature as it is subjective (Holland \& Smit, 2010a) and there is no standard measure of winegrape or wine quality (Coombe \& lland, 2004). High-quality wines are associated with "low frost damage in mild winters, early and even budburst, flowering and development during warm springs, and optimal maturation with low summer temperature variability"(Holland \& Smit, 2010a, p. 126). One existing research approach quantifies wine quality through seasonal vintage ratings by global wine publications. Jones and colleagues (2005) compared wine rankings from Sotheby's, and the Wine Enthusiast to variations in seasonal temperatures and monthly mean temperatures from 1950 to 1999 across 27 prominent global wine regions. The findings conclude that climate variations influence vintage quality ratings and increasing temperatures since 1950 have improved wine quality (Jones, White, Cooper, \& Storchmann, 2005). The results also indicate there is less season-to-season variation and, depending on the region and wine type, a $1^{\circ} \mathrm{C}$ warmer vintage can improve ratings by $10-22$ points (Jones, White, et al., 2005). The authors acknowledge that climate change will likely be region-specific as changes in cooler climates could lead to more consistent vintage quality, whereas warmer climate regions might become too hot to produce the same quality grape (Holland \& Smit, 2010a; Jones, White, et al., 2005). The study concluded that with increasing temperatures, some regions in northern France and Germany would continue to produce high-quality wines, whereas Spain, California and South Australia may experience a decline in quality (Jones, White, et al., 2005). Storchmann (2005) analysed wine quality from 1700 to 2003 in Schloss Johannisberg in the German Rheingau region. The region has historical vintage classifications such as "top wine", "sour", and "lesser vintage". Storchmann's (2005) approach was to group and rank vintage categories and then regress the ranks against available weather data. 
The model shows a rise in temperature of $1^{\circ} \mathrm{C}$ throughout the growing season will increase the probability of harvesting a top vintage from approximately $20 \%$ to $50 \%$ (Storchmann, 2005). This research also supports the findings from Jones and colleagues (2005) that Germany will continue to produce high-quality wines.

A further application to examining wine quality is the use of objective data as a proxy for wine quality rather than subjective quality ratings. In California, climate models and historical data suggest a shift in climate conditions that will make high-quality wine production more difficult in the future (Cahill et al., 2007). The findings indicate a shift from optimal to marginal climate conditions will impair the quality of wine, as well as cause a potential decline in yields of up to $5 \%$ (Cahill et al., 2007). In Australia, a model compared market prices and climate data to ascertain the potential changes in the industry. Wine quality may be reduced by $7 \%$ to $39 \%$ by 2030 , and from $9 \%$ to $76 \%$ by 2050, including considerations for climatic uncertainties (Webb, Whetton, \& Barlow, 2008a). Conversely, a study using climate and market data as well as the chemical composition of flavour and aroma compounds by Webb and colleagues (2008b) found that the varietals Cabernet Franc and Pinot Noir are the most sensitive to temperature changes, while Semillon, Chardonnay and Shiraz are the least responsive. The optimum January temperatures in Australia were also calculated: Cabernet Sauvignon is $18.5^{\circ} \mathrm{C}$; Shiraz, $19.1^{\circ} \mathrm{C}$; Verdelho, $20.7^{\circ} \mathrm{C}$; and Ruby Cabernet $21.5^{\circ} \mathrm{C}$ (Webb, Whetton, \& Barlow, 2008b). Webb and colleagues (2008b) note that they would expect similar findings in other regions, but they could differ based on regional cultivars and quality standards. In the Bordeaux region Crus Classés, the chemical composition of Merlot is more sensitive than those of Cabernet Sauvignon, suggesting that warm, dry summers result in high sugar and low acid levels at harvest (Jones \& Storchmann, 2001).

The quality of winegrapes is an important consideration when factoring in the impacts of climate change as the prices and revenues are dependent on the conditions of the growing season (Ashenfelter \& Storchmann, 2016b). Evidence shows that the price for wine produced by the same winemaker from winegrapes grown on the same vines can fluctuate by a factor of twenty or more annually (Ashenfelter, 2010). Furthermore, wines produced in different regions can procure a range of prices depending on how conducive the climate is (Ashenfelter \& Storchmann, 2010). The growing conditions of 
the grapes can also affect the longevity of wine. Ashenfelter and Storchmann (2016b) evaluated the price fluctuations in wine that can be stored for a long time; often the wine will hold its nominal value and increase in real value with age. Another economic variable discussed in the literature is the effect of aging and pricing. It was found that Merlot demonstrates more maturing potential and in turn will profit more from the aging process than Cabernet Sauvignon (Jones \& Storchmann, 2001). This is supported by Chevet, Lecocq, and Visser (2011) who found that in France the temperature has a positive impact on yield and price.

Evidence shows that natural oscillations in climate variability are as equal important in the short and medium term as climate change (Jones \& Goodrich, 2008). Over a 30-year period in five Spanish wine regions, wine quality was rated 'very good' or excellent' when an El Niño event occurred the previous or the same year (Rodó \& Comín, 2000). However, in the Dão (Viseu) region of Portugal, there were no significant correlations between quality of wine and ENSO, nor in California (Jones \& Goodrich, 2008). Conversely, the Pacific Decadal Oscillation (PDO) has shown to be beneficial to wine quality in California as it had higher temperatures in spring and winter, less frost and a longer growing season (Nemani et al., 2001).

The different approaches to analysing wine quality restrict the ability to compare case studies in the literature. The present changes in climate show an increase in overall quality, yet the long-term projections suggest a decline as the berry composition changes and requires more chemical manipulation. Wine quality in any given region can best be managed by selecting the most suitable winegrape cultivar. This suggests an alteration in the global industry is to be expected, which will change the geography of wine.

\subsubsection{Climate Change IMPACtS on TERROIR}

Viticulture was traditionally produced in a narrow geographic and climatic zone between $30^{\circ}$ to $50^{\circ} \mathrm{N}$ and $30^{\circ}$ to $40^{\circ} \mathrm{S}$ (Amerine et al., 1980). However, the temperatures within these zones do not adequately represent the geography of wine as parts of the tropics have successfully grown winegrapes (Evaldo Fensterseifer, 2007; Jones \& Alves, 2012; 
Schultz \& Jones, 2010). The geography of wine is best described based on viticulture in the isotherm range of $12^{\circ} \mathrm{C}$ to $22^{\circ} \mathrm{C}$ during the growing season in both hemispheres (Jones, 2006b; Jones \& Alves, 2012; Jones et al., 2012; Schultz \& Jones, 2010), as shown in Figure 3.3.

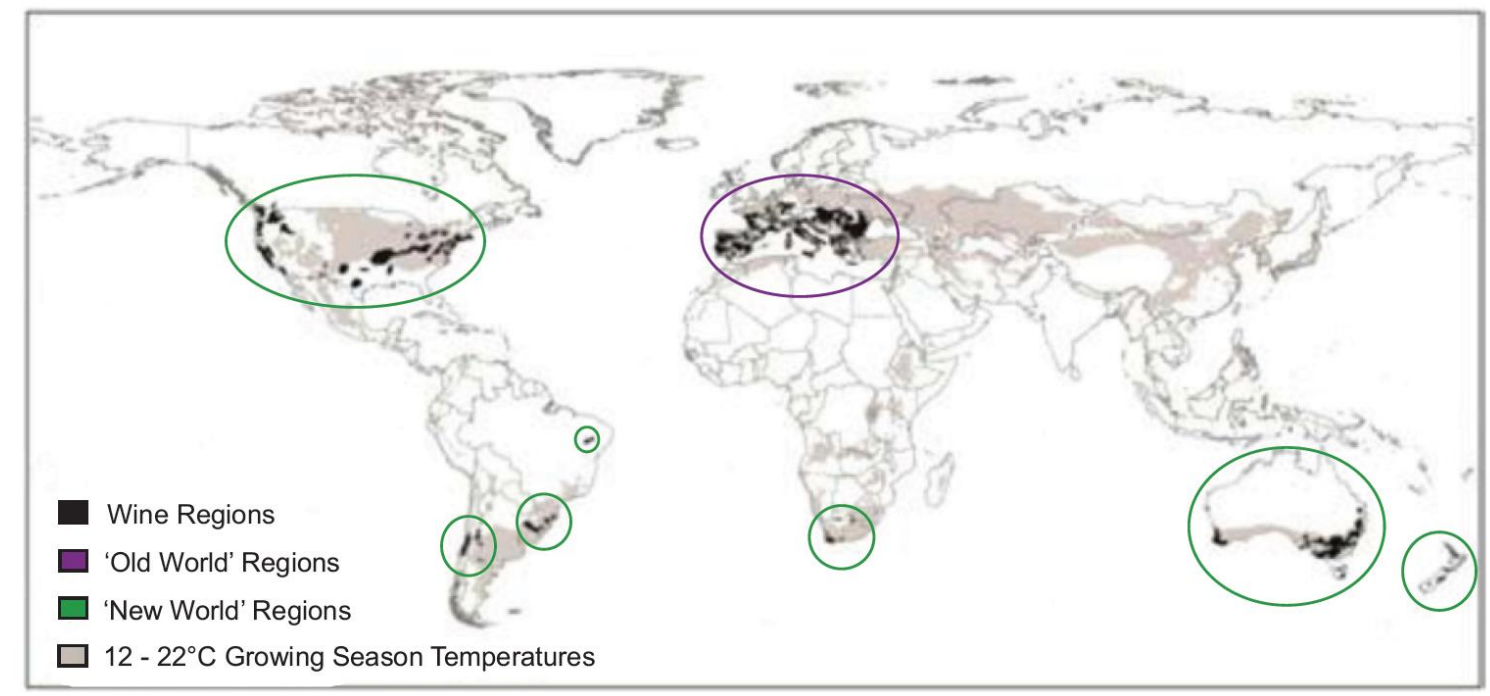

Fig. 3.3. Global wine regions based on the growing season temperatures. Adapted from Jones et al. (2012, p. 115).

The seasonal temperatures range of $12^{\circ} \mathrm{C}$ to $22^{\circ} \mathrm{C}$ portrays mid-latitude suitability with parts of the subtropics and tropics also experiencing suitable seasonal temperatures (Jones et al., 2012; Jones, White, et al., 2005; Schultz \& Jones, 2010). However, as shown in Figure 3.3, not all the regions with temperatures conducive to grape-growing necessarily cultivate winegrapes. Jones and colleagues (2012, p. 115) explain that regional climate variables can limit winegrowing, such as "winter minimum temperatures, fall and spring frosts, length of growing season and water availability". Alternatively, there are regions with seasonal temperatures above $22^{\circ} \mathrm{C}$ that have developed adaptation practices to cope with the heat stress (Holland \& Smit, 2010b; Mayer, 2013; Webb et al., 2010). The climate in which wine is cultivated can alter both the flavour profiles and change the wine characteristics (Table 3.1). 
Table 3.1. Differences in wine characteristics based on climate zones. Adapted from Jones et al. (2012, p. 115).

\begin{tabular}{|l|l|l|l|}
\hline Wine characteristics & \multicolumn{1}{|c|}{ Cool climate } & $\begin{array}{c}\text { Intermediate to } \\
\text { warm climate }\end{array}$ & $\begin{array}{c}\text { Warm to hot } \\
\text { climate }\end{array}$ \\
\hline White flavour & Apple, Pear & Peach, Melon & Mango, Pineapple \\
\hline Red Flavour & Cranberry, Cherry & Berry, Plum & Fig, Prune \\
\hline Fruit style & Lean, Tart & Ripe, Juicy & Overripe, Lush \\
\hline Body & Light & Medium & Full \\
\hline Acidity & Crisp, Tangy & Integrated & Soft, Smooth \\
\hline Overall style & Subtle, Elegant & Medium intensity & Bold \\
\hline
\end{tabular}

Using the example of Pinot Noir, a cultivar grown between $14^{\circ} \mathrm{C}$ and $16^{\circ} \mathrm{C}$, the characteristics can differ considerably from being light and subtle to more full-bodied and juicy. When cultivated outside of the cool to intermediate climates, the style is more likely to be unripe or overripe, affecting the typicity (Jones et al., 2012). The climate in which winegrapes are cultivated determines the varieties, but the viticulture and viniculture adapt to the local conditions, creating the wine styles regions are known for (Pincus, 2003).

Terroir is an important concept when discussing regional suitability. Terroir is described as a complex interaction between the physical, cultural and socioeconomic factors that are used to define wine styles and the type of wine from a particular place (Holland \& Smit, 2010a; Moran, 2016). Terroir is a dominant theme in the literature as the climate will affect the region and the land producing winegrapes (Holland \& Smit, 2010a; Seguin $\&$ de Cortazar, 2005). The research suggests climate change will cause a geographic shift in wine production. However, the 'Old World' wine producing countries are geographically constrained under the strict regulations of the appellation systems (Holland \& Smit, 2010a). The implications of climate change in the European wine industry are that it could lead to challenges to the legal and territory framework of terroir, as the need for adaptation outweighs the appellation requirement for traditional winemaking (Moran, 2006). Terroir suitability in the 'New World' countries is less strict as viticultural zoning regulations allow for more flexibility in viticultural practices and winemaking (van Leeuwen \& Darriet, 2016; Vaudour \& Shaw, 2005). Atkinson (2011) analyses terroir in Burgundy red wines and found that change is inevitable but difficult for winegrowers as regulations restrict them. White and colleagues (2009) explain that the concept of terroir is changing due to New World competition, changes in climate 
and technological advances. Furthermore, terroir is no longer dependent on regional geography or culture, requiring more flexibility in the use of the term (M. A. White et al., 2009). Although scholars recommend changing appellations and being more amenable towards adaptation, there is little research on the effects this would have (Holland \& Smit, 2010a).

Shifting regional suitability of viticulture disrupts the framework of terroir, as climate modelling predicts how wine regions will shift due to climate change. Hannah and colleagues (2013) found that globally by 2050 , under the highest emissions scenario, the suitable viticulture land will decrease between $25 \%$ and $73 \%$. Under the lowest emission scenario, the suitable land will decrease between 19\% and 62\% (Hannah et al., 2013). Areas that are currently restricted by climate conditions may become more suitable in the future. Hannah and colleagues (2013) propose regional shifts into high elevations and latitudes. Throughout southern Europe, climate effects will be detrimental to grape cultivation as conditions will be too hot and dry for production. However, at higher elevations, precipitation, humidity and temperature will be more appropriate for grape growing (Malheiro, Santos, Fraga, \& Pinto, 2010). In Canada, wine cultivation is currently restricted due to winter temperatures. However, warmer temperatures will be favourable for production and could potentially lead to industry expansion (Caprio \& Quamme, 2002; Rayne et al., 2009).

The increase in temperature and humidity can have adverse effects by increasing the spread of grapevine pests and disease (Mozell \& Thach, 2014). The expected temperature rise in Europe will cause an increase in the susceptibility to moths and powdery mildew (Caffarra, Rinaldi, Eccel, Rossi, \& Pertot, 2012). Bois and colleagues (2017) evaluated the current prevalence of the grapevine pests and diseases globally to determine the relationship they have with the changing climate. The preliminary results from the global survey indicate that downy mildew is the most severe on an international scale, followed by powdery mildew (Bois, Zito, \& Calonnec, 2017). Downy mildew was predominantly reported in intermediate to hot climates with sub-humid to humid conditions. Whereas, powdery mildew was reported in a larger range of temperature conditions, particularly with lower rainfall (Bois et al., 2017). Powdery mildews are not common in wet or cool conditions, and conversely, downy mildews are 
more common in regions with frequent rainfall, yet there are cases where they have both been reported that are outside these conditions (Bois et al., 2017). The research suggests that diseases are spreading more as the temperature increases and are not contained to a specific climate. This can affect regional suitability as areas that were previously not affected by grapevine pests or disease, may experience an increase in the frequency and intensity (Mozell \& Thach, 2014).

Another variable that will influence regional suitability is rising sea levels. Global mean sea level will rise due to loss of grounded or land-based ice (Church et al., 2013). The IPCC projects sea level will rise between a minimum of $0.5 \mathrm{~m}$ and maximum of $1.2 \mathrm{~m}$ by 2100 (Church et al., 2013). Tate (2001) discusses sea level rise using a projected $5 \mathrm{~m}$ to emphases the risk. Wine regions such as Bordeaux, Portugal, New Zealand, Australia's swan district, and California will be inundated with sea water and flooding. Furthermore, regions that are at risk due to potential tsunami effects include, Oregon, Washington, British Columbia, Chile, Argentina and New Zealand (Tate, 2001). Coastal flooding and increased salinity are additional impacts of sea level rise that can affect regional suitability as they reduce grapevine health (Mozell \& Thach, 2014).

Climate suitability can be analysed using climate indices to compare growing seasons and identify potential future regions (Moriondo et al., 2013). The most commonly cited indices are the Winkler Index (WI) - also known as the Heat Summation Index (Amerine \& Winkler, 1944), and the Huglin Index (HI) - also known as the Heliothermal Index (Huglin, 1978). The WI calculates growing degree days over a growing season. An increase of $1^{\circ} \mathrm{C}$ in mean temperature adds 214 growing degree days for a season (Sharma et al., 2013). The $\mathrm{HI}$ is used to categorise grape growing regions into bioclimatic classes based on temperature and latitude variables (Lereboullet, Beltrando, Bardsley, \& Rouvellac, 2014). An increase of 100 to 600 units by 2050 in the HI would suggest a latitudinal shift of grapevine production. Southern regions in Europe would be too hot to produce high-quality wines, although new areas along the northern fringes could be suitable (Stock, Gerstengarbe, Kartschall, \& Werner, 2005). Tatem (2005) agrees with the findings and notes the potential expansion of vine growing in northern Europe, notably Denmark, Norway and Sweden through satellite imagery. Both the WI and the $\mathrm{HI}$ support the findings of earlier grapevine phenology and harvest times throughout 
Europe (Jones, Duchêne, et al., 2005), supporting their use in climate variability research. Other indices are available; however, they are criticised for being too simplistic, appropriate for only one region, and overall there is no universal index available (Gladstones, 1992; Jones, Duff, Hall, \& Myers, 2010).

Climate modelling using the of $\mathrm{HI}$ and $\mathrm{WI}$, as well as the Biologically Effective Degree Days (BEDD), and the Water Deficit Index has found that European climate will become progressively warmer and drier, and winegrape suitability will shift upwards in elevation and potentially poleward (Moriondo et al., 2013). The southern regions of Europe are expected to become unsuitable for winegrape cultivation due to increased temperature and a lack of water availability. Comparably, in the United States, modelling using the WI and extreme event frequencies shows a decline by up to $81 \%$ in premium wine region suitability by the late $21^{\text {st }}$ Century (M. A. White, Diffenbaugh, Jones, Pal, \& Giorgi, 2006). The shift will contract the industry to a narrow west coast region or up to the northern regions, due to heat accumulations, frost constraints and the frequency of hot days ( $M$. A. White et al., 2006). Similarly, Australia will experience a poleward shift as modelling using growing season temperature, ripening time, BEDD, and seasonal length found the northern regions to be unsuitable for winegrape cultivation. Furthermore, the model showed that if ripening occurs earlier in the season, the quality will decline due to regions adverse climatic conditions (Hall \& Jones, 2009).

\subsection{AdAPTATION AND THE WINE INDUSTRY}

Agriculture is the most vulnerable sector to climate change (Porter et al., 2014), and is expected to be the second most economically damaged sector due to climate change (OECD, 2015). The global wine industry will be affected, yet the implications of climate change are constrained by the physical and biological aspects of viticulture and viniculture (Holland \& Smit, 2010a). Climate change can pose a risk or opportunity depending on the extent of the projected changes and the adaptive capacity of the winegrowers. Adaptation strategies can help manage the effects of climate change and can be targeted to the system, community or region (Smit \& Pilofosova, 2003; Stock et al., 2005). This section discusses the adaptive capacity of the wine industry by evaluating the difference in adaptation and mitigation; adaptation strategies available in wine 
cultivation; and the literature examining winegrowers' perceptions and attitudes to climate change and adaptation.

\subsubsection{ADAPTATION AND THE WINE INDUSTRY}

Both mitigation and adaptation strategies are needed to reduce the negative impacts of climate change. Mitigation focuses on reducing the impact of climate change by decreasing greenhouse gas emissions or through enhancing carbon sinks (Ignaciuk, 2015). Most opportunities for mitigation lie outside the viticultural sector. Adaptation looks at either reducing the negative impacts of climate change or enhancing the positive opportunities by adjusting ecological, social or economic systems (IPCC, 2014b). Mitigation policy is set at the government level ${ }^{1}$, where policies to negotiate and constrain the levels of GHG emissions are considered (UNFCCC, 2009a). However, considerable further climate change is inevitable given the rising trajectory of concentrations of GHG (UNFCCC, 2009a). Additionally, inertia in the climate system will guarantee continual change following GHG emission reduction even to near zero levels, suggesting that adaptation needs to be planned and implemented alongside mitigation (Friedlingstein \& Solomon, 2005). The IPCC (2014, p. 5) defines adaptation as "the process of adjustment to actual or expected climate and its effects. In human systems, adaptation seeks to moderate or avoid harm or exploit beneficial opportunities. In some natural systems, human intervention may facilitate adjustment to expected climate and its effects". Adaptation in the climate change discourse covers various aspects of how adaptation can take form (Pelling, 2010; Smit, Burton, Klein, \& Wandel, 2000).

Implementing adaptation is a two-step process. The first step is perceiving climate change and understanding the associated risks and opportunities. The second requires taking action to minimise the implications of climate change (Tripathi \& Mishra, 2017). Adaptation is multi-tiered and preferably occurs at the national, regional, and local level; local stakeholders are expected to be more affected by climate change hence local level adaptation is the most appropriate (UNFCCC, 2009b). The impact of climate variability

\footnotetext{
${ }^{1}$ Mitigation can occur at the business level to reduce greenhouse gas output. Some wineries are accredited as carbon neutral, although, this is at the company's discretion and expense (Thompson \& Forbes, 2011).
} 
depends on the capacity to adapt to those risks (O'Brien, O'Keefe, Rose, \& Wisner, 2006). At farm-level, the decision makers have to work in a complex environment that is affected by political, economic, institutional and biophysical conditions, all of which can directly or indirectly alter management and adaptation decisions (Belliveau, Smit, \& Bradshaw, 2006; Wandel \& Smit, 2000). Additionally, farmers have internal factors that will influence their adaptive capacities such as personal characteristics, farming practices and individual circumstances (Bryan et al., 2013). Furthermore, farmers are also influenced by their community, and the interactions and perceptions of neighbours can sway their adaptive capacity at farm level (Abid, Schilling, Scheffran, \& Zulfiqar, 2016).

There are two types of adaptation responses that have been identified-autonomous and planned. Autonomous adaptation is a reactive response to climate variability which occurs after a significant event and is not policy driven. It is often assumed to be a smooth and instantaneous transition (Schneider \& Lane, 2006). Comparatively, planned adaptation can be defined further by either passive or anticipatory forms (Schneider \& Thompson, 1985). Passive adaptation is reactive to nature and can be a rough transition that occurs over an extended period. This form of adaptation is slow as it reacts to environmental changes occurring in the climate system and delays can be expected as random events occur which alter perceptions of what is happening in the climate system (Schneider \& Lane, 2006). Understanding of what is true climate change compared to random climate fluctuations is important for passive adaptation to avoid maladaptation. Planning for a specific system under a new climate regime that uses incorrect data can be damaging for small businesses due to the financial costs of implementing and remedying the maladaptation (Schneider \& Lane, 2006). Anticipatory adaptation is policy driven and focuses on human-induced disturbances. It includes technical actions, such as building infrastructure; as well as political actions, such as setting up networks to improve knowledge and information sharing on adaptive actions. As the focus is on policy-based approaches with support and networking, an assumption is that maladaptation is less likely to happen (Schneider \& Lane, 2006). Passive adaptation occurs as part of a routine, while anticipatory adaptation occurs as a deliberate, planned action (Carter, Marry, Harasawa, \& Nishioka, 1994). 
The response terms can be categorised further into adaptation actions. These actions can counter the positive and negative effects of climate change, and often involve different stakeholders at various levels of implementation (Pelling, 2010). Reactive adaptation, which includes both passive and autonomous adaptations, takes place during or after an event as the adaptation reacts to the need for adjustment. Whereas proactive adaptation, which includes planning adaptations (both passive and anticipatory), is action that take place before a risk manifests into a hazard (Pelling, 2010). Passive responses can fall into either category as they can involve risk reduction for future events, but reactive to a response such as disasters. Additionally, reactive adaptation can lead to proactive change, where the action is both reacting to an event while anticipating future risk (Pelling, 2010).

Another form of adaptation considers pathways, which includes incremental adaptation and transformational adaptation. Rickards and Howden (2012) explain incremental adaptation as managing the current system by making improvements, while transformational adaptation manifests as large-scale changes to a system. Incremental is viewed as a transition to change, whereas transformational is more radical and allencompassing (Pelling, 2010). These two pathways often overlap as transformational adaptation requires incremental changes to ensure the new system is effective and to make adjustments for ongoing change (Rickards \& Howden, 2012).

\subsubsection{ADAPTATION CAPACITY OF THE WINE INDUSTRY}

Winegrapes are a perennial crop with a commercial lifespan of 20 to 50 years; therefore it is crucial that winegrowers plan for the future (Lereboullet, Beltrando, \& Bardsley, 2013b). Adapting grapevines to climate variability can be challenging; however, winegrowers have shown their resilience and adaptability to previous changes in climate (Ashenfelter \& Storchmann, 2016a). Jones (2007a) proposes that winegrowers need to be proactive with adaptation by evaluating the climate change impacts and planning for effective action.

Adaptation is necessary for improving and managing the effects of climate change. In California, if key stakeholders undertook effective adaptation practices, it is estimated 
they could avoid $50 \%$ of the potential loss of viable land in the North Coast area and up to $15 \%$ in the Central Coast (Diffenbaugh, White, Jones, \& Ashfaq, 2011). Effective adaptation often depends on farmers' training, preparation and specialisation in their field (Bernetti, Menghini, Marinelli, Sacchelli, \& Sottini, 2012). Implementing regulation change and having winegrower support in public policies could lead to a greater than $50 \%$ chance of maintaining the same level of income as the industry currently earns (Bernetti et al., 2012). However, the information and policy support needed for winegrowers is different for implementing incremental or transformational adaptation (Park et al., 2012). There are differences between the business models and the adaptation strategies used, especially between grape-growers and wine producers. In Australia, there is a high adaptive capacity, with research findings suggesting it is easier for smaller scale companies to undertake and achieve transformational adaptation (Park et al., 2012). Larger companies have no evidence of undertaking transformational change, and the medium-sized wineries only partially use transformation adaptation (Park et al., 2012). The main adaptive actions are focused on water management as winegrowers are mostly concerned with water use, efficiency and technology (Galbreath, 2012). Moreover, a regional analysis in Tasmania shows there is a lack of knowledge sharing occurring with winegrowers (Galbreath, 2012).

Adaptive capacity in the wine industry is dependent on social collaboration, farming decisions, and winemaking decisions. Furthermore, to assess farm-scale vulnerabilities and environmental stress in the wine industry, consideration is needed for the sensitivities and exposures of climate change (Nicholas \& Durham, 2012). Winegrowers respond to environmental stresses individually, yet with pests and disease management they tend to work more collectively in their management approach (Nicholas \& Durham, 2012). Winegrowers are predominantly reactive, managing the problem as it occurs, or in the case of short-term anticipatory change, managing near-future risks. The respondents also indicated that they rely on their own experiences to make decisions, which Nicholas and Durham (2012) critique as poor guidance given the changing variability in climate. Shifting vineyard location can reduce overall exposure, while changing planting decisions can reduce sensitivity, which would improve winegrowers vulnerabilities to climate change (Nicholas \& Durham, 2012). 
Adaptation is occurring throughout the global wine industry. The adaptation strategies are predominantly reactive or anticipatory in the short term. However, the actions need to be designed and tailored for the specific site. Being proactive with adaptation can lessen the risk of climate and regional unsuitability while securing economic stability in the industry. Small-scale wineries can implement transformational adaptation action more easily, than large-scale wineries, suggesting the large-scale wineries need to begin planning for changes in the industry. Furthermore, adaptive action is more likely to occur independently, which adds another barrier to knowledge sharing in the industry, and a limitation for less profitable companies.

\subsubsection{AdAPTATION StRATEGIES}

There is a history of adaptation in the wine industry with winegrowers long using natural observation of the growing season to inform decision-making (Ashenfelter \& Storchmann, 2016a). In historical Europe, there were cultivation shifts to coincident with temperature changes. Between 900 and 1300AD, temperatures were approximately $1{ }^{\circ} \mathrm{C}$ warmer than present and cultivation of winegrapes occurred in the northern coastal regions by the Baltic Sea and South England. Furthermore, by the $12^{\text {th }}$ and $13^{\text {th }}$ Century when the temperature was around $1.7^{\circ} \mathrm{C}$ warmer, harvest dates occurred a month earlier than present day (Jones, 2007b). The wine industry is capable of adapting to climate change, both during both the viticultural and vinicultural stage (Table 3.2). However, the capacity to adapt can be limited to the site, region or country. 
Table 3.2. Global wine adaptation types and strategies for climate change.

\begin{tabular}{|c|c|c|}
\hline Production stage & Adaptation types & Adaptive strategies \\
\hline \multirow{18}{*}{ Viticulture } & \multirow{3}{*}{ Canopy management } & Pruning \\
\hline & & Cover crop \\
\hline & & Trellising \\
\hline & \multirow{2}{*}{ Water management } & Water storage \\
\hline & & Irrigation \\
\hline & \multirow{2}{*}{ Frost management } & Wind machines \\
\hline & & Helicopters \\
\hline & Wind management & Windbreaks \\
\hline & \multirow{2}{*}{ Heat management } & Vine orientation \\
\hline & & Shade cloth \\
\hline & \multirow{3}{*}{ Pest and disease management } & Integrated Pest Management (IPM) \\
\hline & & Pesticides \\
\hline & & Fungicides \\
\hline & \multirow{3}{*}{ Cultivars and Rootstock } & New varietals \\
\hline & & Genetic manipulation \\
\hline & & Selective breeding \\
\hline & \multirow{2}{*}{ Location } & Relocation of vineyards \\
\hline & & Change in regulations \\
\hline \multirow{5}{*}{ Viniculture } & Acid addition & \\
\hline & \multirow{3}{*}{ De-alcoholisation } & Yeast \\
\hline & & Reverse osmosis \\
\hline & & Ultrafiltration \\
\hline & Blending & \\
\hline
\end{tabular}

Within viticulture, there is a range of adaptation options available to manage different climate stresses. Canopy management involves the manipulation of the grapevine through pruning to either enhance or reduce leaf exposure. Trellis design can also alter the structure of the grapevine. Growing crops in the inter-rows can reduce soil heat stress and can protect exposed vines (Webb et al., 2010). To manage water and reduce drought stress, drip irrigation is an efficient strategy and has lower costs for operation and maintenance (Keller, 2010; Lereboullet, Beltrando, \& Bardsley, 2013a). A long-term strategy is implementing a water storage facility on-sites that allow water collection and redistribution outside regulated water permits. Water management can additionally be used to limit frost stress, although wind machines are the main strategy. For severe frost events, helicopters can be used to cover a wider range. To prevent wind exposure, trees can be planted along the periphery of the vineyard, creating a barrier. Altering vine orientation from north-south to east-west can reduce the afternoon sun exposure on a 
large scale (Webb et al., 2010). Shade clothes can also be placed on exposed grapevines to prevent direct exposure during extreme heat waves. Pest and disease management occurs either through use of chemicals, such as pesticides and fungicides, or with an IPM system, which is more holistic in design (Wilson \& Danne, 2017).

Aside from viticulture management strategies, there are transformational adaptation options. Changing varietals and locations appears simple, yet with geographical indicators and land allocation regulations, an additional step of changing the policies and regulations that restrict cultivation is needed. Another approach is to graft different rootstocks onto the vines to encourage growth in different climates. In Australia, it is recommended to use drought-tolerant rootstock as they performed better than drought-sensitive and original rootstocks (Webb et al., 2010). Selective breeding is another strategy which allows winegrowers to grow crops specifically designed for certain climatic conditions. Part of this could occur either through conventional methods or genetic manipulation (Webb et al., 2011).

In viniculture, adaptation can occur by changing the natural composition of wine. Adding acids during winemaking can offset the natural acid reduction in the berry allowing stability for fermentation (Mira de Orduña, 2010). For earlier harvests of white winegrapes with low acid concentrations, an option is to leave white wine fermenting longer as this can protect the wine from oxidation and conserve the aroma (Mozell \& Thach, 2014). Additionally, new blending techniques such as mixing wines from different regions can offset vintage variability (Vink, Deloire, Bonnardot, \& Ewert, 2009). To reduce sugar concentrations, the use of different yeast strains that are more alcoholtolerant can reduce the alcohol percentage (Vink et al., 2009). Other methods of dealcoholisation include ultrafiltration and reverse osmosis, although these can change the balance of the wine and increase spoilage (Mira de Orduña, 2010).

Other considerations for adaptation include establishing a climate change plan for the region to determine the effect climate change will have. Jones and Alves (2011) recommend establishing a plan that incorporates relevant information and useable data. It should include a reference index for harvest quality to monitor changes. The climate data should be narrowed to a specific region with observations being recorded 
for specific climate projections. Additionally, the regional climate should be studied with a focus on atmospheric circulation to determine the effect on grape production. Furthermore, the region should identify viticultural zones using topography and soil variations to establish potential risk and relocation. Finally, a handbook of technical information should be created to outline adaptation options and potential impacts of climate change to winegrowers, so they are aware of the challenges or opportunities (Jones \& Alves, 2012).

\subsubsection{PeRCEPtions AND AtTItUdes to AdAPtation}

There is an expectation that agricultural workers are well attuned to changes in the climate system and more cognisant of weather patterns (Battaglini, Barbeau, Bindi, \& Badeck, 2009). Farmers can reduce the adverse effects of climate change and utilise the opportunities through adaptation (Bryant et al., 2000). Climate change perceptions and attitudes of key stakeholders have not been the dominant discourse as adaptation within the wine industry has focused on extreme weather events, adaptive behaviour and intentions for change (Battaglini et al., 2009). Consequently, to understand the decision-making process or the capacity to adapt, research needs to start with winegrowers' perceptions of climate change.

The adaptation and decision-making literature is predominantly concentrated in the 'New World' context as winegrowers have more freedom in production, and thus can plan for climatic change. Winegrowers are aware of climate change and often see the outcomes as negative and a risk for wine production (Belliveau et al., 2006; Fleming, Park, \& Marshall, 2015; Hadarits, Smit, \& Diaz, 2010). However, not all winegrowers agree that climate change is negative, as Australian winegrowers discuss a $0.2^{\circ} \mathrm{C}$ to $1^{\circ} \mathrm{C}$ increase in temperature will improve their Cabernet Sauvignon quality and that temperature increases would make "viticulture and winemaking easier" (Galbreath, 2011). Decision-making taking into account climate change is more likely to occur from a wine producer than a grape-grower, as it was found that grape-growers are more sceptical about anthropogenic climate change (Fleming et al., 2015). 
Adaptation will most likely be incremental rather than transformational as it allows winegrowers to respond by stages rather than make long-term plans for climate change (Fleming et al., 2015). Incremental adaptation is perceived as a direct strategy to 'manage' climate change - as noted above - can be either reactive or anticipatory. Reactive, short-term strategies are mostly directed at the growing season and include thinning crops, making sparkling wine, reducing the price of wine, or claiming insurance for the loss of crops (Belliveau et al., 2006). The incremental long-term adaptation strategies are include spray management, water management through drip irrigation, and in some cases wind machines (Belliveau et al., 2006; Galbreath, 2011). Some more long-term, strategic adaptations are being implemented. These adaptations are incremental and include harvesting earlier, site selection, purchasing insurance for protection, integrated pest management, and planting varieties with grafted rootstock (Belliveau et al., 2006). Transformational adaptation includes changing locations, exiting the industry, or altering the industry (Fleming et al., 2015). This would entail more uncertainty for the winegrower and often when planning, winegrowers would prefer confidence that such adaptation strategies will be profitable (Galbreath, 2011).

The main vulnerability winegrowers discuss is the economic aspects of wine production (Belliveau et al., 2006; Fleming et al., 2015; Hadarits et al., 2010). In Chile, the costs associated with wine production fluctuate as producers have little influence on the regulations and international standards which can limit the overall wine industry's productivity (Hadarits et al., 2010). For Canadian winegrowers, the capacity to adapt is informed by resources and technology, and access to government support (Belliveau et al., 2006). Australian winegrowers cited similar economic factors of international standards and job security, but also note the oversupply of winegrapes in the market and how that can threaten financial security (Fleming et al., 2015). In decision-making, winegrowers are more likely to adjust their management approach for market considerations and profitability (Hadarits et al., 2010). Furthermore, financial constraints limit adaptation planning as the focus is more on short-term action (Fleming et al., 2015).

Fleming and colleagues (2015) identified 'attachment to place' as a potential constraint for the industry. Winegrowers have a strong emotional bond to place, and even if 
winegrowers were financially able to relocate, some would choose to remain as it is an 'occupational commitment' (Fleming et al., 2015). The notion of leaving the wine industry and changing occupation overall is perceived as being very difficult. Although some winegrowers are adapting and planning, the uncertainty of climate change and the unknown is viewed as hindering their success (Galbreath, 2011). Furthermore, Hadarits and colleagues (2010) found that climate change was not a priority, even though adaptation strategies would be appropriate given the projected changes in climate.

'Old World' winegrowers share similar perceptions to those in the 'New World'. However, the scope of the research on adaptation implementation is limited. Winegrowers attribute climate change to decreasing yields, blocks in maturation, declining health in the grapevine, earlier harvests, and spring frosts to climate change (Lereboullet et al., 2014). Effects of climate change appear country specific. Battaglini and colleagues (2009) found Italian winegrowers perceived future effects of climate change as negative, French winegrowers indicated a balance between positive and negative, and German winegrowers perceived future climate change effects as positive. A later study in France found that winegrowers perceived climate change as negative, with winegrowers describing the difficulty in producing quality fruit because of reduced water availability (Lereboullet et al., 2014). This further contrasts with the Battaglini and colleagues' (2009) study as most European winegrowers observed an increase in quality. Variables most affected by climate change also include quantity and disease. Italian winegrowers found a decline in quality, whilst pests and disease were viewed as a negative consequence of climate change by all three European countries (Battaglini et al., 2009).

As with the 'New World' wine industry, economic stability is seen in the 'Old World' as a key sensitivity for winegrowers. A major concern of climate change is water stress and low yields, with winegrowers linking this to producers further having to balance their incomes through careful planning and adjustment of production blocks to meet economic stability (Lereboullet et al., 2014). However, without adaptation, this will be a continual problem. 'Old World' winegrowers need to increase their adaptive capacity but are constrained by local traditions, lack of financial security, and stakeholder 
perceptions of change (Lereboullet et al., 2014). Furthermore, there is a lack of emphasis on climatic factors which limits effective planning (Lereboullet et al., 2014).

Battaglini and colleagues (2009) identified two lines of thought with regard to adaptation: 1) potential climate changes and problems requiring adaptation; and 2) planned adaptation with grape varieties (Battaglini et al., 2009). Rain and water were mentioned 180 times as a crucial requirement for wine quality, indicating the need for adaptive irrigation management. Additionally, pests and diseases were perceived as being negative, suggesting the need for adaptive management and research in this area. In Germany, winegrowers indicated they were open to testing new winegrape varieties, whereas the French winegrowers declared it not possible for them to change. However, both the French and Italian winegrowers would change varieties as a direct response to climate change rather than independently (Battaglini et al., 2009). Battaglini and colleagues (2009) further elaborate on this difference, explaining German winegrowers have more flexibility in their winegrape selections under their national regulations, compared to Italian and French winegrowers who have a restricted variety list. Most winegrowers indicated they do not know what winegrape variety they would use in case of climate change, suggesting there is a lack of information and a level of discomfort with change in the industry (Battaglini et al., 2009). Lereboullet and colleagues (2014) expand on this and agree that irrigation, relocation of vines, and new varietals are adaptive actions that would benefit the French region and would not hinder their market capacity. However, adaptive change is presently restricted by a divide in key decisionmakers perceptions' regarding changing the current system (Lereboullet et al., 2014).

\subsection{New Zealand Wine Research}

The academic research on climate change and New Zealand wine is limited. The main focus is regional suitability for viticulture using climatic indices and geographic information system (GIS) data. This section highlights the relative lack of research on the effects of climate change on New Zealand wine.

New Zealand cultivates cool climate wines and is experiencing a regime shift (Shanmuganathan, Narayanan, \& Sallis, 2012). Based on wine quality data retrieved 
from Michael Cooper's wine atlas vintage ratings from 1993 to 2006, the increase in temperatures in the extreme north and south influence vintage ratings positively for white wine varieties, but not for red varieties (Shanmuganathan et al., 2012). February rainfall along with December and March rain, and September high daily mean temperatures are conducive for increasing white wine varieties' vintage ratings across all wine regions in New Zealand. For red wine varieties, the aforementioned climatic conditions negatively affect vintage ratings, except for Central Otago, where the increased in rainfall and humidity leads to improved red vintage ratings, possibly due to the late harvest in this region (Shanmuganathan et al., 2012).

A varietal shift has additional consequences in terms of regional suitability. More than $70 \%$ of New Zealand vineyards are located on alluvium and gravels as they are freedraining. Additionally, only $7 \%$ of vineyards are located on slopes greater than $5^{\circ}(\operatorname{Imre}$ \& Mauk, 2009). In Marlborough, more than 90\% of award-winning wines are produced on alluvium and aggradation gravels. In Hawkes Bay, $18 \%$ of grapevines are situated on the Gimblett Gravels, with more than $50 \%$ of award-winning wines produced on these gravels. Interestingly, the ward-winning red varieties are grown in cooler conditions than in other wine producing countries, which is possibly because gravelly soils can retain heat (Imre \& Mauk, 2009). These findings suggest appropriate site selection is essential. If cultivation were to shift the wine styles would change, as the growing conditions will differ per site (Imre \& Mauk, 2009).

Climate indices used for regional suitability require more research in the New Zealand context (J. D. Anderson et al., 2012). However, a study of regional suitability in Marlborough found the region's thermal environment is influenced by both altitude and distance from the seas (Sturman et al., 2017). Furthermore, present growing season temperatures suggest the optimum winegrape variety for the Marlborough region is Pinot Noir, rather than Sauvignon Blanc. There are historical and cultural factors that influence grape selection. Sauvignon Blanc produced in Marlborough has a grassy style, with the winegrapes harvested at a lower level of ripeness. The cool climate and the terroir of Marlborough create the distinctive wine style of Marlborough Sauvignon Blanc (Sturman et al., 2017). 
New Zealand's climate has changed over time. Temperatures in Marlborough have increased, as well as the occurrence of frost (Sturman \& Quénol, 2013). These changes are due to clearer skies along the East Coast, with Sturman and Quénol (2013) attributing this to more frequent anticyclones, fewer low-pressure systems, and increased zonal and southerly flow as part of the SAM and ENSO. The changes occurring in Marlborough appear to be inconsistent with observed changes in Central Otago, Nelson and Hawkes Bay. The findings indicate that temperature change is occuring differently along the eastern side of the South Island over the last 50 years (Sturman \& Quénol, 2013). The study suggests climate variability is unlikely to be uniform across New Zealand and more research is needed to understand the changes at a local or regional scale given the different topography. Some initial research has been conducted to assess the climatic suitability of the Waipara Basin in Canterbury for viticulture cultivation. The results suggest that the climate in the Waipara Basin is variable and that the most important viticulture component that affects grapevine development is temperature (Sluys, 2006).

Additional research into New Zealand wine shows that grapevine harvest dates for Marlborough Sauvignon Blanc have fluctuated up to five weeks in the last ten years (Agnew, Raw, Bishell, \& Grab, 2015). The results also show that in Marlborough flowering has varied from 7 to 21 days between 2004 - 2014 (Agnew et al., 2015). Other research covers producing lower alcohol wines and lower calorie 'lighter' wines. The programme is market driven as there is demand both domestically and on the international scale (Ministry for Primary Industries, 2017). This research is still in early stages of development and is yet to be linked to changes in climate. The National Institute of Water and Atmospheric Research (NIWA) recognises that climate change will affect grape production in New Zealand. NIWA (2007) reports by 2030, New Zealand will experience earlier ripening and possible reductions in grape quality. However, red wine styles will be cultivated more in the south with potentially higher yields. Pests are also likely to increase in presence, with New Zealand wine becoming more susceptible as the country warms (NIWA, 2007).

New Zealand wine research is ongoing and given the unique climate variability between regions, more specific information is needed to assess how climate change will impact 
wine production. Climate and regional variability of future wine production has been the central focus within the literature, although more research is underway such as a longitudinal grapevine phenology analysis. The research on New Zealand wine suggests a shift in regional suitability with possible varietal change needed.

\subsection{Research Gap AND Summary}

The effects of climate change have been observed and studied mostly in Europe, North America and Australia. However, little research has been carried out in the New Zealand context. Although this research can be used to indicate how climate change can affect wine production, impacts can only be inferred in the New Zealand context as there is no specific data available. Furthermore, the main focus of the New Zealand climate change and wine literature is on regional suitability. There appears to be no research on New Zealand winegrowers' perceptions, nor on adaptation planning. Therefore, this thesis aims to fill this research gap by beginning a discussion with winegrowers about how climate change will affect the New Zealand industry. The research focus is to understand winegrowers' decision-making and adaptation planning for the changing climate in New Zealand. The research questions are:

1. How do winegrowers perceive climate change in the context of the New Zealand wine industry?

2. How are winegrowers engaging in decision-making for climate change adaptation?

3. What are the barriers to adaptation planning in the New Zealand wine industry? 


\section{CHAPTER 4: ADAPTATION PLANNING}

\section{"IL BUON VINO NON HA BISOGNO DI FRASCA - GOOD WINE NEEDS NO LEAFY BRANCH" \\ - ITALIAN PROVERB}

\subsection{INTRODUCTION}

This chapter aims to outline and integrate the two conceptual frameworks used in the study to understand decision-making and adaptation planning. Conceptual frameworks are used to guide the research design by providing structure and tools to critically examine and interpret findings (Pearson, Nelson, Crimp, \& Langridge, 2011). This research is centred on the adaptation processes framework developed by Moser and Ekstrom (2010) which diagnoses barriers to climate change. This framework can be applied to understand winegrowers' decision-making capacity. Subsequently, the chapter reviews and applies the concept of co-production of knowledge (Jasanoff, 2004). As the study uses winegrowers' perceptions, the research is grounded in shared knowledge and bridging the gap between scientists and users. The chapter concludes by discussing the intersections of the frameworks and how they are applied in the study.

\subsection{Decision-making for Climate Change Adaptation}

Adaptation is recognised as a strategy that needs to be implemented concurrently with mitigation (Moser \& Luers, 2008). However, in many contexts, there is a severe lack of adaptation being implemented, causing an 'adaptation deficit' (Burton, 2009; Eisenack et al., 2014). In New Zealand, there a lack of emphasis by planners and decision-makers on adaptation (Ford, Berrang-Ford, \& Paterson, 2011; N. E. White \& Buultjens, 2013). Furthermore, "adaptation strategies tend to be very low priority for the general public" (Blackett, Smith et al. 2010, p. 1). It is necessary to understand the decision-making process to identify the opportunities and constraints which affect the capacity to adapt 
(Moser \& Luers, 2008). Additionally, recognising the roles of key industry decisionmakers can give more understanding to the barriers that impede adaptation planning (Eisenack et al., 2014). Moser and Luers (2008) argue that building adaptive capacity of decision-makers requires awareness, analytic capacity, and action. Therefore, this research supposes that if winegrowers have the willingness to consider and understand the climate change issue, they are able to apply their awareness and analytical skills to make decisions and take effective action. However, this assumption needs to consider the range of barriers at the different stages of adaptation planning. The framework by Moser and Ekstrom (2010) addresses this by diagnosing the barriers to adaptation planning in a systematic approach.

\subsection{Adaptation Processes Framework}

The adaptation processes conceptual framework is used to identify barriers through planned adaptation (Moser \& Ekstrom, 2010). The processes of adaptation are based on three rational decision-making phases, which include nine sub-phases, as shown in Figure 4.1. The understanding phase requires the detection of the problem (i); gathering and use of the information (ii); and the (re)definition of the problem (iii). The planning phase includes developing options (iv); assessing options (v); and selecting options (vi), which leads to the management phase. The option needs to implemented (vii); the outcome monitored (vii); and finally the option needs to be evaluated (ix). 


\section{Understanding}

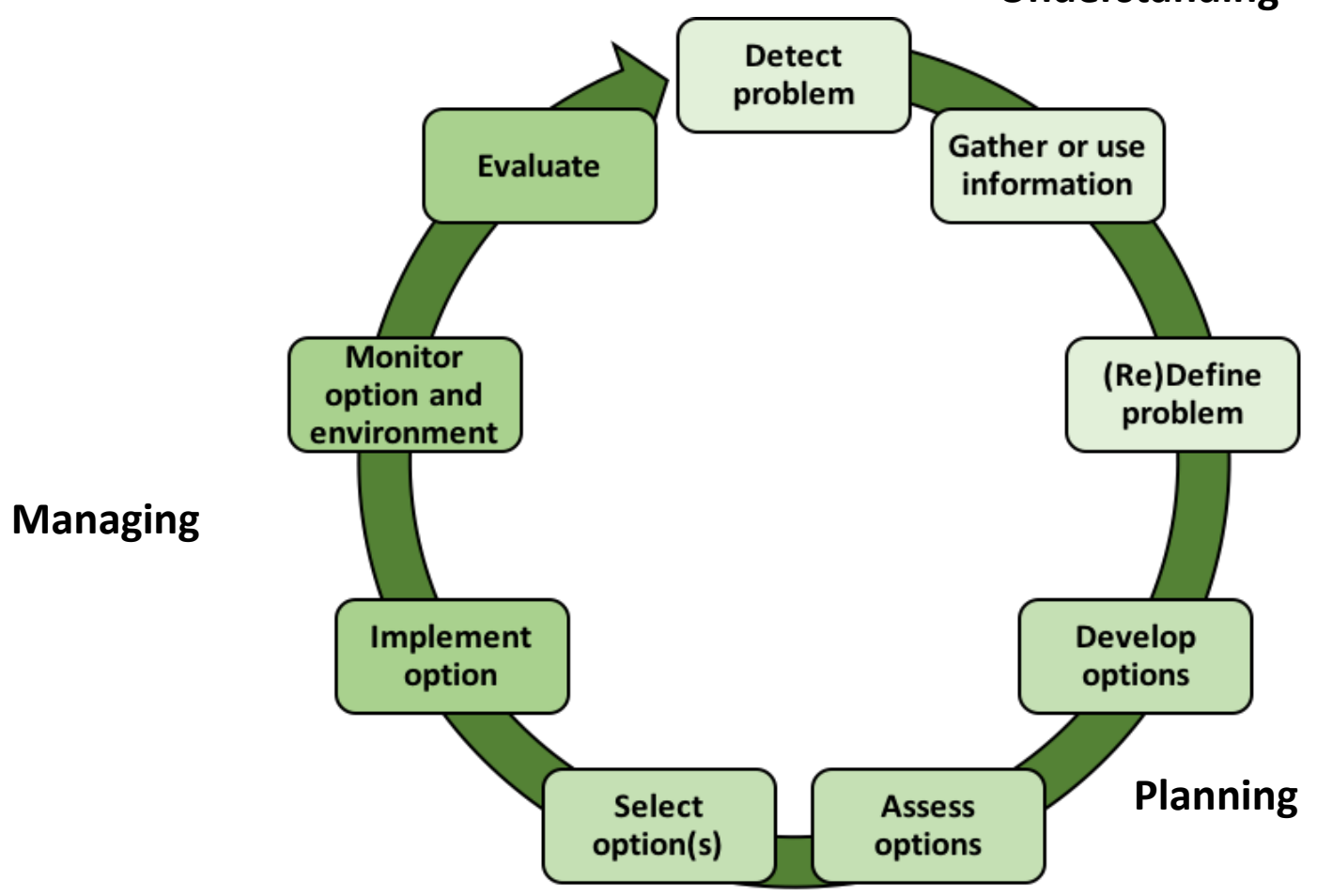

Fig. 4.1. Phases and sub-phases of the adaptation process framework. Adapted from Moser and Ekstrom (2010, p. 22027).

The final stages of the model are important when considering uncertainty as monitoring and evaluation are essential for institutional and social change (Gunderson \& Holling, 2002). Although the framework appears neat and 'linear', it can often become fragmented in practice because of the potential barriers at each stage (Moser \& Ekstrom, 2010). Skipping a stage can lead to subsequent barriers that will continue to hinder progress (Scheider, 2014). Overall the framework is designed to be 1) socially focused but ecologically constrained; 2) action-centric but context-aware; 3) process focussed but action/outcome-orientated; and 4)iterative and messy but portrayed as linear for convenience (Ekstrom, Moser, \& Torn, 2010; Moser \& Ekstrom, 2010). To understand the process of decision-making, Moser and Ekstrom (2010) distinguish between actors, who are not prescribed or static; the larger context in which the actors are situated; and the system which they seek to change (Figure 4.2). Actors may only make changes to the system if the governance context (laws and regulations) allows or requires alterations. 


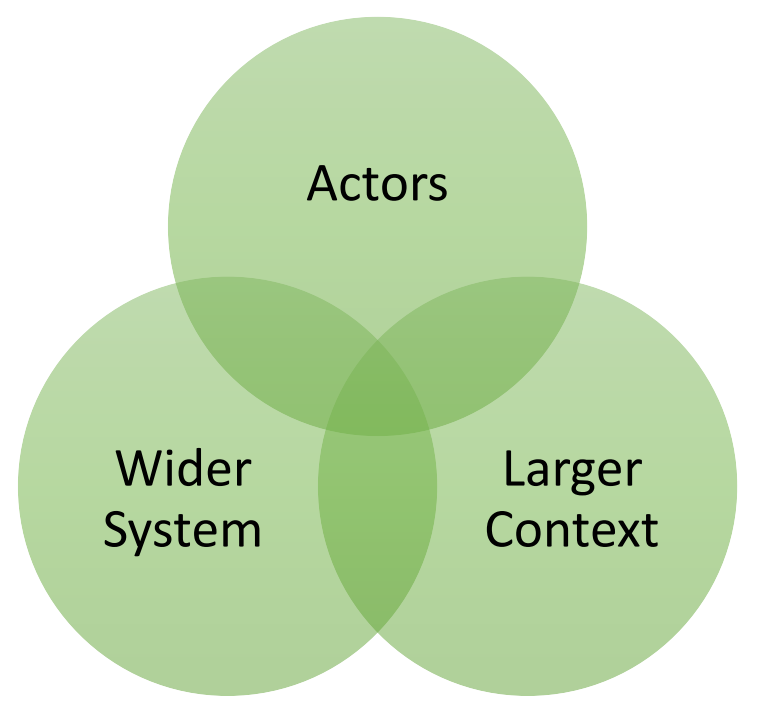

Fig. 4.2. Intersection of actors, context and wider system.

In the context of this study, the actors are the winegrowers, and in the larger context the industry organisation, New Zealand Wine, which governs the wineries and represents wineries interests at a higher level. The wider system is the wine industry, which is arguably in need of reform (Figure 4.3).

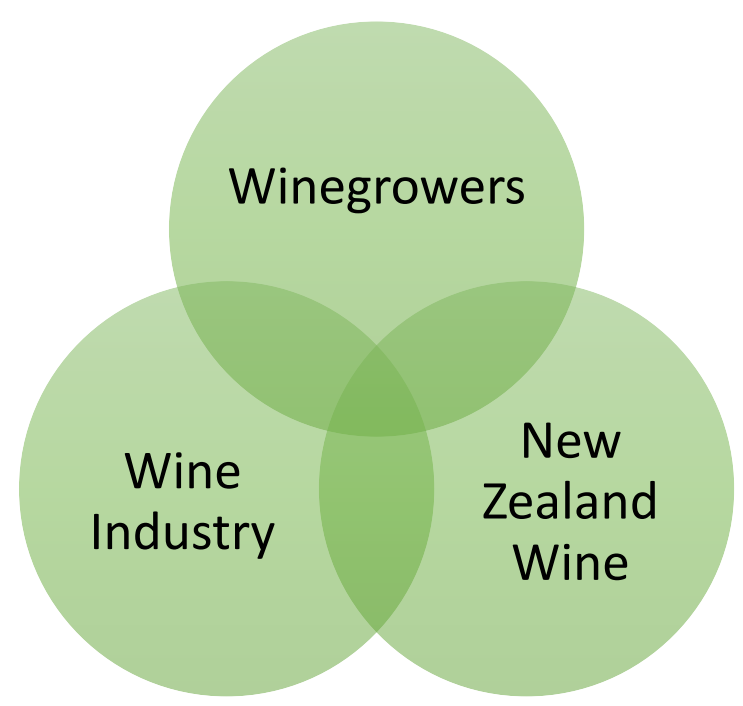

Fig. 4.3. Intersection of winegrowers, the organisation New Zealand Wine, and the wine industry system.

The adaptation processes framework is relevant for this research as it mirrors the local reality reflected in the winegrowers' shared stories. The framework's detailed process is inclusive of the actors, the context and the wider system., while the approach is comprehensive and flexible. Therefore, it can be used to understand and interpret the barriers and how to overcome them. 


\subsection{Barriers to Adaptation Planning}

The IPCC characterises adaptation barriers as "factors that make it harder to plan and implement adaptation actions or that restrict options" (Klein et al., 2014, p. 16). However, the concept of barriers can be argued as a justification for low adaptive capacity and why action is not being undertaken (Eisenack et al., 2014). The adaptation process framework outlines that barriers can be established by the actors, the context, and the system of concern (Moser \& Ekstrom, 2010). The potential barriers can be identified throughout the framework, as often the barriers will either stop, delay or divert the adaptation process (Scheider, 2014). A barrier can be an independent factor or can work concurrently with others. Different barriers can occur throughout the phases of Moser and Ekstrom's (2010) framework, and some repeatedly appear throughout the process.

Moser and Ekstrom (2010) explain that although the system of concern will produce signals of change, it is up to the actors to recognise and interpret what is happening (Table 4.1). The governance of the broader context can produce a signal or pass it on the actors. However, without leadership or guidance, the actors' capacity or willingness to adapt will decline (Tribbia \& Moser, 2008). The detection of the signal is the first stage of recognising the problem, and without acceptance, no planning will be undertaken. The signal could also fail to emerge if too much uncertainty or variability is involved as the problem cannot be recognised (Ekstrom et al., 2010; Moser \& Ekstrom, 2010). There is also evidence of a disconnect between science and practice, and the use of information which can further impact the transmission of the signal (Vogel, Moser, Kasperson, \& Dabelko, 2007). 
Table 4.1. Barriers to climate change adaptation in the phases of the adaptation processes framework. Adapted from Moser \& Ekstrom (2010, p.22028-22029).

\begin{tabular}{|c|c|}
\hline Understanding & Potential Barriers \\
\hline Detect problem & $\begin{array}{l}\text { Existence of signal } \\
\text { Detection of signal } \\
\text { Threshold of concern } \\
\text { Threshold of response need and feasibility }\end{array}$ \\
\hline $\begin{array}{l}\text { Gather or use of } \\
\text { information }\end{array}$ & $\begin{array}{l}\text { Interest and focus } \\
\text { Availability and accessibility } \\
\text { Relevance and legitimacy } \\
\text { Credibility and trust } \\
\text { Receptivity of information } \\
\text { Willingness and capability to use information }\end{array}$ \\
\hline (Re)Define problem & $\begin{array}{l}\text { Threshold of concern } \\
\text { Threshold of response need } \\
\text { Threshold of response feasibility } \\
\text { Level of agreement }\end{array}$ \\
\hline Planning & Potential Barriers \\
\hline Develop options & $\begin{array}{l}\text { Leadership } \\
\text { Ability to identify and agree on goals } \\
\text { Ability to identify and agree on criteria } \\
\text { Ability to develop and agree on options } \\
\text { Control of process } \\
\text { Control of options }\end{array}$ \\
\hline Assess options & $\begin{array}{l}\text { Availability of information to assess options } \\
\text { Accessibility or usability of information } \\
\text { Availability of methods to assess and compare } \\
\text { options } \\
\text { Perceived importance, credibility, and legitimacy } \\
\text { of information and methods } \\
\text { Level of agreement on goals, criteria, and options }\end{array}$ \\
\hline Select option(s) & $\begin{array}{l}\text { Agreement in selection } \\
\text { Responsibility, influence and control over options } \\
\text { Threshold of concern for potential negative } \\
\text { consequences } \\
\text { Threshold of perceived option feasibility } \\
\text { Clarity of authority and responsibility for option }\end{array}$ \\
\hline Managing & Potential Barriers \\
\hline Implement option & $\begin{array}{l}\text { Threshold of intent } \\
\text { Authorisation } \\
\text { Sufficient resources } \\
\text { Accountability } \\
\text { Clarity/specificity of options } \\
\text { Legality and procedural feasibility } \\
\text { Sufficient momentum to overcome obstacles }\end{array}$ \\
\hline
\end{tabular}




\begin{tabular}{|l|l|}
\hline & Existence of monitoring plan \\
& Agreement and clarity on monitoring targets and \\
goals & Availability and acceptability of established \\
Monitor option and & methods \\
environment & Availability of technology \\
Availability and sustainability of economic \\
resources \\
Availability and sustainability of human capital \\
Ability to store, organise, analyse, and retrieve \\
data \\
\hline Evaluate & Threshold of need and feasibility of evaluation \\
& Availability of expertise, data, and evaluation \\
methodology & Willingness to learn \\
& Willingness to revisit previous decisions \\
& Legal limitations on reopening prior decisions \\
& Social or political feasibility of revisiting previous \\
decisions
\end{tabular}

Throughout the three phases, leadership, authority and skill are crucial as the inability to agree on goals, problems and criteria can establish a further barrier (Moser \& Ekstrom, 2010). Furthermore, depending on the level of governance and control on the organisation, some of the options are restricted due to political interests, funding and jurisdiction coordination (Cash \& Moser, 2000; Renn, 2008). Research indicates that not many organisations pass the planning phase and begin the management phase (Adger, Lorenzoni, \& O’Brien, 2009; Berkhout, Hertin, \& Gann, 2006; Dovers, 2009). The reasons relate to the number of barriers before and during the 'implementation' sub-phase which restrict progress. Furthermore, adaptation is relatively new and it will take time for effective decision-making to progress beyond planning.

Moreover, other barriers can impede the implementation of the framework: leadership; resources; communication and information; values and beliefs. Without effective leadership, there will be no momentum for understanding or planning for the problem (Moser \& Ekstrom, 2010). Leadership is critical for decision-making as the role encompasses guidance and motivation, with leaders being viewed as trustworthy and their actions seen as legitimate (Zand, 1997). Resources are essential throughout the stages but are often used more in the planning and management stage of adaptation. Technology, staff capabilities, and financial capital are all resources that help in ensuring 
options are successful (Moser \& Ekstrom, 2010). When organisations are asked why they have yet to start planning or implementing adaptation options, it is often stated that they have inadequate resources, but the type of resource that is lacking varies (Tribbia \& Moser, 2008). Effective communication is needed to ensure the actors understand the problem and that the information is passed on to the other stakeholders. When information is shared, it is critical that the knowledge remains consistent. Therefore, communication between stakeholders needs careful consideration to ensure the correct message is forwarded (Moser \& Ekstrom, 2010). Information that is misunderstood can disrupt the adaptation process, but so can the social interactions of the actors involved (Moser, 2009). Values and beliefs affect the decision-making process as actors often use their pre-existing values and beliefs to interpret new information (Archie, Dilling, Milford, \& Pampel, 2012; Archie, Dilling, Milford, \& Pampel, 2014). Beliefs are vividly seen in relation to climate change and the willingness to adapt. When actors 'believe in' climate change, they are more likely to plan and implement adaptation. When actors believe climate change to be unreal, they have yet to reach the point when the presenting evidence can overcome preconceived views, and are unable to progress through the framework (Blennow \& Persson, 2009; Moser \& Ekstrom, 2010).

\subsection{SUMMARY}

The coupling of adaptation planning and co-production of knowledge provides the architecture for this research. The adaptation processes framework provides the core foundation for evaluating winegrowers' adaptive capacity and for distinguishing the barriers impeding adaptation progress. 


\section{CHAPTER 5: METHODOLOGY}

\section{“NELLA BOTTE PICCOLA C'É IL VINO BUONO \\ - IN SMALL BARRELS, THERE IS GOOD WINE" \\ - ITALIAN PROVERB}

\subsection{INTRODUCTION}

This chapter discusses the mixed methods research design and outlines the epistemological approach, the positionality of the researcher, and the ethical obligations of the study. The quantitative study method is discussed first, followed by an outline of the survey design and participant recruitment. This section also discusses the sample characteristics, before addressing the main data analysis. The qualitative approach outlining the case studies employed for this research, and the interview process is discussed next. This section also explains the thematic analysis employed for analysing the interview data. The chapter concludes by addressing the methodologies explored in the research, summarising why they are appropriate.

\subsection{Mixed Methods Research}

A mixed methods research approach was selected to understand winegrowers' perceptions of climate change in a relatively comprehensive way. Mixed methods provide stronger evidence by combining the different types of data and overcomes the weaknesses of selecting a single type of research approach (Johnson \& Onwuegbuzie, 2004). Mixed methods enable the research process to be more flexible and versatile in exploring solutions to the problem (Creswell, 2014). This research uses an explanatory sequential mixed methods approach. The process is described as employing quantitative research and analysing the data to inform the qualitative research. By using the quantitative results, the qualitative component can build on the findings to further analyse the problem and enhance the scope of the research (Creswell, 2014). This method was chosen as it allows the researcher to gather primary data about winegrowers' perceptions of climate change by analysing their decision-making 
capabilities. The use of a survey supplemented with interviews allows the researcher to identify the stages of the adaptation processes described by Moser and Ekstrom (2010) (see Chapter 4). Furthermore, the mixed methods research approach integrates the coproduction of knowledge, as winegrowers' knowledge and opinions are amalgamated throughout the survey, and then their perceptions inform the interviews. This framework is embedded throughout the research design and is used to reveal the barriers impeding climate change adaptation planning in the wine industry.

\subsubsection{Existemological Position}

This research uses a pragmatic epistemological approach to frame the study design. Pragmatism is favoured in mixed-methods research as it can be applied to both quantitative and qualitative research (Creswell, 2014). The pragmatic worldview tries to understand the problem by analysing the real-world situation to provide practical solutions (Frazier, 1981). Rather than focusing on specific methods, pragmatic researchers aim to use all approaches available to understand the problem (Creswell, 2014; Rossman \& Wilson, 1985). The approach is designed to be action-centred and user-orientated as knowledge is understood through experiences (Kitchen \& Tate, 2013). A pragmatic epistemological approach allows freedom in selecting the methods, techniques and procedures to understand the research problem (Creswell, 2014). Pragmatism is applied in this research through the mixed methodologies selected.

\subsubsection{POSITIONALITY}

Positionality is the concept which explains how a researcher's experience or position can influence the collection and interpretation of data (Teye, 2012). In qualitative research, the researcher's beliefs, political stance and cultural background can influence the research process by affecting how questions are framed and posed (Bourke, 2014). It is essential to recognise the interaction between the researcher and participant when conducting qualitative research (Tarrant, 2013). In pragmatism, knowledge is situated in experience, so when incorporating participants' perceptions into the findings, the researcher needs to identify his or her positionality to ensure the interpretation of data is not influenced by the researcher's belief (Manderson, Bennett, \& Andajani-Sutjahjo, 
2006; Rose, 1997). I am a university educated, young female researcher. My university education is focused on the environment and geography, and I am from the wine producing region of Marlborough. This positionality can inform the study given the power relations with participants (Cormode \& Hughes, 1999) and the notion of insider and outsider research (Mohammad, 2001).

The participants interviewed in this research were predominantly male and had an established career in the wine industry. During an interview with a female, some men may provide information in a more technical and less emotive manner (Manderson et al., 2006). While, this is not always the case, Tarrant (2013) recommends acknowledging the potential dynamic and being aware of how information is portrayed. Throughout the interviews, the power relations remained reasonably equal. As a young researcher without a background in viticulture or viniculture, I found the exchange moved sometimes into a teacher/student dynamic as participants discussed the wine industry. This can be attributed to the age difference, and how interviewees can try to evoke an association with the researcher (Tarrant, 2013). Furthermore, the setting where interactions are held can influence the power relations and the content discussed (Manderson et al., 2006). Participants are likely to link their examples to the space in which they are interviewed (Elwood \& Martin, 2000). The interviews took place at the participant's workplace, which allowed for ease of location and safety, but additionally, they had more control of the conversation and could link part of the discussion to their winery.

The dynamic of insider/outsider in the research process can also affect the researcher's positionality. An insider is a researcher who is studying a group they belong to, and often the researcher is given more trust and access to information (Teye, 2012). On the other hand, an outsider is a researcher who is studying a group from the periphery. As an outsider, the researcher can be more objective and the information gathered can be viewed with less bias (Mohammad, 2001). The position of insider/outsider can be adaptable as it is circumstantial to the dynamics of positionality in the research (Mullings, 1999). Although I am not directly involved in the wine industry, I have family connections who work in the Marlborough wine region. These connections were mentioned to facilitate access to participants to interview and to distribute the survey 
to winegrowers in the industry. When interviewing in other wine regions, I drew on my connection to Marlborough to build a rapport with the participants and placed myself as a semi-insider.

\subsubsection{ETHICAL OBLIGATIONS}

Ethics approval was granted on 4 May 2017 by the Human Ethics Committee of Victoria University of Wellington; ethics approval number 24523 (see Appendix B and C). The primary consideration for ethical approval was the assurance that participation of both the survey and interview participants would be treated with appropriate anonymity and confidentially so neither business nor personal identification was possible. The survey data was aggregated for analysis, so results are not attributable. Interview participant names remain confidential as they are referred to only by their region and an allocated number. An example is Marlborough Winegrower 1.

For both the survey and interviews information sheets outlining the intentions of the research were distributed before the collection of data (see Appendix D and Appendix E). Additionally, informed consent was obtained for both research methods. Participants were required to give consent before beginning the survey (see Appendix F), and interviewees had to sign the consent form outlining their agreement to participate and be audio-recorded before we started our conversation (see Appendix G). The interview participants had the right to withdraw from the research by 30th September 2017. No participants withdrew from this study. Survey responses were anonymous and thus could not be withdrawn, but participants could exit the survey at any time.

\subsection{Quantitative SuRVey RESEARCH}

The research was designed to understand winegrowers' perceptions of climate change and adaptation planning in the New Zealand industry. Using a pragmatic approach, the research focused on understanding attitudes, opinions and trends within a population (Creswell, 2014). A survey was employed as the quantitative research instrument as it provides an approach by which perceptions of winegrowers in the New Zealand wine industry could be systematically examined and compared using a range of measures 
(Kitchen \& Tate, 2013). The survey was structured to address the research goals by assessing perceptions of climate change; the status of adaptation planning; opinions about information for decision-making; perceived barriers to adaptation planning; and views about the key decision-making drivers within the wine industry.

\subsection{SURVEY DESIGN}

To obtain data about winegrowers' perceptions of climate change and adaptation throughout New Zealand, an online survey was conducted building upon previous adaptation surveys (Archie et al., 2012; Archie et al., 2014; Tribbia \& Moser, 2008). This study emphasises adaptation planning specifically for wine production. The survey included targeted questions about climate change knowledge and impacts, adaptation planning, barriers to planning, the use of scientific information, and demographics. The survey comprised 30 questions (Appendix $\mathrm{H}$ ), including open-ended, rank order, Likert scale, and multiple-choice questions. Besides the informed consent question, all questions were optional and could be skipped at will. Consequently, some questions elicited more responses than others.

Participants were recruited using purposeful selected sampling methods (Creswell, 2014) as this study explicitly targeted New Zealand winegrowers. An extensive web search was employed to collect information on New Zealand wineries. The sample was limited to winegrowers that had publicly available contact information in May 2017. The recruitment email included the link to the survey, and the information sheet was attached (Appendix I). Purposeful sampling allowed the research to target decisionmakers in the wine industry as the participants included managers, owners, winemakers, and grape-growers. The survey was distributed to 502 wineries via email from June to August 2017, with the survey closing in September 2017. The literature emphasises the importance of reminders to increase the response rate (Archie, 2014; Dillman, 2000). Therefore, the survey was emailed to the sample winery list three times over the recruitment period. 


\subsection{SURVEY DEVELOPMENT}

The survey was developed using Qualtrics web survey software as provided by Victoria University of Wellington. An online survey was the most appropriate distribution method as the sample population had access to computers through their employment and the email was sent to staff accounts. Additionally, online surveys are more manageable for both the researcher and participants, they are faster for distribution and response, and are more cost-effective (Sue \& Ritter, 2012). However, there are also potential disadvantages in employing an online survey. For example, survey emails could be marked as spam and receipt of multiple invitations to a survey may discourage participation (Sue \& Ritter, 2012).

Before distribution, the survey was pre-tested on ten qualified respondents who were affiliated with the wine industry. The pilot test was to ensure the questions were worded clearly and the questions were appropriate to the purposefully selected sample. The pilot test highlighted that the wording was more relevant for winemakers than grapegrowers. Therefore, questions were reworded and in some cases, new questions were developed to be more inclusive for both types of participants.

\subsection{SURVEY SAMPLE}

In total 133 winegrowers accessed the survey online. Of those, 115 completed the entire survey. The overall response rate was $26.5 \%$, which is in the typical range for an online survey launched after 2000 (Sheehan, 2006). The distribution of responses per region is approximately proportionate to the size of the wine regions (Figure 5.1). 


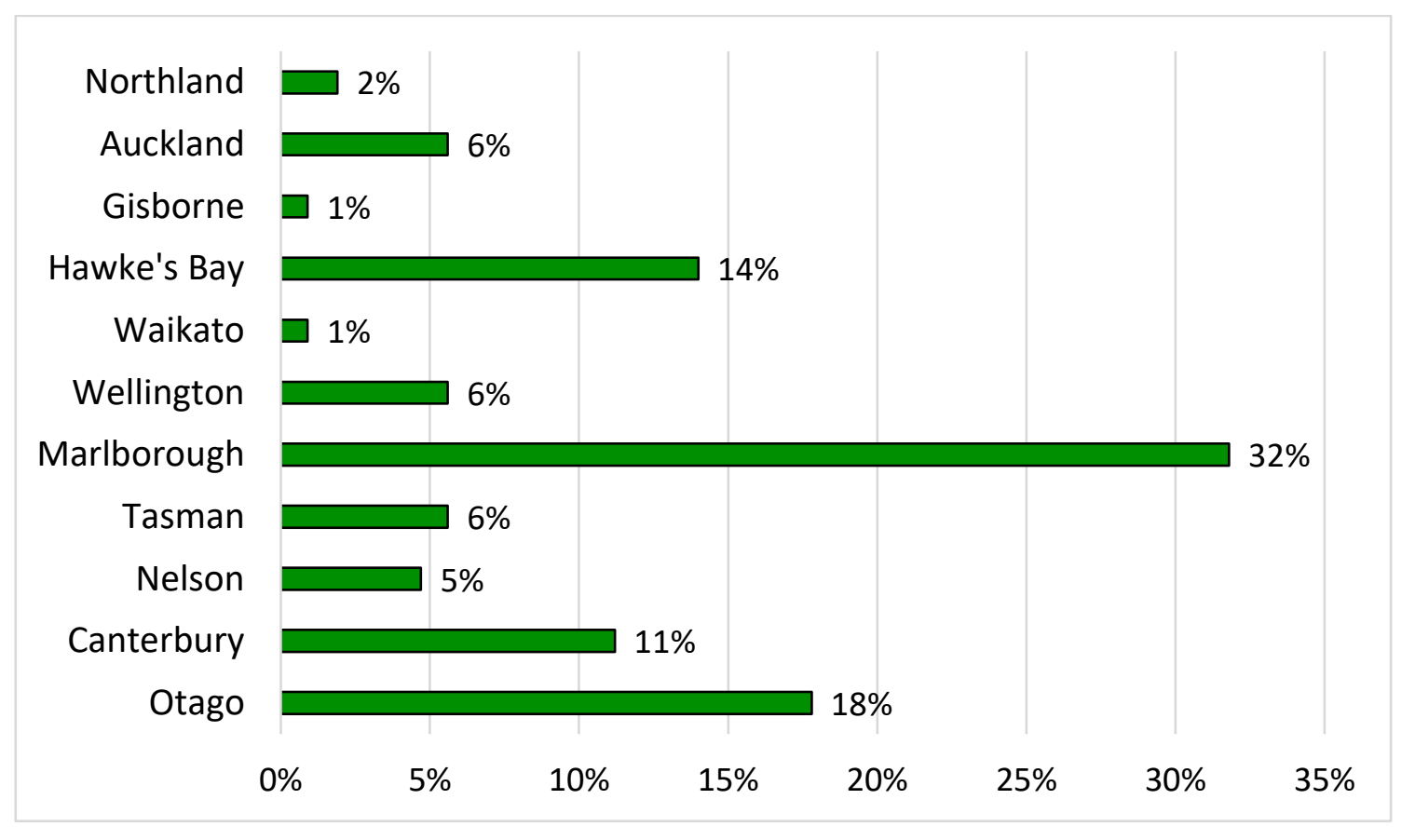

Fig. 5.1. Regional distribution of survey responses.

The distribution reflects a fairly representative sample of New Zealand winegrowers. Additional questions were asked regarding personal characteristics of participants to establish the demographic characteristics of the sample. Standard questions about age, gender, and education were asked to give a profile of the sample, as well as employment and length of residence to ensure a range of experience in the wine industry was included.

The sample consisted of $80.4 \%$ male and $19.6 \%$ female respondents. The participants' ages ranged from 25 to 70 years, with $33 \%$ of participants in the 40 to 49 age bracket. The sample was highly educated with $41 \%$ of participants have completed a Bachelor's degree and a further $33 \%$ with some form of post-graduate qualification. The participants include winemakers (25\%); winery managers (7\%); winery owners (29\%); viticulturists (11\%); vineyard managers (10\%); and employees who work in various other fields (17\%). Consequently, this sample is predominantly wine producers (61\%), rather than grape producers (21\%), which could potentially cause a predisposition in the perceptions of the sample. Most of the participants have worked in their region for a period with $79 \%$ of the sample having worked in the region for 10 or more years. The demographics suggest that there is a wide-range of experience for different parts of the industry. As this survey is looking at winegrowers' perceptions across New Zealand, the 
sample offers varied opinions and knowledge levels about the wine industry. However, the data collected is not representative of the views of all winegrowers.

\subsection{SURVEY ANALYSIS}

The survey data collected was predominantly descriptive in nature, so simple statistical analysis was conducted. The data was analysed using IBM's Statistical Package for Social Sciences (SPSS) version 23. The analyses used were chi-square tests, Pearson's correlations, ordered logistical regression, and cross-tabs to establish statistical differences between the sample data.

\subsection{Qualitative InTERVIEW Research}

The study's use of qualitative methods is founded on the assumption that the world is shaped by human processes that influence the way the world is interpreted and perceived (Limb \& Dwyer, 2001). Qualitative research methods were utilised to supplement survey responses and understand the perceptions and opinions of winegrowers further. Pragmatism lends itself to the research design as interviews were the most appropriate research method to analyse winegrowers' responses as they can produce a more in-depth and complex understanding of participants' viewpoints (Creswell, 2014). Furthermore, interviews can elaborate on the quantitative component of the research and complement the research findings (Creswell, 2014). The chosen method explored three wine regions as case studies (see below), invoking semistructured interviews with participants and a thematic analysis of the transcriptions. Qualitative methodologies in this research allow for winegrowers to express their perceptions of climate change adaptation through a discussion of their experiences, viewpoints and motivations (Hay, 2010).

\subsection{Case Studies}

This research lends itself to a case study approach as it focuses on the contemporary issue of what climate change means for winegrowers in a specific context (Yin, 2014). 
Furthermore, the case study approach can be used to interpret decision-making by examining the participants' reasoning (Yin, 2014). Case studies can be constrained by location and a time frame (Yin, 2014), but this research approach allows flexibility for the researcher to gain a deeper understanding of the context and phenomena (Yin, 2014). Exploring three regions as case studies to allowed the comparison of climate change impacts across different locations while looking at winegrowers' perceptions of adaptation.

The regions of Marlborough, Central Otago, and Hawke's Bay were purposefully selected as they are the primary producers of wine in New Zealand, allowing a range of winegrowers to be interviewed, from various sized companies. The selection also gives a fair representation of climatic variability relevant to most wine growing in New Zealand, with each region having a distinctive microclimate. A brief overview of the different regions climate and soil profiles is provided below. The case study approach was the most appropriate method to compare the varied responses from participants across different wine regions. Winegrowers from within one region can be expected to experience similar benefits or constraints from climate change, allowing a more detailed profile of the impacts of climate change to develop. At the same time, the case study approach allows a comparison of winegrowers' perceptions between the regions, as each region can be expected to respond somewhat differently.

\subsubsection{MARLBOROUGH}

Marlborough is the primary wine producing region of New Zealand, with Marlborough Sauvignon Blanc known as an international brand (New Zealand Wine, 2017d). The region has an annual average of 2,475 sunshine hours, with many areas receiving less than 800 millimetres $(\mathrm{mm}$ ) of rainfall (Chappell, 2016). Summer droughts are frequent, and the overall climate is continental with a northwest wind flow. The region is also susceptible to both air and ground frosts during the cooler months and at higher elevations (Chappell, 2016). The soils consist of stony gravels, with the southern valleys more clay oriented. They are predominantly glacial and free-draining (Imre \& Mauk, 2009). 


\subsubsection{Central Otago}

Central Otago in the third largest wine producing region in New Zealand and it is internationally renowned for its cultivation of Pinot Noir (New Zealand Wine, 2017a). This mountainous region is the driest in New Zealand and receives less than $400 \mathrm{~mm}$ of rain annually. Exposed parts of Central Otago can experience strong winds, while other locations are more sheltered (Macara, 2015). The region has an average of 2,000 sunshine hours a year. Consequently, Central Otago resembles a semi-arid region in a continental landscape, with frequent cold winters and hot summers (Macara, 2015). The soils consist of layers of silt, mixed with river gravels and sand, yet they are free-draining (Imre \& Mauk, 2009).

\subsubsection{HAWKE'S BAY}

Hawke's Bay is the second largest wine producing region, and has built an international reputation for cultivating high-quality Cabernet and Merlot blends, Syrah, Pinot Noir and Chardonnay (New Zealand Wine, 2017c). The region has an average of 2,000 sunshine hours annually and experiences very light winds, which can enhance the frequency of both ground and air frosts during the cooler months (Chappell, 2013). Rainfall is sporadic in Hawke's Bay, causing dry spells throughout the region. The average annual rainfall can be less than $800 \mathrm{~mm}$, although in the hillier regions it can be up to $2000 \mathrm{~mm}$ (Chappell, 2013). The soil profile for the region is varied with parts of Hawke's Bay wine grown on the famous Gimblett Gravels, while other parts are grown on gravely sub-soils, sandy loams, clay, and on limestone (Imre \& Mauk, 2009).

\subsection{INTERVIEW DESIGN}

Data for the qualitative research was collected through open-ended semi-structured interviews. Interviews allow for more detailed answers on perceptions, experiences, and opinions, which provide an in-depth understanding of the information gathered through the survey (Kitchen \& Tate, 2013). Open-ended semi-structured interviews also allow for more freedom in enquiry while maintaining a conversational tone throughout the process (Kitchen \& Tate, 2013). The questions and topics discussed in the interview refer 
directly to the overall thesis research questions and act to supplement the information gathered in the quantitative survey. For the interview guide, see Appendix J.

Participant recruitment was accomplished by emailing wineries and requesting an interview with a winegrower to discuss climate change and adaptation in the case study region (see Appendix K). Participant recruitment used purposefully selected sampling to factor in the different sizes of wineries in the regions ${ }^{2}$; the range of sustainable business models ${ }^{3}$, and to include both grape-growers and winemakers. This sampling method provided diversity in the participants and their perceptions, which can help the researcher explore the problem further (Creswell, 2014). Although a variety of wineries were selected to identify winegrowers, the interview content is not necessarily fully representative of the winery. There is an acknowledged bias from purposive sampling as the participants are more likely to understand the impacts of climate change given that they agreed to be interviewed on the topic. However, as the interviews were designed to explore the survey results in more detail, any bias is unlikely to affect the overall picture developed (Suri, 2011).

\subsection{INTERVIEW PROCESS}

Overall, 15 winegrowers were interviewed for approximately thirty minutes each, with five interviews occurring in each region. All participants work in the wine industry in either viniculture or viticulture. The limited number of interviews conducted limits the ability to conclude that the responses are characteristic of the entire population of winegrowers. However, through the case study approach and interviewing a range of participants selected on the basis of specific criteria, the data collected can lend more nuanced understanding to the quantitative data. The interviews were conducted during August and September 2017. The interviews were face-to-face to allow for a more personal conversation and to provide a setting for the participant where they could refer to examples, while the researcher could observe (Kitchen \& Tate, 2013). The interviews

\footnotetext{
${ }^{2}$ The wineries size was subjective and determined based on the output of wines - scale ranges from boutique (small) to industrial (large).

${ }^{3}$ Consideration was given to the sustainable accreditation each winery has. Example of accreditation includes Sustainable Winegrowing New Zealand; organic or biodynamic; and carbon neutral (New Zealand Wine, 2017g).
} 
began with orientation questions to establish the participants' knowledge and background of how climate change can impact wine production. These questions allowed the participant to think about the context of the research and prompted the responses on this topic. A salient consideration was to ensure that the researcher's opinions did not inform the participants' perceptions of the topics. Questions held a neutral tone and emphasis was placed on asking for the participant's thoughts. The questions were open-ended and semi-structured to provide insight into participants' experiences and opinions on climate change and adaptation. A topic guide was used to facilitate the interviews, but the conversation was allowed to diverge if the information was interesting and relevant (Bryman, 2008). The questions were framed using plain language and participants were informed they could stop the interview at any time. All interviews were audio-recorded with permission and later transcribed verbatim for thematic analysis.

\subsection{ThEMATIC ANALYSIS}

Thematic analysis was chosen for this research as it is flexible and allows the qualitative data to be processed into themes and sub-themes to highlight patterns and linkages for interpretation (Braun \& Clarke, 2006). Thematic analysis is appropriate for pragmatic research as it also allows the researcher freedom in the implementation of analysis to answer the problem (Braun \& Clarke, 2006). This research predominantly uses a deductive thematic analysis approach, with underpinnings of inductive thematic analysis.

A deductive thematic analysis is a top-down approach as it begins with coding the interviews based on themes pre-determined by the literature and the research questions (Braun \& Clarke, 2006). The themes used in this research were derived from the similarities in the literature to examine how the findings complement or contradict previous studies. Furthermore, the themes are derived from the research questions as the interviews supplement the survey data. This allows the researcher to compare the responses and deduce commonalities in the research. An inductive thematic analysis is a bottom-up approach to analysing the data and then assigning themes (Braun \& Clarke, 2006). The inductive approach allows the interviews to be analysed separately with the 
focus on the content. For themes to be effectively assigned, the researcher must read the data multiple times to recognise patterns (Braun \& Clarke, 2006). This research used both deductive and inductive thematic analyses as the knowledge of the topic and patterns previously observed cannot be ignored and separated from the qualitative analysis (Braun \& Clarke, 2006). The data was analysed multiple times to ensure sufficient coding and repeated thematic analysis was undertaken to check for emerging themes.

The thematic coding process used NVivo 11 qualitative software. The transcribed interviews were imported into NVivo and for each transcript, the researcher coded themes that had commonalities to the research questions and the literature. Additional themes were coded using inductive analysis. The data was analysed multiple times to ensure all themes were coded.

\subsection{SUMMARY}

This study takes a pragmatic epistemological approach to mixed methods research. This chapter has discussed the researcher's positionality, identifying the research focus of climate change and adaptation that aligns with the framework chosen to guide the research process. The chapter discussed the survey and interview research approach employed for the study to emphasise the pertinence of mixed methodology for understanding winegrowers' decision-making processes for adaptation planning. 


\section{CHAPTER 6: RESULTS}

\section{"VINUM LUX SOLIS EST, AB AQUA COERCITA \\ - WINE IS SUNLIGHT, HELD TOGETHER BY WATER"}

- GALILEO GALLILEI

\subsection{INTRODUCTION}

The chapter presents the findings of the original survey and interviews with winegrowers throughout New Zealand. The results are separated into three sections per the research questions of this thesis:

1) How do winegrowers perceive climate change in the context of the New Zealand wine industry?

2) How are winegrowers engaging in decision-making for climate change adaptation?

3) What are the barriers to adaptation planning in the New Zealand wine industry? The survey and interview findings are discussed in tandem, with the interviews designed to be supplementary to the survey data. Therefore, the interviews often expand and provide context to the perceptions reported in the survey. The interview responses were amalgamated into three case studies to give a summary of the three main regions; however, the case studies do not represent all opinions of winegrowers from their region. The survey responses have a potential bias as the survey recruitment process outlined the focus on climate change, which could have led to a sample self-selected towards climate-concerned individuals.

\subsection{Climate Change Perceptions}

The research was designed to explore how winegrowers perceive climate change as a background to how decisions are made for adaptation planning. To contextualise the responses of the sample, respondents were asked to select which climate change statement they agreed with most. The purpose of this question was to get an indication of winegrowers' beliefs about climate change. Over half the respondents agreed that 
climate change is real and happening now (66\%), and $20 \%$ agreed that climate change is probably happening and we will see the impacts in the future. Only $10 \%$ of the sample reported climate change may become a problem in the long-term future and a mere $3 \%$ thought climate change is probably not happening now and will not be a problem in the future (Figure 6.1).

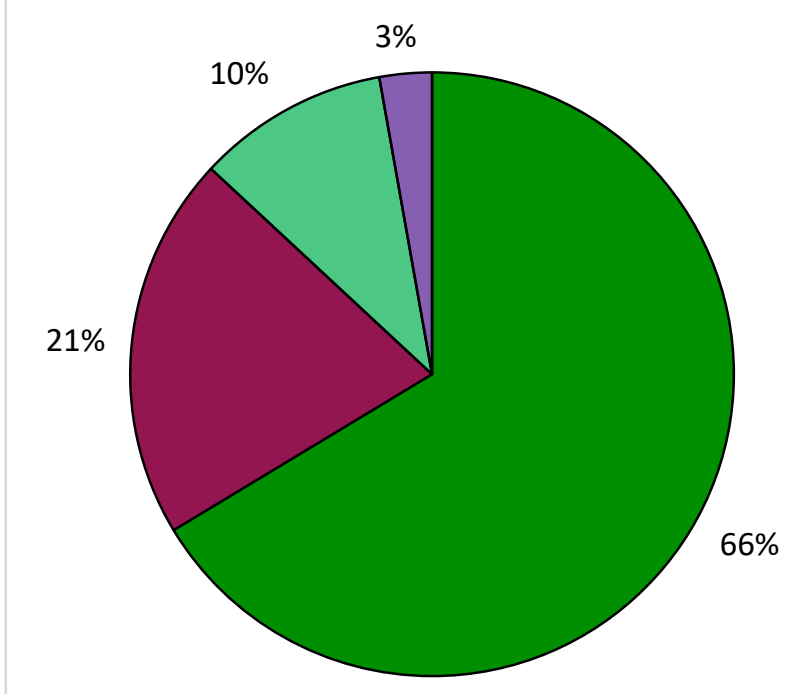

$\square$ Climate change is real and already happening now

$\square$ Climate change is probably happening and we will see the impacts in the near future

$\square$ Climate change may become a problem in the longer-term future

$\square$ Climate change is probably not happening now and will not cause problems in the future

Fig. 6.1. Respondent beliefs about climate change as an issue, $\mathrm{N}=107$.

When analysed on a regional basis, the pattern for each region is similar to that of the whole sample (Figure 6.2). Although differences were not statistically significant, likely due to the small sample size of the regional groups, respondents from Marlborough agree more strongly that climate change is real and happening now (76\%). No Otago respondents show agreement with the statement that climate change is probably not happening and will not cause problems in the future. Arguably, respondents from Hawke's Bay indicated the least concern about climate change compared to the other regions. 
Climate change is real and already happening now

Climate change is probably happening and we will start seeing the impacts in the near future

Climate change may become a problem in the longer-term future

Climate change is probably not happening now and will not cause problems in the

future

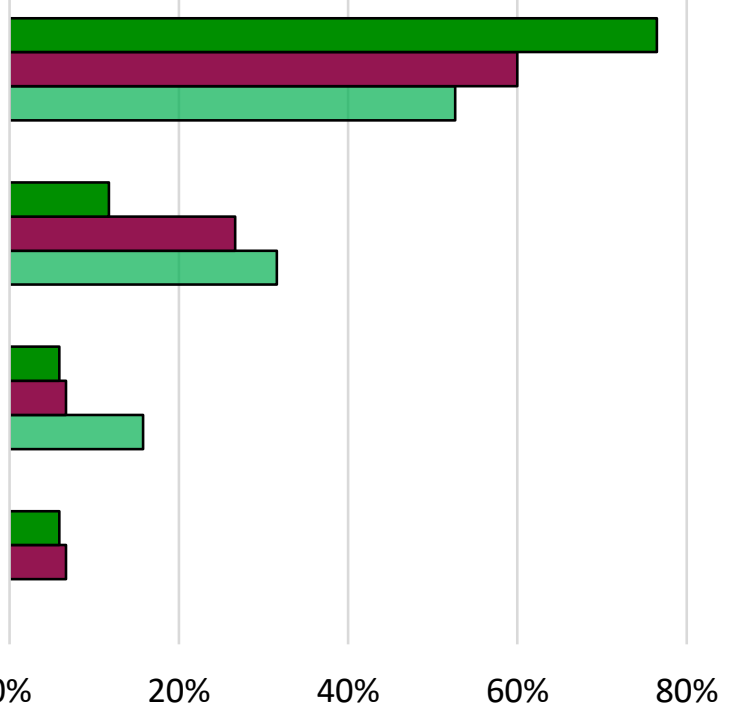

Marlborough $\square$ Hawke's Bay $\square$ Otago

Fig. 6.2. Respondents' perceptions of climate change as an issue based on the case study regions. Marlborough N=34, Hawke's Bay N=15 and Otago N=19.

The sample was further categorised based on the respondents' occupations within the wine industry (Table 6.1). Wine producers include winemakers, winery managers and winery owners, whereas grape producers are either viticulturists or vineyard managers. The other occupation includes respondents who worked in multiple positions or as assistants within the industry (Figure 6.3).

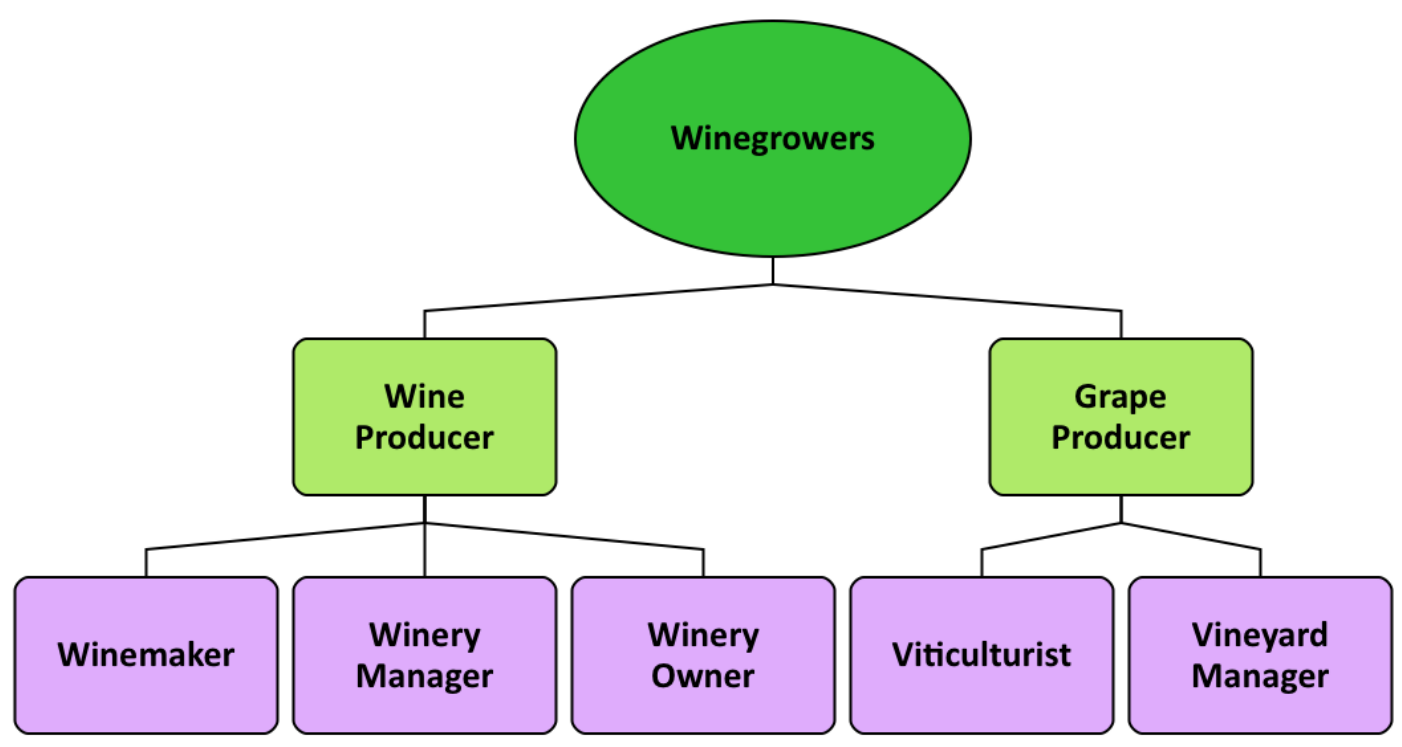

Fig. 6.3. Mind map of different winegrower occupations. 
The findings show similar results to the whole sample. However, wine producers agreed more strongly with the statement that climate change is real and happening now, than respondents from the other occupation groups. The Chi-Square Independence Test indicated a statistically significant difference between beliefs about climate change and occupation $\left(\chi^{2}(3)=7.936, p=0.047\right)$ (Table 6.2). The association is positive and substantial under a Cramér's V Correlation with $\phi_{c}=0.047$ (Table 6.3). Wine producers in this sample were more concerned about climate change, whereas grape producers were the least concerned about climate change.

Table 6.1. Cross-tabulation of climate change belief and wine producers.

\begin{tabular}{|l|c|c|c|}
\hline \multicolumn{1}{|c|}{ Climate Change Belief } & Wine Producer & $\begin{array}{c}\text { Other } \\
\text { Occupations }\end{array}$ & Total \\
\hline $\begin{array}{l}\text { Climate change is real and } \\
\text { happening now }\end{array}$ & 50 & 22 & 72 \\
\hline $\begin{array}{l}\text { Climate change is probably } \\
\text { happening and we will start } \\
\text { seeing the impacts in the } \\
\text { near future }\end{array}$ & 12 & 10 & 22 \\
\hline $\begin{array}{l}\text { Climate change may become } \\
\text { a problem in the longer-term } \\
\text { future }\end{array}$ & 3 & 8 & 11 \\
\hline $\begin{array}{l}\text { Climate change is probably } \\
\text { not happening now and will } \\
\text { not cause problems in the } \\
\text { future }\end{array}$ & 1 & 1 & 2 \\
\hline Total & 66 & 41 & 107 \\
\hline
\end{tabular}

Table 6.2. Chi-Square independence test for climate change belief and wine producers.

\begin{tabular}{|l|c|c|c|}
\hline & Value & df & $\begin{array}{c}\text { Asymptotic } \\
\text { Significance (2-sided) }\end{array}$ \\
\hline Pearson Chi-Square $\chi^{2}$ & $7.936^{\mathrm{a}}$ & 3 & 0.047 \\
\hline Likelihood Ratio & 7.826 & 3 & 0.05 \\
\hline Linear-by-Linear Association & 2.965 & 1 & 0.085 \\
\hline N of Valid Cases & 107 & & \\
\hline
\end{tabular}

a. 3 cells (37.5\%) have expected count less than 5 . The minimum expected count is 0.77 . 
Table 6.3. Symmetric measures for climate change belief and wine producers.

\begin{tabular}{|l|l|c|c|c|c|}
\hline \multicolumn{2}{|c|}{} & Value & $\begin{array}{c}\text { Asymptotic } \\
\text { Standard } \\
\text { Error }\end{array}$ & $\begin{array}{c}\text { Approximat } \\
\text { e T }^{\mathbf{b}}\end{array}$ & $\begin{array}{c}\text { Approximate } \\
\text { Significance }\end{array}$ \\
\hline \multirow{2}{*}{$\begin{array}{l}\text { Nominal } \\
\text { by } \\
\text { Nominal }\end{array}$} & Phi & 0.272 & & & 0.047 \\
\cline { 2 - 6 } & $\begin{array}{l}\text { Cramer's V } \phi_{c} \\
\text { Coefficient }\end{array}$ & 0.272 & & & 0.047 \\
\hline $\begin{array}{l}\text { Interval } \\
\text { by } \\
\text { Interval }\end{array}$ & Pearson's R & 0.167 & 0.097 & 1.738 & $0.085^{c}$ \\
\hline $\begin{array}{l}\text { Ordinal } \\
\text { by } \\
\text { Ordinal }\end{array}$ & $\begin{array}{l}\text { Spearman } \\
\text { Correlation }\end{array}$ & 0.199 & 0.097 & 2.079 & $0.040^{c}$ \\
\hline N of Valid Cases & 107 & & & \\
\hline
\end{tabular}

a. Not assuming the null hypothesis.

b. Using the asymptotic standard error assuming the null hypothesis.

c. Based on normal approximation.

\subsubsection{WINEGROWERS' KNOWLEDGE OF ClimATE CHANGE}

The interviews began with a series of questions to open the discussion about the winegrowers' knowledge on climate change. The conversation about the impacts of climate change on wine production was useful in determining the participants' opinion and attitudes on the climate change issue. Of the 15 interviews, only one winegrower perceived climate change with a degree of scepticism. The winegrower discussed the context of climate change and the potential outcomes for wine production; however, the participant reiterated the reliance on models and the uncertainty of what is being modelled:

"One of the problems with climate change, I guess, is are you extrapolating from a general trend or from a blip. You need to be very careful with the modelling. You can be a bit sceptical of the models sometimes. Whether it's long-term or if it's a blip, I'm not sure"

- Hawke's Bay 2. 
All 15 winegrowers demonstrated an understanding of the climate change issue; however, one winegrower from each of the three regions showed a more general understanding of how climate change can affect the wine industry:

"Any change in climate affects the wine. Every season is different - cooler or warmer seasons will have different effects on wine: the quality, the timing, the quantity, the whole thing"

- Marlborough 2.

"The grapes change depending on the climate. Some years they could be fruitier with more sugar. Other years, watery and not as flavoursome" - Hawke's Bay 3.

"Warming temperatures are going to affect what will ripen, what can ripen, and how quickly they ripen and the more extreme weather events will give everyone a run for their money"

- Otago 5.

The other winegrowers demonstrated a diverse knowledge of the climate change issue and how future climate variables will affect their wine region or vineyard location. A thematic analysis of the interviews shows the theme 'climate change perceptions' was coded a total of 133 times for the combined interviews. Climate change perceptions were coded as a core theme based on research question one. This theme was further coded based on the information the winegrowers discussed, which were perceived as climate change effects and outcomes (Figure 6.4). 


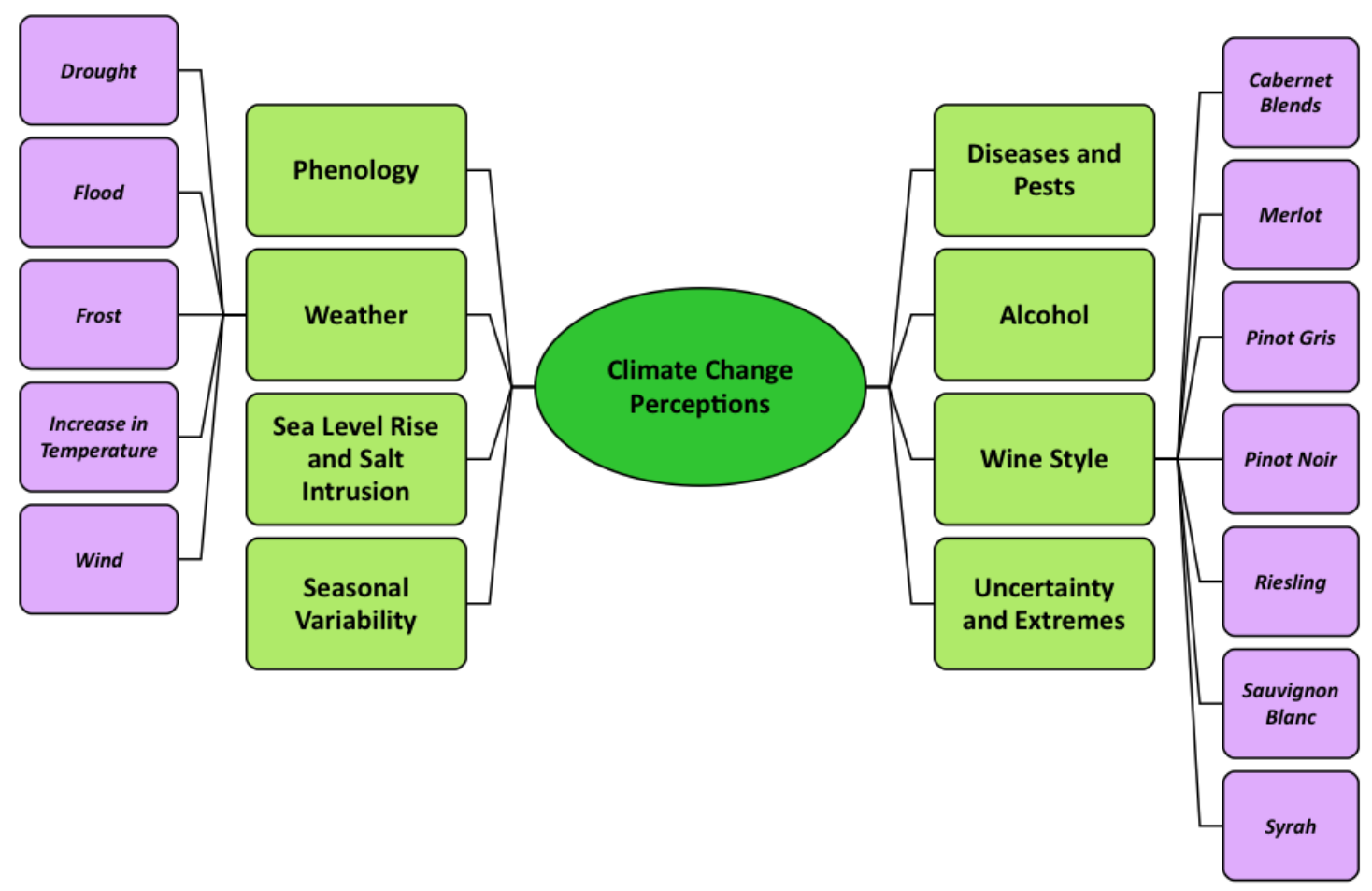

Fig. 6.4. Mind map of themes coded for climate change perceptions. The light green boxes represent the main discussion themes throughout the interviews, and the purple boxes represent the sub-coded themes of certain variables that were specifically referenced multiple times.

Each new discussion point about climate change impacts was coded as a perception. Overall, Marlborough winegrowers referenced the themed 'climate change perceptions' the most with 63 counts, followed by Hawke's Bay (36) and Otago (34). This shows that Marlborough participants would refer to various impacts of climate change more than participants from the other regions. When winegrowers discussed their knowledge of climate change, they would often discuss different weather components together and how it would impact the growing season:

\footnotetext{
"Overall the temperature might be warming but there is more likely to be damaging frosts, big wet weather events occurring at harvest"

- Hawke's Bay 1.
}

The evidence from the interviews suggests that winegrowers believe in climate change as the winegrowers could demonstrate their knowledge about how climate change can affect wine production. When discussing changing climate most winegrowers would refer to winegrape suitability as an example of how under future climate scenarios the dominant wine style could change: 
"Perhaps we would shift from a white dominant region to a red dominant. Just using Syrah as an example, it likes the gravelly soil; at two degrees warmer, it would be an ideal climate for Syrah, and it could be the variety that is best suited to the new climatic conditions"

- Marlborough 5.

"With two degrees and working with degree-days, it would get us to around Barossa Valley. That's the extreme. We would certainly be looking at other varieties. Tempranillo seems to travel around well. Albariño, Viognier, Vermentino, Verdelho. They are all varieties people have tried; we have a Grenache in our block. It grows fine, but it just need more heat to get the best out of it"

- Hawke's Bay 4.

"Pinot Noir is the dominant variety, but if we get more extreme summer temperatures, it's very susceptible to sunburn being a thin skin variety, so that might not help"

- Otago 3.

As winegrowers were discussing wine styles changing, it was often portrayed in the context of how climate change would affect them personally and the industry. The twodegree projected temperature increase was often the moment when winegrowers became aware of climate suitability and how the possible shift in varietals might come into play in the future and affect them. One particular winegrower noted towards the end of the interview that:

"I guess we will have to start thinking about it [climate change] and have something in the back of our mind"

- Hawke's Bay 5.

Throughout this interview process, most winegrowers shared similar thoughts and realisations of how climate change can impact wine production, and would often reiterate the need for decision-making about the future. This suggests that although winegrowers believe and understand climate change to be real with impacts either 
occurring now or in the near future, there is often a lack of connection between the direct impacts and the general topic of climate change, or with concrete plans to adapt.

\subsubsection{Climate Change Vulnerabilities}

To assess perceptions of local vulnerability to climate change, survey respondents were asked to rate the likelihood of potential impacts of climate change on grape production. The intent of this question was to understand how winegrowers perceive climate change impacts in their specific region. Winegrowers were asked to rate the likelihood of 19 climatic impacts occurring at the local level on a scale from extremely likely to extremely unlikely. Respondents rank an "increase in local temperatures" as the most likely consequence of climate change with $88 \%$ of respondents reporting that it is extremely or somewhat likely to occur (Figure 6.5). Overall, respondents were more likely to consider negative impacts as more likely than positive outcomes. For example, respondents are more likely to expect local flooding to increase than they are to expect flood incidents to decline as a result of climate change. Furthermore, other positive impacts such as a "decrease in local wildfires" or "positive impact on local ecosystems" were also considered as an unlikely consequence of climate change. 


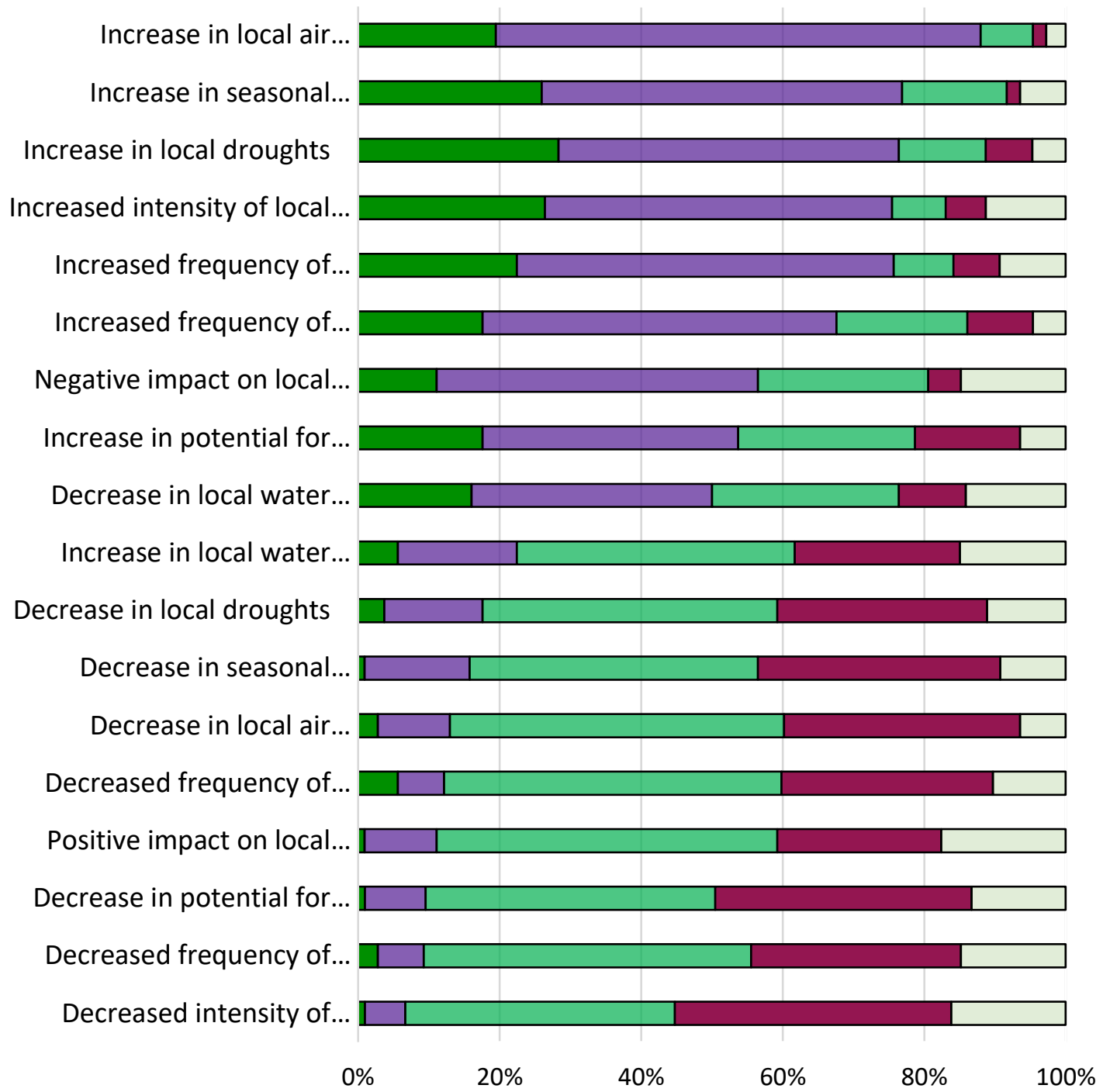

$\square$ Extremely likely $\square$ Somewhat likely $\square$ Somewhat unlikely $\square$ Extremely unlikely $\square$ Unsure

Fig. 6.5. Respondent perceptions of local vulnerability to climate change by potential impacts to winegrape production, $\mathrm{N}=108$.

In the interviews, a potential increase in local air temperature was frequently mentioned as a consequence of climate change. Interestingly, winegrowers do not always perceive this as a negative:

"Varieties like Cabernet Sauvignon at the moment really struggle in Hawke's Bay because it's just a little bit too cool, so in maybe 20 to 30 years that will actually do better here"

- Hawke's Bay 1. 
The perceptions around temperature increases often led to discussions about varietal change and the use of expansion to cooler areas:

"[In] this wine region probably the cooler climate varieties, Riesling, Pinot Gris, the more aromatic white varieties, and definitely Pinot Noir, may not be suitable. Essentially you are moving south. So those varieties that are suited now, in 20 to 30 years might be more suitable to Martinborough, which is cooler" - Hawke's Bay 1.

Winegrowers' discussed seasonal variation alongside future uncertainty and risk events like storms and droughts. In the interviews, winegrowers from Marlborough discussed seasonal variations alongside water accessibility and increasing risks of droughts. One particular example highlighted by all Marlborough interview participants was the summer drought of 2015 . The drought that year was so severe the water supply was capped, with threats of turning off the water allocation. The following year water was available for the entire season. This shows that Marlborough winegrowers were already experiencing seasonal variability but because of the inconsistency between growing seasons, the winegrowers were not associating the variations with climate change.

Weather phenomena can impact wine quality, and with the maritime climate of New Zealand, it is important to understand which climate variables winegrowers perceive as crucial for growing high-quality winegrapes. Thus, the survey asked winegrowers to rank the weather phenomena that influence wine quality. The question aimed to determine which weather elements are the primary focus when discussing wine quality, and what variables are deemed less important. Sunlight (UV) was viewed as the most important (32\%), followed by precipitation (28\%), temperature (22\%), frost (8\%), humidity (7\%), and wind (3\%). Frost and wind were ranked as the least important, yet during the interviews, these variables were mentioned the most. In the interviews, frost accounted for $48 \%$ of total mentioned weather issues, with the highest count in Marlborough:

"Frost is negative cause we don't have much fruit, and it stunts the ripeness of fruit, and it generally makes for not as good wine, so that's a pain"

- Marlborough 2. 
"... after ten years of growing grapes we actually got frost that settled here on this property, and we probably lost about five to ten per cent of production, so that wouldn't even be going to the winery and then those plants were compromised. So that's a direct impact for us"

- Marlborough 4.

Winegrowers in Marlborough feel susceptible to frost and have noticed an increase in the consequences to their production. This suggests that frost might not be coupled with making quality wine, but as an effect of climate change, frost is a key element for wine production. Winegrowers in each region also considered the importance of wind, which accounted for $24 \%$ of the weather references. Wind is a weather related phenomenon that is not necessarily related to climate change, but with an increased frequency of severe weather events, wind can pose a threat to wine production. Otago and Hawke's Bay winegrowers mention how wind impacts wine production by damaging the grapevine or by cooling the plant to a temporary dormant stage, both of which affect the grapevines' capacity to produce quality winegrapes:

"Wind is something that isn't talked about, but we can get equinoxal winds just blowing and blowing leading up to Christmas, and at a certain stage the vines will just shut down for days"

- Hawke's Bay 4.

"Winds being something which is a different negative. The last couple of seasons have seen some really strong winds early spring those are having a negative effect"

- Otago 4.

\subsubsection{OBSERVEd Climate Change IMPACTS}

To determine if New Zealand winegrowers viewed climate change as a risk in the industry, the study asked respondents to rank how climate change was impacting wine production variables. The purpose of this question was to get respondents thinking about how climate change has already impacted wine production and what they have observed over time. The question asked winegrowers to report the impact of observed 
changes for a range of variables that have direct outcomes for the wine industry. The findings show respondents have observed negative impacts on harvest quality, harvest quantity and grape disease (Table 6.4).

Table 6.4. Respondents observed climate change impacts on wine production, $\mathrm{N}=97$.

\begin{tabular}{|l|c|c|c|}
\hline & Positive Impact & No Impact & Negative Impact \\
\hline Harvest Quality & $7 \%$ & $47 \%$ & $45 \%$ \\
\hline Harvest Quantity & $9 \%$ & $38 \%$ & $53 \%$ \\
\hline Grape Pests & $3 \%$ & $76 \%$ & $21 \%$ \\
\hline Grape Disease & $5 \%$ & $35 \%$ & $60 \%$ \\
\hline Frost Damage & $5 \%$ & $73 \%$ & $22 \%$ \\
\hline Winery Tourism & $13 \%$ & $84 \%$ & $2 \%$ \\
\hline Export Sales & $4 \%$ & $91 \%$ & $6 \%$ \\
\hline
\end{tabular}

A cross-tabulation analysis was employed to determine whether there were differences in reported harvest quality, harvest quantity, and grape disease responses between the major wine regions of New Zealand. Both harvest quantity and grape disease report statistically significant differences (Table 6.5). For harvest quantity, the Chi-Square Independence Test indicated a statistically significant difference between harvest quantity and the wine region $\left(\chi^{2}(6)=13.677, p=0.033\right)$. The association is positive and substantial under a Cramér's V Correlation with $\phi_{c}=0.033$ (see Appendix L for full statistical analysis). The negative impacts of harvest quantity in this sample are experienced throughout New Zealand but are mostly observed outside the main wine producing regions.

Table 6.5. Chi-Square independence test for reported harvest quantity and wine region in New Zealand.

\begin{tabular}{|l|c|c|c|}
\hline & Value & df & $\begin{array}{c}\text { Asymptotic } \\
\text { Significance (2-sided) }\end{array}$ \\
\hline Pearson Chi-Square $\chi^{2}$ & $13.677^{a}$ & 6 & 0.033 \\
\hline Cramer's $\vee \phi_{c}$ & 0.266 & & 0.033 \\
\hline N of Valid Cases & 97 & & \\
\hline
\end{tabular}

Comparatively, the findings from grape disease show a more positive association than harvest quantity (Table 6.6). The Chi-Square Independence Test indicated a statistically significant difference between grape disease and the wine region $\left(\chi^{2}(6)=15.839\right.$, $p=0.015)$. The association is strongly positive and substantial under a Cramér's $V$ Correlation with $\phi_{c}=0.015$ (see Appendix M for full statistical analysis). This shows that 
there is a difference in disease prevalence throughout New Zealand and in some regions grape disease has been reported as more negative than others.

Table 6.6. Chi-Square independence test for reported grape disease and wine region in New Zealand.

\begin{tabular}{|l|c|c|c|}
\hline & Value & df & $\begin{array}{c}\text { Asymptotic } \\
\text { Significance (2-sided) }\end{array}$ \\
\hline Pearson Chi-Square $\chi^{2}$ & $15.839^{a}$ & 6 & 0.015 \\
\hline Cramer's $\vee \phi_{c}$ & 0.286 & & 0.015 \\
\hline N of Valid Cases & 97 & & \\
\hline
\end{tabular}

Although harvest quality had no association with the wine region, it was the only wine production variable that had a statistically significant difference with reported climate change beliefs (Table 6.7). The Chi-Square Independence Test indicated a statistically significant difference between harvest quality and climate change belief $\left(\chi^{2}(6)=16.263\right.$, $\mathrm{p}=0.012$ ). The association is strongly positive and substantial under a Cramér's $\mathrm{V}$ Correlation with $\phi_{c}=0.012$ (see Appendix $\mathrm{N}$ for full statistical analysis). Winegrowers who are experiencing a negative impact of harvest quality were more likely to believe climate change is real and happening now.

Table 6.7. Chi-Square independence test for observed harvest quality and winegrowers' climate change beliefs.

\begin{tabular}{|l|c|c|c|}
\hline & Value & df & $\begin{array}{c}\text { Asymptotic } \\
\text { Significance (2-sided) }\end{array}$ \\
\hline Pearson Chi-Square $\chi^{2}$ & $15.839^{a}$ & 6 & 0.015 \\
\hline Cramer's $\vee \phi_{c}$ & 0.286 & & 0.015 \\
\hline $\mathrm{N}$ of Valid Cases & 97 & & \\
\hline
\end{tabular}

As climate change affects each winegrape variety differently, the study analysed harvest quality, harvest quantity and grape disease based on the dominant wine varietals in New Zealand (Table 6.8). Similar to the whole sample, respondents have observed negative trends for harvest quantity and grape disease for all the main varietals. 
Table 6.8. Respondent observed climate change impacts on wine production based on the five dominant wine varietals in New Zealand. All values expressed as percentage.

\begin{tabular}{|l|c|c|c|c|c|c|c|c|c|}
\hline \multicolumn{1}{|c|}{ Variables } & \multicolumn{3}{c|}{ Harvest Quality } & \multicolumn{3}{c|}{ Harvest Quantity } & \multicolumn{3}{c|}{ Grape Disease } \\
\hline \multicolumn{1}{|c|}{ Impact } & + & $\mathbf{x}$ & - & + & $\mathbf{x}$ & - & + & $\mathbf{x}$ & - \\
\hline Sauv. Blanc & 6 & 35 & 58 & 13 & 26 & 61 & 10 & 23 & 65 \\
\hline Pinot Noir & 5 & 48 & 48 & 12 & 34 & 54 & 3 & 29 & 68 \\
\hline Chardonnay & 4 & 39 & 57 & 13 & 39 & 48 & 4 & 35 & 61 \\
\hline Pinot Gris & 7 & 48 & 45 & 10 & 34 & 55 & 5 & 31 & 62 \\
\hline Merlot & 8 & 53 & 38 & 8 & 40 & 52 & 5 & 38 & 58 \\
\hline
\end{tabular}

Sauv. Blanc $=$ Sauvignon Blanc

$+=$ Positive Impact

$\mathrm{x}=$ No Impact;

$-=$ Negative Impact;

However, only Pinot Gris was found to have a statistically significant association with grape disease (Table 6.9). The Chi-Square Independence Test indicated a statistically significant difference between grape disease and Pinot Gris $\left(\chi^{2}(2)=7.766, p=0.021\right)$. The association is strongly positive and substantial under a Cramér's V Correlation with $\phi_{c}$ $=0.021$ (see Appendix $O$ for full statistical analysis). This shows that winegrowers who cultivate Pinot Gris are more likely to observe negative impacts of grape disease, than winegrowers who grow other varietals.

Table 6.9. Chi-Square independence test for reported grape disease and Pinot Gris.

\begin{tabular}{|l|c|c|c|}
\hline & Value & df & $\begin{array}{c}\text { Asymptotic } \\
\text { Significance (2-sided) }\end{array}$ \\
\hline Pearson Chi-Square $\chi^{2}$ & $7.766^{\mathrm{a}}$ & 2 & 0.021 \\
\hline Cramer's $\vee \phi_{c}$ & 0.283 & & 0.021 \\
\hline N of Valid Cases & 97 & & \\
\hline
\end{tabular}

Interviewees reported an observed increase in grape disease occurring throughout New Zealand. The main type of grape disease reported was powdery mildew, followed by botrytis and downy mildew. However, not all participants were correlating the rise of disease with climate change; some view it as part of the sexual stage of reproduction and season variability:

“...warmer temperatures during summer and drier climates make us probably even more susceptible to powdery mildew. But conversely, it probably makes us less susceptible to botrytis because the risk of harvest rainfall at harvest time is 
reduced as well. Although you could turn that around again and say that the more powdery mildew we get, the more susceptible we are to Botrytis. Quite often you get the Botrytis infection off the back of the powdery mildew infection" - Marlborough 5.

"We've had some diseases; powdery mildew has reared its head. Whether that is climate related, I don't know. There are different forms of it that have emerged recently. I don't know whether it's so much climate-related or coincidental that it's come along" - Hawke's Bay 4.

"We have an increasing pressure from powdery mildew for the last 5 or 6 seasons. We are not attributing that to climate change though, it's more a sexual reproduction stage" - Otago 4.

Often harvest quality and quantity are discussed in association with other events. An example from a winegrower in Hawke's Bay highlights how susceptible grapevines are to disease because of climatic conditions, and as a consequence, the climate also affects the quality of the winegrape and the harvest quantity:

"We got two diseases: powdery mildew and botrytis. We have seen an increase in pressure in Hawke's Bay and some Marlborough. I think part of that is things are getting a bit warmer and that disease tends to do better when It's warmer. Part of it's the sexual stage of powdery mildew coming to New Zealand. We have had an increase in Botrytis. Vintage '17 was a great example. We had that storm come through. It was warm, a lot of rain, in between harvest, so a huge impact on quality. We are not actually making some wines this year because we didn't get the quality we needed. Certainly with more extreme events, and getting all that rain around harvest, Botrytis can certainly be an issue and being a bit warmer powdery mildew"

- Hawke's Bay 1.

Winegrowers from Marlborough and Hawke's Bay further discuss the rise in grape disease concerning their spray programmes. It was noted that with seasonal variation, timing and managing the spray period can be difficult and expensive. 


\subsubsection{PeRCEIVED Future OUtLOOK}

Next, the survey looked at the perceptions of the future outlook for the wine industry. Respondents were asked how they rated the long-term outlook for the different sectors in New Zealand to understand how winegrowers view the future of the industry under the assumption of future climate change. Wine production in New Zealand, in the different regions and for the individual wineries, all report a positive long-term future outlook (Figure 6.6).

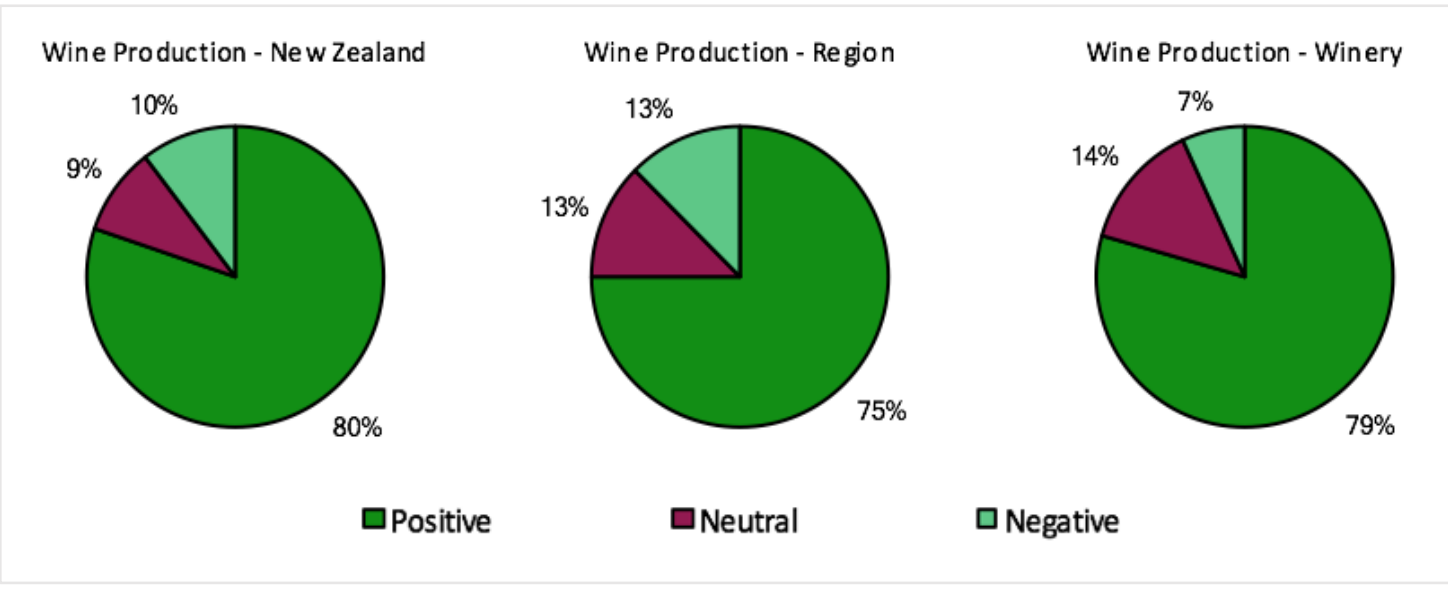

Fig. 6.6. Respondent perceptions of the future outlook of the New Zealand wine industry. Wine production in New Zealand $\mathrm{N}=106$. Wine production in your region, $\mathrm{N}=104$. Wine production in your winery, $\mathrm{N}=102$.

The responses across the three questions show at least a $75 \%$ consensus that the wine industry will do well under future climate scenarios. Wine production for the respondent's own winery was reported the least positive; however, respondents view the outlook for their region as positive, suggesting that the respondents believe their industry is well situated to handle the changing climate. The interview participants discussed the New Zealand industry outlook compared to other 'New World' wine regions and the 'Old World' wine industry. Winegrowers view New Zealand as positively situated within the global industry because New Zealand wine is produced under the 'New World' model; thus winegrowers perceive the industry as more resilient:

"['Old World' winegrowers] are still able to make great wine, but if they are making a Syrah that's coming out of Burgundy, no-one is going to want to buy 
it. We can cope. We don't have those rules and regulations. We don't have hard and fast appellations and varietals"

- Otago 5.

Furthermore, statements were made regarding the age and the size of the New Zealand wine industry compared to other international producers. Winegrowers perceive this as a positive, highlighting the flexibility with adaptation and expansion:

"I think we are in a great position because we can adjust and move and change what we are doing. We are such a young industry, and we have changed so much within sort of 30 years. We are able to change. Whereas a generalisation of some of those 'Old World' wines are that they've done it that way for so long they are going to keep doing it that way"

- Marlborough 3.

Overall, winegrowers in New Zealand understand the climate change issue and how it can affect wine production; however, wine producers are more positive than grape producers about climate change. The findings indicate that winegrowers are observing climatic impacts on harvest quality, harvest quantity and grape diseases. Although these impacts are perceived as negative for wine production, winegrowers view the long-term outlook for the New Zealand wine industry as positive.

\subsection{Decision-making and AdAPtATIONS}

One of the main aims of this research was to understand winegrowers' decision-making for implementing climate change adaptation strategies. The survey was designed to establish whether winegrowers were engaged in adaptation planning and to assess how far along the wine industry is in the adaptation process. The study approached the research question by asking respondents whether their winery or vineyard had developed strategies or plans to deal with the potential impacts of climate change. The responses were varied with $64 \%$ reporting no strategies or plans for climate change adaptation, $16 \%$ reporting that their winery or vineyard had developed adaptation plans and $16 \%$ reporting that an adaptation plan was being implemented (Figure 6.7). The remaining $5 \%$ reported they were unsure. 


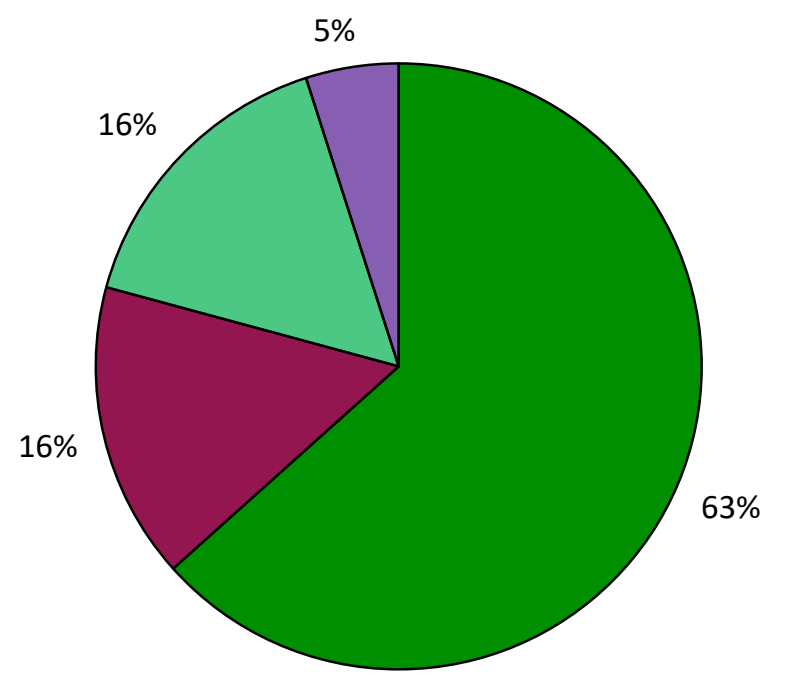

No adaptation plans

Yes, adaptation plan is currently being developed

$\square$ Yes, adaptation plan is being carried out

Unsure

Fig. 6.7. Respondent reported adaptation planning and implementation of strategies in the New Zealand wine industry, $\mathrm{N}=107$.

No statistical differences were found in comparing wine producer and grape producer responses to this question. Respondents from the three main wine producing regions, Marlborough, Hawke's Bay, and Otago responded similarly to the sample as a whole. However, the differences were not statistically significant, likely due to the relatively small sample size of the regional groups.

Adaptation to climate change was coded as a core theme based on research question two. This theme was further coded based on the information the winegrowers discussed, which were perceived as adaptation plans and management strategies (Figure 6.8). The thematic analysis shows the theme 'adaptation to climate change' was coded 146 times for the combined interviews, showing that the central focus of the interviews was on adaptation planning. Although winegrowers reported they were not planning for adaptation, the interview results show that winegrowers were aware and were thinking about appropriate adaptation strategies. 


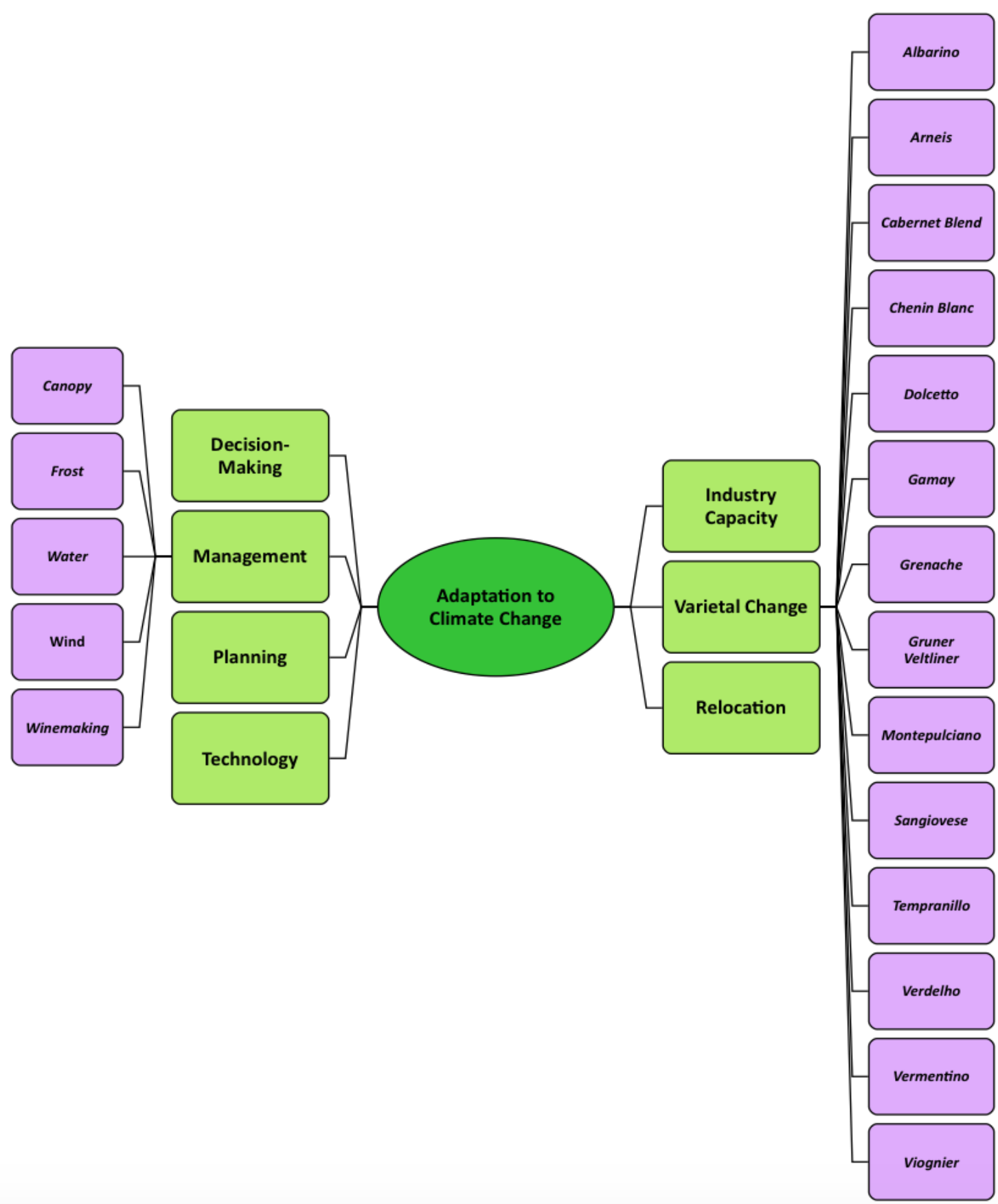

Fig. 6.8. Mind map of themes coded for adaptation to climate change. The light green boxes represent the main discussion themes in the interviews, and the purple boxes represent the sub-coded themes of certain variables that were specifically referenced multiple times.

The survey found that most winegrowers were not planning for adaptation. However, the participants expressed that they are aware of potential climate change impacts but perceive this as a future issue:

"When it's really warm, you do notice a difference in the wine, and you have to change your viticultural practices to suit it. So two degrees in the coming years 
might just be a simple case of needing to change how we do things, so we keep the same styles"

- Marlborough 1.

"If it [temperature] changed in say 80 years, from now to 2100, we would have time. It's not going to change overnight; it would be a gradual process"

- Hawke's Bay 5.

"From our perspective, it's a five, ten, twenty-year project to what's the impact of those changes and what's the timeline that those changes are going to occur on?"

- Otago 1.

Interview responses suggest winegrowers understand the impacts of climate change but perceive the effects as a future issue. Winegrowers seem confident they can adapt to changes as they present themselves as they expect climate change impacts to be gradual. They do not foresee major disruption-such as changes in temperaturebecause they expect they will notice the change. Therefore, there is less attention to proactive planning, with respondents being comfortable about the likely rate of change, and responding when necessary.

\subsubsection{Varietal Change as adaptation}

As the New Zealand wine industry is regionally defined by the climate and wine style cultivated, the study wanted to assess if winegrowers were planning to change their winegrape varietals for climate-related reasons. The purpose of the question was to see whether climate change was a driver of industry change or if the varietal change was a result of other industry market pressures. The responses show that $70 \%$ of respondents had no major plans to change the varietals they grow, and any plans for varietal change appear to be market driven (13\%) (Figure 6.9). A small number of winegrowers reported plans to change due to both climate and market reasons (8\%). When prompted for an explanation for selecting both market and climate reasons in an open-ended survey question, the respondents cited expansion of the vineyard and needing new plantings, 
while others mentioned wanting to experiment with new varieties. Other responses include changing varieties for new rootstocks that are resistant to viruses and diseases.

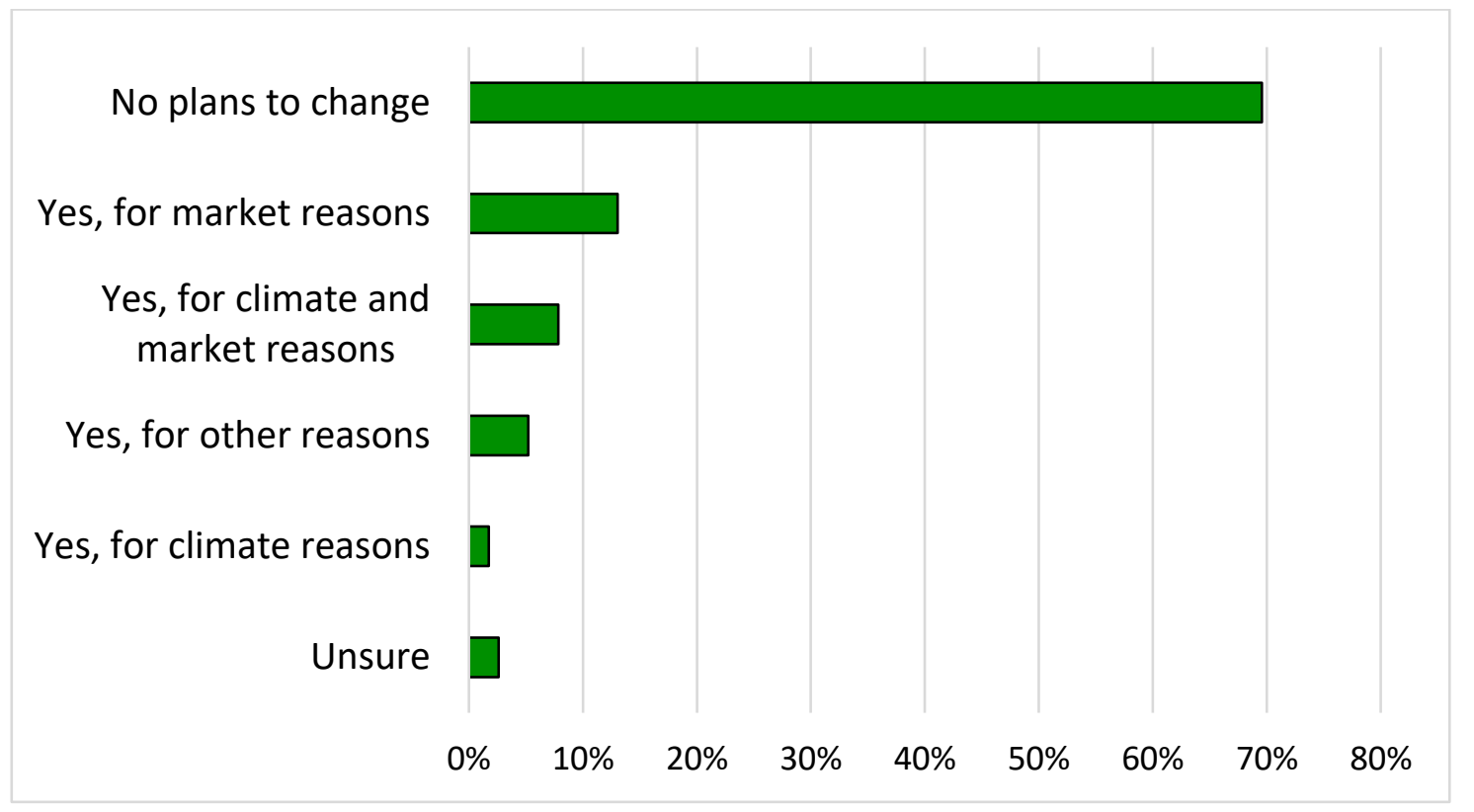

Fig. 6.9. Respondent reported plans to change winegrape varietal for climate or market reasons, $\mathrm{N}=115$.

No statistical differences were found in comparing occupational responses nor for regional responses to this question. This shows winegrowers were reporting similar findings across New Zealand and within the industry. Next, winegrowers were asked what varieties they would consider switching to for their selected reason. Chardonnay and Pinot Noir grapevines were mentioned as varieties for those responding to market pressures. Chardonnay was further mentioned as a variety for changes in market and climate reasons, with a respondent noting that Chardonnay was an option for change as it is an early ripening winegrape. New wine varietals were mentioned to the open-ended question about market or climate reasons. Albariño was cited the most for both options and other new varieties mentioned were Dolcetto, Grenache, Mourvèdre, Malbec, St. Laurent, and Montepulciano d'Abruzzo, all of which are red wine styles. The only other white wine variety mentioned apart from Albariño was Chenin Blanc.

The survey responses indicate few winegrowers plan to change varieties; however, in the interviews varietal change was mentioned 47 times as part of an adaptation strategy with changing temperatures. In addition to the new winegrape varieties cited in the survey, participants from the interviews cited cultivating more of the white varieties: 
Arneis, Grüner Veltliner, Verdelho, Vermentino, Viognier, and more of the red varieties: Cabernet Franc, Gamay, Sangiovese and Tempranillo.

The study was interested in the potential changes of winegrape varieties throughout New Zealand as this would impact the geography of wine and the terroir. To further assess the potential varietal change, the dominant wines produced in New Zealand were compared to the respondents' plans for change. The winegrowers who cultivate Pinot Noir were less likely to change winegrape varieties: $72 \%$ of respondents reported no plans to change. However, winegrowers who produce Merlot were more likely to have plans for varietal change, with $52 \%$ of the respondents selecting variations of yes for plans to change (Table 6.10).

Table. 6.10. Respondent reported plans for changing winegrape varieties for market or climate reasons compared to the dominant five wines cultivated in New Zealand.

\begin{tabular}{|l|c|c|c|c|c|}
\hline & S. Blanc & Pinot Noir & Chardonnay & Pinot Gris & Merlot \\
\hline $\begin{array}{l}\text { No plans to } \\
\text { change }\end{array}$ & $67 \%$ & $72 \%$ & $67 \%$ & $61 \%$ & $45 \%$ \\
\hline $\begin{array}{l}\text { Yes, for market } \\
\text { reasons }\end{array}$ & $17 \%$ & $13 \%$ & $14 \%$ & $17 \%$ & $29 \%$ \\
\hline $\begin{array}{l}\text { Yes, for climate } \\
\text { and market } \\
\text { reasons }\end{array}$ & $7 \%$ & $7 \%$ & $9 \%$ & $9 \%$ & $16 \%$ \\
\hline $\begin{array}{l}\text { Yes, for other } \\
\text { reasons }\end{array}$ & $3 \%$ & $5 \%$ & $5 \%$ & $6 \%$ & $7 \%$ \\
\hline $\begin{array}{l}\text { Yes, for climate } \\
\text { reasons }\end{array}$ & $1 \%$ & $1 \%$ & $3 \%$ & $3 \%$ & $0 \%$ \\
\hline Unsure & $4 \%$ & $3 \%$ & $3 \%$ & $4 \%$ & $3 \%$ \\
\hline Total (N) & 69 & 88 & 79 & 70 & 31 \\
\hline
\end{tabular}

S.Blanc = Sauvignon Blanc

Although Merlot was indicated to be a variety winegrowers were willing to change, the Chi-Square Independence Test indicates a statistically significant difference between varietal change plans and the cultivation of Merlot $\left(\chi^{2}(1)=8.938, p=0.003\right)$ (Table 6.11). The association is positive and substantial under a Cramér's V Correlation with $\phi_{c}=0.003$ (see Appendix P for full statistical analysis). This shows that not all Merlot winegrowers plan to change varietals. 
Table 6.11. Cross-tabulation of reported varietal change and Merlot cultivation.

\begin{tabular}{|l|c|c|c|}
\hline & Value & df & $\begin{array}{c}\text { Asymptotic } \\
\text { Significance (2-sided) }\end{array}$ \\
\hline Pearson Chi-Square $\chi^{2}$ & $7.766^{\mathrm{a}}$ & 2 & 0.003 \\
\hline Cramer's $V \phi_{c}$ & 0.295 & & 0.003 \\
\hline N of Valid Cases & 103 & & \\
\hline
\end{tabular}

During the interviews, winegrowers mentioned the varieties Chardonnay, Merlot, Pinot Noir and Syrah as options for alternative production. Syrah was the most discussed variety for increasing temperatures, and given the small level of current Syrah production in New Zealand, there could be a future shift in the varieties New Zealand produces. However, interviewees had mixed perceptions about growing Syrah in New Zealand or the need to change varieties in the immediate future:

"I don't think we have to make any decisions anytime soon because even in 25 years if we have shifted another quarter a degree, we'll still going to be in the realms of Sauvignon country... If the growing degree number shifted by 300 of the average now, our red would become Syrah"

- Marlborough 5.

"Chardonnay is quite adaptable, and it's about the same about our Sauvignon Blanc, but the rest, Cabernet and Syrah could do with getting a bit hotter. Its great now, it's not too cool, but we could get a bit hotter"

- Hawke's Bay 5.

"I know in Martinborough where I worked a few years ago they've replanted Syrah, a hotter climate variety up there in anticipation that things are going to change and they are going to have adapt with it"

- Otago 2.

The winegrowers indicated they are thinking in the short term and although varietal change will happen in the future, with warming occurring incrementally, the current wine styles have the potential to also improve. Part of planning for varietal change is observing changes within the growing season; therefore, the study compared varietal change plans with harvest quality (Table 6.12). The Chi-Square Independence Test indicated a statistically significant difference between varietal change plans and harvest 
quality $\left(\chi^{2}(2)=7.148, p=0.028\right)$. The association is positive and substantial under a Cramér's V Correlation with $\phi_{c}=0.028$ (see Appendix $Q$ for full statistical analysis). This indicates that negative impacts in terms of harvest quality can affect winegrowers' decisions about varietal plans.

Table 6.12. Chi-Square independence test for reported varietal change and observed harvest quality.

\begin{tabular}{|l|c|c|c|}
\hline & Value & df & $\begin{array}{c}\text { Asymptotic } \\
\text { Significance (2-sided) }\end{array}$ \\
\hline Pearson Chi-Square $\chi^{2}$ & $7.148^{\mathrm{a}}$ & 2 & 0.028 \\
\hline Cramer's $\vee \phi_{c}$ & 0.287 & & 0.028 \\
\hline N of Valid Cases & 87 & & \\
\hline
\end{tabular}

Furthermore, as Syrah was a winegrape varietal that winegrowers noted would do well under increasing temperatures, the study compared varietal change plans with winegrowers who responded in the survey as cultivating Syrah (Table 6.13). The ChiSquare Independence Test indicated a statistically significant difference between varietal change plans and Syrah cultivation $\left(\chi^{2}(1)=11.304, p=0.001\right)$. The association is strongly positive and substantial under a Cramér's V Correlation with $\phi_{c}=0.001$ (see Appendix R for full statistical analysis). This shows winegrowers who cultivate Syrah are more likely to change varieties.

Table 6.13. Chi-Square independence test for reported varietal change and Syrah cultivation.

\begin{tabular}{|l|c|c|c|}
\hline & Value & df & $\begin{array}{c}\text { Asymptotic } \\
\text { Significance (2-sided) }\end{array}$ \\
\hline Pearson Chi-Square $\chi^{2}$ & $11.304^{\mathrm{a}}$ & 1 & 0.001 \\
\hline Cramer's $\vee \phi_{c}$ & 0.287 & & 0.001 \\
\hline N of Valid Cases & 103 & & \\
\hline
\end{tabular}

\subsubsection{WINEGROWERS' AdAPTATION MANAGEMENT StRATEGIES}

The study was interested in how winegrowers were adapting to climate change; thus, the survey asked the respondents what plans or strategies they have developed to manage the potential impacts of climate change. The question was designed to assess what areas of the wine industry are being affected by climate change and whether this is consistent throughout New Zealand. The findings indicate that disease management is the primary adaptation strategy being developed as it accounts for $17 \%$ of total planning. 
Grape-growing management plans account for $16 \%$, while drought management accounts for $14 \%$ of total adaptation planning. Harvest and pest management were also relatively common form of adaptation planning. Aside from viticultural management plans, winemaking techniques were being developed, although this only accounts for $10 \%$ of total planning (Figure 6.10).

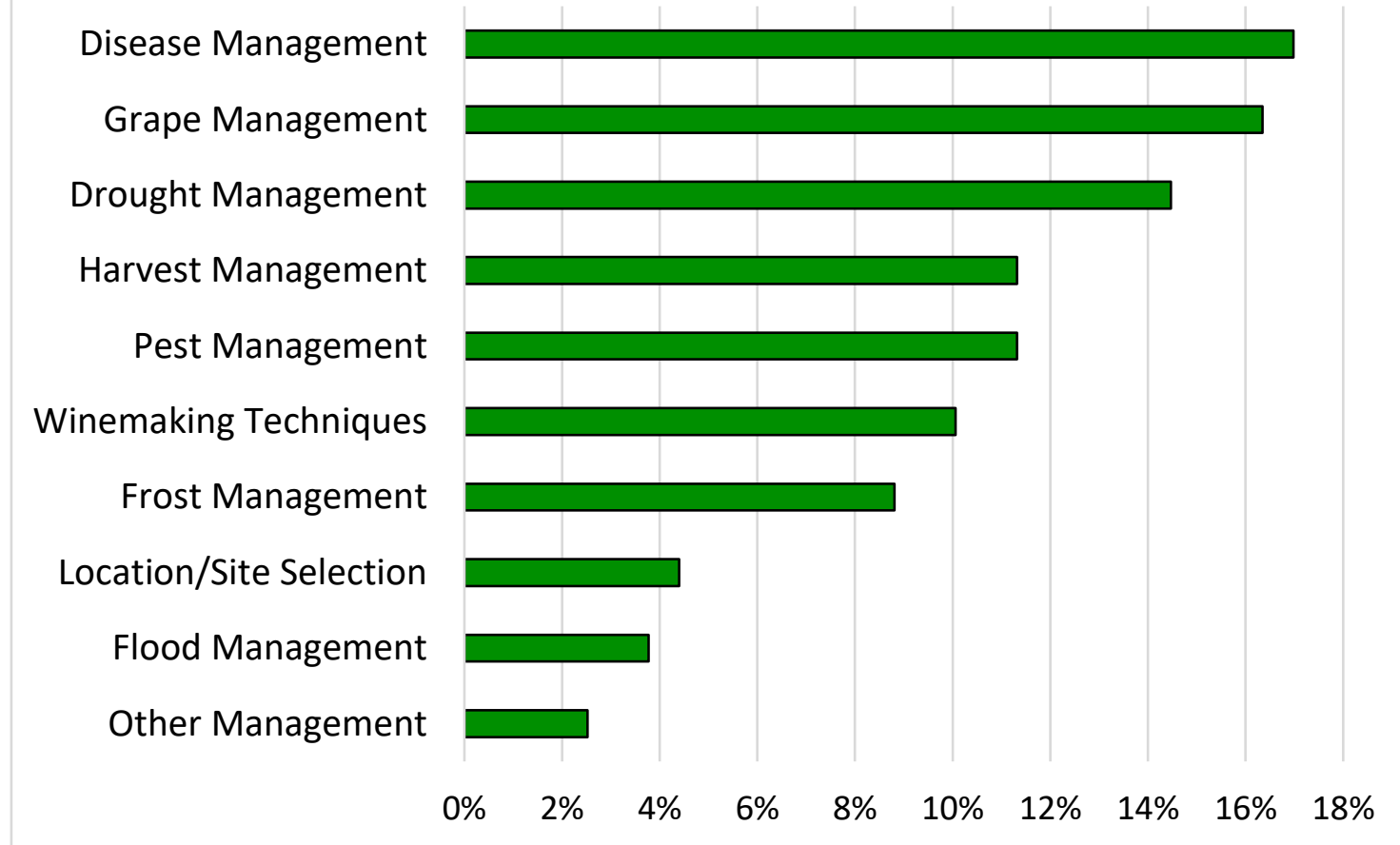

Fig. 6.10. Respondent reported management plans for climate change adaptation, $\mathrm{N}=101$. Participants could select multiple options.

On the regional scale, Marlborough and Hawke's Bay winegrowers are similar to the whole sample (Figure 6.11). The differences were not statistically significant. Marlborough winegrowers' main reported strategy accounting for $19 \%$ of planning, was drought management. Hawke's Bay winegrowers are mostly concerned with both disease and grape-growing as both management plans account for $19 \%$ of total planning respectively. However, Hawke's Bay winegrowers have indicated no plans for frost management. Otago winegrowers' primary strategy is frost management, which accounts for $19 \%$ of their planning. Furthermore, Otago is the leading wine region reporting attention to flood management. 


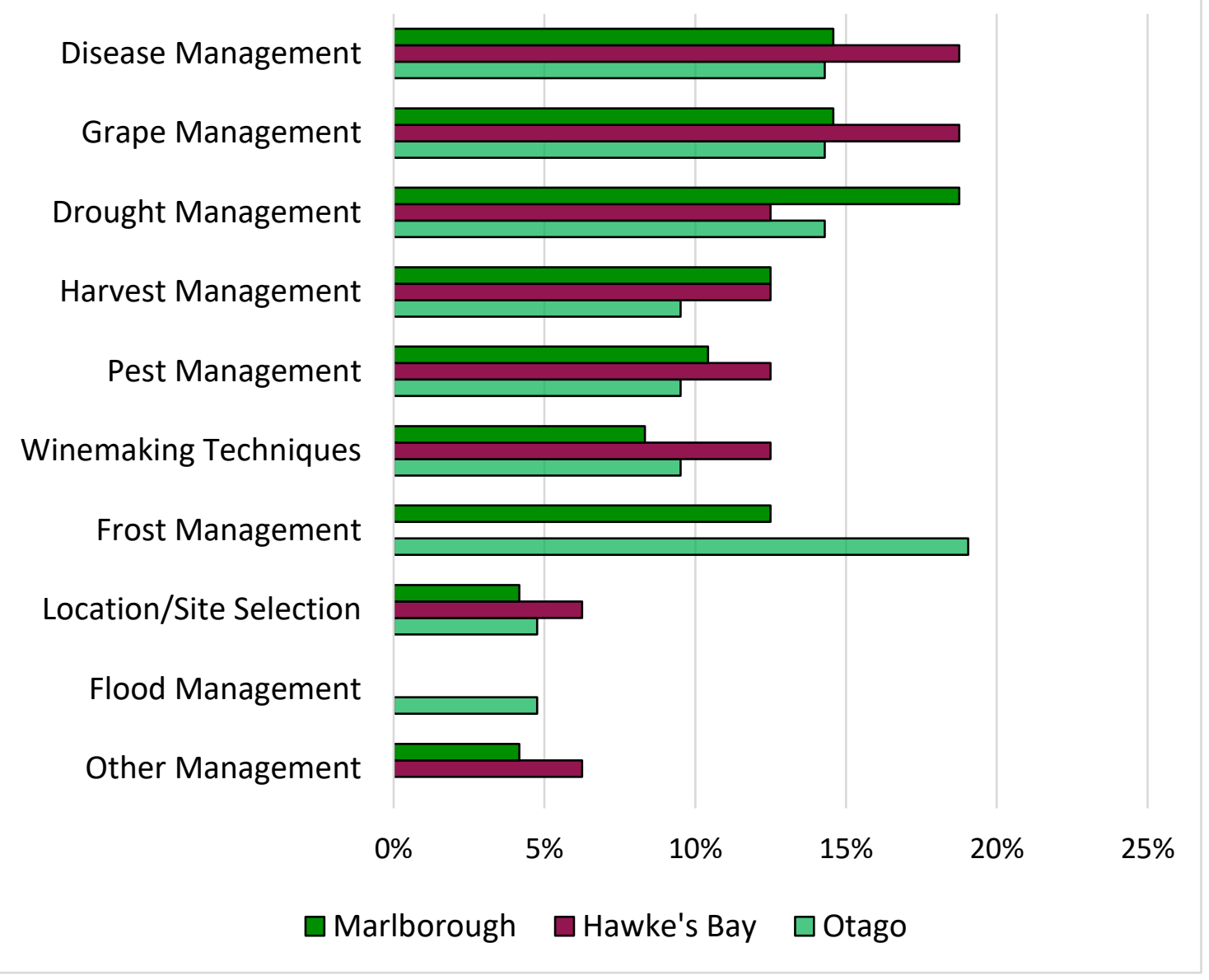

Fig. 6.11. Respondent reported management plans for climate change adaptation based on the three main wine producing regions of New Zealand.

The break-down of winegrower occupation against management plans indicates wine producers plan for harvest, winemaking, and the location or site selection, while no grape producers selected these options. It is expected that wine producers will be more involved in winemaking techniques than grape producers; however, the findings suggest the wine producers have more decision-making discretion than grape producers given the indication that both harvest and location/site selection were reported among wine producer management plans.

Grape disease was perceived as a climate change impact, but it is also the main area requiring management, which winegrowers react to by planning and implementing adaptation strategies. Therefore, the study compared observed grape disease and adaptation planning (Table 6.14). The Chi-Square Independence Test indicated a statistically significant difference between observed grape disease and reported adaptation planning $\left(\chi^{2}(2)=6.228, p=0.044\right)$. The association is strongly positive and 
substantial under a Cramér's V Correlation with $\phi_{c}=0.044$ (see Appendix S for full statistical analysis). This indicates that winegrowers who observe more impacts of grape disease are more likely to plan for adaptation.

Table 6.14. Chi-Square independence test for observed grape disease and reported adaptation planning.

\begin{tabular}{|l|c|c|c|}
\hline & Value & df & $\begin{array}{c}\text { Asymptotic } \\
\text { Significance (2-sided) }\end{array}$ \\
\hline Pearson Chi-Square $\chi^{2}$ & $6.228^{\mathrm{a}}$ & 2 & 0.044 \\
\hline Cramer's $\vee \phi_{c}$ & 0.260 & & 0.044 \\
\hline N of Valid Cases & 92 & & \\
\hline
\end{tabular}

The main types of adaptation discussed in the interviews were management strategies, which were referenced 69 times overall. Marlborough interviewees referred to management strategies the most with 33 counts, followed by Otago with 23 counts. Water and frost adaptation were the most cited management plans, referenced 28 and 18 times, respectively. Water was mentioned the most by Marlborough interviewees, with a focus on the need for effective drought management. Conversely, Hawke's Bay winegrowers also discussed water management, but held a different view on preparing for future options and the decision-making required:

"We are actively building reservoirs, so all our new developments have water storage pretty much. And for some of our existing vineyards we are pulling out vines to put in water storage"

- Marlborough 3.

"Water storage, I've thought about it but it seems impractical and haven't thought much beyond. Dam storage is going to take up arable land if you're going to have a big dam next door to your vineyard. One of our blocks is 15 hectares, to store enough water to water that for the summer - that's a massive amount of land you would have to take out of production"

- Hawke's Bay 4.

There is a definite difference in perceptions regarding water management for the two regions, and other winegrowers in New Zealand reiterate the contrast. Otago winegrowers discuss water management in the context of having access to Lake Dunstan 
and a readily available water supply. However, in regard to implementing water storage facilities and systems, winegrowers perceive drip irrigation as enough.

Furthermore, frost management was similarly referenced the most by Marlborough winegrowers, followed by Otago. As part of the frost management plans, participants would often discuss frost fans and the use of helicopters as part of their management plans:

"We use a mixture of frost fans - that's our main one. Helicopters on significant nights so some areas that are considered low risk we will get a forecast that'll say frost so we will bring in a helicopter"

- Marlborough 3.

"We largely thought we were frost free. There was a little tickle up for a couple years, but I noticed since 2013 that we've started getting a chopper in. The first years one time, then the next year was twice and then the following year was three times"

- Otago 3.

Otago winegrowers appear to be more hesitant with their decision-making when implementing long-term strategies and begin planning when they know they have a problem. However, in Marlborough, frost fans are implemented more or less immediately depending on site location based on previous knowledge.

"Some of them [winegrowers] will put the frost fans in as soon as they plant the grapes - within the first year - because they historically know that areas like the Waihope Valley or the Wairau Valley, they know they can't grow grapes without frost fans"

- Marlborough 4.

Marlborough winegrowers appear to implement adaptation strategies more so than the other regions as they are contending with both water and frost management. The findings from the interviews suggest Marlborough winegrowers are more active in implementing adaptation, which contrasts with the survey data. This could be an 
outcome based on what winegrowers perceive to be a climate change adaptation strategy compared to seasonal management. However, this could also be an indication of some bias in the participants who agreed to be interviewed.

Location and site selection were adaptation management plans only noted by wine producers in the survey and accounted for $4 \%$ of total reported planning in the industry. However, winegrowers during the interviews would often discuss future relocation as a form of adaptation. This can be attributed to the interview process which prompted discussion on climate change impacts such as sea level rise and temperature increases. Relocation was mentioned 25 times overall, with most comments made by Marlborough winegrowers. Sauvignon Blanc was a central focus for relocation and was often cited by other winegrowers in New Zealand. As Sauvignon Blanc is the leading wine in the industry, the winegrowers have indicated that as long as Sauvignon Blanc is still produced the relocation of wine regions will not affect the New Zealand industry. The trend for relocation was a shift to the south, with winegrowers in Marlborough suggesting shifts down the east coast of the South Island towards the Canterbury region:

"The opportunity is all the production moves from Marlborough and heads down the east coast of the South Island where there is truckloads of water. There's plenty of suitable soils, but currently, the temperatures aren't right. Maybe our adaptation is just to move... It stops it being Marlborough Sauvignon Blanc but it is still New Zealand Sauvignon Blanc, and that's still the most important thing for the New Zealand wine industry is people to choose wine on price, then they choose a grape variety and then they choose a country. I think that would still work for us as an industry"

- Marlborough 5.

"You are seeing that gradual shift south over time in the industry. There's areas like in Central and Waipara, 20 years ago those regions were pretty out there, and now they are quite established wine regions"

- Hawke's Bay 1. 
"If Sauvignon Blanc production shifts South then it will happen. As long as they are making the product that is still consistent, the world won't care" - Otago 5.

In addition to site relocation, sea level rise was only discussed in the context of the Marlborough wine region. Salt intrusion was already an issue and winegrowers were aware of the potential impacts sea level rise will have:

\footnotetext{
"At this stage, there is enough water to push the salt off and drain it away" - Marlborough 4.
}

"Rising sea levels could move everything inland. There'll be some impacts probably down the coast where some vineyard land will become unsuitable because of saltwater intrusion"

- Marlborough 5.

"If Marlborough floods from the sea, that would suck. It's a scary thing to think about. It's a vast flat valley completely open to the sea, a couple metres of sea level rise and then boom. If it doesn't flood the whole valley, the salt is going to be leaching the whole way through. If I was a grower in Marlborough, I would be thinking about the future direction of the winery"

- Otago 5.

Only one Hawke's Bay winegrower thought they were at risk by being coastal, but it was not something previously considered or of immediate concern. Similarly, Marlborough winegrowers, when prompted about future planning, referred to the relocation of the industry and how it is a regional issue more than an individual issue. There was a sense of inevitability, and winegrowers were accepting the risk to cultivate winegrapes, focusing on the short-term benefits.

As previously mentioned, overall, winegrowers perceive climate change as a future issue rather than an immediate concern. The adaptation strategies that are being planned or implemented are reactive and incremental to experienced changes in climate, such as frost and water management. However, respondent perceptions of future impacts 
suggest that winegrowers are aware of potential changes in the wine industry, and are considering more transformational adaptations such as changes in winegrape varieties or the relocation of production.

\subsection{Barriers to Adaptation Planning}

To assess the progress of adaptation planning, the barriers limiting implementation need to be evaluated. The survey asked respondents to rank the top three most important factors preventing adaptation planning (Figure 6.12). Winegrowers perceive issues related to information as the most common barriers, with the top three choices all describing a deficit in the available information. A lack of locally specific information, the uncertainty in available information and a lack of useful information were the primary barriers, followed by budget constraints.

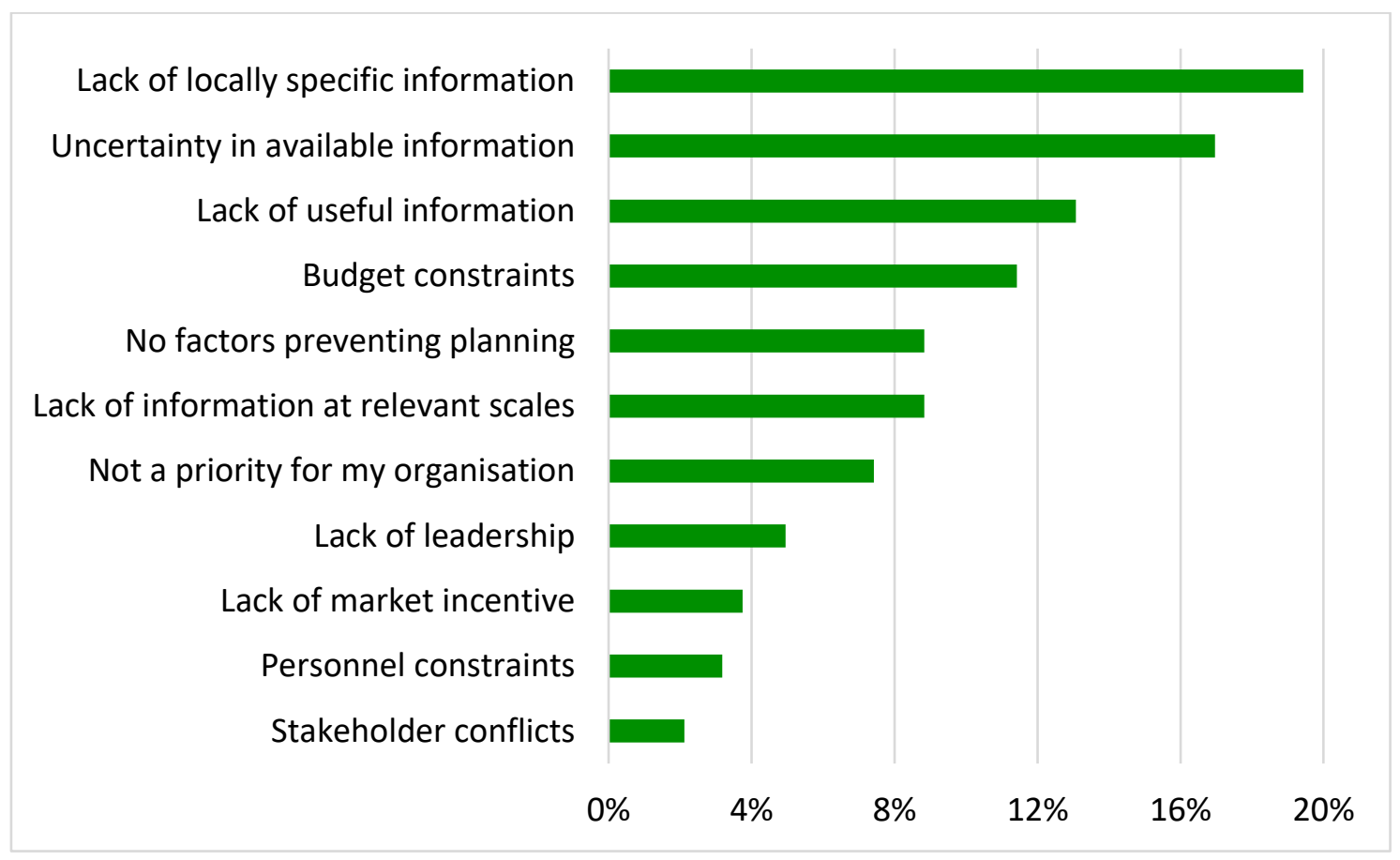

Fig. 6.12. Respondent reported factors preventing adaptation planning, $N=106$.

Although the differences are not statistically significant, at the regional scale, Marlborough and Hawke's Bay winegrowers respond similarly, while Otago respondents indicated that there are essentially no factors preventing adaptation planning, while some respondents reported a lack of locally specific information and uncertainty in available information as barriers to planning. 
A follow-up question asked winegrowers to rate a series of pre-determined issues which are often perceived as hurdles to implementing adaptation plans. Respondents report that the most significant hurdles they must overcome are a "lack of perceived solution options", "the available science being at the wrong scale", "budget constraints", and "managing the currently pressing issues". However, overall the main barriers for adaptation implementation are a lack of perceived solution options, available science being at the wrong scale, and budget constraints (Figure 6.13). The options that were perceived as not really a barrier were legal pressures to maintain the status quo, opposition from stakeholder groups, and science being difficult to understand. This suggests winegrowers understand the science of climate change, but the available information is at the wrong scale for them to use for implementing adaptation plans, which is also consistent with the findings shown in Figure 6.12. 
Lack of perceived solution options

Available science is at the wrong scale

Budget constraints

Currently pressing issues are all-consuming

Insufficient staff time to get informed about the issue or gather information

Insufficient staff resources to analyse and assess relevent information

Science is too uncertain

Lack of public awareness or demand to take action

Not a high priority in my organisation

Lack of perceived importance to the public

Lack of social acceptability of strategies that take climate change into account

No legal mandate to take climate change impacts into account

Science is difficult to understand

Opposition from stakeholder groups

Legal pressure to maintain status quo
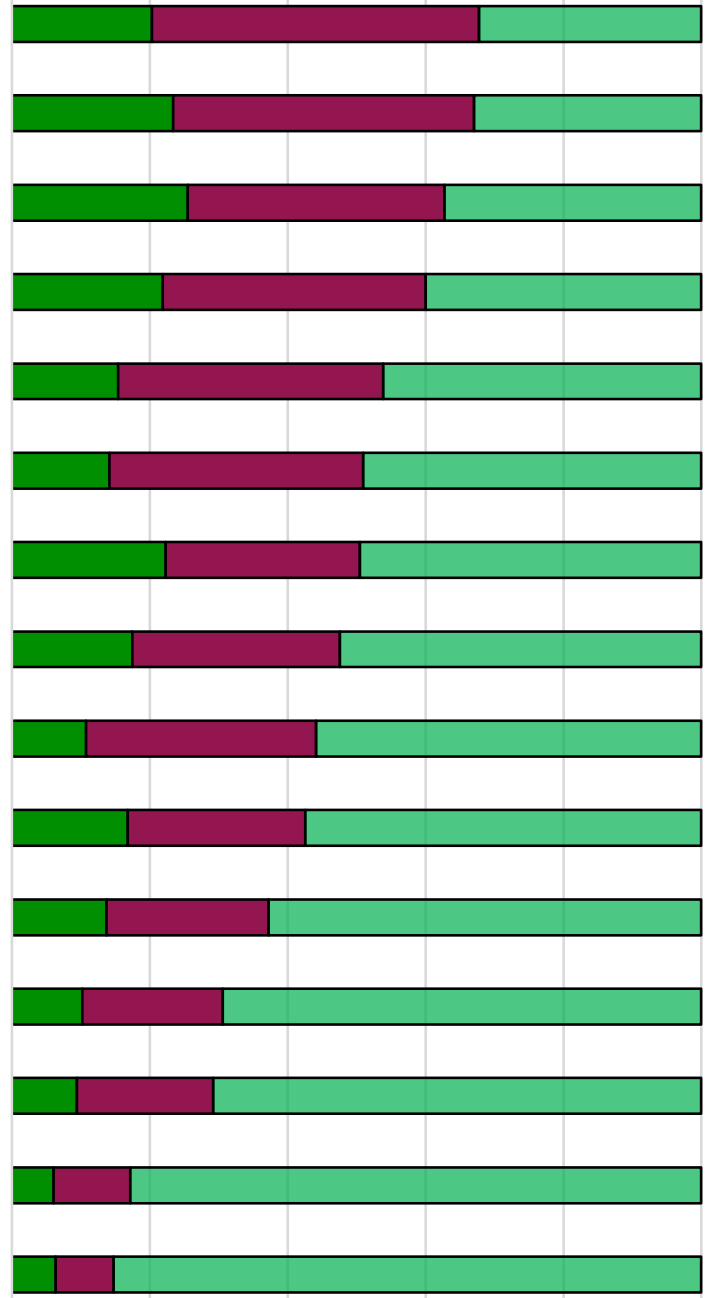

$0 \%$

$20 \% \quad 40 \%$

$60 \%$

$80 \%$

$100 \%$

Large Hurdle

Small Hurdle

$\square$ Not a Hurdle

Fig. 6.13. Respondent reported hurdles to adaptation implementation. Respondents could select large hurdle, small hurdle and no hurdle, $\mathrm{N}=102$.

Barriers to adaptation planning was coded as a core theme based on research question three. This theme was further coded based on the information the winegrowers discussed (Figure 6.14). The thematic analysis shows that the theme "barriers to adaptation planning' was coded 97 times for the combined interviews. These responses were prompted in the interviews; however, compared to adaptation planning, respondents were more reluctant to discuss perceived barriers. 


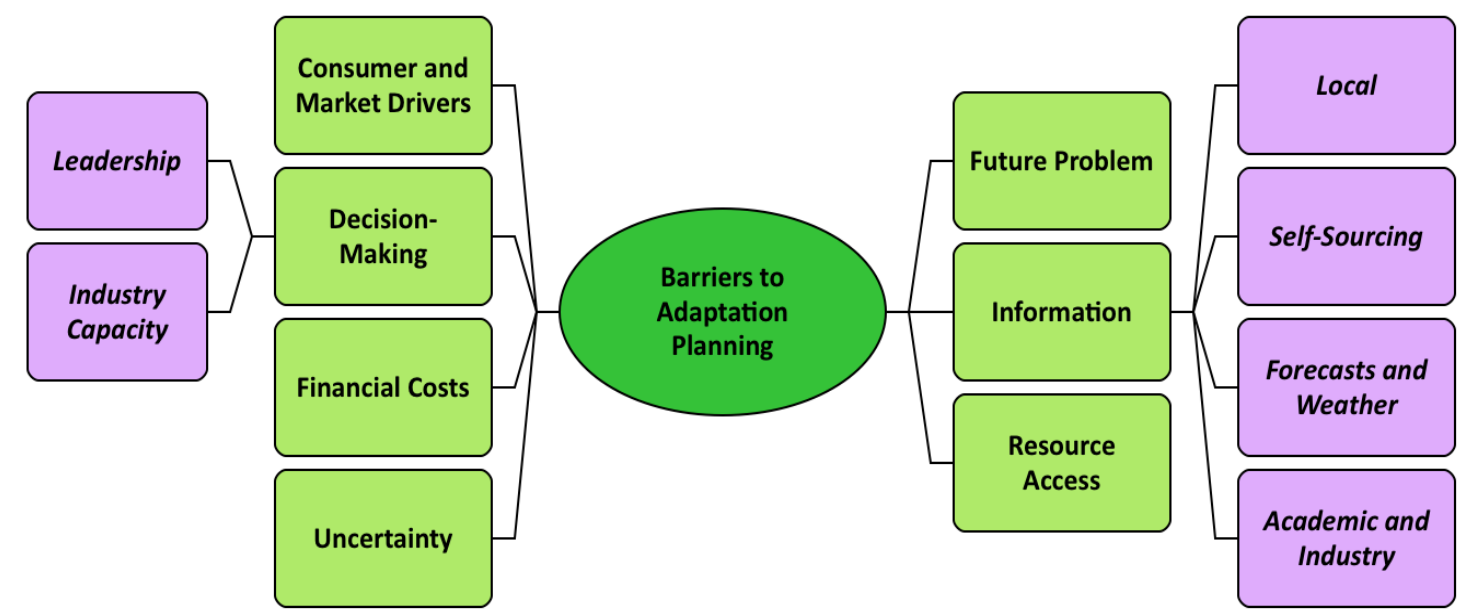

Fig. 6.14. Mind map of themes coded for barriers to adaptation planning. The light green boxes represent the main discussion themes in the interviews, and the purple boxes represent the sub-coded themes of certain variables that were specifically referenced multiple times.

The limited number of codes can further be attributed to many winegrowers citing no major barriers during the interview process. However, 'no barriers' was usually associated with winegrowers discussing the information and not knowing what to plan for. Aside from information specific barriers, another key barrier discussed which corresponds with the findings in Figures 6.12 and 6.13, is the budget (economic) constraints.

\subsubsection{PERCEIVED BARRIERS LIMITING ADAPTATION}

The main economic factor discussed in the interviews for all regions was the cost of varietal change or relocation. This adaptation strategy is often perceived as inevitable, yet the financial cost for some winegrowers is perceived as too high, especially given the size difference between wineries or vineyards. Winegrowers working in larger companies would often refer to the company's other wineries located in other regions and how as a business they are more adaptable given the diverse climate suitability for a range of wine styles. However, smaller growers do not have the capacity for expansion or relocation and are more concerned with risk and uncertainty. One example of how risk and uncertainty link with economic factors is from a grape producer in Marlborough:

"The choice would be do you sell up to someone else who has got the money to do that and just walk away from the pressure of that uncertainty. The bottom 
line is money ... Comparing this harvest [2017] to 2016, three weeks before the 2016 harvest, you just walk out there and think this looks so good. The flavours were good, the BRICs were up... we kept thinking is it going to rain and it didn't. This year the rain came at all the wrong time.... and with three weeks to go, we started to see rot... We were just manually walking through the vineyard and cutting out the rot. People behind us - they've got a 20-acre block - we didn't see anyone going through the block and they got right through to harvest, and the winemaker came along and said it's too late - we're not taking it, there's too much rot. So they left it on the vine. We struggled to get enough good quality fruit, I mean we were still picking off the rotten fruit the day they came" - Marlborough 4.

This winegrower further noted the financial impacts a bad season can have, but as a small producer, the capacity for change is limited. Few winegrowers discussed leadership and decision-making, which supports the perceptions from the survey. While, decision-making was discussed in all the regions, it was cited most in Otago. Leadership and decision-making were also associated with the economic issues. The findings indicate that decisions were made or contemplated based on financial security:

"... if I want to put in a half-million-dollar dam, I need to know to highlight it three or four years in advance. You can't just build a dam and have it up for the year you don't know if there's going to be a drought next year. So we put this into our capital plans, you assess it, you weight it up against investing in other things around the business and you put a proposal through to people in management or upper, and they make a decision"

- Marlborough 5.

"It's just that if you get one [frost event] in a big vineyard, it's worth the price of a frost fan. It's certainly an issue. The investment and type of people investing in vineyards got the know and will make the strategic decision not to be wiped out" - Hawke's Bay 5.

"All the pricing, costings, all the vineyard layout, all the building, how much I'm paid, how much the staff are paid - it's all based off the yield. So if we are going 
to have to go to new varieties and yields are lower because they are not irrigated, there is going to be a huge change up in the profitability"

- Otago 2.

\subsubsection{INFORMATION AS A BARRIER to AdAPTATION PLANNING}

This research was interested in how information could affect the decision-making process for adaptation planning. To assess what information was the most useful to winegrowers, a series of questions were asked. First, the survey asked at which scale is information the most useful in planning for adaptation to climate change. The findings show that $73 \%$ of respondents consider regional information the most useful (Figure $6.15)$.

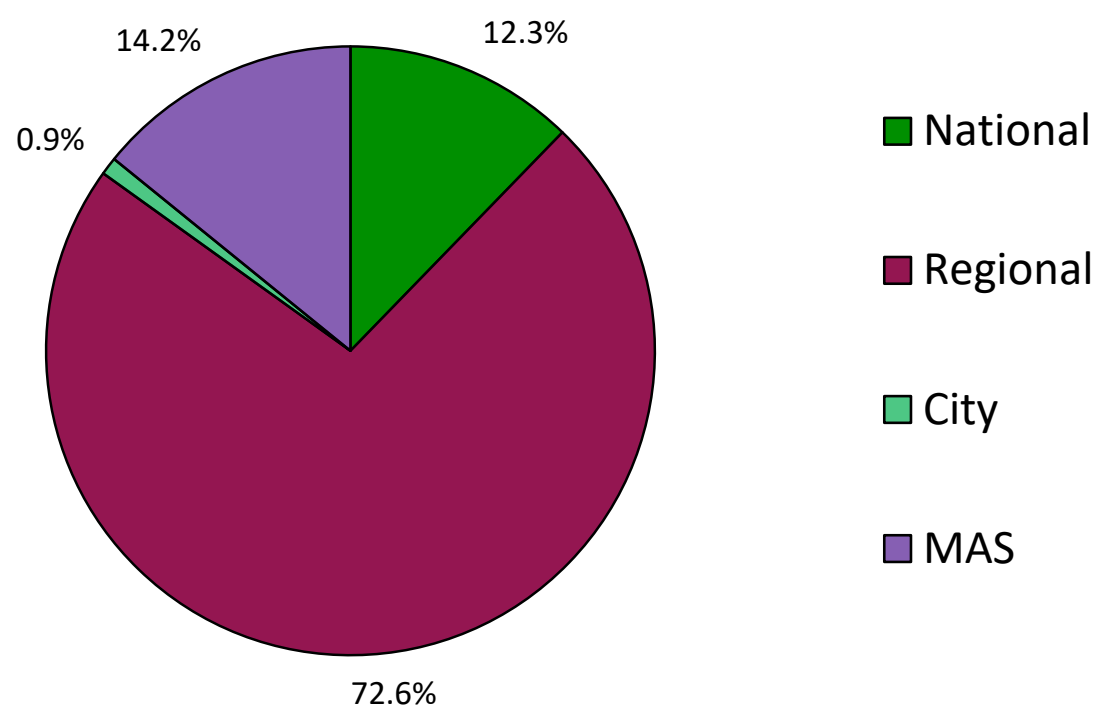

Fig. 6.15. Respondent reported scale of useful information, $\mathrm{N}=106$. MAS = management area specific and refers to specific location such as a vineyard.

Furthermore, when asked if a lack of information at the previous specific scale prevents planning for adaptation to climate change, the survey respondents reported that it could impede adaptation planning: $44 \%$ responded with maybe, $28 \%$ responded yes, and $28 \%$ responded no.

Previous work on these topics has identified issues related to information as a potential barrier to adaptation planning (Archie et al., 2012; Archie et al., 2014; Tribbia \& Moser, 
2008). The survey asked respondents to rate the usefulness of different types of climate information for determining the risks to their region from climate change. The purpose of the question was to contextualise what information winegrowers view as useful to enable effective adaptation planning. The results show winegrowers view all types of information as valuable (Table 6.15).

Table. 6.15. Respondent reported perceptions of the usefulness of climate information, $N=107$.

\begin{tabular}{|l|c|c|c|c|}
\hline \multicolumn{1}{|c|}{$\begin{array}{c}\text { Climate information } \\
\text { variables }\end{array}$} & Very useful & $\begin{array}{c}\text { Slightly } \\
\text { useful }\end{array}$ & Not useful & Total $\boldsymbol{n}=$ \\
\hline $\begin{array}{l}\text { Weather and or seasonal } \\
\text { climate forecast }\end{array}$ & $76 \%$ & $18 \%$ & $6 \%$ & 105 \\
\hline $\begin{array}{l}\text { Climate projections for the } \\
\text { next few years }\end{array}$ & $55 \%$ & $33 \%$ & $11 \%$ & 105 \\
\hline $\begin{array}{l}\text { Information on how to } \\
\text { assess the vulnerability of } \\
\text { specific areas }\end{array}$ & $56 \%$ & $35 \%$ & $9 \%$ & 99 \\
\hline Historical climate data & $54 \%$ & $41 \%$ & $5 \%$ & 107 \\
\hline $\begin{array}{l}\text { Long-term climate } \\
\text { projections }\end{array}$ & $58 \%$ & $36 \%$ & $6 \%$ & 105 \\
\hline
\end{tabular}

Additionally, this research was interested in understanding whether information about the impacts of climate change on viticulture and wine would change how winegrowers are adapting (Figure 6.16). The purpose of the question was to understand if information about climate change would be useful to winegrowers and whether this would help to remove a barrier for adaptation planning. 


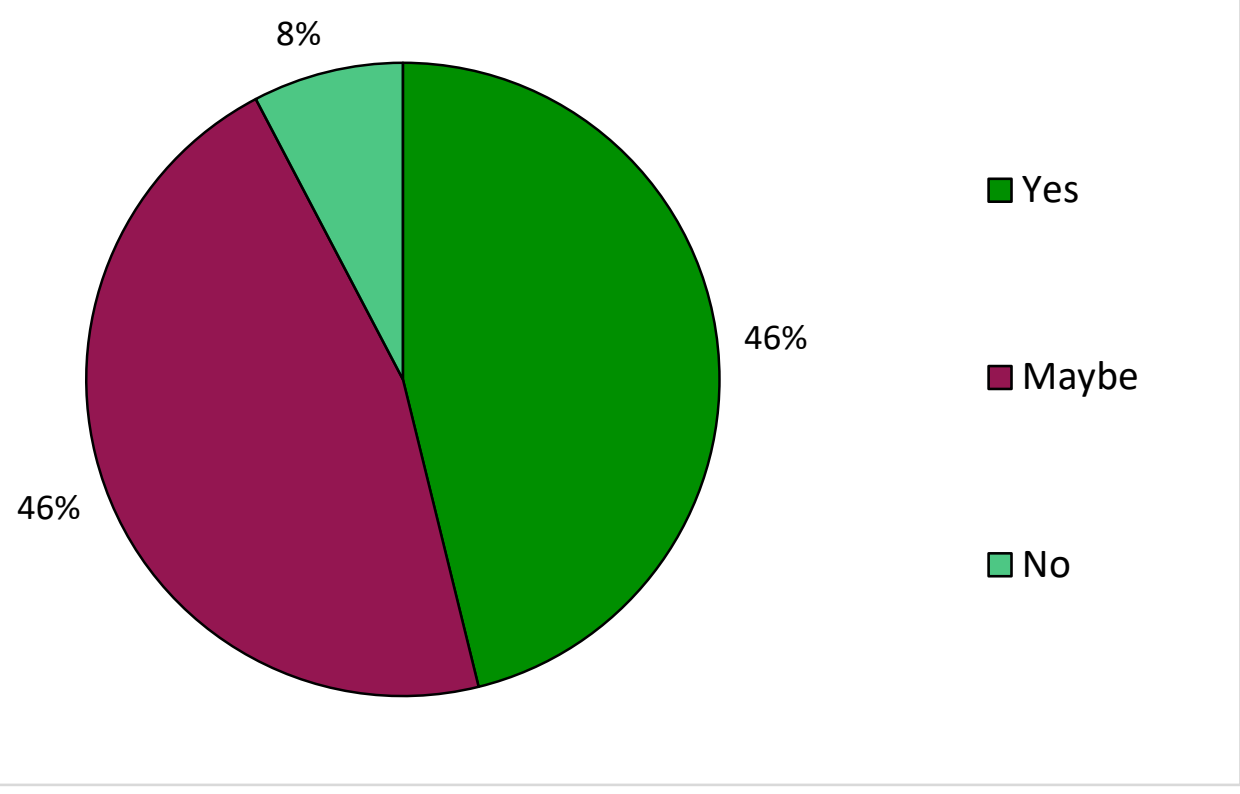

Fig. 6.16. Respondent reported usefulness of additional information for changing adaptation plans, N=104

The results show $46 \%$ of the respondents said yes they would change their plan, while the other $46 \%$ responded with maybe, indicating that $92 \%$ of respondents think additional information might change the way they plan. From the sample, only $8 \%$ responded that they would not change how they plan with additional information.

The interviewees reported information as a main barrier for adaptation planning. However, winegrowers' perceptions of information needed appear to differ among the regions, judging from interview data. Otago winegrowers discuss information in the context of "credible information". The winegrowers indicate climate change information does not relate to the wine industry specifically, so the data is not tangible for their use:

"It would be really good to go out to the industry with some hard data and say this is the information we have collected, and this is the trends we are seeing. That gives people incentives to think what are we going to do to respond to this. Even little things like budburst, that moving forward as harvest dates move forward. You're starting to talk about seasons shifting, it would be interesting to see that officially collected"

- Otago 3. 
Otago winegrowers perceive the need for more research to make confident decisions. Furthermore, the winegrowers are interested in local knowledge and how climate change directly will impact their region:

\begin{abstract}
"What's happening at a national level but we know our climate here is varied to the rest of New Zealand. It's the only pseudo-continental climate within New Zealand. From our perspective, local knowledge and local updates would be super valuable within the Central Otago region"

- Otago 1.
\end{abstract}

Winegrowers in Hawke's Bay discussed the context of the information they use in their decision-making process. The participants' responses indicate that the New Zealand wine industry has a reliance on literature from Australia:

\footnotetext{
"We especially follow the journals from Australia. There is a reasonable amount of stuff, but it's not always that easy to plough through. They're cutting back on their research too which is a bit annoying"

- Hawke's Bay 5.
}

The responses from the Hawke's Bay winegrowers shows information is often selfsourced at the discretion of the winery. Information from Australia is not always applicable to New Zealand but does give an insight into scenarios which could affect the New Zealand wine industry. Marlborough winegrowers have corresponding responses with both Hawke's Bay and Otago participants. The findings show Marlborough winegrowers are engaged with the research in wine production through the Marlborough Research Institute. Some winegrowers indicated they have a reasonable knowledge of climate change, and the 'need' for more information is directed towards a consensus in the academic literature and agreement on the outcomes of climate change:

\footnotetext{
"I think we have a reasonable idea of what's going on. I don't think we need any more information. It might be information from multiple sources and trying to take it all in and assess its impacts on this business is somewhat difficult as there is so much information, but it's better than none. It would be nice to have some
} 
consensus around the basics of climate change in terms of we could all universally agree that it is happening, so it means that resources are going to be put into research. And then just good data, reliable data on what the potential is going to be like and identifying the changes"

- Marlborough 5.

The responses from Marlborough winegrowers show conflicting perceptions regarding the information needed and what information is used. Information is perceived as the main barrier impeding adaptation planning. However, the findings show information at the local level using the New Zealand climate and wine data is the most usable and relevant to winegrowers' capacity for adaptation planning.

\subsection{SUMMARY}

New Zealand winegrowers have a good understanding of the climate change issue, yet survey and interview responses suggest only a few winegrowers have begun planning or implementing adaptation strategies. The winegrowers have observed climatic impacts on harvest quality, harvest quantity, and grape diseases, which are also the areas winegrowers are primarily focused on and are managing. Responses to questions about barriers to climate change have shown that information and economic constraints are the main factors impeding adaptation. However, the decisions to adapt are market driven as wine production is a primary industry in New Zealand. 


\section{CHAPTER 7: DISCUSSION}

\section{“DOVE REGNA IL VINO NON REGNA IL SILENZIO - WHERE WINE REIGNS, SILENCE DOES NOT REIGN"}

- ITALIAN PROVERB

\subsection{INTRODUCTION}

Research into the effects of climate change on New Zealand wine production has been limited until now. The aim of this study was to assess the adaptive capacity of New Zealand winegrowers by examining perceptions of climate change and decision-making for adaptation planning. This research provides a greater understanding of how climate change can affect wine production in New Zealand and what adaptation strategies are perceived to be most applicable for the future industry. This chapter discusses the findings of the study by linking the results with the relevant literature and conceptual frameworks.

\subsection{Winegrowers' Perceptions on Climate Change}

One of the primary goals of this study was to assess winegrowers' beliefs and knowledge about climate change and the New Zealand wine industry. The purpose was to gain an understanding of the perceived impacts of climate change specific to New Zealand wine production, but also to determine how winegrowers' beliefs about climate change affect decision-making for adaptation. Differences in climate change beliefs impact decisionmaking as individuals respond and plan based on their perceived perception of the level of climate change (Adger, Barnett, Chapin III, \& Ellemor, 2011; Moser \& Ekstrom, 2010). Survey findings from the present study found $66 \%$ of winegrowers believe "climate change is real and happening now", while $21 \%$ believe "climate change is probably happening and we will see the impacts in the near future". Statistical analysis from this survey showed wine producers were more likely to believe climate change is real and happening now, than grape producers. A similar difference was found in Australia where 
wine producers had a stronger belief than grape producers that climate change is real (Fleming, Park, \& Marshall, 2015). Fleming and colleagues (2015) explained that winemakers are usually the main decision-makers in the wine industry as they occupy more business-orientated roles, while grape-growers are more focused on vineyard management. Agricultural farmers have been found to be more sceptical of climate change as they work with unreliable weather forecasting and unpredictable seasons, which may affect trust in climate modelling (Crane, Roncoli, \& Hoogenboom, 2011). Grape producers in this sample conveyed how seasonal variation and inconsistency between growing years limited their capacity to observe or notice climate change trends:

"Part of the issue is that there is no consistency in the climate. We are not consistently seeing four years out of five being dry"

- Marlborough 4.

By comparison, wine producers in this study discussed climate change in more detail throughout the interviews and consider climate change impacts from a business perspective. These findings suggest that either winegrower occupations influence climate change belief or possibly that those inclined to pursue grape growing are predisposed to different beliefs in the first place.

\subsubsection{Winegrowers' KNOWLEDGe and Climate Change EXPOSURE}

Throughout both the survey and interviews, winegrowers demonstrated a good understanding of how climate change will impact wine production in New Zealand. In the interviews, winegrowers often drew on their own knowledge and experiences to provide examples of how climate change will impact their winery or vineyard. Overall, there was a consensus among both survey and interview respondents that the main impacts of climate change would most likely be increases in temperature, more seasonal variation, local drought, and increased frequency and intensity of local storms. Each of these variables is perceived as a local vulnerability throughout New Zealand. Winegrowers mostly consider the impacts as negative given the potential damage they can cause during the growing season. Interestingly, winegrowers' attitudes towards 
increasing temperature are not always negative. The findings from the interviews show increasing temperature for some winegrowers is a positive outcome as it can improve winegrape quality of varieties like Syrah and Cabernet Sauvignon. Production of these varietals is currently limited in New Zealand, but some winegrowers from Hawke's Bay and Otago thought the increase in temperature could enhance the flavour profile of the winegrape, which would positively impact their production. Other winegrowers from within those regions and Marlborough also considered temperature increases as detrimental for more commercial wine styles like Sauvignon Blanc. Similar to the findings explored in this study, mixed perceptions; both positive and negative, toward temperature increases are also seen in Australia. Galbreath (2011) found winegrowers who cultivate Syrah and Cabernet Sauvignon were more likely to be positive in their responses to increasing temperatures as winegrape quality may improve, but winegrowers who cultivate cooler-climate wine styles are more likely to respond negatively. Thus, the direction of winegrower attitudes on climate change impacts appear to depend on which varietal is produced.

\subsubsection{Sensitivities in Wine Production}

Weather phenomena have been identified as key sensitivities for winegrowers who produce high-quality wine (Battaglini, Barbeau, Bindi, \& Badeck, 2009). The survey responses found sunlight, precipitation, and temperature (in order of importance) to be the most crucial weather elements for making high-quality wine. Sunlight hours are crucial for wine production and, given the short growing season for many New Zealand wine regions, access to optimum sunlight is critical for producing a developed winegrape. The relative importance of precipitation could be a reflection of previous growing season conditions and the lack of water available due to droughts. The fact temperature is perceived as less important than precipitation could suggest winegrowers are not yet experiencing effects of increased temperature. Nevertheless, temperature is important for the phenological stages of development.

The result from this study shows similarities with findings from European winegrowers. However, Battaglini and colleagues (2009) found the most important weather phenomena in Europe were precipitation, temperature and sunlight (in order of importance). Adaptive capacity in the 'Old World' is restricted by appellations of control, 
so winegrowers have limited influence on how wine is produced. Given the droughts now occurring throughout Europe, the high value of precipitation could be expected as the need for irrigation becomes more prominent. The findings from this study are also consistent with that of Hadarits and colleagues (2010), who observed precipitation and temperature to be the main weather sensitivities for Chilean winegrowers.

Frost and wind were found in this study to be the least influential weather elements for making quality wine. However, in the interviews both variables were perceived as having an impact on overall wine production. In Marlborough, frost has become particularly prevalent with winegrowers reporting frost events occurring in locations previously unaffected. Frost events have become a greater risk for winegrowers, and as a consequence, effective decision-making for adaptation is needed:

[Neighbours] have just now put in two frost machines. They would be about 2 kilometres from here. They lost half a 20-acre block to frost and decided to spend $\$ 120,000$ on frost machines, which is a bit scary. How is it going to affect us? We don't have frost machines but what are we meant to do?"

- Marlborough 4.

Winegrowers often overlooked wind unless they were prompted in the interviews. Interviewees explained that wind damaged grapevines by breaking shoots, burning outer vines, and in some cases cooling plants to dormancy. In some cases, winegrowers are using the outer grapevines as sacrificial to protect the quality and yield for harvest:

[The impacts of severe wind result in] burning the vine tips, sometimes snapping offshoots...Sometimes the outside rows are sacrificial"

- Otago 4.

\subsubsection{Climate Change Impacts on Wine Production}

Globally, climate change has been observed as impacting wine production (Jones, White, Cooper, \& Storchmann, 2005). However, little is known or understood as to how climate change is impacting the New Zealand wine industry. As climate change is experienced more on a local scale (Measham et al., 2011), the survey asked winegrowers what type 
of impacts they had observed for some key wine production variables. Respondents reported that harvest quality, harvest quantity and grape disease are being negatively affected due to climate change.

A statistical analysis of reported harvest quality impacts showed winegrowers were more likely to believe climate change is real and happening now where they observed negative impacts on harvest quality. This indicates that when winegrowers observe a decline in harvest quality, they are more likely to believe the negative impact was a result of climate change. This suggests grape producers' beliefs about climate change can change when they personally experience such impacts.

A different statistical analysis of reported harvest quantity impacts was carried out. The finding here is that harvest quantity is being negatively impacted due to climate change across New Zealand. This is to be expected given the different regionalised microclimates and tailored management plans. It was not impossible to determine in this study what was considered the most negative impact between regions as this was beyond the scope of research; however, future research could explore this avenue.

The observed negative impacts of grape disease varied to a statistically significant extent between the regions, showing a similar finding to reported negative impacts on harvest quantity. A difference between regions would be expected as each region employs its own localised management strategy. Interestingly, grape disease management for wine production often facilitates regional collaboration prompting effective decision-making to prevent the spread of disease (Nicholas \& Durham, 2012). Another statistical analysis found negative impacts of grape disease were the most prevalent in the winegrape varietal Pinot Gris. This result supports the previous regional distribution finding as Pinot Gris is cultivated in most wine regions in New Zealand. A final statistical analysis of grape disease impacts found that the more negative the impacts of grape disease, the more likely winegrowers will be to plan for adaptation. This suggests an increase in grape disease is an industry prompt to undertake adaptation, especially considering the prevalence of disease spread. 
Grape disease was often mentioned in the interviews, with powdery mildew, downy mildew and Botrytis cited by New Zealand winegrowers as the most prevalent species. The increase in grape disease can be linked to climate change as there is a correlation between temperature change and the occurrence of various grape diseases (Bois, Zito, \& Calonnec, 2017). However, some New Zealand winegrowers are not attributing the increase of grape disease to climate change, as mildews are in a stage of sexual reproduction. Consequently, some winegrowers argued that the prevalence of grape disease is an expected industry outcome at this stage. Powdery mildew, downy mildew and Botrytis are some of the most prevalent grape diseases globally, with distributions beginning to occur outside 'normal' parameters (Bois et al., 2017). Therefore, winegrowers need to become more aware of the correlation between climate change and grape disease, and consider developing long-term strategies that will effectively manage the expected increase.

The observed negative trends for harvest quality, harvest quantity and grape disease show some similarities and differences from those in the study by Battaglini and colleagues (2009) study. Harvest quantity and grape disease are reported as negative impacts associated with climate change in both studies. Harvest quality was seen as improving due to climate change in Europe (Battaglini et al., 2009). This suggests that the quality of New Zealand wine might possibly improve with the rise in temperatures. However, such a result would also depend on trends in other key elements affecting productivity.

\subsection{Adaptation Planning in the New Zealand Wine Industry}

One aim of this study was to investigate the current state of adaptation planning in the different wine regions of New Zealand. It has been suggested winegrowers have a high capacity for climate change adaptation and planning (Cahill, 2009; Nicholas \& Durham, 2012; Park et al., 2012). Despite this, 63\% of the survey respondents in this study reported that adaptation planning is not currently taking place in their winery or region. This indicates fewer winegrowers are planning for adaptation or implementing these plans. No statistically significant correlation was found between belief in climate change and planning for adaptation. This implies winegrowers' adaptation planning is not 
directly related to or influenced by their beliefs about climate change. Furthermore, there was no statistical association between occupations and the regions within New Zealand, suggesting most winegrowers have responded similarly.

\subsubsection{Adaptation Strategies for Wine Production}

This research was interested in what management strategies winegrowers currently employ as climate change could impact them. The survey responses found disease, grape and drought management were the main management plans strategies as adaptation in the wine industry. Given the abovementioned findings of grape disease influencing adaptation planning, this result is to be expected. Similarly, a drought management focus is also expected as winegrowers previously indicated the importance of precipitation for quality wine production. However, grape management was mentioned less throughout both the survey and interviews. Grape producers described grape management strategies as the general maintenance of the vineyards, including canopy manipulation:

\footnotetext{
"It could be having more exposure for your fruit or less exposure. How much canopy you grow. One of the biggest would be how much leaf exposure you have over the top of your fruit. Whether you have a heap, or none, or in between. Its variety dependent, site dependent, location dependent in Marlborough. You're able to change those things relatively easily but I think those would be the key things you would look at changing"

- Marlborough 1.
}

Grape management is less intensive as it occurs throughout the growing season compared to focused disease or drought management. Disease management requires developing spray programmes and removing infected leaves to prevent the spread, whereas drought management in New Zealand focuses on drip irrigation and implementation of water storage. One winegrower noted that they are looking at newer technology for water management but are hesitant to implement untested strategies:

"One of the things we are potentially looking at in the future is underground irrigation... It would certainly be one option for better use and management [of 
water] that we would potentially consider. Other companies are doing it, and it's good to see other commercial examples of it as they provide the sort of prototype and test cases for us to make some decisions on it. We try not to be the version 1.0 on anything and let someone else make all the mistakes first" - Marlborough 5.

Another frequently highlighted management strategy in the interviews was the implementation of frost management. Frost occurrence was reported throughout all regions, and frost fans were perceived as effective in managing localised frost events. In particular, some larger wineries will implement frost fans immediately if frost is observed within the vineyard. They perceive the risk of yield loss to be greater than the cost of purchasing and implementing the frost fans. However, this is not reflective of smaller scale winegrowers, as for them the cost of frost fan implementation may outweigh the benefit. In severe cases, helicopters were reported as another strategy for frost management. However, the use of this strategy is also dependent on industry scale and whether the business can afford the additional costs. Despite their effectiveness, the use of helicopters is unsustainable in the long-term as it is resource intensive. These management strategies are predominantly reactive to changes observed in the wine industry. The findings of this research support the work of Belliveau et al. (2006) and Nicholas and Durham (2012) in finding that winegrowers are less likely to react and plan for climate change unless they are directly affected.

\subsubsection{Varietal Change and Relocation}

Varietal change and relocation have often been cited as the adaptation strategies most suitable for combating increased temperature due to climate change (Holland \& Smit, 2010a). However, the survey results from this study show $70 \%$ of New Zealand winegrowers have no plans to change their current winegrape varietals, nor any plans to relocate. The other $30 \%$ are changing mostly for market-related reasons. Interestingly, the few winegrowers who cited reasons for changing based on climate were planning to introduce more resilient rootstock species, and to experiment with the suitability of new varietals. 
Although winegrowers have indicated no immediate plans for varietal change, in the interviews they would often discuss climate change in the context of which winegrapes would be most appropriate for cultivation. Comparing the survey and interview responses of this study, the main varietals in the New Zealand wine industry we can expect to see more in the future are Pinot Noir and Chardonnay. Winegrowers are reportedly planting more of these two to meet market demand, which is essentially the primary driver for decision-making in the wine industry. Interestingly, winegrowers mentioned other varietals that are less commonly produced in New Zealand. Albariño was the most agreed-on new emerging varietal identified by winegrowers in both the survey and interviews. It is a white wine that produces a style well suited to the New Zealand wine industry's market, but more importantly, Albariño has a higher optimum plant temperature making it an ideal variety for the warmer future.

Winegrowers in the interviews would often associate the projected increases in temperature with Merlot and Syrah cultivation in New Zealand. However, statistical analysis revealed that winegrowers who grow both these varietals are more likely to change cultivars. This suggests that although these varietals will be more suited to warmer temperatures in the future, winegrowers may be thinking in the shorter term and considering other factors - especially meeting market and consumer demand.

This study was interested in what potential climate change impacts would lead to varietal change. Statistical analysis from this study showed winegrowers are more likely to plan for varietal change if they have observed negative impacts on harvest quality due to climate change. Harvest quality was the only wine production variable that had a statistical difference in varietal change, suggesting a reduction in harvest quality could lead to more varietal change. This finding contrasts with a previous study, which found winegrowers to be more concerned about harvest quantity than quality (Lereboullet et al., 2014). Understanding the difference between why winegrowers are more concerned about harvest quality than quantity was beyond the scope of this research; however, future research could investigate how winegrowers perceive the impact of each variable in changing cultivars. 
Relocation was a less common theme in this study compared to varietal change. Similarly, to varietal change, winegrowers during the interviews would often discuss temperature change in the context of their industry. When discussing future climate scenarios in which temperatures increase by $2^{\circ} \mathrm{C}$ or more, winegrowers would indicate the need for a shift in region towards more marginal land or down along the east coast of New Zealand. Some of the potential new locations would be more regionally suitable for grapevine production than the present sites. A winegrower discussed the shift of cultivating to more marginal land in the context of Marlborough:

"... going South through Marlborough more might be more plantable because of the way the climate is changing it'll be more viable. Maybe have some vineyards down in the areas of Ward and through the Flaxbourne area..." - Marlborough 1.

An example of an industry relocation would be the shift down toward the boundary between Marlborough and Canterbury as the soils are appropriate there and there is available water. These findings suggest New Zealand winegrowers are resilient and economically driven. This contrasts with other research in which winegrowers were found to be reluctant to relocate or shift as they have formed an attachment to place (Fleming et al., 2015; Lereboullet et al., 2014). This could be partially explained by the New Zealand industry being so young compared to other wine regions around the world.

\subsubsection{ADAPTIVE CAPACITY OF WINEGROWERS}

This research found that New Zealand winegrowers are generally reactive in their approach to planning, with winegrowers preferring to implement incremental types of adaptation. The reactive approach - previously discussed - involves winegrowers not planning for the future but taking adaptive action when required. However, some of this reactive thinking is leading to more proactive strategies. An example is winegrowers implementing frost fans while planting the grapevines because they are aware of temperature variation and frost risk. Part of this can be explained by winegrowers' capacity to build on their own knowledge and experiences within the industry, while it is also linked with the economics of wine production and the need to secure a yearly profit. This finding was expected as previous work in other 'New World' countries have 
reported similar findings (Belliveau et al., 2006; Cahill, 2009; Fleming et al., 2015, Galbreath, 2011, 2012; Nicholas \& Durham, 2012; Park et al., 2012).

Interestingly, when approached in terms of the scale of companies and adaptive capacity, the New Zealand wine industry shows a stark contrast to the findings of other studies. Smaller wineries are found to have more adaptive capacity than larger wineries (Park et al., 2012), yet the interviews in this research show smaller wineries being hindered by financial costs and the uncertainty in deciding what action to take. By contrast, the larger wineries appear to be more receptive and willing to take action. Furthermore, the larger wineries were found to be implementing more proactive transformational adaptation. An example of this identified in this study was water storage facilities on-site for future proofing against drought that is occurring within the region. However, smaller wineries perceive this type of adaptation as too expensive and in some cases not necessary while they have access to local water allocations. Therefore, this research found larger wineries to have a higher adaptive capacity compared to smaller companies.

\subsection{Barriers to AdAPtation PlanNing}

The final goal of this study was to assess which barriers winegrowers perceive as hindering their progress in adaptation planning. The purpose was to identify barriers within the wine industry to further adaptation planning and action within the wine industry, but also to assess which stage of the adaptation process winegrowers are currently at. In the survey, the most commonly reported barriers preventing adaptation planning were a "lack of locally specific information", "uncertainty in available information", a "lack of usable information", and "budget constraints". Information was expected to be a barrier as it is frequently acknowledged in the literature to be a barrier for climate change adaptation planning (Archie et al., 2012; Archie et al., 2014; Measham et al., 2011; Tribbia \& Moser, 2008).

These results correlate with the main hurdles identified in this study's survey. Winegrowers perceive the main hurdles in the adaptation process as a "lack of solution options", "the available science being at the wrong scale", and "budget constraints". The 
lack of available solutions is related to a lack of usable information as winegrowers in the interviews would often mention they would plan for adaptation if they knew both what to plan for and how to implement a strategy. The barrier "available science at the wrong scale" was consistently found in the research, which illustrates winegrowers' preference for information to be presented at the local scale specific to the wine industry. Winegrowers understand the science of climate change, which was demonstrated throughout the study but, without access to region-specific climate change information, they can only make inference from generalised New Zealand projections. Given the diverse climate and regional differences, more localised projections and scenarios could give an insight into which adaptation strategies need to be budgeted and planned for, but also which varieties would be best suited in future and where to cultivate them. More importantly, it would also provide some certainty and context for solution options. An example could be the implications for future drought conditions. With more certainty winegrowers can commit to long-term transformational adaptations like water storage.

\subsubsection{INFORMATION AS A BARRIER}

In general, information about climate change impacts on viticulture is extensive and is available to users. However, this information is not fully relevant to the New Zealand wine industry. A "lack of information" can be considered in terms of whether information exists or whether it is accessible to the users (Archie et al., 2012; Archie et al., 2014). Winegrowers are aware of information at the global scale, with winegrowers in the interviews discussing what information they use for decision-making. Some winegrowers subscribe to academic literature from Australia to further their knowledge of how climate change is affecting winegrape production more widely, as some of the research can apply to New Zealand:

"Australia has good research culture - so they have had a much better statefunded research facility for a long time. The Australia New Zealand wine magazine is quite Australian focussed but also covered the New Zealand industry to a degree"

- Otago 1. 
However, access to publications and research is often restricted to larger wine companies who are willing to purchase these subscriptions or companies who have an interest in 'environmental issues'. Smaller wineries are more reliant on New Zealand Wine for research and publications, which usually covers a more all-round business perspective than specifically focusing on one topic such as climate change. Additionally, some winegrowers prefer non-academic literature such as media articles because they are more digestible for the reader. Some of the information could be extracted-such as on adaptation techniques-but for the most part, climate change science academic literature can be difficult to absorb and unpack the salient information (Archie et al., 2014; Cash et al., 2003).

A lack of New Zealand specific information using New Zealand regional data was identified as a major barrier by winegrowers in both the survey and interviews. Interestingly, the "lack of locally specific information" was linked with both the "uncertainty in available information" and a "lack of usable information". The current climate change data and projections for the future of both wine production and New Zealand are not related or presented tangibly. New Zealand climate change projections are mostly applicable on a national level and are generalised into broad expectations, which winegrowers perceive as inappropriate for them. Industry-specific information that is related to climate change was perceived as more "usable". An example from the interviews showed commonality amongst winegrowers wanting information that uses New Zealand growing season data such as increased frost to provide evidence that climate change is happening now. Furthermore, winegrowers also mentioned that uncertainty with information was often linked to a lack of scientific consensus over projected droughts, frosts and temperature variations.

The findings from the survey identified the types of information winegrowers are most interested in which are "weather and/or seasonal forecasts", and "longterm climate projections". Weather and seasonal forecasts are considered with scepticism by winegrowers as they are viewed as unreliable. Given the effects of late-season rainfall or storms, it is highly desirable winegrowers have advance 
warning about weather events to prepare and plan for harvest. The long-term climate projections can give winegrowers an indication of what to expect in the coming years, and if this information is specific to regional wine production, the projected temperature change data could provide a foundation for planning more transformational adaptations like varietal change or relocation. With less reliable information, there is a lack of trust in what is available. A lack of localised and targeted information is a common barrier identified in the literature (Archie et al., 2014). However, finer-scale climate change data can add more uncertainty for future projections than larger-scale information (Dessai, Hulme, Lempert, \& Pielke Jr., 2009; Tribbia \& Moser, 2008). Therefore, consideration is needed to determine how to communicate regional climate change projections without creating undue uncertainty for winegrowers.

\subsubsection{BUDGET CONSTRAINTS AS A BARRIER}

In addition to reported information barriers, budget constraints were also commonly cited and referenced by winegrowers as a barrier for adaptation planning. Budget constraints was a reoccurring theme throughout this research both explored as market and consumer demands, and financial constraints.

This research found winegrowers were particularly influenced by the pressure to meet the market and consumer demands, which can often detract the focus of planning for climate change adaptation. The survey responses found that market reasons were the main motivation for changing varietals. Throughout the interviews, the winegrowers would continuously reiterate they were purposefully selecting wine styles that the international market wants and expects. This was emphasised with the potential varietal shift to more red wine production. One winegrower noted:

"if you can grow a good Gamay, you can grow a good Pinot Noir, which is worth more in the long-run" - Otago 4.

The winegrower put more value into the varietal that was worth economically more. Market and consumer demand is a barrier because it drives an unwillingness on the part of winegrowers to adapt to changing conditions, when the long-term benefit may be 
more beneficial. Until the market and consumer tastes shift, the New Zealand wine industry will remain Sauvignon Blanc dominated; with more Pinot Noir emerging in the coming years. This finding is apparent in the 'New World' wine industry with market and consumer demands being identified as a key sensitivity of winegrowers making them vulnerable to climate change impacts (Belliveau et al., 2006; Hadarits et al., 2010).

Financial constraints are a barrier apparent in smaller industry production. The findings from the interviews show that winegrowers in larger wineries are more inclined to implement adaptation and are less constrained by budget concerns. However, the winegrowers must plan and propose adaptation solutions to the owners, who make the final call. Conversely, smaller wineries or independent winegrowers feel constrained and are reluctant to implement adaptation because of the final cost and uncertainty of whether it will be work. This hesitancy was found in Australia, with small winegrowers feeling the pressure of climate change more than the larger wineries (Galbreath, 2011). It has been found that smaller industry winegrowers are more vulnerable as the operate on a year to year basis compared to larger wineries which can absorb the loss of a year and continue production unaffected (Hadarits et al., 2010; Lereboullet et al., 2014).

\subsubsection{AdAPTATION PROCESSES FRAMEWORK}

Most respondents indicated they were not planning for climate change, suggesting New Zealand winegrowers are in the understanding phase of the adaptation processes framework or are in the early stages of the planning phase (Moser \& Ekstrom, 2010). As the respondents understand how climate change impacts wine production, it can be assumed winegrowers are either waiting to detect the problem at a significant scale or are waiting for 'usable' information to be gathered to make effective decisions (Moser \& Ekstrom, 2010). The signal of climate change was apparent and detected in the industry as respondents reported negative impacts of climate change on harvest quality, harvest quantity and grape disease. However, most winegrowers have yet to cross the threshold of concern or the need to respond. Budget constraints have been identified as one of the major cross-cutting issues by Moser and Ekstrom (2010). However, it is difficult to determine where in the adaptation process budget constraints become a major barrier. Budget constraints can also work as an incentive for some to implement 
adaptation. The interviewees discussed the importance of market and financial outcomes, reflecting that if climate change impacts were affecting the economic profit of the company, they would be more inclined to remedy the situation. Information was however perceived as a barrier this process, with winegrowers indicating the need for more New Zealand wine-related research in the field of climate change, and information available at the regional scale, to enable timely discussion to invest in adaptation. This can lead to more effective decision-making towards proactive transformation adaptation planning. The findings from this study suggest that, given their budget constraints, most winegrowers are waiting in the planning phase to make more informed decisions in the future when the information is readily available (Moser \& Ekstrom, 2010). However, the respondents who are implementing adaptation such as frost and water are in the management phase, monitoring the success of the strategy.

\subsection{WINEGROWERS' DECISION-MAKING CAPACITY}

The wine industry needs to start planning for effective transformational adaptation in the near future or accelerate such planning where they have begun. Incremental adaptation has proven effective for localised management issues such as frost or drip irrigation. However, as the growing season conditions become hotter and drier, these strategies will become increasingly ineffective. Some larger wineries have already begun planning and implementing on-site water storage facilities because they are aware of the increased risk of drought. The cost-benefit assessments for the future of the company overcame the present financial barrier. Aside from economic barriers, smaller wineries argue they are unable to implement these types of strategies because they are constrained by land allocation. If they were to pull grapevines out, for example to allow for greater water storage, they would be essentially losing a significant part of their yield and income. More capacity building is needed with smaller winegrowers to ensure they are still able to operate under future climate change scenarios.

Proactive transformational adaptation options available for both smaller and larger wineries can include changing planting decisions and shifting to more marginal land (Nicholas \& Durham, 2012). Varietal change is an important transformational adaptation that few New Zealand winegrowers are considering. Similar to other 'New World' wine 
producers, market and consumer demands are the driving force behind the New Zealand wine industry's decision-making capacity. At present, winegrowers are reluctant to change varietals while they are still profitable. However, experimentation is occurring in New Zealand with some proactive winegrowers planting a few rows of new varieties of Vitis vinifera.

New Zealand winegrowers have an adaptive capacity but have yet to fully explore the options for the future. They are largely reactive to change and will focus on implementing incremental adaptation as it is financially more affordable, but also shortterm. The larger wineries in New Zealand appear to have more adaptive capacity than smaller winegrowers due to less tight economic constraints. However, market and consumer demand essentially drives the wine industry and will dominate decisionmaking.

\subsection{Research Contributions}

Wine production in New Zealand is expected to expand and intensify to reach the target of $\$ 2$ billion in export value by 2020 (New Zealand Winegrowers, 2017). Therefore, it is important to understand how winegrowers perceive climate change to assess the potential risks and need for adaptation. This thesis has contributed to the limited body of existing literature regarding climate change and wine production in New Zealand. Furthermore, this thesis contributes to the global scholarship on wine and climate change, where there has been a dearth of New Zealand specific research, as well as adding to the field of winegrowers' perceptions of climate change and adaptation. The use of a survey gave a general overview of winegrowers' perceptions of climate change and adaptation planning in New Zealand. Complementing this, interviews across the various wine regions have contributed a wider and more in-depth analysis of the decision-making process. The findings of this thesis show winegrowers believe climate change to be real and happening now, yet only a small proportion of winegrowers are implementing adaptation strategies, which are predominantly incremental and reactive. However, some of the larger wineries appear to be planning for more transformational adaptation such as water storage facilities to counter the effects of drought. Varietal change was perceived as another transformational adaptation but has yet to be 
seriously considered by winegrowers, whose focus is on market and consumer demands in decision-making. Economic factors and a lack of 'usable' information were perceived as the main barriers for adaptation planning with winegrowers less likely to make longterm decisions when faced with uncertainty. Consequently, the results of this research emphasises the need for more research into climate change effects on New Zealand wine, but also more engagement between researchers and winegrowers to ensure relevant information is shared and usable for decision-making.

\subsection{Limitations of the Study and Future Research}

The study utilised for this research was the first of its kind in New Zealand. The research was designed to be exploratory and applicable to all wine regions. The questions were structured to give an insight and provide an overview of what is happening in the New Zealand wine industry. This resulted in broad research that has the capacity to be further analysed. Follow-up research can be narrower in design, tailoring questions that relate specifically to the wine region in question. An example of this could be research to analyse the reactive strategies, determine when they were implemented, and winegrowers' proactive outlook for future management.

There were limitations due to the sampling technique used. Purposefully selected sampling restricts access to the survey and who participates. Winegrowers were the target audience and were recruited electronically through emails sent to wineries in New Zealand. The sample had a higher proportion of wine producers $(61 \%$ of those approached) than grape producers (21\%), presumably an outcome of emails going directly to wineries for redistribution to staff. Therefore, the sample was not representative of New Zealand winegrowers. Additionally, Hawke's Bay winegrowers were underrepresented which could have limited the validation of regional comparisons. Future research may address this problem by using a survey tool that could reach a wider percentage of industry specialists to gain a more representative sample.

Another limitation of this research was the timeframe for the thesis, and thus the length of the survey. The timeframe limited the survey length to encourage a higher 
participation rate in a shorter period. This reduced the amount of potential data gathered, by limiting the detail practiced in the survey, and the number of respondents. In addition, the interviews were conversational and general in nature. With a longer timeframe, a 'before and after harvest' interview design could have been explored to see how perceptions shift when influenced by climate variability.

The results of this thesis provide a good starting point for future research. Potential research projects with the focus on the New Zealand wine industry include analysing phenological cycles and harvest advancement for the different wine regions, and also the scope for attention to different winegrape varietals. Wine research to date has had a central focus on Marlborough and Sauvignon Blanc; however, with potential varietal and location shift, future research needs to expand into other wine regions and more marginal locations. Collection of data on annual climatic variables (such as frost prevalence) needs to be matched with analysis at the regional scale to provide winegrowers with evidence on what sort of climate change is happening now. This data needs to be specific to wine production in order to change winegrower perceptions that climate change is a future risk. This data can also be used to analyse climatic change on wine quality, thus building on the international scholarship and incorporating New Zealand into the global conversation. Furthermore, this data should be included in a series of vulnerability assessments across the different regions to specifically analyse the exposures and sensitivities for a more comprehensive picture of climate change impacts and perceptions. 


\section{CHAPTER 8: CONCLUSION "VINUM ANIMI SPECULUM - WINE IS THE MIRROR OF THE MIND"}

- AESCHYLUS

To conclude this thesis a brief overview of the main aims and findings will first be reiterated. This will be followed by a commentary on the limitations of the study, remarks on the wider implications of the study, and recommendations for future research into the subject of 'climate change and wine' in the New Zealand context. Lastly, some final thoughts will be offered on the outlook for the New Zealand wine industry under a changing climate.

The aim of this thesis was to explore decision-making in the wine industry by assessing the adaptive capacity of winegrowers. There were three objectives for the research: 1) to understand winegrowers' perceptions of the climate change issue; 2) to assess adaptation planning in the wine industry; and 3) to understand the perceived barriers for implementing adaptation which limits the winegrowers' adaptive capacity.

The main findings indicate that winegrowers have relevant knowledge of the climate change issue relating to viticulture and viniculture. However, the impacts of climate change are perceived as a longer-term threat. This constrains winegrowers' adaptive capacity generally - most winegrowers have no plans for adaptation. The winegrowers who were either implementing or planning adaptation were predominantly in reactive mode and concentrated on issues already experienced in their respective regions. Varietal change and relocation were the main transformational types of adaptation referenced by winegrowers, but were perceived as long-term strategies which are conditional on consumer and market demand. Long-term planning is hindered by regional climate change uncertainty as winegrowers are reluctant to implement adaptation without industry-specific and region-specific information.

The New Zealand wine industry as a whole has a high adaptive capacity. However, more collaboration between winegrowers and researchers is needed to ensure information is 
usable for effective decision-making. Larger industry winegrowers were found to have a higher adaptive capacity as they were more financially secure, enabling them to implement transformational adaptation. By contrast, small industry winegrowers are more economically constrained, limiting their adaptive capacity.

This research provided a clearer picture than has hitherto been available of the context and foundation for what is happening in the New Zealand wine industry. Although the industry is new, there is the capacity for researchers and winegrowers to co-produce relevant knowledge and implement effective adaptation. The IPCC (2014a, p. 76) defines adaptation as "the process of adjustment to actual or expected climate and its effects in order to either lessen or avoid harm or exploit beneficial opportunities". The wine New Zealand wine industry is perceived as able to benefit from climate change with the assistance of adaptation. Where than continues to be the case over the long term is, of course, uncertain, but prospects are certainly perceived positively by most winegrowers in the short term. The varietals may change and the locations of some vineyards and wineries might shift, but with a warmer growing season, there is the capacity to continue producing high-quality wine in New Zealand. However, adaptation planning alongside future research is needed to fully exploit these future opportunities. In the long-term, there may be more difficulties, in currently warmer areas such as Hawke's Bay, in terms of water availability, disease, and 'reactivity' is likely to cease being the most used adaptation strategy. Nevertheless, this study has demonstrated both awareness on the part of winegrowers' perceptions about climate change and a generally positive approach of adaptation. 


\section{REFERENCES}

Abid, M., Schilling, J., Scheffran, J., \& Zulfiqar, F. (2016). Climate change vulnerability, adaptation and risk perceptions at farm level in Punjab, Pakistan. Science of the Total Environment, 547, 447-460.

Adger, W. N., Lorenzoni, I., \& O’Brien, K. L. (Eds.). (2009). Adapting to climate change: Thresholds, Values, Governance. Cambridge, England: Cambridge University Press.

Agnew, R., Raw, V., Bishell, R., \& Grab, F. (2015). Phenological Monitoring. Marlborough: Plant and Food Research.

Aleixandre, J. L., Aleixandre-Tudó, J. L., Bolaños-Pizarro, M., \& Aleixandre-Benavent, R. (2016). Viticulture and oenology scientific research: The Old World versus the New World wine-producing countries. International Journal of Information Management, 36(3), 389-396.

Alston, J. M., Fuller, K. B., Lapsley, J. T., \& Soleas, G. (2011). Too much of a good thing? Causes and consequences of increases in sugar content of California wine grapes. Journal of Wine Economics, 6(2), 135-159.

Amerine, M. A., Berg, H., Kunkee, R., Ough, C., Singleton, V., \& Webb, A. (1980). The Technology of Wine Making. Westport, CT: AVI Publishing Company.

Amerine, M. A., \& Winkler, A. J. (1944). Composition and quality of musts and wine of California grapes. Hilgardia, 15(6), 493-675.

Anderson, J. D., Jones, G. V., Tait, A., Hall, A., \& Trought, M. C. T. (2012). Analysis of viticulture region climate structure and suitability in New Zealand. Journal International Des Sciences De La Vigne Et Du Vin, 46(3), 149-165.

Anderson, K., Findlay, C., Fuentes, S., \& Tyerman, S. D. (2008). Viticulture, wine and climate change. Adelaide, Australia: University of Adelaide.

Archie, K. (2014). Mountain communities and climate change adaptation: barriers to planning and hurdles to implementation in the Southern Rocky Mountain Region of North America. Mitigation and Adaptation Strategies for Global Change, 19(5), 569-587.

Archie, K., Dilling, L., Milford, J., \& Pampel, F. (2012). Climate change and western public lands: a survey of US federal land managers on the status of adaptation efforts. Ecology and Society, 17(4), 20. 
Archie, K., Dilling, L., Milford, J., \& Pampel, F. (2014). Unpacking the 'information barrier': Comparing perspectives on information as a barrier to climate change adaptation in the interior mountain West. Journal of Environmental Management, 133, 397-410.

Ashenfelter, O. (2010). Predicting the prices and quality of Bordeaux wine. Journal of Wine Economics, 5(1), 40-52.

Ashenfelter, O., \& Storchmann, K. (2010). Using a hedonic model of solar radiation to assess the economic effect of climate change: the case of Mosel Valley vineyards. Review of Economics and Statistics, 92(2), 333-349.

Ashenfelter, O., \& Storchmann, K. (2016a). Climate Change and Wine: A Review of the Economic Implications. Journal of Wine Economics, 11(1), 105-138.

Ashenfelter, O., \& Storchmann, K. (2016b). The Economics of Wine, Weather, and Climate Change. Review of Environmental Economics and Policy, 10(1), 25-46.

Atkinson, J. (2011). Terroir and the Côte de Nuits. Journal of Wine Research, 22(1), 3541.

Barnuud, N. N., Zerihun, A., Mpelasoka, F., Gibberd, M., \& Bates, B. (2014). Responses of grape berry anthocyanin and titratable acidity to the projected climate change across the Western Australian wine regions. International Journal of Biometeorology, 58(6), 1279-1293.

Battaglini, A., Barbeau, G., Bindi, M., \& Badeck, F.-W. (2009). European winegrowers' perceptions of climate change impact and options for adaptation. Regional Environmental Change, 9(2), 61-73.

Belliveau, S., Smit, B., \& Bradshaw, B. (2006). Multiple exposures and dynamic vulnerability: evidence from the grape industry in the Okanagan Valley, Canada. Global Environmental Change, 16(4), 364-378.

Bergvist, J., Dokoozlian, N. K., \& Ebisuda, N. (2001). Sunlight exposure and temperature effects on berry effects on berry growth and composition of Cabernet Sauvignon and Grenache in the Central San Joaquin Valley of California. American Journal of Enology and Viticulture, 52(1), 1-7.

Berkhout, F., Hertin, J., \& Gann, D. M. (2006). Learning to adapt: Organisational adaptation to climate change impacts. Climatic Change, 78(1), 135-156.

Bernetti, I., Menghini, S., Marinelli, N., Sacchelli, S., \& Sottini, V. A. (2012). Assessment of climate change impact on viticulture: Economic evaluations and adaptation 
strategies analysis for the Tuscan wine sector. Wine Economics and Policy, 1(1), 73-86.

Bindi, M., Fibbi, L., Gozzini, B., Orlandini, S., \& Miglietta, F. (1996). Modelling the impact of future climate scenarios on yield and yield variability of grapevine. Climate Research, 7(3), 213-224.

Blennow, K., \& Persson, J. (2009). Climate change: Motivation for taking measure to adapt. Global Environmental Change, 19(1), 100-104.

Bois, B., Zito, S., \& Calonnec, A. (2017). Climate vs grapevine pests and diseases worldwide: the first results of a global survey. Oeno One, 51(2), 133-139.

Bourke, B. (2014). Positionality: Reflecting on the research process. The Qualitative Report, 19(33), 1-9.

Braun, V., \& Clarke, V. (2006). Using thematic analysis in psychology. Qualitative Research in Psychology, 3(2), 77-101.

Bryan, E., Ringer, C., Okoba, B., Roncoli, C., Silvestri, S., \& Herrero, M. (2013). Adapting agriculture to climate change in Kenya: household strategies and determinants. Journal of Environmental Management, 114, 26-35.

Bryant, C., Smit, B., Brklacich, M., Johnston, T., Smithers, J., Chiotti, Q., \& Singh, B. (2000). Adaptation in Canadian agriculture to climatic variability and change. Climatic Change, 45(1), 181-201.

Bryman, A. (2008). Why do researchers integrate/combine/mesh/blend/mix/merge/fuse quantitative and qualitative research. In M. M. Bergman (Ed.), Advances in Mixed Methods Research (pp. 87-100). Thousand Oaks, CA: SAGE Publications Inc.

Bureau, S. M., Razungles, A. J., \& Baumes, R. L. (2000). The aroma of Muscat of Frontignan grapes: effect of the light environment of vine and bunch on volatiles and glycoconjugates. Journal of Science of Food and Agriculture, $80(14), 2012-2020$.

Burton, I. (2009). Climate change and adaptation deficit. In E. L. F. Schipper \& I. Burton (Eds.), Earthscan Reader on Adaptation to Climate Change (pp. 89-95). Sterling, VA: Earthscan.

Caffarra, A., Rinaldi, M., Eccel, E., Rossi, V., \& Pertot, I. (2012). Modelling the impact of climate change on the interaction between grapevine and its pests and 
pathogens: European grapevine moth and powdery mildew. Agriculture, Ecosystems \& Environment, 148, 89-101.

Cahill, K. N. (2009). Global change in local places: Climate change and the future of the wine industry in Sonoma and Napa, California. (Ph.D), Stanford University, Stanford, California.

Cahill, K. N., Lobell, D. B., Field, C. B., Bonfils, C., \& Hayhoe, K. (2007). Modeling climate and climate change impacts on winegrape yields in California. American Journal of Enology and Viticulture, 58(3), 414.

Campbell, G., \& Guibert, N. (2007). Introduction: The History and Culture of Wine. In G. Campbell \& N. Guibert (Eds.), Wine, society, and globalization: Multidisciplinary perspectives on the wine industry (pp. 1-16). New York, NY: Palgrave Macmillan.

Caprio, J. M., \& Quamme, H. A. (2002). Weather conditions associated with grape production in the Okanagan Valley of British Columbia and potential impacts of climate change. Canadian Journal of Plant Science, 82(4), 755-763.

Carter, T. P., Marry, M. L., Harasawa, H., \& Nishioka, N. (1994). IPCC Technical Guidelines for Assessing Climate Change Impacts and Adaptations. London, England: University College London Press.

Cash, D. W., Clark, W. C., Alcock, F., Dickson, N. M., Eckley, N., Guston, D. H., . . . Mitchell, R. B. (2003). Knowledge systems for sustainable development. Proceedings of the National Academy of Sciences of the United States of America, 100(14), 8086-8091.

Chappell, P. R. (2013). The climate and weather of Hawke's Bay (3rd ed.). Auckland, New Zealand: NIWA Science and Technology.

Chappell, P. R. (2016). The climate and weather of Marlborough (2nd ed.). Auckland, New Zealand: NIWA Science and Technology.

Chevet, J.-M., Lecocq, S., \& Visser, M. (2011). Climate, grapevine phenology, wine production, and prices: Pauillac (1800-2009). American Economic Review: Papers and Proceedings, 101(3), 142-146.

Chuine, I., Yiou, P., Seguin, B., Daux, V., \& Laudurie, E. L. R. (2004). Historical phenology: grape ripening as a past climate indicator. Nature, 432(7015), 289290.

Church, J. A., Clark, P. U., Cazenave, A., Gregory, J. M., Jevrejeva, S., Levermann, A., . . Unnikrishnan, A. S. (2013). Sea Level Change. In T. F. Stocker, D. Qin, G.-K. 
Plattner, M. Tignor, S. K. Allen, J. Boschung, A. Nauels, Y. Xia, V. Bex, \& P. M. Midgley (Eds.), Climate Change 2013: The Physical Science Basis. Contribution of Working Group I to the Fifth Assessment Report of the Intergovernmental Panel on Climate Change. Cambridge, England: Cambridge University Press.

Conde, C., Silva, P., Fontes, N., Dias, A. C. P., Tavares, R. M., Sousa, M. J., . . . Gerós, H. (2007). Biochemical changes throughout grape berry development and fruit and wine quality. Food, 1(1), 1-22.

Coombe, B. G., \& Iland, P. (2004). Grape berry development and winegrape quality. In P. R. Dry \& B. G. Coombe (Eds.), Viticulture (2 ed., pp. 210-248). Adelaide, Australia: Winetitles.

Coriolis. (2014). iFAB 2013 Beverages Review. Retrieved from Auckland, New Zealand: http://www.mbie.govt.nz/info-services/sectors-industries/foodbeverage/documents-image-library/Beverages sector review 2013 -PDF 2 MB.pdf

Cormode, L., \& Hughes, A. (1999). The economic geographer as a situated researcher of elites. Geoforum, 30(4), 299-300.

Creswell, J. W. (2014). Research Design: Qualitative, Quantitative, \& Mixed Methods Approaches (4th ed.). London, England: Sage Publications.

Dessai, S., Hulme, M., Lempert, R., \& Pielke Jr., R. (2009). Climate prediction: a limit to adaptation? In W. N. Adger, I. Lorenzoni, \& K. L. O'brien (Eds.), Adapting to climate change: Thresholds, values, governance. Cambridge, England: Cambridge University Press.

Destremau, K. (2015). Economic contribution of the New Zealand wine sector (2015). Wellington, New Zealand: New Zealand Institute of Economic Research.

Diffenbaugh, N. S., White, M. A., Jones, G., \& Ashfaq, M. (2011). Climate adaptation wedges: a case study of premium wine in the western United States. Environmental Research Letters, 6(2), 1-11.

Dillman, D. A. (2000). Mail and internet surveys: the tailored design method (2nd ed.). New York, NY: Wiley \& Sons.

Dougherty, P. (2012). Introduction to the Geographical Study of Viticulture and Wine Production. In P. Dougherty (Ed.), The Geography of Wine. Dordrecht, Netherlands: Springer.

Dovers, S. (2009). Normalizing adaptation. Global Environmental Change, 19(1), 4-6. 
Duchêne, E., \& Schneider, C. (2005). Grapevine and climatic changes: a glance at the situation in Alsace. Agronomy for Sustainable Development, 25(1), 93-99.

Eisenack, K., Moser, S. C., Hoffmannn, E., Klein, R. J., Oberlack, C., Pechan, A., . . Termeer, C. (2014). Explaining and overcoming barriers to climate change adaptation. Nature Climate Change, 4(10), 867-872.

Ekstrom, J. A., Moser, S. C., \& Torn, M. (2010). Barriers to Adaptation: A Diagnostic Framework. Sacramento, CA: California Energy Commission.

Elwood, S. A., \& Martin, D. G. (2000). "Placing" Interviews: Location and Scales of Power in Qualitative Research. The Professional Geographer, 52(4), 649-657.

Evaldo Fensterseifer, J. (2007). The emerging Brazilian wine industry: challenges and prospects for the Serra Gaúcha wine cluster. International Journal of Wine Business Research, 19(3), 187-206.

FAO. (2015). Climate Change and Food Security: Risks and Responses. Rome, Italy: Food Agricultural Organization of the United Nations.

FAO. (2016). The State of Food and Agriculture: Climate Change, Agriculture and Food Security. Rome, Italy: Food Agricultural Organization of the United Nations.

FAO. (2017). The Future of Food and Agriculture: Trends and Challenges. Rome, Italy: Food Agricultural Organization of the United Nations.

Fleming, A., Park, S. E., \& Marshall, N. A. (2015). Enhancing adaptation outcomes for transformation: climate change in the Australian wine industry. Journal of Wine Research, 26(2), 99-114.

Ford, J. D., Berrang-Ford, L., \& Paterson, J. (2011). A systematic review of observed climate change adaptation in developed nations. Climatic Change, 106(2), 327336.

Frazier, J. W. (1981). Pragmatism: geography and the real world. In M. E. Harvey \& B. P. Holly (Eds.), Themes in Geographic Thought (pp. 61-72). London, England: Croom Helm.

Friedlingstein, P., \& Solomon, S. (2005). Contributions of past and present human generations to committed warming caused by carbon dioxide. Proceedings of the National Academy of Sciences of the United States of America, 102(31), 10832-10836. 
Gabzdylova, B., Raffensperger, J. F., \& Castka, P. (2009). Sustainability in the New Zealand wine industry: drivers, stakeholders and practices. Journal of Cleaner Production, 17(11), 992-998. doi:10.1016/j.jclepro.2009.02.015

Galbreath, J. (2011). Study explores climate change responses. The Australian and New Zealand Grapegrower and Winemaker, 565, 54-56.

Galbreath, J. (2012). Climate change and the Tasmanian Wine Cluster. Grapegrower and Winemaker, 584, 82-84.

Gillett, N. P., Thompson, D. W. J., Kell, T. D., \& Jones, P. D. (2006). Regional climate impacts of the Southern Annular Mode. Geophysical Research Letters, 33, L23704.

Gladstones, J. (1992). Viticulture and Environment. Adelaide, Australia: Winetitles.

Gladstones, J. (2004). Climate and Australian Viticulture. In P. Dry \& B. G. Coombe (Eds.), Viticulture Volume 1- Resources. Adelaide, Australia: Winetitles.

Godden, P., \& Gishen, M. (2005). Trends in the composition of Australian wine. Australian \& New Zealand Wine Industry Journal, 20(5), 21-46.

Gordon, N. D. (1986). The Southern Oscillation and New Zealand weather. Monthly Weather Review, 114, 371-387.

Green, J. A., Parr, W. V., Breitmeyer, J., Valentin, D., \& Sherlock, R. (2011). Sensory and chemical characterisation of Sauvignon blanc wine: Influence of source of origin. Food Research International, 44(9), 2788-2797.

Gunderson, L., \& Holling, C. S. (2002). Panarchy: Understanding Transformations in Systems of Humans and Nature. Washington, DC: Island Press.

Hadarits, M., Smit, B., \& Diaz, H. (2010). Adaptation in viticulture: A case study of producers in the Maule region of Chile. Journal of Wine Research, 21(2-3), 167178.

Hagen, K. M., Keller, M., \& Edwards, C. G. (2008). Survey of biotin, pantothenic acid, and assimilable nitrogen in wine grapes from the Pacific Northwest. American Journal of Enology and Viticulture, 59(4), 432-436.

Hall, A., \& Jones, G. V. (2009). Effect of potential atmospheric warming on temperature-based indices describing Australian winegrape growing conditions. Australian Journal of Grape and Wine Research, 15(2), 97-119.

Hannah, L., Roehrdanz, P. R., Ikegami, M., Shepard, A. V., Shaw, M. R., Tabor, G., . . Hijmans, R. J. (2013). Climate change, wine, and conservation. Proceedings of 
the National Academy of Sciences of the United States of America, 110(17), 6907-6912.

Haselgrove, L., Botting, D., Van Heeswijck, R., Hoj, P. B., Dry, P. R., Ford, C., \& Iland, P. G. (2000). Canopy microclimate and berry composition: the effect of bunch exposure on the phenolic composition of Vitis vinifera L. cV. Shiraz grape berries. Australian Journal of Grape and Wine Research, 6(2), 141-149.

Hay, I. (2010). Qualitative Research Methods in Human Geography. Oxford, England: Oxford University Press.

Hendon, H. H., Thompson, D. W. J., \& Wheeler, M. C. (2007). Australian rainfall and surface temperature variations associated with the Southern Hemisphere Annular Mode. Journal of Climate, 20(11), 2452-2467.

Holland, T., \& Smit, B. (2010a). Climate Change and the Wine Industry: Current Research Themes and New Directions. Journal of Wine Research, 21(2-3), 125136.

Holland, T., \& Smit, B. (2010b). An Emerging Agenda for Wine Industry Research: Vulnerability to Climate Change. American Journal of Enology and Viticulture, 61(3), 438A-438A.

Huglin, P. (1978). Noveau mode d'évaluation des possibilités héliothermiques d'un milieu viticole.

Ignaciuk, A. (2015). Adapting Agriculture to Climate Change: A Role for Public Policies. OECD Publishing: Paris, France.

Imre, S. P. I., \& Mauk, J. L. (2009). Geology and Wine 12. New Zealand Terroir. Geoscience Canada, 36(4), 145-159.

IPCC. (2014a). Climate Change 2014: Synthesis Report. Contribution of Working Groups I, II and III to the Fifth Assessment Report of the Intergovernmental Panel on Climate Change. Geneva, Switzerland: Intergovernmental Panel on Climate Change.

IPCC. (2014b). Summary for policymakers Climate Change 2014: Impacts, Adaptations, and Vulnerability. Part A: Global and Sectoral Aspects. Contribution of Working Group II to the Fifth Assessment Report of the Intergovernmental Panel on Climate Change (pp. 1-32). Cambridge, England: Cambridge University Press. Jackson, D., \& Schuster, D. (2001). The Production of Grapes and Wine in Cool Climates. Wellington, New Zealand: Gypsum Press and Daphne Brassell Associates Ltd. 
Jasanoff, S. (2004). States of knowledge: the co-production of science and the social order. London, England: Routledge.

Jay, T., \& Taylor, M. (2013). A case of champagne: a study of geographical indications. Corporate Governance eJournal, 29, 1-31.

Johnson, R. B., \& Onwuegbuzie, A. J. (2004). Mixed methods research: A research paradigm whose time has come. Educational Researcher, 33(7), 14-26.

Jones, G. V. (2006a). Climate and terroir: Impacts of climate variability and change on wine. In R. W. Macqueen \& L. D. Meinert (Eds.), Fine wine and terroir - the geoscience perspective. St. John's, Newfoundland: Geological Association of Canada.

Jones, G. V. (2006b). Climate change and wine: observations, impacts and future implications. Wine Industry Journal, 21(4), 21-26.

Jones, G. V. (2007a). Climate Change and the global wine industry. Paper presented at the Australian Wine Industry Technical Conference, Adelaide, Australia.

Jones, G. V. (2007b). Climate change: observations, projections, and general implications for viticulture and wine production. Paper presented the Conference on Global Warming: What Potential Impacts on the Vineyards?, Beaune, France.

Jones, G. V., \& Alves, F. (2012). Impact of climate change on wine production: a global overview and regional assessment in the Douro Valley of Portugal. International Journal of Global Warming, 4(3-4), 383-406.

Jones, G. V., \& Davis, R. E. (2000). Climate influences on grapevine phenology, grape composition, and wine production and quality for Bordeaux, France. American Journal of Enology and Viticulture, 51(3), 249-261.

Jones, G. V., Duchêne, E., Tomasi, D., Yuste, J., Braslavska, O., Schultz, H., . . . Guimberteau, G. (2005). Changes in European winegrape phenology and relationships with climate. Paper presented at the XIV International GESCO Viticulture Congress, Geisenheim, Germany.

Jones, G. V., Duff, A. A., Hall, A., \& Myers, J. (2010). Spatial analysis of climate in winegrape growing regions in the western United States. American Journal of Enology and Viticulture, 61(3), 313-326. 
Jones, G. V., \& Goodrich, G. B. (2008). Influence of climate variability on wine regions in the western USA and on wine quality in the Napa Valley. Climate Research, 35(3), 241-254.

Jones, G. V., Reid, R., \& Vilks, A. (2012). Climate, Grapes, and Wine: Structure and Suitability in a Variable and Changing Climate. In P. H. Dougherty (Ed.), The Geography of Wine: Regions, Terroir and Techniques (pp. 109-133). Dordrecht, Netherlands: Springer.

Jones, G. V., \& Storchmann, K. (2001). Wine market prices and investment under uncertainty: an econometric model for Bordeaux Crus Classés. Agricultural Economics, 26(2), 115-133.

Jones, G. V., White, M. A., Cooper, O. R., \& Storchmann, K. (2005). Climate change and global wine quality. Climatic Change, 73(3), 319-343.

Keller, M. (2010). Managing grapevines to optimise fruit development in a challenging environment: a climate change primer for viticulturists. Australian Journal of Grape and Wine Research, 16, 56-69.

Kennison, K. R., Gibberd, M., Pollnitz, A. P., \& Wilkinson, K. L. (2008). Smoke-derived taint in wine: the release of smoke-derived volatile phenols during fermentation of Merlot juice following grapevine exposure to smoke. Journal of Agricultural and Food Chemistry, 56(16), 7379-7383.

Kitchen, R., \& Tate, N. J. (2013). Conducting Research in Human Geography: Theory, Methodology \& Practice. New York, NY: Routledge.

Klein, R. J. T., Midgley, G. F., Preston, B. L., Alam, M., Berkhout, F. G. H., Dow, K., \& Shaw, M. R. (2014). Adaptation opportunities, constraints, and limits. In C. B. Field, V. R. Barros, D. J. Dokken, K. J. Mach, M. D. Mastrandrea, T. E. Bilir, M. Chatterjee, E. L. Ebi, Y. O. Estrada, R. C. Genova, B. Girma, E. S. Kissel, A. N. Levy, S. MacCracken, P. R. Mastrandrea, \& L. L. White (Eds.), Climate Change 2014: Impacts, Adaptation, and Vulnerability. Part A: Global and Sectoral Aspects. Contribution of Working Group II to the Fifth Assessment Report of the Intergovernmental Panel on Climate Change (pp. 899-943). Cambridge, England: Cambridge University Press.

Kliewer, W. M. (1977). Effect of high temperatures during the bloom-set period on fruit set, ovule fertility, and berry growth of several grape cultivars. American Journal of Enology and Viticulture, 28(2), 215-222. 
Lereboullet, A.-L., Beltrando, G., \& Bardsley, D. K. (2013a). Assessing vulnerability and framing adaptive options of two Mediterranean wine growing regions facing climate change: Roussillon (France) and McLaren Vale (Australia). EchoGéo, 23. Lereboullet, A.-L., Beltrando, G., \& Bardsley, D. K. (2013b). Socio-ecological adaptation to climate change: A comparative case study from the Mediterranean wine industry in France and Australia. Agriculture Ecosystems \& Environment, 164, 273-285.

Lereboullet, A.-L., Beltrando, G., Bardsley, D. K., \& Rouvellac, E. (2014). The viticultural system and climate change: coping with long-term trends in temperature and rainfall in Roussillon, France. Regional Environmental Change, 14(5), 19511966.

Limb, M., \& Dwyer, C. (2001). Qualitative methodologies for geographers: Issues and debates. London, England: Arnold.

Macara, G. R. (2015). The climate and weather of Otago (3rd ed.). Auckland, New Zealand: NIWA Science and Technology.

Malheiro, A. C., Santos, J. A., Fraga, H., \& Pinto, J. G. (2010). Climate change scenarios applied to viticultural zoning in Europe. Climate Research, 43(3), 163-177.

Manderson, L., Bennett, E., \& Andajani-Sutjahjo, S. (2006). The Social Dynamics of the Interview: Age, Class, and Gender. Qualitative Health Research, 16(10), 13171334.

Marx, W., Haunschild, R., \& Bornmann, L. (2017). Climate change and viticulture - a quantitative analysis of a highly dynamic research field. Vitis, 56(1), 35-43.

Mastrandrea, M. D., Heller, N. E., Root, T. L., \& Schneider, S. H. (2010). Bridging the gap: linking climate-impacts research with adaptation planning and management. Climatic Change, 100(1), 87-101.

Mayer, A. (2013). Climate Change Already Challenging Agriculture: Wine and coffee producers respond to hotter, drier conditions. BioScience, 63(10), 781-787.

McCarthy, M. D., Jones, L. D., \& Due, G. (1992). Irrigation-principles and practices. In B. G. Coombe \& P. Dry (Eds.), Viticulture (Vol. 2: Practices, pp. 104-128). Adelaide, Australia: Winetitles.

Measham, T. G., Preston, B. L., Smith, T. F., Brooke, C., Gorddard, R., Withycombe, G., \& Morrison, C. (2011). Adapting to climate change through local municipal 
planning: barriers and challenges. Mitigation and Adaptation Strategies for Global Change, 16(8), 889-909.

Ministry for Primary Industries. (2017). Lighter Wines. Retrieved from https://www.mpi.govt.nz/funding-and-programmes/primary-growthpartnership/primary-growth-partnership-programmes/lighter-wines/ Ministry of Business Innovation and Employment. (2018a). Geographical indications. Retrieved from https://www.iponz.govt.nz/about-ip/geographical-indications/ Ministry of Business Innovation and Employment. (2018b). Geographical indications register. Retrieved from https://www.iponz.govt.nz/about-ip/geographicalindications/register/?location=nz\&sort=north-to-south

Mira de Orduña, R. (2010). Climate change associated effects on grape and wine quality and production. Food Research International, 43(7), 1844-1855.

Mohammad, R. (2001). Insiders and/or outsiders: Positionality, theory and practice. In M. Limb \& C. Dwyer (Eds.), Qualitative methods for geographers: Issues and debates (pp. 101-117). London, England: Arnold.

Moran, W. (2006). Crafting terroir: people in cool climates, soils and markets. Paper presented at the Sixth International Cool Climate Symposium for Viticulture and Oenology, Christchurch, New Zealand.

Moran, W. (2016). New Zealand Wine: The Land, the Vines, the People. Auckland, New Zealand: Auckland University Press.

Moriondo, M., Jones, G. V., Bois, B., Dibari, C., Ferrise, R., Trombi, G., \& Bindi, M. (2013). Projected shifts of wine regions in response to climate change. Climatic Change, 119(3-4), 825-839.

Moser, S. C. (2009). Whether our levers are long enough and the fulcrum strong? Exploring the soft underbelly of adaptation decisions and actions. In W. N. Adger, I. Lorenzoni, \& K. L. O’Brien (Eds.), Adapting to Climate Change: Thresholds, Values, and Governance (pp. 313-334). Cambridge, England: Cambridge University Press.

Moser, S. C., \& Ekstrom, J. A. (2010). A framework to diagnose barriers to climate change adaptation. Proceedings of the National Academy of Sciences, 107(51), 22026-22031. 
Moser, S. C., \& Luers, A. L. (2008). Managing climate risks in California: the need to engage resource managers for successful adaptation to change. Climatic Change, 87(1), 309-322.

Mozell, M., R., \& Thach, L. (2014). The impact of climate change on the global wine industry: Challenges and solutions. Wine Economics and Policy, 3(2), 81-89.

Mullings, B. (1999). Insider or outsider, both or neither: some dilemmas of interviewing in a cross-cultural setting. Geoforum, 30(4), 337-350.

Nemani, R. R., White, M. A., Cayan, D. R., Jones, G. V., Running, S. W., Coughlan, J. C., \& Peterson, D. L. (2001). Asymmetric warming over coastal California and its impact on the premium wine industry. Climate Research, 19(1), 25-34.

New Zealand Wine. (2017a). Central Otago. Retrieved from https://www.nzwine.com/en/our-regions/central-otago/

New Zealand Wine. (2017b). Discover our regions. Retrieved from https://www.nzwine.com/en/our-regions/

New Zealand Wine. (2017c). Hawke's Bay. Retrieved from https://www.nzwine.com/en/our-regions/hawkes-bay/

New Zealand Wine. (2017d). Marlborough. Retrieved from https://www.nzwine.com/en/our-regions/marlborough/

New Zealand Wine. (2017e). New Zealand Wine - Small Beginnings to the Global Stage. Retrieved from https://www.nzwine.com/en/news-media/new-zealand-winesmall-beginnings-to-the-global-stage/

New Zealand Wine. (2017f). Sauvignon Blanc. Retrieved from https://www.nzwine.com/en/our-winestyles/sauvignon-blanc/

New Zealand Wine. (2017g). Sustainable Winegrowing NZ. Retrieved from https://www.nzwine.com/en/sustainability/sustainable-winegrowing-nz/ New Zealand Wine. (2017h). Winestyles. Retrieved from https://www.nzwine.com/en/our-winestyles/ New Zealand Winegrowers. (2017). Annual Report 2017 (N. Z. W. Asscociation Ed.). Auckland, New Zealand: New Zealand Winegrowers Association.

Nicholas, K. A., \& Durham, W. H. (2012). Farm-scale adaptation and vulnerability to environmental stresses: Insights from winegrowing in Northern California. Global Environmental Change-Human and Policy Dimensions, 22(2), 483-494. 
NIWA. (2007). IPCC identifies climate change impacts \& vulnerability for New Zealand. Retrieved from https://www.niwa.co.nz/news/ipcc-identifies-climate-changeimpacts-vulnerability-new-zealand

O'Brien, G., O'Keefe, P., Rose, J., \& Wisner, B. (2006). Climate change and disaster management. Disaster, 30(1), 64-80.

OECD. (2015). The Economic Consequences of Climate Change. Paris, France: OECD Publishing.

Park, S. E., Marshall, N. A., Jakku, E., Dowd, A. M., Howden, S. M., Mendham, E., \& Fleming, A. (2012). Informing adaptation responses to climate change through theories of transformation. Global Environmental Change-Human and Policy Dimensions, 22(1), 115-126.

Parr, W. V., Green, J. A., White, K. G., \& Sherlock, R. R. (2007). The distinctive flavour of New Zealand Sauvignon blanc: Sensory characterisation by wine professionals. Food Quality and Preference, 18(6), 849-861.

Parr, W. V., Sherlock, R. R., \& Green, J. A. (2007). The importance of green: Sensory and chemical analyses of New Zealand Sauvignon blanc. The Australian \& New Zealand Grapegrower \& Winemaker, 35, 62-68.

Pearson, L. J., Nelson, R., Crimp, S., \& Langridge, J. (2011). Interpretive review of conceptual frameworks and research models that inform Australia's agricultural vulnerability to climate change. Environmental Modelling \& Software, 26(2), 113-123.

Pelling, M. (2010). Adaptation to climate change: from resilience to transformation. London, England: Routledge.

Pereira, G. E., Gaudillere, J. P., van Leeuwen, C., Hilbert, G., Maucourt, M., Deborde, C., ... Rolin, D. (2006). 1H NMR metabolite fingerprints of grape berry: comparison of vintage and soil effects in Bordeaux grapevine growing areas. Analytica Chimica Acta, 563(1-2), 346-352.

Pincus, R. (2003). Wine, place and identity in a changing climate. Gastronomica, 3(1), 87-93.

Plant and Food Research. (2013). Distinctive flavours and sustainably produced wines for premium markers. Retrieved from https://www.plantandfood.co.nz/growingfutures/wine 
Porter, J. R., Xie, L., Challinor, A. J., Cochrane, K., Howden, S. M., Iqbal, M. M., . . Travasso, M. I. (2014). Food security and food production systems. In C. B. Field, V. R. Barros, D. J. Dokken, K. J. Mach, M. D. Mastrandrea, T. E. Bilir, M. Chatterjee, K. L. Ebi, Y. O. Estrada, R. C. Genova, B. Girma, E. S. Kissel, A. N. Levy, S. MacCracken, P. R. Mastrandrea, \& L. L. White (Eds.), Climate Change 2014: Impacts, Adaptation, and Vulnerability. Part A: Global and Sectoral Aspects. Contribution of Working Group II to the Fifth Assessment Report of the Intergovernmental Panel on Climate Change (pp. 485-533). Cambridge, England: Cambridge University Press.

Possingham, J. V. (2004). On the growing of grapevines in the tropics. Acta Horticulturae, 662, 39-44.

Rayne, S., Forest, K., \& Friesen, K. J. (2009). Projected climate change impacts on grape growing in the Okanagan Valley, British Columbia. Nature Proceedings. doi:10.1038/npre.2011.3162.2

Renn, O. (2008). Risk Governance: Coping with Uncertainty in a Complex World. London, England: Earthscan.

Rickards, L., \& Howden, M. (2012). Transformational adaptation: agriculture and climate change. Crop and Pasture Science, 63(3), 240-250.

Rodó, X., \& Comín, F. A. (2000). Links between large-scale anomalies, rainfall and wine quality in the Iberian Peninsula during the last three decades. Global Change Biology, 6(3), 267-273.

Rose, G. (1997). Situating knowledge: positionality, reflexivities and other tactics. Progress in Human Geography, 21(3), 305-320.

Rossman, G. B., \& Wilson, B. L. (1985). Numbers and words: Combining quantitative and qualitative methods in a single large-scale evaluation study. Evaluation Review, 9(5), 627-643.

Santisi, J. (2011). Warming up the wine industry. E: Environmental Magazine, 22(6), 1517.

Scheider, P. P. (2014). Local reality and the climate change adaptation dilemma: Beyond technical fixes and 'business as usual'. (Doctor of Philosophy), Massey University, Manawatu, New Zealand.

Schneider, S. H., \& Lane, J. (2006). Dangers and Thresholds in Climate Change and the Implications for Justice. In W. N. Adger, J. Paavola, S. Huq, \& M. J. Mace (Eds.), 
Fairness in Adaptation to Climate Change (pp. 23-52). London, England: The MIT Press.

Schneider, S. H., \& Thompson, S. L. (1985). Future Changes in the Atmosphere. In R. Repetto (Ed.), The Global Possible (pp. 363-430). New Haven, CT: Yale University Press.

Schultz, H. R. (2000). Climate change and viticulture: A European perspective on climatology, carbon dioxide and UV-B effects. Australian Journal of Grape and Wine Research, 6(1), 2-12.

Schultz, H. R., \& Jones, G. V. (2010). Climate Induced Historic and Future Changes in Viticulture. Journal of Wine Research, 21(2-3), 137-145.

Schultz, H. R., \& Lebon, E. (2005). Modelling the effect of climate change on grapevine water relations. Paper presented at the Proceedings of the 7th International Symposium on Grapevine Physiology and Biotechnology, Leuven, Belgium.

Schultz, H. R., \& Stoll, M. (2010). Some critical issues in environmental physiology of grapevines: future challenges and current limitations. Australian Journal of Grape and Wine Research, 16, 4-24.

Seguin, B., \& de Cortazar, I. G. (2005). Climate warming: Consequences for viticulture and the notion of 'terroirs' in Europe. Acta Horticulturae, 689, 61-69.

Shanmuganathan, S., Narayanan, A., \& Sallis, P. (2012). Climate Change and Grape Wine Quality: A GIS Approach to Analysing New Zealand Wine Regions. In N. Chhetri (Ed.), Human and Social Dimensions of Climate Change (pp. 227-242). London, England: InTech.

Sharma, J., Upadhyay, A. K., Adsule, P. G., Sawant, S. D., Sharma, A. K., Satisha, J., . . . Ramteke, S. D. (2013). Effect of climate change on grape and its value-added products. In H. Singh, N. Rao, \& K. Shivashankar (Eds.), Climate-Resilient Horticulture: Adaptation and Mitigation Strategies (pp. 67-80). New Delhi, India: Springer.

Sheehan, K. B. (2006). E-mail survey response rates: A Review. Journal of ComputerMediated Communication, 6(2), 0.

Sluys, S. L. (2006). Climatic influences on the grapevine: A study of viticulture in the Waipara Basin. (Master of Science in Geography), University of Canterbury, Christchurch, New Zealand. 
Smit, B., Burton, I., Klein, R. J., \& Wandel, J. (2000). An anatomy of adaptation to climate change and variability. In S. M. Kane \& G. Yohe, W. (Eds.), Societal Adaptation to Climate Variability and Change (pp. 223-251). Dordrecht, Netherlands: Springer.

Smit, B., \& Pilofosova, O. (2003). From adaptation to adaptive capacity and vulnerability reduction. In J. B. Smith, R. J. T. Klein, \& S. Huo (Eds.), Climate change, Adaptive Capacity and Development (pp. 85-114). London, England: Imperial College Press.

Spayd, S. E., Tarara, J. M., Mee, D. L., \& Ferguson, J. C. (2002). Separation of sunlight and temperature effects on the composition of Vitis vinifera cv. Merlot berries. American Journal of Enology and Viticulture, 53(3), 171-182.

Stock, M., Gerstengarbe, F. W., Kartschall, T., \& Werner, P. C. (2005). Reliability of climate change impact assessments for viticulture. In L. E. Williams (Ed.), Proceedings of the Seventh International Symposium on Grapevine Physiology and Biotechnology (pp. 29-40).

Storchmann, K. (2005). English weather and Rhine wine quality: An ordered probit model. Journal of Wine Research, 26(2), 105-120.

Sturman, A., \& Quénol, H. (2013). Changes in atmospheric circulation and temperature trends in major vineyard regions of New Zealand. International Journal of Climatology, 33(12), 2609-2621.

Sturman, A., Zawar-Reza, P., Soltanzadeh, I., Katurji, M., Bonnardot, V., Parker, A. K., . . . Schulmann, T. (2017). The application of high-resolution atmospheric modelling to weather and climate variability in vineyard regions. Oeno One, 51(2), 99-105. doi:10.20870/oeno-one.2016.0.0.1538

Sue, V. M., \& Ritter, L. A. (2012). Conducting online surveys (2nd ed.). Thousand Oaks, CA: SAGE Publications Ltd.

Suri, H. (2011). Purposeful sampling in qualitative research synthesis. Qualitative Research Journal, 11(2), 63-75.

Tarrant, A. (2013). Negotiating Multiple Positionalities in the Interview Setting: Researching Across Gender and Generational Boundaries. The Professional Geographer, 66(3), 493-500.

Tate, A. B. (2001). Global Warming's Impact on Wine. Journal of Wine Research, 12(2), 95-109. 
Tatem, A. J. (2005). Global climate matching: satellite imagery as tool for mapping vineyard suitability. Journal of Wine Research, 16(1), 19-31.

Teye, J. K. (2012). Benefits, challenges, and dynamism of positionalities associated with mixed methods research in developing countries: evidence from Ghana. Journal of Mixed Methods Research, 6(4), 379-391.

Thompson, D., \& Forbes, S. L. (2011). Going 'green' to find 'gold' in wine: a case study of a sustainable New Zealand wine producer. Paper presented at the 6th International Conference of the Academy of Wine Business Research, Bordeaux, France.

Tomasi, D., Jones, G. V., Giust, M., Lovat, L., \& Gaiotti, F. (2011). Grapevine Phenology and Climate Change: Relationships and Trends in the Veneto Region of Italy for 1964-2009. American Journal of Enology and Viticulture, 62(3), 329-339.

Tribbia, J., \& Moser, S. C. (2008). More than information: What coastal manager need to plan for climate change. Environmental Science \& Policy, 11(4), 315-328.

Tripathi, A., \& Mishra, A. K. (2017). Knowledge and passive adaptation to climate change: An example from Indian farmers. Climate Risk Management, 16, 195207.

UNFCCC. (2009a). Decision 2/CP. 15. Copenhagen Accord. Copenhagen: The United Nations Retrieved from https://unfccc.int/resource/docs/2009/cop15/eng/11a01.pdf.

UNFCCC. (2009b). Part Two: Decisions Adopted by the Conference of Parties. Paper presented at the Report on the Conference of Parties on its fifteenth session, Copenhagen, Denmark.

van Leeuwen, C., \& Darriet, P. (2016). The Impact of Climate Change on Viticulture and Wine Quality. Journal of Wine Economics, 11(1), 150-167.

Vaudour, E., \& Shaw, A. B. (2005). A worldwide perspective on viticultural zoning. South African Journal for Enology and Viticulture, 26(2), 117-141.

Vermeulen, S. J., Challinor, A. J., Thornton, P. K., Campbell, B. M., Eriyagama, N., Vervoort, J. M., . . Smith, D. R. (2013). Addressing uncertainty in adaptation planning for agriculture. Proceedings of the National Academy of Sciences, 110(21), 8357-8362.

Vierra, G. (2004). Pretenders at the table - are table wines no longer food friendly? Wine Business Monthly, 11, 14-21. 
Vink, N., Deloire, A., Bonnardot, V., \& Ewert, J. (2009). Terroir, Climate Change, and the Future of South Africa's Wine Industry. Retrieved from Adelaide, Australia: https://www.adelaide.edu.au/wineecon/events/2030workshop/pubs/Vink_WC0210.pdf

Vogel, C., Moser, S. C., Kasperson, R. E., \& Dabelko, G. D. (2007). Linking vulnerability, adaptation, and resilience science to practice: Pathways, players, and partnerships. Global Environmental Change, 17(3-4), 349-364.

Wandel, J., \& Smit, B. (2000). Agricultural risk management in light of climate variability and change. In H. Milward, K. Beesley, B. Ilbery, \& L. Harrington (Eds.), Agricultural and Environmental Sustainability in the New Countryside (pp. 30-39). Winnipeg, Canada: Hignell Printing Limited.

Webb, L. B. (2006). The impact of projected greenhouse gas-induced climate change on the Australian wine industry. (PhD), University of Melbourne, Melbourne, Australia.

Webb, L. B., Clingeleffer, P. R., \& Tyerman, S. D. (2011). The Genetic Envelope of Winegrape Vines: Potential for Adaptation to Future Climate Challenges. In S. Yadav, S., R. J. Redden, J. Hatfield, L., H. Lotze-Campen, \& A. E. Hall (Eds.), Crop Adaptation to Climate Change (pp. 464-481). Oxford, England: John Wiley and Sons.

Webb, L. B., Whetton, P. H., \& Barlow, E. W. R. (2007). Modelled impact of future climate change on the phenology of winegrapes in Australia. Australian Journal of Grape and Wine Research, 13(3), 165-175.

Webb, L. B., Whetton, P. H., \& Barlow, E. W. R. (2008a). Climate change and winegrape quality in Australia. Climate Research, 36(2), 99-111.

Webb, L. B., Whetton, P. H., \& Barlow, E. W. R. (2008b). Modelling the relationship between climate, winegrape price and winegrape quality in Australia. Climate Research, 36(2), 88-98.

Webb, L. B., Whiting, J., Watt, A., Wigg, F., Dunn, G., Needs, S., \& Barlow, E. W. R. (2010). Managing Grapevines through Severe Heat: A Survey of Growers after the 2009 Summer Heatwave in South-eastern Australia. Journal of Wine Research, 21(2-3), 147-165.

White, M. A., Diffenbaugh, N. S., Jones, G. V., Pal, J. S., \& Giorgi, F. (2006). Extreme heat reduces and shifts United States premium wine production in the 21st 
century. Proceedings of the National Academy of Sciences of the United States of America, 103(30), 11217-11222. doi:10.1073/pnas.0603230103

White, M. A., Whalen, P., \& Jones, G. V. (2009). Land and wine. Nature Geoscience, $2(2), 82-84$.

White, N. E., \& Buultjens, J. (2013). Climate Change Policy Responses of Australian and New Zealand National Governments. In M. V. Reddy \& K. Wilkes (Eds.), Tourism, Climate Change and Sustainability (pp. 117-132). Oxon, England: Routledge.

Wilson, H., \& Danne, K. M. (2017). Review of Ecologically-Based Pest Management in California Vineyards. Insects, 8(4), 108.

Winkler, A. J., Cook, J. A., Kliewer, W. M., \& Lider, L. A. (1974). General Viticulture (2nd ed.). Berkeley, CA: University of California Press.

Yin, R. K. (2014). Case Study Research: Design and Methods (5th ed.). Thousand Oaks, CA: SAGE Publications Ltd.

Zand, D. E. (1997). The Leadership Triad: Knowledge, Trust and Power. Oxford, England: Oxford University Press. 


\section{APPENDIX A}

New Zealand winegrape varieties and the total hectares of production.

Adapted from New Zealand Wine, (2017d).

\begin{tabular}{|l|c|}
\hline \multicolumn{1}{|c|}{ New Zealand Wine Styles } & Hectares \\
\hline Albariño & 27 \\
\hline Arneis & 33 \\
\hline Cabernet Sauvignon & 255.6 \\
\hline Chardonnay & $3,119.1$ \\
\hline Chenin Blanc & 22 \\
\hline Gamay Noir & 8 \\
\hline Gewürztraminer & 226 \\
\hline Grüner Veltliner & 46 \\
\hline Merlot & 1,204 \\
\hline Montepulciano & 9 \\
\hline Pinotage & 25 \\
\hline Pinot Blanc & 11 \\
\hline Pinot Gris & 2,458 \\
\hline Pinot Noir & 5,519 \\
\hline Riesling & 752 \\
\hline Sangiovese & 8 \\
\hline Sauvignon Blanc & 21,400 \\
\hline Sauvignon Gris & 113 \\
\hline Semillon & 48 \\
\hline Syrah & 431 \\
\hline Tempranillo & 20 \\
\hline Verdelho & 719 \\
\hline Viognier & \\
\hline
\end{tabular}




\section{APPENDIX B}

Human Ethics Committee Approval Letter Amendment

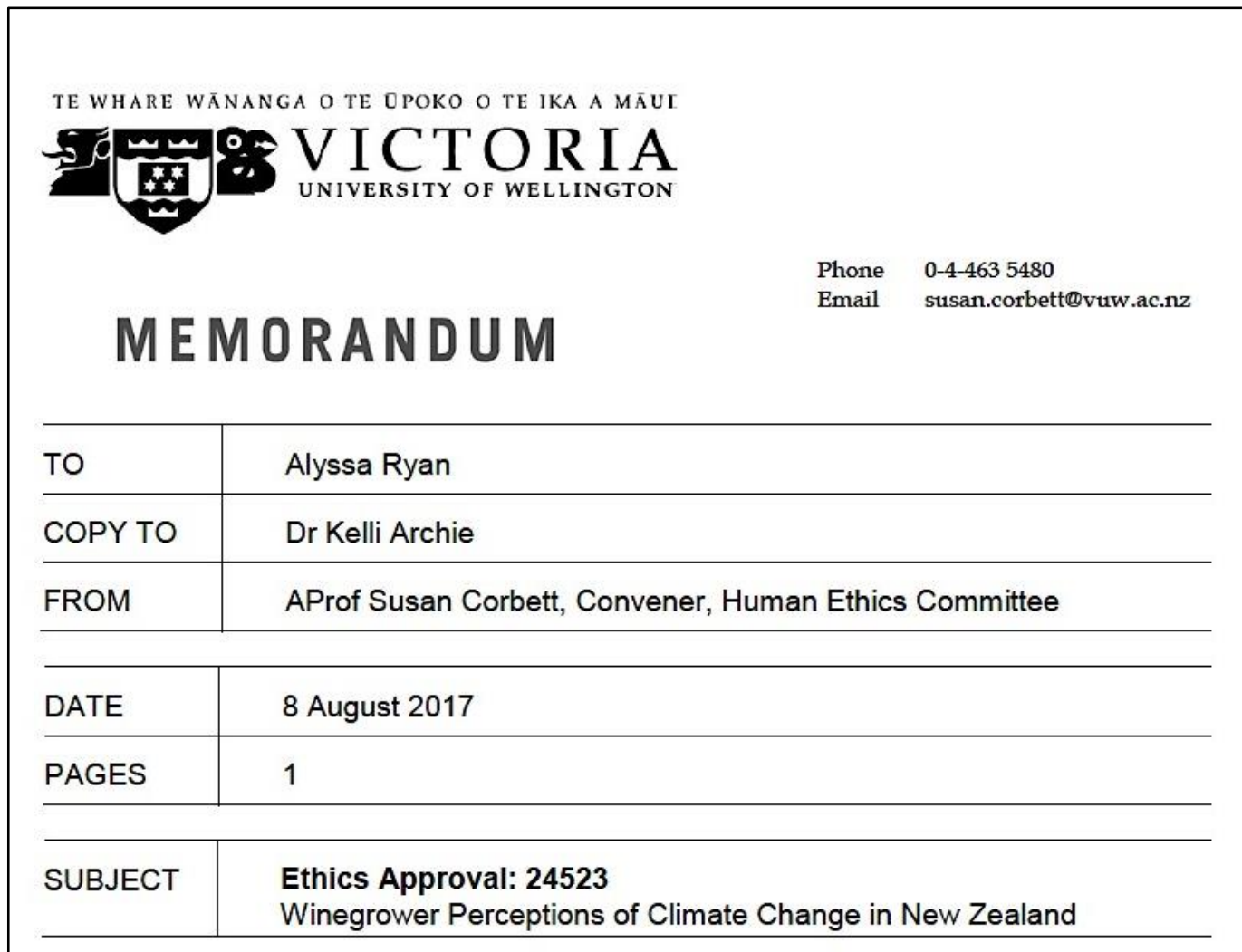

Thank you for your application for ethical approval, which has now been considered by the Standing Committee of the Human Ethics Committee.

Your application has been approved from the above date and this approval continues until 1 September 2018. If your data collection is not completed by this date you should apply to the Human Ethics Committee for an extension to this approval.

Best wishes with the research.

Kind regards

Susan Corbett

Convener, Victoria University Human Ethics Committee 


\section{APPENDIX C}

Human Ethics Committee Approval Letter Original

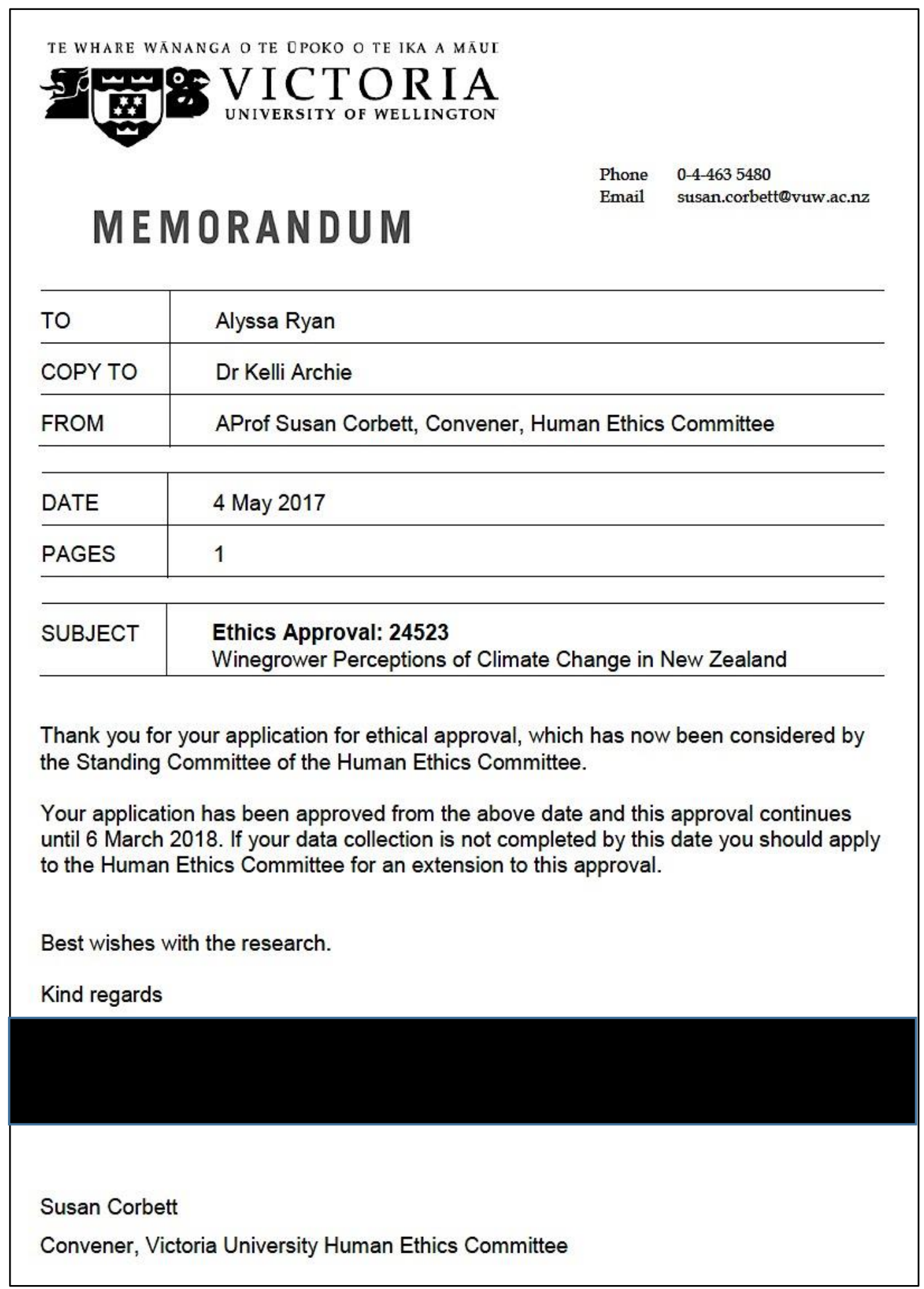




\section{APPENDIX D}

\section{Survey Information Sheet}

\section{Winegrower Perceptions of Climate Change in New Zealand}

\section{INFORMATION SHEET FOR PARTICIPANTS}

Thank you for your interest in this project. Please read this information before deciding whether or not to take part. Thank you in advance for considering my request.

\section{Who am I?}

My name is Alyssa Ryan and I am a Masters student in Environmental Studies at Victoria University of Wellington. This research project is work towards my thesis.

\section{What is the aim of the project?}

This project aims to analyse perceptions of climate change in the New Zealand wine industry. Climate change may cause changes to regional growing conditions that would have significant impacts on wine production. This research seeks to explore the future capacity of the wine industry by evaluating winegrowers understanding of climate change and the possible adaptation strategies that can be used as a solution.

This research has been approved by the Victoria University of Wellington Human Ethics Committee. Application number: 0000024523. Ethics Approval: 24523.

\section{How can you help?}

If you agree to take part the survey will ask questions about your perceptions of the impacts of climate change and how the wine industry is responding. The survey will take approximately 15 minutes. Once you click into the survey, the information you provide will be used and as it is anonymous, the information provided cannot be withdrawn. However, you can stop the survey at any time, without giving a reason.

\section{What will happen to the information you give?}

This research is anonymous which means that the researchers named below will not be aware of your identity andyour identity will not be disclosed in any reports, presentations, publications or public documentation.

Only the researchers named here will have access to the survey data and the summaries will be kept securely and destroyed two years after the research concludes. 


\section{What will the project produce?}

The information from my research will be used in my Master thesis and will be published in an academic journal.

\section{If you accept this invitation, what are your rights as a research participant?}

You do not have to accept this invitation if you don't want to. If you do decide to participate, you have the right to:

- choose not to answer any question;

- be able to ask any questions about the study by emailing the researcher;

- be able to read any reports of this research by emailing the researcher to request a copy.

If you have any questions or problems, who can you contact?

If you have any questions, either now or in the future, please feel free to contact either:

Student:

Alyssa Ryan

Master in Environmental Studies

School of Geography, Environment and Earth Sciences

alyssa.ryan@vuw.ac.nz

\section{Supervisor:}

Kelli M. Archie, PhD

Thesis Supervisor

Climate Change Research Institute

School of Geography, Environment and Earth Sciences

044635058

kelli.archie@vuw.ac.nz

\section{Human Ethics Committee information}

If you have any concerns about the ethical conduct of the research you may contact the Victoria University HEC Convener: Associate Professor Susan Corbett. Email susan.corbett@vuw.ac.nz or telephone +64-4-463 5480. 


\section{APPENDIX E}

Interview Information Sheet

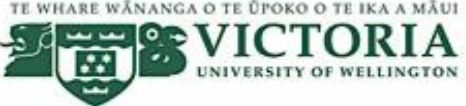

\section{Winegrower Perceptions of Climate Change in New Zealand}

\section{INFORMATION SHEET FOR PARTICIPANTS}

Thank you for your interest in this project. Please read this information before deciding whether or not to take part. Thank you in advance for considering my request.

Who am I?

My name is Alyssa Ryan and I am a Masters student in Environmental Studies at Victoria University of Wellington. This research project is work towards my thesis.

\section{What is the aim of the project?}

This project aims to analyse perceptions of climate change in the New Zealand wine industry. Climate change may cause changes to regional growing conditions that would have significant impacts on wine production. This research seeks to explore the future capacity of the wine industry by evaluating winegrowers understanding of climate change and the possible adaptation strategies that can be used as a solution.

This research has been approved by the Victoria University of Wellington Human Ethics Committee. Application number: 0000024523. Ethics Approval: 24523.

\section{How can you help?}

If you agree to take part, I will interview you either on the phone or at public location at your convenience. I will ask you questions about your perceptions of the impacts of climate change and how the wine industry is responding. The interview will take approximately 30 minutes and will be recorded and transcribed. You can stop the interview at any time, without giving a reason and you can withdraw from the study by contacting me at any point before $30^{\text {th }}$ September 2017. If you withdraw, the information you provided will be destroyed or returned to you.

\section{What will happen to the information you give?}

This research is confidential which means that the researchers named below will be aware of your identity but the interview data will be aggregated and your identity will not be disclosed in any reports, presentations, publications or public documentation. 
Only the researchers named here will have access to the interview data and all transcripts, summaries and recordings will be kept securely and destroyed two years after the research concludes.

What will the project produce?

The information from my research will be used in my Master thesis and will be published in an academic journal.

If you accept this invitation, what are your rights as a research participant?

You do not have to accept this invitation if you don't want to. If you do decide to participate, you have the right to:

- choose not to answer any question;

- ask for the recorder to be turned off at any time during the interview;

- withdraw from the study before 01/09/2017

- ask any questions about the study at any time;

- receive a copy of your interview recording;

- read over and comment on a written summary of your interview;

- agree on another name for me to use rather than your real name;

- be able to read any reports of this research by emailing the researcher to request a copy.

If you have any questions or problems, who can you contact?

If you have any questions, either now or in the future, please feel free to contact either:

Student:

Alyssa Ryan

Master in Environment Studies

School of Geography, Environment and Earth Sciences

alyssa.ryan@vuw.ac.nz
Supervisor:

Kelli M. Archie, PhD

Thesis Supervisor

Climate Change Research Institute

School of Geography, Environment and Earth Sciences

044635058

kelli.archie@vuw.ac.nz

Human Ethics Committee information

If you have any concerns about the ethical conduct of the research you may contact the Victoria University HEC Convener: Associate Professor Susan Corbett. Email susan.corbett@vuw.ac.nz or telephone +64-4-463 5480. 


\section{APPENDIX F}

\section{Survey Informed Consent}

\section{Qualtrics Survey Consent Statement}

This project investigates perceptions of climate change in the New Zealand wine industry. Climate change has the potential to cause changes to regional growing conditions that could have significant impacts on New Zealand wine production. Questions will explore topics such as recent changes in climate and weather conditions, barriers to adaptation and the use of climate related information in order to evaluate the future capacity of the wine industry. There is no direct benefit of participation, but information gathered through this project has the potential to improve the flow of adaptation relevant information and to potentially facilitate the successful adaptation of the New Zealand wine industry to the impacts of climate change.

This research is anonymous, which means that the researchers Alyssa Ryan and Dr. Kelli Archie will not be aware of your identity and your identity will not be disclosed in any reports, presentations, publications or public documentation.

Once you begin the survey, the information you provide cannot be withdrawn. However, you can choose to skip questions and exit the survey at any time. The survey will take approximately 15 minutes.

Clicking the next button implies your consent to take part in this research. Thank you in advance for your time. 


\title{
APPENDIX G
}

\author{
Interview Informed Consent
}

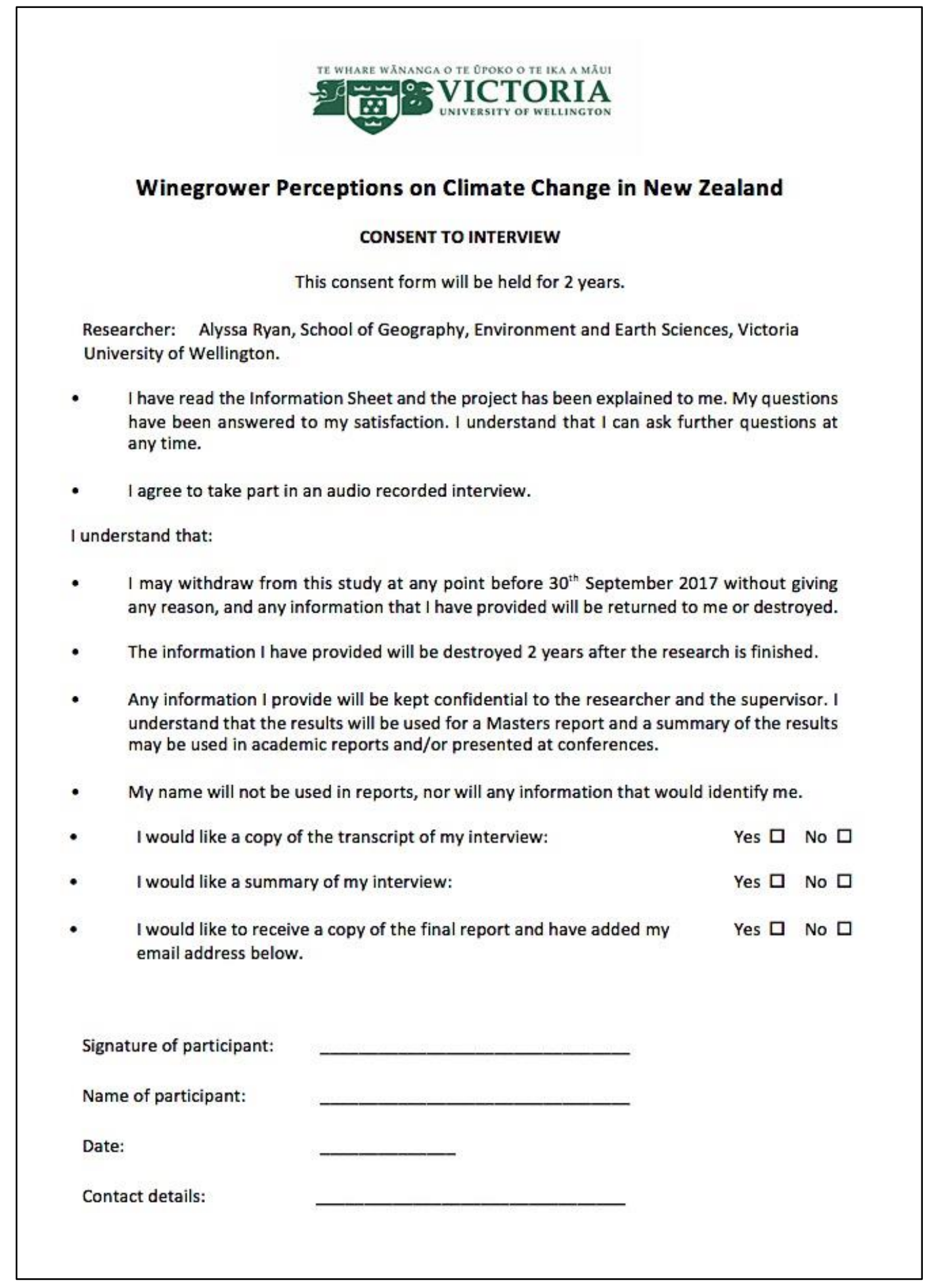




\section{APPENDIX H}

\section{Survey Questions}

\section{Winegrowers perceptions of climate change in New Zealand}

Q1 This project investigates perceptions of climate change in the New Zealand wine industry. Climate change has the potential to cause changes to regional growing conditions that could have significant impacts on New Zealand wine production. Questions will explore topics such as recent changes in climate and weather conditions, barriers to adaptation and the use of climate related information in order to evaluate the future capacity of the wine industry. There is no direct benefit of participation, but information gathered through this project has the potential to improve the flow of adaptation relevant information and to potentially facilitate the successful adaptation of the New Zealand wine industry to the impacts of climate change.

This research is anonymous, which means that the researchers Alyssa Ryan and Dr. Kelli Archie will not be aware of your identity and your identity will not be disclosed in any reports, presentations, publications or public documentation.

Once you begin the survey, the information you provide cannot be withdrawn. However, you can choose to skip questions and exit the survey at any time. The survey will take approximately 15 minutes.

Clicking the next button implies your consent to take part in this research. Thank you in advance for your time.

Q2 Please rank the weather elements that influence wine quality in your region? (In order of importance with 1 being the most important).

Air temperature

Sunlight (UV)

Frosts

Wind

Precipitation

Humidity 
Q3 What varieties of grapes do you currently grow or purchase?

$\square$ Cabernet Sauvignon
Chardonnay
Gewurztraminer
Merlot
Muller Thurgau
Pinot Gris
Pinot Noir
Riesling
Sauvignon Blanc
Syrah
Other (please specify)

Q4 Do you have any plans to change the grape variety that you currently grow?

Yes, for climate related reasons

Yes, for market related reasons

Yes, for climate and market related reasons

Yes, for other reasons (please specify)

No plans to change

Unsure 
Q5 What are the new varieties that you would consider growing as a result of changes in climatic conditions?

Q6 What are the new varieties that you would consider growing as a result of changes in market conditions?

Q7 What are the new varieties that you would consider growing as a result of changes in climate and market conditions?

Q8 What are the new varieties that you would consider growing as a result of other changes?

Q9 According to the Intergovernmental Panel on Climate Change, it is extremely likely that anthropogenic greenhouse gas emissions are contributing to the changing climate. Globally, the projected warming by the end of the century will be above $1.5^{\circ} \mathrm{C}$, with more realistic scenarios projected above $2^{\circ} \mathrm{C}$. 
Q10 We realise that the impacts of climate change will potentially differ regionally and seasonally. For example, your region may experience more precipitation during the winter and less precipitation during the summer which means that you could have both an increase and decrease in water availability depending on the time of year. Based on your knowledge and views: how might climate change impact your region?

\begin{tabular}{|c|c|c|c|c|c|}
\hline & $\begin{array}{l}\text { Extremely } \\
\text { likely }\end{array}$ & $\begin{array}{l}\text { Somewhat } \\
\text { likely }\end{array}$ & $\begin{array}{c}\text { Somewhat } \\
\text { unlikely }\end{array}$ & $\begin{array}{c}\text { Extremely } \\
\text { unlikely }\end{array}$ & Unsure \\
\hline $\begin{array}{l}\text { Increased } \\
\text { frequency of } \\
\text { local flooding }\end{array}$ & 0 & 0 & 0 & 0 & 0 \\
\hline $\begin{array}{l}\text { Decreased } \\
\text { frequency of } \\
\text { local flooding }\end{array}$ & 0 & 0 & 0 & 0 & 0 \\
\hline $\begin{array}{c}\text { Positive } \\
\text { impacts on } \\
\text { local } \\
\text { ecosystems }\end{array}$ & 0 & 0 & 0 & 0 & 0 \\
\hline $\begin{array}{l}\text { Negative } \\
\text { impacts on } \\
\text { local } \\
\text { ecosystems }\end{array}$ & 0 & 0 & 0 & 0 & 0 \\
\hline $\begin{array}{l}\text { Increase in } \\
\text { potential for } \\
\text { local wildfire }\end{array}$ & 0 & 0 & 0 & 0 & 0 \\
\hline $\begin{array}{l}\text { Decrease in } \\
\text { potential for } \\
\text { local wildfire }\end{array}$ & 0 & 0 & 0 & 0 & 0 \\
\hline $\begin{array}{l}\text { Increased } \\
\text { frequency of } \\
\text { local storms }\end{array}$ & 0 & 0 & 0 & 0 & 0 \\
\hline $\begin{array}{l}\text { Decreased } \\
\text { frequency of } \\
\text { local storms }\end{array}$ & 0 & 0 & 0 & 0 & 0 \\
\hline
\end{tabular}




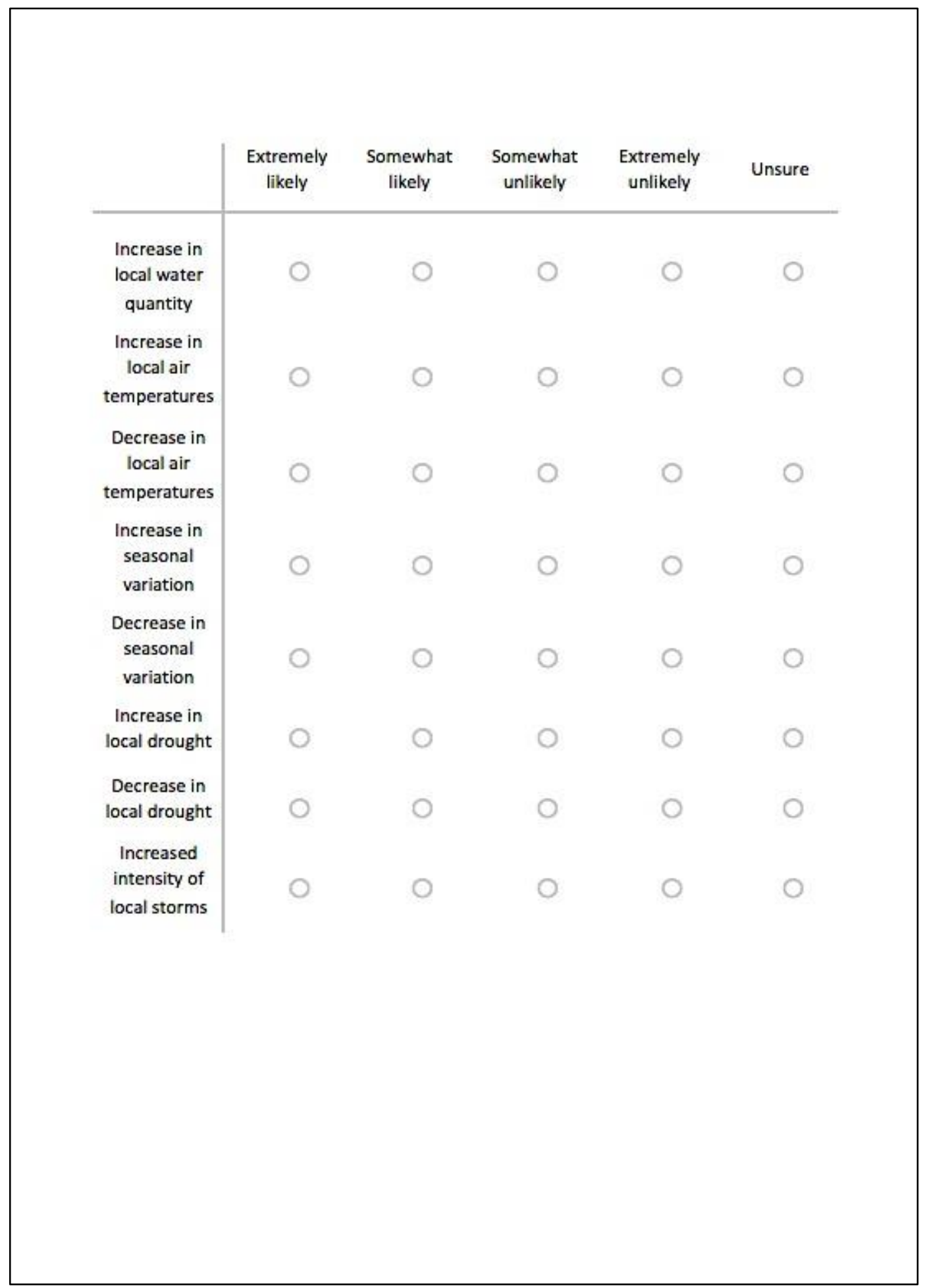


Q11 Have the changes you identified in the previous question already had an impact in your region on:

\begin{tabular}{|c|c|c|c|c|}
\hline & $\begin{array}{l}\text { Positively } \\
\text { impacted }\end{array}$ & No impact & $\begin{array}{l}\text { Negatively } \\
\text { impacted }\end{array}$ & Unsure \\
\hline $\begin{array}{l}\text { Harvest } \\
\text { quantity }\end{array}$ & O & $\mathrm{O}$ & 0 & 0 \\
\hline Harvest quality & $\mathrm{O}$ & 0 & 0 & $\mathrm{O}$ \\
\hline Grape pests & O & 0 & $\mathrm{O}$ & 0 \\
\hline Grape diseases & 0 & $\mathrm{O}$ & 0 & 0 \\
\hline Frost damage & 0 & 0 & 0 & $\mathrm{O}$ \\
\hline Winery tourism & $\mathrm{O}$ & 0 & 0 & 0 \\
\hline Export sales & 0 & 0 & 0 & 0 \\
\hline
\end{tabular}

Q12 Which of the following statements regarding climate change do you agree with most?

Climate change is real and already happening now

Climate change is probably happening and we will start seeing the impacts in the near future

Climate change may become a problem in the longer-term future

Climate change is probably not happening now and will not cause problems in the future 
Q13 Has your winery/vineyard developed strategies or plans to deal with the potential impacts of climate change?

\footnotetext{
Yes, plan is currently being developed

Yes, plan is currently being carried out

No

Unsure
}

Q14 Regardless of whether they have been implemented or not, what types of strategies or plans has your winery/vineyard developed to deal with the potential impacts of climate change? (Please select all that apply).

Drought management plans

Flood management plans

Pest management plans

Disease management plans

Frost management plans

Changes in planting locations/sites

Grape growing management plans

Harvest management plans

Adjustment in winemaking techniques

Other (please specify) 
Q15 On average how many hectares of grapes are grown in your vineyard?

$<100$ hectares

$100-299$ hectares

$300-499$ hectares

500 - 999 hectares

$1000-1999$ hectares

$2000-2999$ hectares

$3000-3999$ hectares

$4000+$ hectares

N/A we do not grow our own grapes

Unsure

Q16 On average how many cases of wine do you produce annually?

$<50,000$

$50,000 \cdot 99,999$

$100,000 \cdot 149,999$

$150,000 \cdot 199,999$

$200,000 \cdot 299,999$

$300,000 \cdot 399,999$

$400,000+$

N/A we do not produce our own wine

Unsure 
Q17 To what extent do you agree with the following statement: "I am well informed about the potential impacts of climate change on the wine industry in my region."

Strongly agree

Somewhat agree

Neither agree nor disagree

Somewhat disagree

Strongly disagree

Unsure

Q18 How do you rate the long-term outlook for the following sectors of the New Zealand wine industry:

\begin{tabular}{|c|c|c|c|c|c|c|}
\hline & $\begin{array}{c}\text { Extremely } \\
\text { Positive }\end{array}$ & $\begin{array}{l}\text { Somewhat } \\
\text { Positive }\end{array}$ & $\begin{array}{l}\text { Neither } \\
\text { Positive } \\
\text { or } \\
\text { Negative }\end{array}$ & $\begin{array}{l}\text { Somewhat } \\
\text { Negative }\end{array}$ & $\begin{array}{l}\text { Extremely } \\
\text { Negative }\end{array}$ & Unsure \\
\hline $\begin{array}{c}\text { Wine } \\
\text { production } \\
\text { in New } \\
\text { Zealand }\end{array}$ & $\mathrm{O}$ & 0 & 0 & 0 & 0 & 0 \\
\hline $\begin{array}{l}\text { Wine } \\
\text { production } \\
\text { in your } \\
\text { region }\end{array}$ & 0 & 0 & 0 & 0 & 0 & 0 \\
\hline $\begin{array}{c}\text { Wine } \\
\text { production } \\
\text { in your } \\
\text { winery }\end{array}$ & 0 & 0 & 0 & 0 & 0 & 0 \\
\hline
\end{tabular}


Q19 The next few questions will more specifically focus on adaptation and your use of climate related information. Adaptation to climate change is typically defined as an adjustment in activities in response to actual or expected changes in climate, which moderates harm or exploits beneficial opportunities. From your perspective, what are the most important factors preventing you from planning for adaptation to climate change? (Please select your top three choices).

Budget constraints

Lack of information at relevant scales

Lack of leadership

Lack of locally specific information

Lack of useful information

Not a priority in my organisation

Personnel constraints

Lack of market incentives

Stakeholder conflicts

Uncertainty in available information

There are no factors preventing me from planning for adaptation

Unsure

Other (please specify) 
Q20 At what scale is information most useful to you in planning for adaptation to climate change?

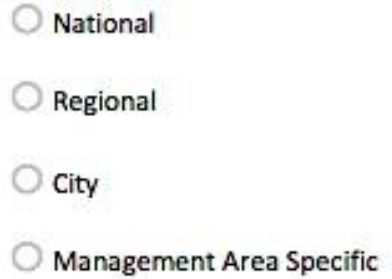

Q21 Does a lack of information at the scale you specified in the previous question prevent you from planning for adaptation to climate change?
Yes
Maybe
No
Unsure 
Q22 Please rate the usefulness of the following types of information (whether or not you currently use them) for determining the risks to your region from climate change?

\begin{tabular}{|c|c|c|c|c|c|c|}
\hline & $\begin{array}{c}\text { Extremely } \\
\text { useful }\end{array}$ & $\begin{array}{l}\text { Very } \\
\text { useful }\end{array}$ & $\begin{array}{c}\text { Moderately } \\
\text { useful }\end{array}$ & $\begin{array}{l}\text { Slightly } \\
\text { useful }\end{array}$ & $\begin{array}{c}\text { Not at all } \\
\text { useful }\end{array}$ & Unsure \\
\hline $\begin{array}{l}\text { Weather } \\
\text { and or }\end{array}$ & & & & & & \\
\hline $\begin{array}{l}\text { seasonal } \\
\text { climate } \\
\text { forecasts }\end{array}$ & 0 & 0 & 0 & 0 & 0 & 0 \\
\hline $\begin{array}{c}\text { Climate } \\
\text { projections }\end{array}$ & & & & & & \\
\hline $\begin{array}{l}\text { for the next } \\
\text { few years }\end{array}$ & 0 & 0 & 0 & 0 & 0 & 0 \\
\hline $\begin{array}{l}\text { Information } \\
\text { on how to }\end{array}$ & & & & & & \\
\hline $\begin{array}{c}\text { assess the } \\
\text { vulnerability } \\
\text { of specific } \\
\text { areas }\end{array}$ & 0 & 0 & 0 & 0 & 0 & 0 \\
\hline $\begin{array}{l}\text { Historical } \\
\text { climate data }\end{array}$ & 0 & 0 & 0 & 0 & 0 & 0 \\
\hline $\begin{array}{l}\text { Long-term } \\
\text { climate } \\
\text { projections }\end{array}$ & 0 & 0 & 0 & 0 & 0 & 0 \\
\hline
\end{tabular}

Q23 Would additional information about the impacts of climate change on viticulture and wine in your region change the way you plan for adaptation?
Yes
No
Maybe
I don't know 
Q24 Whether or not your winery/vineyard has already taken action to prepare for the possible impacts of climate change, how much of a barrier do you perceive the following issues to be in taking action on climate change?

\begin{tabular}{l|l} 
& Large Barrier Small Barrier Not a Barrier \\
\hline $\begin{array}{c}\text { Lack of public } \\
\text { awareness or } \\
\text { demand to take } \\
\text { action }\end{array}$ \\
Insufficient staff \\
time to get \\
informed about \\
the issue or \\
gather relevant \\
information \\
Available \\
science is at the \\
wrong scale \\
Lack of \\
perceived \\
importance to \\
the public \\
Science is \\
difficult to \\
understand \\
Insufficient staff \\
resources to \\
analyse and \\
assess relevant \\
information \\
Legal pressure \\
to maintain \\
status quo
\end{tabular}




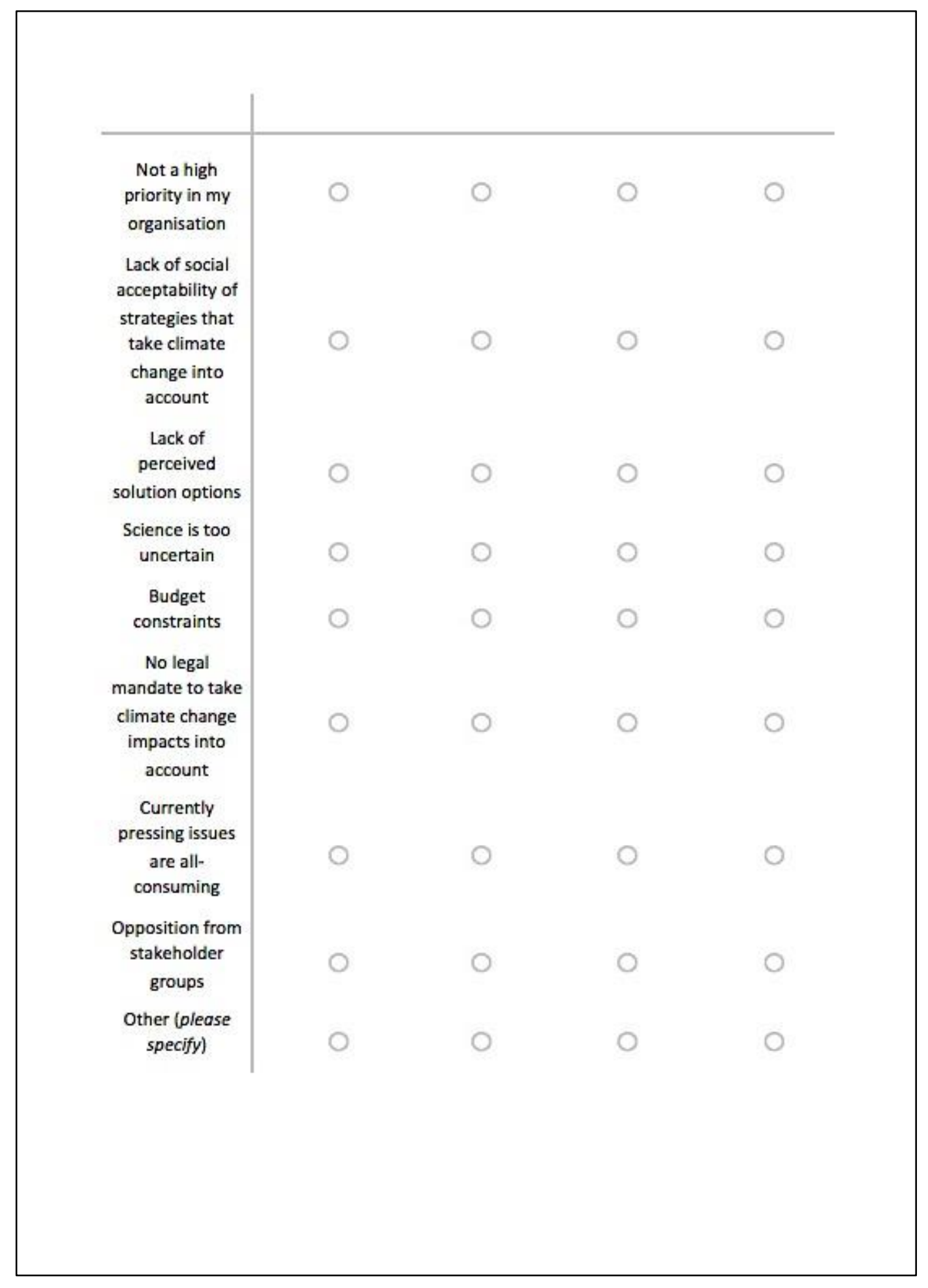


Q25 What is your current position in the wine industry?

Winemaker

Winery Manager

Viticulturist

Winery Owner

Vineyard Manager

Other (please specify)

Q26 How old are you?

$18-24$ years

$25-29$ years

$30-34$ years

$35-39$ years

$40-44$ years

$45-49$ years

$50-54$ years

$55-59$ years

$60-64$ years

$65-69$ years

$70+$ years 
Q27 What gender do you associate with?

Male

Female

Other

Q28 What is the highest level of education you have completed?

Less than NCEA Level 3

NCEA Level 3 or equivalent

Some university (no degree)

Bachelor's degree

Post-graduate or professional degree 
Q29 What region do you currently work in?

Northland

Auckland

Waikato

Bay of Plenty

Gisborne

Hawke's Bay

Taranaki

Manawatu-Wanganui/Waikato

Wellington

Marlborough

Tasman

Nelson

West Coast

Canterbury

Otago

Southland 
Q30 How many years have you worked in this region?

$0-4$ years

$5-9$ years

$10-14$ years

$15-19$ years

$20+$ years

Thank you for taking your time to be a part of this research.

If you have any questions regarding this survey or wish to have a copy of the final results, please send an email to Alyssa Ryan at alyssa.ryan@vuw.ac.nz 


\section{APPENDIX I}

\section{Survey Recruitment Email}

\section{Victoria University of Wellington - Research Request}

Dear Winegrower,

My name is Alyssa Ryan and 1 am a Masters student in Environmental Studies at Victoria University of Wellington. I am currently working on a project towards my thesis.

The project aims to analyse perceptions of climate change in the New Zealand wine industry, to explore the future capacity of the wine industry by evaluating winegrowers understanding of climate change and the possible adaptation strategies that can be used as a solution.

I have attached a link to a survey, which will ask questions about your perceptions of the impacts of climate change and how the wine industry is responding. The survey will take approximately 15 minutes and is anonymous. Once you click into the survey, the information provided cannot be withdrawn as you will be unidentifiable. However, you can stop the survey at any time, without giving a reason.

\section{SURVEY LINK}

I have also attached an information sheet further detailing the project.

Thank you for your consideration.

Kind regards,

Alyssa Ryan

Masters in Environmental Studies

School of Geography, Environment and Earth Sciences 


\section{APPENDIX J}

\section{Interview Guide}

Interview Questions Guideline $\mathbf{-} \mathbf{3 0}$ minutes

- Go over the recording and consent

Themes for interviews:

- Climate change impacts to wine production

- Information received about climate change

- Climate change and temperature

- Varietal change

- Regional shifts

- Adaptation planning

- Climate change risks for winery/region/New Zealand

- Perceived barriers for winery/region/New Zealand

- Observed changes in climate
- Positive

- Negative

- Future outlook of climate change

- Climate change concerns
- Pests
- Disease
- Frost
- Wind
- Droughts
- Seasonal variations

- Information for adaptation 


\section{APPENDIX K}

Interview Recruitment Email

\section{Victoria University of Wellington - Interview Research Request}

Kia ora Winegrower,

My name is Alyssa Ryan and I am a Masters student in Environmental Studies at Victoria University of Wellington. I am currently working on a project towards my thesis.

The project aims to analyse perceptions of climate change in the New Zealand wine industry, by evaluating winegrowers' understanding of climate change and the possible adaptation strategies that can be used as a future solution.

I will be conducting interviews in Wine Region on the Day to the Day in Month, and was wondering if you/your winegrower would be interested in participating in my research. I am looking for winegrowers to interview about their perceptions of climate change and adaptation planning. The interview will take approximately 30 minutes of your time, and I can meet you at a pre-determined time. The interview will be confidential and you will not be identifiable in this research.

I have attached an information sheet further detailing the project, and a consent form outlining what will be required.

If this sounds like something you are interested in, 1 look forward to hearing from you.

Thank you for your consideration, and please let me know if you have any questions.

Kind regards,

Alyssa Ryan

Masters in Environmental Studies

School of Geography, Environment and Earth Sciences 


\section{APPENDIX L}

Cross-tabulation of reported harvest quantity and wine regions in New Zealand.

\begin{tabular}{|l|c|c|c|c|}
\hline \multirow{2}{*}{\multicolumn{1}{|c}{ Regions }} & \multicolumn{3}{c|}{ Harvest Quantity } & \multirow{2}{*}{ Total } \\
\cline { 2 - 4 } & Positive & No Impact & Negative & \\
\hline Marlborough & 5 & 15 & 12 & 32 \\
\hline Hawke's Bay & 1 & 7 & 6 & 14 \\
\hline Otago & 1 & 12 & 4 & 17 \\
\hline Other Regions & 0 & 12 & 22 & 34 \\
\hline Total & 7 & 46 & 44 & 97 \\
\hline
\end{tabular}

Chi-Square independence test for reported harvest quantity and wine regions in New Zealand.

\begin{tabular}{|l|c|c|c|}
\hline & Value & df & $\begin{array}{c}\text { Asymptotic } \\
\text { Significance (2-sided) }\end{array}$ \\
\hline Pearson Chi-Square & $13.677^{\mathrm{a}}$ & 6 & 0.033 \\
\hline Likelihood Ratio & 15.274 & 6 & 0.018 \\
\hline Linear-by-Linear Association & 6.528 & 1 & 0.011 \\
\hline N of Valid Cases & 97 & & \\
\hline
\end{tabular}

a. 4 cells (33.3\%) have expected count less than 5 . The minimum expected count is 1.01 .

Symmetric measures for reported harvest quantity and wine regions in New Zealand.

\begin{tabular}{|l|l|c|c|c|c|}
\hline \multicolumn{2}{|c|}{} & Value & $\begin{array}{c}\text { Asymptotic } \\
\text { Standard } \\
\text { Error }\end{array}$ & $\begin{array}{c}\text { Approximate } \\
\text { T }^{\mathbf{b}}\end{array}$ & $\begin{array}{c}\text { Approximate } \\
\text { Significance }\end{array}$ \\
\hline \multirow{2}{*}{$\begin{array}{l}\text { Nominal } \\
\text { by } \\
\text { Nominal }\end{array}$} & Phi & 0.376 & & & 0.033 \\
\cline { 2 - 6 } & $\begin{array}{l}\text { Cramer's V } \\
\text { Contingency }\end{array}$ & 0.266 & & & 0.033 \\
\hline $\begin{array}{l}\text { Interval } \\
\text { by } \\
\text { Interval }\end{array}$ & Pearson's R & -0.261 & 0.094 & -2.633 & 0.033 \\
\hline $\begin{array}{l}\text { Ordinal } \\
\text { by } \\
\text { Ordinal }\end{array}$ & $\begin{array}{l}\text { Spearman } \\
\text { Correlation }\end{array}$ & -0.255 & 0.098 & -2.567 & $0.012^{c}$ \\
\hline N of Valid Cases & 97 & & & \\
\hline
\end{tabular}

a. Not assuming the null hypothesis.

b. Using the asymptotic standard error assuming the null hypothesis.

c. Based on normal approximation. 


\section{APPENDIX M}

Cross-tabulation of reported grape disease and wine regions in New Zealand.

\begin{tabular}{|l|c|c|c|c|}
\hline \multirow{2}{*}{ Regions } & \multicolumn{3}{c|}{ Grape Disease } & \multirow{2}{*}{ Total } \\
\cline { 2 - 4 } & Positive & No Impact & Negative & \\
\hline Marlborough & 2 & 8 & 20 & 30 \\
\hline Hawke's Bay & 1 & 4 & 9 & 14 \\
\hline Otago & 0 & 13 & 4 & 17 \\
\hline Other Regions & 2 & 9 & 25 & 36 \\
\hline Total & 5 & 34 & 58 & 97 \\
\hline
\end{tabular}

Chi-Square independence test for reported grape disease and wine regions in New Zealand.

\begin{tabular}{|l|c|c|c|}
\hline & Value & df & $\begin{array}{c}\text { Asymptotic } \\
\text { Significance (2-sided) }\end{array}$ \\
\hline Pearson Chi-Square & $15.839^{\mathrm{a}}$ & 6 & 0.015 \\
\hline Likelihood Ratio & 15.846 & 6 & 0.015 \\
\hline Linear-by-Linear Association & 0.001 & 1 & 0.974 \\
\hline N of Valid Cases & 97 & & \\
\hline
\end{tabular}

a. 5 cells (41.7\%) have expected count less than 5 . The minimum expected count is 0.72 .

Symmetric measures for reported grape disease and wine regions in New Zealand.

\begin{tabular}{|c|c|c|c|c|c|}
\hline & & Value & $\begin{array}{c}\text { Asymptotic } \\
\text { Standard } \\
\text { Error }^{\mathrm{a}}\end{array}$ & $\begin{array}{c}\text { Approximate } \\
\mathrm{T}^{\mathrm{b}}\end{array}$ & $\begin{array}{c}\text { Approximate } \\
\text { Significance }\end{array}$ \\
\hline \multirow{3}{*}{$\begin{array}{l}\text { Nominal } \\
\text { by } \\
\text { Nominal }\end{array}$} & Phi & 0.404 & & & 0.015 \\
\hline & Cramer's V & 0.286 & & & 0.015 \\
\hline & $\begin{array}{l}\text { Contingency } \\
\text { Coefficient }\end{array}$ & 0.375 & & & 0.015 \\
\hline $\begin{array}{l}\text { Interval } \\
\text { by } \\
\text { Interval }\end{array}$ & Pearson's R & 0.003 & 0.103 & 0.032 & $0.975^{c}$ \\
\hline $\begin{array}{l}\text { Ordinal } \\
\text { by } \\
\text { Ordinal }\end{array}$ & $\begin{array}{l}\text { Spearman } \\
\text { Correlation }\end{array}$ & -0.009 & 0.102 & -0.089 & $0.929^{c}$ \\
\hline \multicolumn{2}{|c|}{$\mathrm{N}$ of Valid Cases } & 97 & & & \\
\hline
\end{tabular}

a. Not assuming the null hypothesis.

b. Using the asymptotic standard error assuming the null hypothesis.

c. Based on normal approximation. 


\section{APPENDIX N}

Cross-tabulation of observed harvest quality and winegrowers' climate change beliefs.

\begin{tabular}{|l|c|c|c|c|}
\hline \multirow{2}{*}{ Climate Change Belief } & \multicolumn{3}{c|}{ Harvest Quality } & \multirow{2}{*}{ Total } \\
\cline { 2 - 5 } & Positive & No Impact & Negative & 67 \\
\hline $\begin{array}{l}\text { Climate change is real and } \\
\text { happening now }\end{array}$ & 5 & 20 & 42 & 67 \\
\hline $\begin{array}{l}\text { Climate change is probably } \\
\text { happening and we will start } \\
\text { seeing the impacts in the near } \\
\text { future }\end{array}$ & 2 & 8 & 9 & 19 \\
\hline $\begin{array}{l}\text { Climate change may become a } \\
\text { problem in the longer-term future }\end{array}$ & 2 & 7 & 0 & 9 \\
\hline $\begin{array}{l}\text { Climate change is probably not } \\
\text { happening now and will not cause } \\
\text { problems in the future }\end{array}$ & 0 & 2 & 0 & 2 \\
\hline Total & 9 & 37 & 51 & 97 \\
\hline
\end{tabular}

Chi-Square independence test for observed harvest quality and winegrowers' climate change beliefs.

\begin{tabular}{|l|c|c|c|}
\hline & Value & df & $\begin{array}{c}\text { Asymptotic } \\
\text { Significance (2-sided) }\end{array}$ \\
\hline Pearson Chi-Square & $16.263^{\mathrm{a}}$ & 6 & 0.012 \\
\hline Likelihood Ratio & 20.319 & 6 & 0.002 \\
\hline Linear-by-Linear Association & 3.717 & 1 & 0.054 \\
\hline N of Valid Cases & 97 & & \\
\hline
\end{tabular}

a. 7 cells $(58.3 \%)$ have expected count less than 5 . The minimum expected count is 0.19 .

Symmetric measures for observed harvest quality and winegrowers' climate change beliefs.

\begin{tabular}{|c|c|c|c|c|c|}
\hline & & Value & $\begin{array}{c}\text { Asymptotic } \\
\text { Standard } \\
\text { Error }^{\mathrm{a}}\end{array}$ & $\begin{array}{c}\text { Approximate } \\
\mathrm{T}^{\mathrm{b}}\end{array}$ & $\begin{array}{l}\text { Approximate } \\
\text { Significance }\end{array}$ \\
\hline \multirow{3}{*}{$\begin{array}{l}\text { Nominal } \\
\text { by } \\
\text { Nominal }\end{array}$} & Phi & 0.409 & & & 0.012 \\
\hline & Cramer's V & 0.290 & & & 0.012 \\
\hline & $\begin{array}{l}\text { Contingency } \\
\text { Coefficient }\end{array}$ & 0.379 & & & 0.012 \\
\hline $\begin{array}{l}\text { Interval } \\
\text { by } \\
\text { Interval }\end{array}$ & Pearson's R & 0.197 & 0.094 & 1.956 & $0.053^{c}$ \\
\hline $\begin{array}{l}\text { Ordinal } \\
\text { by } \\
\text { Ordinal }\end{array}$ & $\begin{array}{l}\text { Spearman } \\
\text { Correlation }\end{array}$ & 0.255 & 0.098 & 2.571 & $0.012^{c}$ \\
\hline \multicolumn{2}{|c|}{$\mathrm{N}$ of Valid Cases } & 97 & & & \\
\hline
\end{tabular}

a. Not assuming the null hypothesis.

b. Using the asymptotic standard error assuming the null hypothesis.

c. Based on normal approximation. 


\section{APPENDIX O}

Cross-tabulation of reported grape disease and Pinot Gris.

\begin{tabular}{|l|c|c|c|c|}
\hline \multirow{2}{*}{ Pinot Gris is cultivated } & \multicolumn{3}{|c|}{ Grape Disease } & \multirow{2}{*}{ Total } \\
\cline { 2 - 4 } & Positive & No Impact & Negative & \\
\hline Yes & 3 & 14 & 41 & 58 \\
\hline No & 2 & 20 & 17 & 39 \\
\hline Total & 5 & 34 & 58 & 97 \\
\hline
\end{tabular}

Chi-Square independence test for reported grape disease and Pinot Gris.

\begin{tabular}{|l|c|c|c|}
\hline & Value & df & $\begin{array}{c}\text { Asymptotic } \\
\text { Significance (2-sided) }\end{array}$ \\
\hline Pearson Chi-Square & $7.766^{\mathrm{a}}$ & 2 & 0.021 \\
\hline Likelihood Ratio & 7.756 & 2 & 0.021 \\
\hline Linear-by-Linear Association & 4.814 & 1 & 0.028 \\
\hline N of Valid Cases & 97 & & \\
\hline
\end{tabular}

a. 2 cells (33.3\%) have expected count less than 5 . The minimum expected count is 2.01 .

Symmetric measures for reported grape disease and Pinot Gris.

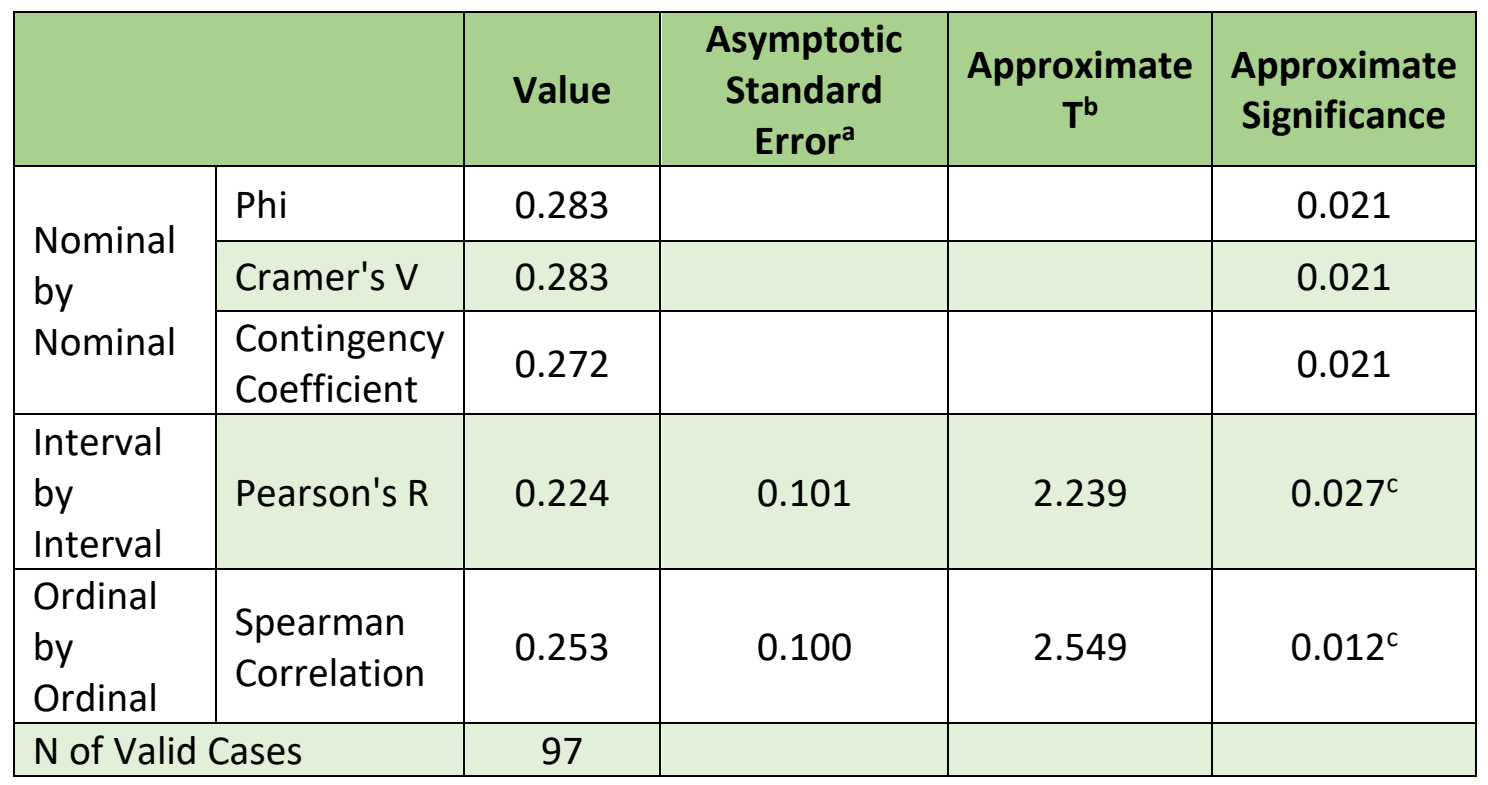
a. Not assuming the null hypothesis.
b. Using the asymptotic standard error assuming the null hypothesis.
c. Based on normal approximation. 


\section{APPENDIX P}

Cross-tabulation of reported varietal change and Merlot cultivation.

\begin{tabular}{|l|c|c|c|}
\hline \multirow{2}{*}{$\begin{array}{c}\text { Variety Change } \\
\text { Plans }\end{array}$} & \multicolumn{2}{|c|}{ Merlot Cultivation } & \multirow{2}{*}{ Total } \\
\cline { 2 - 4 } & Yes & No & 23 \\
\hline $\begin{array}{l}\text { Yes plans to } \\
\text { change }\end{array}$ & 11 & 12 & 80 \\
\hline No plans to change & 14 & 66 & 103 \\
\hline Total & 25 & 78 & \\
\hline
\end{tabular}

Chi-Square independence test for reported varietal change and Merlot cultivation.

\begin{tabular}{|l|c|c|c|}
\hline & Value & df & $\begin{array}{c}\text { Asymptotic } \\
\text { Significance (2-sided) }\end{array}$ \\
\hline Pearson Chi-Square & $8.938^{\mathrm{a}}$ & 1 & 0.003 \\
\hline Likelihood Ratio & 8.126 & 1 & 0.004 \\
\hline Linear-by-Linear Association & 8.851 & 1 & 0.003 \\
\hline N of Valid Cases & 103 & & \\
\hline
\end{tabular}

a. 1 cell (16.7\%) has expected count less than 5 . The minimum expected count is 1.93 .

Symmetric measures for reported varietal change and Merlot cultivation.

\begin{tabular}{|l|l|c|c|c|c|}
\hline \multicolumn{2}{|c|}{} & Value & $\begin{array}{c}\text { Asymptotic } \\
\text { Standard } \\
\text { Error }\end{array}$ & $\begin{array}{c}\text { Approximate } \\
\text { T }^{\text {b }}\end{array}$ & $\begin{array}{c}\text { Approximate } \\
\text { Significance }\end{array}$ \\
\hline \multirow{2}{*}{$\begin{array}{l}\text { Nominal } \\
\text { by } \\
\text { Nominal }\end{array}$} & Phi & -0.295 & & & 0.003 \\
\cline { 2 - 6 } & $\begin{array}{l}\text { Cramer's V } \\
\text { Coefficient }\end{array}$ & 0.295 & & & 0.003 \\
\hline $\begin{array}{l}\text { Interval } \\
\text { by } \\
\text { Interval }\end{array}$ & Pearson's R & -0.295 & 0.108 & -3.098 & 0.003 \\
\hline $\begin{array}{l}\text { Ordinal } \\
\text { by } \\
\text { Ordinal }\end{array}$ & $\begin{array}{l}\text { Spearman } \\
\text { Correlation }\end{array}$ & -0.295 & 0.108 & -3.098 & $0.003^{c}$ \\
\hline \multicolumn{2}{|l}{ N of Valid Cases } & 103 & & & \\
\hline
\end{tabular}

a. Not assuming the null hypothesis.

b. Using the asymptotic standard error assuming the null hypothesis.

c. Based on normal approximation. 


\section{APPENDIX Q}

Cross-tabulation of reported varietal change and observed harvest quality.

\begin{tabular}{|l|c|c|c|c|}
\hline \multirow{2}{*}{ Variety Change Plans } & \multicolumn{3}{|c|}{ Harvest Quality } & \multirow{2}{*}{ Total } \\
\cline { 2 - 5 } & Positive & No Impact & Negative & \\
\hline Yes plans to change & 5 & 7 & 9 & 21 \\
\hline No plans to change & 3 & 30 & 33 & 66 \\
\hline Total & 8 & 37 & 42 & 87 \\
\hline
\end{tabular}

Chi-Square independence test for reported varietal change and observed harvest quality.

\begin{tabular}{|l|c|c|c|}
\hline & Value & df & $\begin{array}{c}\text { Asymptotic } \\
\text { Significance (2- } \\
\text { sided) }\end{array}$ \\
\hline Pearson Chi-Square & $7.148^{\mathrm{a}}$ & 2 & 0.028 \\
\hline Likelihood Ratio & 6.041 & 2 & 0.049 \\
\hline Linear-by-Linear Association & 2.602 & 1 & 0.107 \\
\hline N of Valid Cases & 87 & & \\
\hline
\end{tabular}

a. 1 cell $(16.7 \%)$ has expected count less than 5 . The minimum expected count is 1.93 .

Symmetric measures for reported varietal change and observed harvest quality.

\begin{tabular}{|l|l|c|c|c|c|}
\hline \multicolumn{2}{|c|}{} & Value & $\begin{array}{c}\text { Asymptotic } \\
\text { Standard } \\
\text { Error }\end{array}$ & $\begin{array}{c}\text { Approximate } \\
\text { T }^{\text {b }}\end{array}$ & $\begin{array}{c}\text { Approximate } \\
\text { Significance }\end{array}$ \\
\hline \multirow{2}{*}{$\begin{array}{l}\text { Nominal } \\
\text { by } \\
\text { Nominal }\end{array}$} & Phi & 0.287 & & & 0.028 \\
\cline { 2 - 6 } & $\begin{array}{l}\text { Cramer's V } \\
\text { Coefficient }\end{array}$ & 0.287 & & & 0.028 \\
\hline $\begin{array}{l}\text { Interval } \\
\text { by } \\
\text { Interval }\end{array}$ & Pearson's R & 0.174 & 0.119 & 1.629 & 0.028 \\
\hline $\begin{array}{l}\text { Ordinal } \\
\text { by } \\
\text { Ordinal }\end{array}$ & $\begin{array}{l}\text { Spearman } \\
\text { Correlation }\end{array}$ & 0.135 & 0.117 & 1.261 & $0.217^{c}$ \\
\hline N of Valid Cases & 87 & & & \\
\hline
\end{tabular}
a. Not assuming the null hypothesis.
b. Using the asymptotic standard error assuming the null hypothesis.
c. Based on normal approximation. 


\section{APPENDIX R}

Cross-tabulation of reported varietal change and Syrah cultivation.

\begin{tabular}{|l|c|c|c|}
\hline \multirow{2}{*}{$\begin{array}{c}\text { Variety Change } \\
\text { Plans }\end{array}$} & \multicolumn{2}{|c|}{ Syrah Cultivation } & \multirow{2}{*}{ Total } \\
\cline { 2 - 3 } & Yes & No & 23 \\
\hline $\begin{array}{l}\text { Yes plans to } \\
\text { change }\end{array}$ & 14 & 9 & 80 \\
\hline No plans to change & 19 & 61 & 103 \\
\hline Total & 33 & 70 & \\
\hline
\end{tabular}

Chi-Square independence test for reported varietal change and Syrah cultivation.

\begin{tabular}{|l|c|c|c|}
\hline & Value & df & $\begin{array}{c}\text { Asymptotic } \\
\text { Significance (2-sided) }\end{array}$ \\
\hline Pearson Chi-Square & $11.304^{\mathrm{a}}$ & 1 & 0.001 \\
\hline Likelihood Ratio & 10.697 & 1 & 0.001 \\
\hline Linear-by-Linear Association & 11.195 & 1 & 0.001 \\
\hline N of Valid Cases & 103 & & \\
\hline
\end{tabular}

a. 1 cell (16.7\%) has expected count less than 5 . The minimum expected count is 1.93 .

Symmetric measures for reported varietal change and Syrah cultivation.

\begin{tabular}{|l|l|c|c|c|c|}
\hline \multicolumn{2}{|c|}{} & Value & $\begin{array}{c}\text { Asymptotic } \\
\text { Standard } \\
\text { Error }\end{array}$ & $\begin{array}{c}\text { Approximate } \\
T^{\text {b }}\end{array}$ & $\begin{array}{c}\text { Approximate } \\
\text { Significance }\end{array}$ \\
\hline \multirow{2}{*}{$\begin{array}{l}\text { Nominal } \\
\text { by } \\
\text { Nominal }\end{array}$} & Phi & -0.287 & & & 0.001 \\
\cline { 2 - 6 } & Cramer's V & 0.287 & & & 0.001 \\
\hline & $\begin{array}{l}\text { Contingency } \\
\text { Coefficient }\end{array}$ & 0.276 & & & 0.001 \\
\hline $\begin{array}{l}\text { Interval } \\
\text { by } \\
\text { Interval }\end{array}$ & Pearson's R & -0.174 & 0.101 & -3.529 & $0.001^{c}$ \\
\hline $\begin{array}{l}\text { Ordinal } \\
\text { by } \\
\text { Ordinal }\end{array}$ & $\begin{array}{l}\text { Spearman } \\
\text { Correlation }\end{array}$ & -0.135 & 0.101 & -3.529 & $0.001^{c}$ \\
\hline N of Valid Cases & 103 & & & \\
\hline
\end{tabular}

a. Not assuming the null hypothesis.

b. Using the asymptotic standard error assuming the null hypothesis.

c. Based on normal approximation. 


\section{APPENDIX S}

Cross-tabulation of observed grape disease and reported adaptation planning.

\begin{tabular}{|l|c|c|c|c|}
\hline \multirow{2}{*}{ Adaptation Planning } & \multicolumn{3}{c|}{ Grape Disease } & \multirow{2}{*}{ Total } \\
\cline { 2 - 4 } & Positive & No Impact & Negative & \\
\hline Planning & 3 & 6 & 23 & 32 \\
\hline No Plans & 2 & 26 & 32 & 60 \\
\hline Total & 5 & 32 & 55 & 92 \\
\hline
\end{tabular}

Chi-Square independence test for observed grape disease and reported adaptation planning.

\begin{tabular}{|l|c|c|c|}
\hline & Value & df & $\begin{array}{c}\text { Asymptotic } \\
\text { Significance (2-sided) }\end{array}$ \\
\hline Pearson Chi-Square & $6.228^{\mathrm{a}}$ & 2 & 0.044 \\
\hline Likelihood Ratio & 6.499 & 2 & 0.039 \\
\hline Linear-by-Linear Association & 0.904 & 1 & 0.342 \\
\hline N of Valid Cases & 92 & & \\
\hline
\end{tabular}

a. 2 cells (33.3\%) have expected count less than 5 . The minimum expected count is 1.74 .

Symmetric measures for observed grape disease and reported adaptation planning.

\begin{tabular}{|c|c|c|c|c|c|}
\hline & Value & $\begin{array}{c}\text { Asymptotic } \\
\text { Standard } \\
\text { Error }^{\mathrm{a}}\end{array}$ & $\begin{array}{c}\text { Approximate } \\
\mathrm{T}^{\mathrm{b}}\end{array}$ & $\begin{array}{c}\text { Approximate } \\
\text { Significance }\end{array}$ \\
\hline \multirow{3}{*}{$\begin{array}{l}\text { Nominal } \\
\text { by } \\
\text { Nominal }\end{array}$} & Phi & 0.260 & & & 0.044 \\
\hline & Cramer's V & 0.260 & & & 0.044 \\
\hline & $\begin{array}{l}\text { Contingency } \\
\text { Coefficient }\end{array}$ & 0.252 & & & 0.044 \\
\hline $\begin{array}{l}\text { Interval } \\
\text { by } \\
\text { Interval }\end{array}$ & Pearson's R & 0.100 & 0.111 & 0.950 & $0.345^{c}$ \\
\hline $\begin{array}{l}\text { Ordinal } \\
\text { by } \\
\text { Ordinal }\end{array}$ & $\begin{array}{l}\text { Spearman } \\
\text { Correlation }\end{array}$ & 0.144 & 0.105 & 1.385 & $0.170^{c}$ \\
\hline \multicolumn{2}{|c|}{$\mathrm{N}$ of Valid Cases } & 92 & & & \\
\hline
\end{tabular}

a. Not assuming the null hypothesis.

b. Using the asymptotic standard error assuming the null hypothesis.

c. Based on normal approximation. 